\title{
Implications of forest structure on carbon dioxide fluxes
}

\author{
Dissertation \\ to attain the joint doctoral degree \\ of the Faculty of Forest Sciences and Forest Ecology \\ Georg-August-Universität Göttingen, and \\ the School of natural sciences \\ Bangor University \\ Submitted by \\ Rijan Tamrakar \\ born on the $3^{\text {rd }}$ December 1984 in Bhaktapur, Nepal
}

Göttingen, 05/2020 
1. Referee: Prof. Dr. Christian Ammer

2. Referee: Dr. Mathias Herbst

3. Oral examiner: Dr. Andy Smith

4. Oral examiner: Prof. Dr. Dirk Hölscher

5. Oral examiner: Prof. Dr. Achim Dohrenbusch

Date of oral examination: 28.04 .2020 


\section{Abstract: Implications of forest structure on carbon dioxide fluxes}

Forests provide numerous crucial ecosystem services to society that are sensitive to climate and to extreme climate events such as droughts. One of the services of interest is the ability to sequester the greenhouse gas carbon dioxide $\left(\mathrm{CO}_{2}\right)$. Species mixture and structural heterogeneity has been suggested to reduce the effect of climate variability on forests. It is important to understand how increasing diversity and heterogeneity will help dampen the effect of climate events on $\mathrm{CO}_{2}$ uptake. Currently, knowledge about the ability of different forests to resist or recover from the effect of climate events is limited. To mitigate this knowledge gap, this thesis examines the implications of forest structure on $\mathrm{CO}_{2}$ fluxes. Chapter 1 provides the general background of the topic. Chapter 2 examines the implications of structural diversity for seasonal and annual $\mathrm{CO}_{2}$ fluxes in two temperate deciduous forests for a period of 11 years. The two forest sites have similar mean stand age and near-identical climate conditions but different stand structure. The main question asked was how management and related structural diversity may affect $\mathrm{CO}_{2}$ fluxes. We show that the annual net ecosystem productivity (NEP) was on average $13 \%$ higher in the managed, even-aged, and homogenous forest, than in the unmanaged, uneven-aged, and structurally diverse forest. The homogenous forest was observed to have, however, stronger sensitivities of seasonal NEP and gross primary productivity (GPP) to environmental variables. Chapter 3 relies on data from 21 Fluxnet sites to explore the effect of nine structural parameters on the temporal stability of light-saturated photosynthetic capacity $\left(\mathrm{GPP}_{1000}\right)$ and on its resistance to changes in water availability during droughts. The study addresses two questions, (a) Do structurally diverse forests have lower variation in annual $\mathrm{GPP}_{1000}$ ? (b) Are structurally diverse forests more resistant to drought events? The results show that unmanaged forests and forests managed as high forests, which have higher basal areas and tend to be older and more diverse in size than coppice forests, had more stable

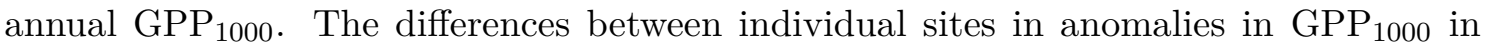
response to droughts were mostly explained by growing season air temperature. Forest structure could have influenced the response to droughts, but in our case the structure effect could not be separated from environmental effects. Chapter 4 presents a new model of soil water and related fluxes in forests, Forest Soil Water Model - FSWM, developed in the $\mathrm{R}$ environment. The model is suitable for predicting soil water in a wide range of forest soils. FSWM incorporates the Gash model for interception, the Ritchie model for soil evaporation and the Richards equation for soil water movement. FSWM's performance was evaluated against soil water measurements at 12 sites. The model performance was good for deciduous broadleaf forests, moderate for mixed forests and evergreen needle leaf forests. FSWM offers flexibility in simulating soil horizons with different depths and it is helpful when comparing modelled with observed values at different soil depths. With these characteristics, FSWM is a flexible and freely available tool for ecosystem and hydrological research. Additionally, two co-author papers are included in the appendix. The first paper assessed the net ecosystem $\mathrm{CO}_{2}$ exchange (NEE), total evapotranspiration and net primary production of two neighbouring beech (Fagus sylvatica L.) forests in central Germany differing in site management. We found the interannual variability was higher in the managed, even-aged stand, and the unmanaged forest was a weaker sink of $\mathrm{CO}_{2}$ during a 
dry year. The second paper investigated the factors influencing the interannual variability (IAV) of photosynthetic capacity at light saturation, a key ecosystem functional property determining gross primary productivity. The study found that the older and species rich forest had reduced IAV of GPP 1000 . In general, the results of this thesis support the idea that unmanaged forests, mostly older and diverse, have lower interannual variability in NEP, GPP and GPP 1000 as the result of their adaptation to the habitat by selecting appropriate species, developing structure to make best use of the light, water, and nutrient resources. During droughts, the effect of the forest structure was not clear. More research covering a large range of different sites is still required to get definitive results involving more structural attributes and sites from different climates.

\section{Key words:}

Carbon dioxide, droughts, photosynthetic capacity, forest structure, interannual variability, soil water model 


\section{Zusammenfassung: Bedeutung der Waldstruktur für Kohlendioxid-Flüsse}

Wälder bieten der Gesellschaft zahlreiche wichtige Ökosystemdienstleistungen (ESS, ecosystem services), die empfindlich gegenüber dem Klima und extremen Klimaereignissen wie bspw. Dürren sind. Eine für diese Arbeit relevante ESS ist die Fähigkeit, das Treibhausgas Kohlendioxid $\left(\mathrm{CO}_{2}\right)$ zu speichern. Es wird vermutet, dass Artendurchmischung und strukturelle Heterogenität, den Effekt von Klimaschwankungen auf Wälder reduzieren können. Es ist wichtig zu verstehen, wie zunehmende Diversität und Heterogenität dazu beitragen können, die Effekte von Klimaereignissen auf die $\mathrm{CO}_{2}$-Aufnahme zu dämpfen. Gegenwärtig ist die Fähigkeit verschiedener Wälder, den Klimaauswirkungen zu widerstehen oder sich von diesen zu erholen noch unbekannt. Diese Arbeit untersucht deshalb die Bedeutung von der Waldstruktur für die $\mathrm{CO}_{2}$-Flüsse, um diese Wissenslücke zu füllen. Kapitel 1 enthält den allgemeinen Hintergrund zur Thematik. Kapitel 2 untersucht die Rolle von struktureller Diversität für die saisonalen und jährlichen $\mathrm{CO}_{2}$-Flüsse in zwei gemäßigten Laubwäldern für einen Zeitraum von elf Jahren. Die beiden Waldgebiete haben ein ähnliches Bestandsalter und nahezu gleiche Klimabedingungen, jedoch ist die Bestandstruktur unterschiedlich. Die Hauptfrage war, wie sich das Management und damit verbundene strukturelle Diversität auf die $\mathrm{CO}_{2}$-Flüsse auswirken kann. Wir zeigen, dass die jährliche Nettoökosystemproduktivität (NEP, net ecosystem productivity) im gemanagten, gleichaltrigen und homogenen Wald im Durchschnitt um $13 \%$ höher war als im unbewirtschafteten, ungleichaltrigen und strukturell vielfältigen Wald. Das homogene Waldgebiet zeigte jedoch eine stärkere Empfindlichkeit der saisonalen NEP und der Bruttoprimärproduktivität (GPP, gross primary productivity) gegenüber Umwelteinflüssen. Kapitel 3 stützt sich auf Daten von 21 Fluxnet-Standorten, um den Effekt von neun strukturellen Parametern auf die zeitliche Stabilität der lichtgesättigten photosynthetischen Kapazität $\left(\mathrm{GPP}_{1000}\right)$ und auf ihre Widerstandfähigkeit gegenüber Veränderungen der Wasserverfügbarkeit während Dürren zu untersuchen. Die Studie befasst sich mit zwei Fragen: (a) Haben strukturell vielfältige Wälder eine geringere Variation der jährlichen GPP $_{1000}$ ? Und (b) Sind strukturell vielfältige Wälder resistenter gegenüber Dürreereignissen? Die Ergebnisse zeigen, dass unbewirtschaftete Wälder und als Hochwald bewirtschaftete Wälder, die höhere Grundflächen haben und tendenziell älter und vielfältiger in der Größe sind, stabilere jährliche GPP $_{1000}$ haben. Die Unterschiede zwischen den einzelnen Standorten hinsichtlich der Anomalien der GPP $_{1000}$ während Dürreperioden wurden hauptsächlich durch die Lufttemperatur in der Vegetationszeit erklärt. Kapitel 4 präsentiert ein neues Modell des Bodenwassers und dem damit verbundenen Flüssen in Wäldern - Forest Soil Water Model (FSWM), welches mithilfe von R entwickelt wurde. Das Modell eignet sich für das Simulieren von Bodenwasser in einem weiten Spektrum von Waldböden. FSWM beinhaltet das Gash-Modell für Interzeption, das Ritchie-Modell für Bodenverdunstung und die Richard-Gleichung für Bodenwasserbewegung. Die Leistungfähigkeit von FSWM wurde anhand von Bodenwassermessungen an 12 Standorten geprüft. Die Modellleistung war gut für Laubwälder, mäßig für Misch- und immergrüne Nadelwälder. FSWM bietet Flexibilität beim Simulieren von Bodenhorizonten mit verschiedenen Tiefen und ist nützlich, wenn modellierte und beobachtete Werte von verschiedenen Bodentiefen miteinander verglichen werden. Mit diesen Eigenschaften ist FSWM ein flexibles und frei verfügbares Werkzeug für Ökosystem- 
und hydrologische Forschung. Es sind zusätzlich zwei Co-Autorenbeiträge im Anhang enthalten. Der erste Aufsatz bewertete den Nettoökosystemaustausch (NEE, net ecosystem exchange) von $\mathrm{CO}_{2}$, die Gesamtevapotranspiration und die Nettoprimärproduktion (NPP, net primary production) für zwei benachbarte Buchenwälder (Fagus syvatica L.) in Mitteldeutschland, die sich im Standortmanagement unterschieden. Wir fanden heraus, dass die zwischenjährliche Variabilität im bewirtschafteten, gleichaltrigen Bestand höher, und die Funktion als $\mathrm{CO}_{2}$-Senke im unbewirtschafteten Wald während eines Trockenjahres niedriger war. Die Waldstruktur hätte die Reaktion auf Dürren beeinflussen können, aber in unserem Fall konnte der Struktureffekt nicht von den Umwelteinflüssen getrennt werden. Der zweite Aufsatz untersuchte Faktoren, die die zwischenjährliche Variabilität (IAV, interannual variability) der photosynthetischen Kapazität bei Lichtsättigung beeinflussen, einer wichtigen funktionalen Eigenschaft des Ökosystems, die die GPP bestimmt. Die Studie ergab, dass der ältere und artenreiche Wald die IAV der photosynthetischen Kapazität bei Lichtsättigung reduzierte. Im Allgemeinen unterstützen die Ergebnisse dieser Arbeit die Idee, dass unbewirtschaftete Wälder, vor allem ältere und artenreiche, eine geringere IAV in NEP, GPP und GPP 1000 aufweisen. Grund hierfür ist ihre Anpassung an das jeweilige Habitat durch die Selektion geeigneter Arten, wodurch eine Waldstruktur entsteht, die Licht, Wasser und Nährstoffressourcen effizienter nutzen kann. Der Effekt der Waldstruktur war während Dürreperioden nicht eindeutig. Um eindeutige Ergebnisse zu bekommen, sind weitere Untersuchungen notwendig, die ein breites Spektrum von verschiedenen Standorten aus verschiedenen Klimazonen und mehr strukturelle Attribute abdecken.

Schlagwörter: Kohlenstoffdioxid, Dürreereignissen, photosynthetischen Kapazität, Waldstruktur, zwischenjährliche Variabilität, Bodenwassermodell 


\section{Declaration}

I hereby declare that I wrote this PhD thesis under the supervision of Prof. Alexander Knohl, Dr. Mark Rayment and Dr. Fernando Moyano. Any sources of information and used literature have been acknowledged.

Göttingen, May 2020

Rijan Tamrakar 



\section{Contents}

1 Introduction 1

1.1 Role of forests in climate mitigation . . . . . . . . . . . . . . . . . 2

1.2 Forest structure . . . . . . . . . . . . . . . . . 3

1.3 Implications of forest structure on droughts . . . . . . . . . . 5

1.4 Soil water models . . . . . . . . . . . . . . . . 7

1.5 Aims and organization of the thesis . . . . . . . . . . . 9

2 Implications of structural diversity for seasonal and annual carbon $\begin{array}{lr}\text { dioxide fluxes in two temperate deciduous forests } & 13\end{array}$

2.1 Abstract . . . . . . . . . . . . . . . . . . . 14

2.2 Introduction . . . . . . . . . . . . . . . . . . . . . . . 14

2.3 Material and methods . . . . . . . . . . . . . . . . . . 16

2.3 .1 Site description . . . . . . . . . . . . . . . . . . 16

2.3.2 Eddy covariance and meteorological measurements . . . . . . . . 18

2.3 .3 Fruit production data . . . . . . . . . . . . . . 18

2.3 .4 Statistical analysis . . . . . . . . . . . . . . . . . . 18

2.4 Results . . . . . . . . . . . . . . . . . . . . . . . . 19

2.4 .1 Meteorological characteristics . . . . . . . . . . . . . . 19

2.4.2 Fruit production (masting) in the study sites . . . . . . . . . . 19

2.4.3 Cumulative net ecosystem productivity (NEP) . . . . . . . . . 20

2.4 .4 Seasonal variability of the $\mathrm{CO}_{2}$ fluxes $\ldots \ldots \ldots$. . . . . . . 22

2.4.5 Meteorological factors controlling seasonal variability in $\mathrm{CO}_{2}$ fluxes . . 25

2.4.6 Seasonal differences in $\mathrm{CO}_{2}$ fluxes between the two sites . . . . . . 25

2.4 .7 Annual estimates of NEP, GPP and Reco . . . . . . . . . . . . 26

2.4.8 Factors contributing to annual variability of NEP, GPP and Reco . . 27

2.5 Discussions . . . . . . . . . . . . . . . . . . 30

2.5.1 Meteorological controls of seasonal $\mathrm{CO}_{2}$ fluxes . . . . . . . . 30

2.5.2 Annual $\mathrm{CO}_{2}$ fluxes and its inter-annual variability . . . . . . . . 30

2.5.3 Effect of fruit production on $\mathrm{CO}_{2}$ fluxes . . . . . . . . . . . . 32

2.5.4 Effect of time on $\mathrm{CO}_{2}$ fluxes . . . . . . . . . . . . 32

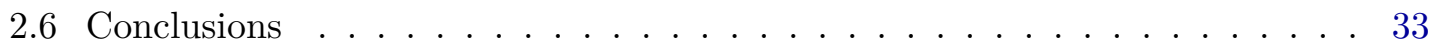

2.7 Supplementary materials . . . . . . . . . . . . . . . . . 34

3 Effect of forest structure on drought response of ecosytem-level photosynthetic capacity

3.1 Abstract . . . . . . . . . . . . . . . . . . . 44 


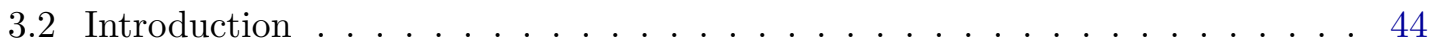

3.3 Material and methods . . . . . . . . . . . . . . . . . . . . . . . 47

3.3 .1 Sites . . . . . . . . . . . . . . . . . . . . 47

3.3.2 Forest structure indices . . . . . . . . . . . . . . . . . 47

3.3.3 Environmental data . . . . . . . . . . . . . . . . . 50

3.3.4 Annual light-saturated gross primary productivity $\left(\mathrm{GPP}_{1000}\right)$. . . . . 50

3.3.5 Drought estimation .................. . 51

3.3.6 Statistical analysis . . . . . . . . . . . . . . . . 52

3.4 Results . . . . . . . . . . . . . . . . . . . . . . 54

3.4.1 Structural characteristics of sites . . . . . . . . . . . . . . 54

3.4.2 Factors explaining inter-site variability in $\mathrm{CV}_{\mathrm{GPP} 1000}$. . . . . . . . 58

3.4.3 Factors affecting $\mathrm{GPP}_{1000}$ anomalies during droughts . . . . . . . . . . 60

3.5 Discussion ......................... 63

3.5.1 Temporal stability of $\mathrm{GPP}_{1000}$................. 63

3.5.2 Effect of forest structure on $\mathrm{GPP}_{1000}$ anomalies . . . . . . . . . . . 65

3.5.3 Limitations of the study . . . . . . . . . . . . . . . 65

3.5.4 Outlook ......................... 66

3.6 Conclusions ......................... . . 66

3.7 Competing interests . . . . . . . . . . . . . . . . . . 66

3.8 Acknowledgements .......................... 66

3.9 Supplementary materials . . . . . . . . . . . . . . . . . 68

4 A flexible forest soil water model (FWSM) in R 75

4.1 Abstract ........................ . 76

4.2 Introduction .......................... . 76

4.3 Materials and methods . . . . . . . . . . . . . . . . . . 78

4.3.1 Model description ...................... . . 78

4.3 .2 Data ........................ . . 83

4.3.3 Model parameterizations ................... 84

4.3.4 Model evaluation . . . . . . . . . . . . . . . . . . . . . 84

4.4 Results and discussions . . . . . . . . . . . . . . . . . . . . . 84

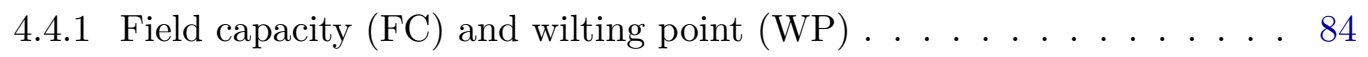

4.4 .2 Model parameterizations . . . . . . . . . . . . . . . 85

4.4 .3 Model evaluation . . . . . . . . . . . . . . . . . . . . 86

4.4.4 Average annual values of different ET components . . . . . . . . . . 89

4.5 Conclusions .......................... . 89

4.6 Supplementary materials . . . . . . . . . . . . . . . . . . . 90

4.6.1 Model evaluation other sites . . . . . . . . . . . . . . . . . 91

4.6.2 Model Parameter correlation . . . . . . . . . . . . . . . . . . . . . 99

4.6.3 Using Priestley Taylor formulation of evapotranspiration . . . . . . . . 100

4.6.4 Evapotranspiration component for DE-Hai from BILJOU model . . . 101

4.6.5 Variation of texture in DE-Hai . . . . . . . . . . . . . . 102 
5 Synopsis

5.1 Higher average long-term net ecosystem productivity (NEP) in a structurally homogeneous forest. . . . . . . . . . . . . . . . . 105

5.2 Lower interannual variability of net ecosystem productivity (NEP) in a heterogeneous forest. . . . . . . . . . . . . . 106

5.3 Lower interannual variability of ecosystem-level photosynthetic capacity in unmanaged forests. . . . . . . . . . . . . . . 107

5.4 The impact of drought on the ecosystem-level light-saturated photosynthetic capacity of forests. . . . . . . . . . . . . . . . . . 107

5.5 Development of an open-source soil water model. . . . . . . . . . . . . . 108

5.6 Outlook . . . . . . . . . . . . . . . . . . . 109

A Difference in carbon uptake and water use between a managed and an unmanaged beech forest in central Germany

A.1 Abstract . . . . . . . . . . . . . . . . . . . . . . . . 112

A.2 Introduction . . . . . . . . . . . . . . . . . . . . . 112

A.3 Material and methods . . . . . . . . . . . . . . . . . . 113

A.3.1 Sites . . . . . . . . . . . . . . . . . . 113

A.3.2 Eddy covariance data . . . . . . . . . . . . . . . . 115

A.3.3 Biometric data . . . . . . . . . . . . . . . . . 115

A.4 Results . . . . . . . . . . . . . . . . . . . . 117

A.5 Discussion . . . . . . . . . . . . . . . . . . . . 120

A.5.1 Methodological uncertainties . . . . . . . . . . . 120

A.5.2 Interannual variability in carbon fluxes . . . . . . . . . . . . 122

A.5.3 Evapotranspiration . . . . . . . . . . . . . . . . . . . 122

A.5.4 Diversity and resilience . . . . . . . . . . . . . . . . 123

A.6 Conclusions . . . . . . . . . . . . . . . . . . . . . . . . . . . . . . . 124

A.7 Acknowledgements . . . . . . . . . . . . . . . . . . . . . 124

B Stand age and species richness dampen interannual variation of ecosystemlevel photosynthetic capacity

B.1 Abstract . . . . . . . . . . . . . . . . . . 126

B.2 Introduction . . . . . . . . . . . . . . . . . . 126

B.3 Material and methods . . . . . . . . . . . . . . . . . 128

B.3.1 Data . . . . . . . . . . . . . . . . . . . . 128

B.3.2 Estimation of photosynthetic capacity and its interannual variability magnitude . . . . . . . . . . . . . . . 130

B.3.3 Statistical analysis . . . . . . . . . . . . . . . . 131

B.4 Results . . . . . . . . . . . . . . . . . . . . . . . 132

B.5 Discussion and conclusion . . . . . . . . . . . . . . . 135

B.6 Acknowledgements . . . . . . . . . . . . . . . . . . . 137

B.7 Author contributions . . . . . . . . . . . . . . . . 137

B.8 Additional information . . . . . . . . . . . . . . . . . . 137

B.8.1 Code availability . . . . . . . . . . . . . . . 137 
B.8.2 Data availability . . . . . . . . . . . . . . . . . . 137

B.8.3 Supplementary information . . . . . . . . . . . . . . . 137

B.8.4 Reprints and permissions information . . . . . . . . . . . 137

B.8.5 Correspondence and requests for materials . . . . . . . . . 137

B.8.6 How to cite this article . . . . . . . . . . . . . . . 138

B.9 Competing interests . . . . . . . . . . . . . . . . 138

$\begin{array}{ll}\text { Bibliography } & 139\end{array}$

$\begin{array}{ll}\text { Curriculum vitae } & 171\end{array}$

$\begin{array}{ll}\text { Acknowledgments } & 173\end{array}$ 
CHAPTER 1

Introduction 


\subsection{Role of forests in climate mitigation}

Forests provide numerous societal services like provisioning (e.g., food, fuelwood, timber, etc.), regulating (e.g., climate regulation, water regulation, pollination, etc.), cultural (e.g., spiritual, recreations, educational, etc.) and supporting (e.g., soil formation, nutrient cycling, primary production) services (Alcamo et al., 2003). Among these services, climate regulation has been hugely discussed and debated in the context of climate change (CANADELl et al., 2008; LAW et al., 2018). Terrestrial ecosystems absorbed $30 \%$ of anthropogenic carbon dioxide $\left(\mathrm{CO}_{2}\right)$ emissions in the last five decades (LE QUÉRÉ et al., 2018) mostly through carbon accumulation in forest biomass and soils (PAN et al., 2011). Temperate forests contributed to $31 \%$ of the global terrestrial carbon sink between 1990 to 2007 (PAN et al., 2011).

In recent years, the frequency of occurrence of meteorological anomalies have increased (IPCC, 2018). In some circumstances, these events have severe impacts on terrestrial ecosystem (BABST et al., 2012; IPCC, 2012; REICHSTEIN et al., 2013). In the case of terrestrial ecosystems, these events can partially offset carbon sinks or even cause net carbon losses releasing $\mathrm{CO}_{2}$ to the atmosphere (CIAIS et al., 2005; GRANIER et al., 2007; XIAO et al., 2011). Global analysis of extreme events indicated that the anomalies in $\mathrm{CO}_{2}$ uptake by vegetation was of similar magnitude to the total terrestrial carbon sink (ZSCHEISCHLER et al., 2013). In addition to immediate responses, many studies have shown that such extreme events can also show time-lagged responses such as mortality, fires or pest infestations (CiaIs et al., 2005; KurZ et al., 2008; PAGE et al., 2002; ZEng et al., 2009).

One of the suggested methods to mitigate the impact of extreme climates on forest ecosystems is creating more diverse forest because species-rich forests provide higher levels of ecosystem functions (GAMFELDT et al., 2013; LIANG et al., 2016; ZHANG et al., 2012). For example, mixed spruce/beech forests (GRIESs et al., 2011; PRETZsCH et al., 2010) and oak / beech (PRETZsCH et al., 2013) mostly outyield pure stands of the same species by about $20 \%$. The influence of species richness on productivity is, however, modulated by climate (JUCKER et al., 2016) and site conditions (PoTTER et al., 2014). Furthermore, the temporal stability in productivity of diverse forests are higher (JUCKER et al., 2014; Morin et al., 2014) than monocultures. The key processes that enhances forest productivity and temporal stability are overyielding (when productivity of a mixture exceeds the average productivity of monocultures of component species - SCHMID et al. 2008), species asynchrony, complementarity (MORIN et al., 2011) and species interaction (JuCKER et al., 2014; Morin et al., 2014).

In addition to creating more species rich forests, efforts have been made to create forest with complex horizontal and vertical structures that resemble old-growth forests (Puettmann et al., 2015) because they are believed to have more ecological resistance and stability (Pommerening, 2002). Forest management practices, particularly in Europe and North America, are towards uneven-aged and multi-species forests (BAUHUs et al., 2009). The presence of trees with different sizes (in terms height and root depth) leads to differential resource availability e.g. water (BRIENEn et al., 2017; DAwson, 1996) and light (DHôte, 1994). Additionally, competition dynamics among trees are affected by 
population hierarchy (ZANG et al., 2012).

\subsection{Forest structure}

Species diversity conflates structural and genetic diversity. Many studies have so far studied effect of species diversity on productivity, or drought sensitivity. In this thesis, we split these factors and focus on the structural diversity.

Forest structure can be defined as horizontal and vertical distribution of trees in forest stand. The horizontal structure can be quantified based on dbh, spatial distribtion of trees, or canopy distribution. The vertical structure on the other hand can be assessed by tree height.

In the recent times, the management of forests in an ecologically sustainable manner is widely considered to be desirable (FARES et al., 2015; RUTishauser et al., 2015; SASAKI et al., 2016). Appropriate indicators to characterize the forests are essential to assess the results of such management activities (LinDENMAYER et al., 2000). Forest stand structural indices can be used in assessing the impact and success of management, and providing further recommendations for choosing the appropriate management strategies (Müller et al., 2000; Pommerening et al., 2013). Further, the values of stand structural indices can be used to differentiate forest management regimes and intensities (YOUnG et al., 2017). Species richness and species diversity are the two most common approaches to describe diversity in forest structure (SPELLERBERG et al., 2003). Other approaches include describing forests in terms of (a) its stand structure i.e. varieties of trees (in terms size), logs, and snags and their spatial arrangement (LindENMAYER et al., 2000) and (b) functions (e.g. carbon sequestration, biomass production, see FRANKLIN et al., 2002). Species composition, structural and functional attributes are usually interdependent (Hakkenberg et al., 2016; Pretzsch et al., 2016). For example Pretzsch et al. (2016) found that the forests with two species were more structurally heterogeneous (diverse vertical structure) than the forests with monoculture of same species. For simplification and to include attributes of all three different approaches, McELHinny et al. (2005) introduced the term 'structural attributes' to characterise the forest structure pooling attributes from all three approaches. Forest stand structure is then described by either single stand structural attributes (e.g. canopy cover, number of species) or combination of different stand structural attributes (e.g. structural complexity index, ZENNER et al. 2000). McElhinny et al. (2005) and Río et al. (2016) have listed indices of around 50 different stand structure attributes. The stand elements characterised by latter include: stand density, species proportion, species composition, horizontal spatial pattern, species intermingling, vertical pattern, size distribution and age composition. Two studies have in particular, examined the inter-relationships and inter-dependencies between these stand structural indices (Schall et al., 2018; Sterba et al., 2006). Schall et al. (2018) found significant correlation between many pairs and thus suggested to use multiple structural indices for reliable classifications of different forest types along axes of stand structures.

Table 1.1 lists studies looking into relationship between different structural indices and forest functions. Most of the studies have assessed the relationship of forest structure indices like stem number, basal area, diameter at breast height $(\mathrm{DBH})$, etc. and productivity (for e.g. Ali et al. 2016; Dănescu et al. 2016; SChall et al. 2018), few others have focused 
Table 1.1: List of studies investigating the relationship between different structural indices and forest functions.

\begin{tabular}{|c|c|c|}
\hline Structural index & Forest functions & Reference \\
\hline Stand density, stand composition & Drought response of radial growth & BELLO et al. (2019b) \\
\hline $\begin{array}{l}\text { Stem number, basal area, canopy pro- } \\
\text { jection area, stand volume, species pro- } \\
\text { portion by the share of conifers, species } \\
\text { richness, the exponential Shannon di- } \\
\text { versity, Pielou's index of segregation, } \\
\text { etc. }\end{array}$ & $\begin{array}{l}\text { Timber volume, timber volume growth } \\
\text { rate }\end{array}$ & SCHALL et al. (2018) \\
\hline $\begin{array}{l}\text { Stand structural complexity index from } \\
\text { effective number of vertical layers }\end{array}$ & Microclimate & $\begin{array}{l}\text { EHBRECHT et al. } \\
(2017)\end{array}$ \\
\hline Stand age, tree species diversity & $\begin{array}{l}\text { Temporal stability of ecosystem-level } \\
\text { photosynthetic capacity }\end{array}$ & Musavi et al. (2017) \\
\hline $\begin{array}{l}\text { Coefficient of variation, Gini coefficient, } \\
\text { Shannon index, and Shannon evenness } \\
\text { of DBH and height distribution, close- } \\
\text { ness to a J-shaped distribution and } \\
\text { skewness of DBH distribution, Shannon } \\
\text { index and Shannon evenness of species }\end{array}$ & Basal area increment & $\begin{array}{l}\text { DĂNESCU et al. } \\
(2016)\end{array}$ \\
\hline $\begin{array}{l}\text { Shannon-Wiener index of species, DBH } \\
\text { and height distribution, stand age }\end{array}$ & Aboveground carbon (C) storage & Ali et al. (2016) \\
\hline $\begin{array}{l}\text { Stand structural complexity index, sil- } \\
\text { vicultural management intensity, natu- } \\
\text { ralness }\end{array}$ & $\begin{array}{l}\text { Diversity of mosses and higher plants, } \\
\text { fungi, birds }\end{array}$ & Gossner et al. (2014) \\
\hline Stand composition and tree size & $\begin{array}{l}\text { Sensitivity of tree ring growth to } \\
\text { droughts }\end{array}$ & MERLin et al. (2015) \\
\hline Canopy rugosity & $\begin{array}{l}\text { Aboveground net primary productivity, } \\
\text { light use efficiency, nitrogen use effi- } \\
\text { ciency }\end{array}$ & $\begin{array}{l}\text { HARDIMAN et al. } \\
(2013)\end{array}$ \\
\hline Canopy rugosity & Net primary productivity & $\begin{array}{l}\text { HARDIMAN et al. } \\
(2011)\end{array}$ \\
\hline $\begin{array}{l}\text { Stand density index, the average height } \\
\text { of dominant and codominant trees (site } \\
\text { index) }\end{array}$ & Periodic annual increment & LONG et al. (2010) \\
\hline $\begin{array}{l}\text { Shannon-Wiener index for basal area, } \\
\text { DBH and height, integrated Shannon- } \\
\text { Wiener index for species and DBH, and } \\
\text { species and height, Gini coefficient of } \\
\text { DBH and height }\end{array}$ & $\begin{array}{l}\text { Periodic annual increment, periodic an- } \\
\text { nual survivor growth, periodic annual } \\
\text { mortality, periodic annual recruitment }\end{array}$ & LEI et al. (2009) \\
\hline $\begin{array}{l}\text { Shannon's index based on species and } \\
\text { basal area }\end{array}$ & $\begin{array}{l}\text { Basal area growth, recruitment, and } \\
\text { mortality }\end{array}$ & LIANG et al. (2007) \\
\hline $\begin{array}{l}\text { Age, dominant height at base age of } \\
100 \text { year (site quality), species mixture, } \\
\text { relative density index, DBH }\end{array}$ & Individual tree basal area increment & HEIN et al. (2006) \\
\hline $\begin{array}{l}\text { Canopy complexity, species richness, fo- } \\
\text { liage height diversity }\end{array}$ & Productivity, insect diversity & IsHiI et al. (2004) \\
\hline $\begin{array}{l}\text { Tree top height, crown closure, vertical } \\
\text { stand structure, conifer proportion }\end{array}$ & Wind damage & DobBertin (2002) \\
\hline $\begin{array}{l}\text { Age, Basal area, DBH, crown cover, } \\
\text { fertility, species richness, Shannon di- } \\
\text { versity index, reciprocal of Simpson di- } \\
\text { versity index, Pielou index of evenness, } \\
\text { Hill's index of diversity }\end{array}$ & Diversity of ground vegetation & PITKÄNEN (1997) \\
\hline
\end{tabular}


on drought sensitivity of radial growth (for e.g. BELLO et al. 2019b; MERLin et al. 2015) and some animal diversity (e.g. DobBertin 2002; Gossner et al. 2014). Results on productivity were mostly positive, i.e. higher values of structural diversity meant higher forest productivity. Different studies used different structural indices. Ali et al. (2016) reported the strongest correlation of stand age followed by indices based on DBH and height, and the effect of species diversity was least on aboveground carbon storage. Similarly, HARDIMAN et al. (2011) concluded that the increase in canopy structural complexity provide a mechanism for the potential maintenance of productivity in ageing forests. HEIN et al. (2006) however did not find forest structure as a predictor of productivity but the site quality.

\subsection{Implications of forest structure on droughts}

Droughts are defined as a period with prolonged deficiency of rainfall or abnormally dry weather sufficiently long to cause a hydrological imbalance (WORLD METEOROLOGICAL Organization, 1992). Droughts can be the result of hydrometeorological anomalies (VAN LOON, 2015) or alteration of the water cycle by anthropogenic activities (VAN LOON et al., 2016). At least 52 exceptional drought events occurred at macro-regional scale between 1951-2016 worldwide (SPINONI et al., 2019). The frequency and severity of drought events are expected to increase in future (SPINONI et al., 2019; SPINONI et al., 2017; TREnBERTH et al., 2014).

Droughts negatively affect forests around the globe (ALLEn et al., 2015; ANDEREGG et al., 2013; Choat et al., 2018; Granier et al., 2007; Reichstein et al., 2013; Reichstein et al., 2007). In trees, water travels from the soil to the leaves, via hydraulic supply network formed by xylem tissue (TYREE et al., 2002). When the water demand for transpiration is higher than the supply in root from the soil, the trees start responding from the molecular to ecosystem level to mitigate the effect of drought (BARBETA et al., 2016). At shorter time-scales, the trees respond by closing their stomata at the leaf-atmosphere interface to down-regulate transpiration (BRÉDA et al., 2006) and by shedding leaves (OGAYA et al., 2006) to limit water loss. At longer time-scales, trees reduce shoot-growth to increase root-to-shoot ratio; enhance fine root growth; develop deeper roots; amass solutes to reduce the water potential in the root tissue (BRUNNER et al., 2015); modifying xylem conduits (PAllardy, 2002). Further severe droughts leads to canopy or whole plant death and cause of which is mostly related to failure of hydraulic networks of trees (ANDEREGG et al., 2012; Davis et al., 2002; NARdini et al., 2013; Venturas et al., 2016). The response strategies, however, varies with biomes (VICENTE-SERRANO et al., 2013), species (OGAYA et al., 2006), and age of trees/stands (CAVENDER-BAREs et al., 2000).

The response of forests to droughts can be modified by tree species mixing and heterogeneous structure (PRETZSCH et al., 2013). However, most of the studies have so far looked at the effect of species diversity on drought sensitivity. Here, we report some recent publication that focus on species diversity (Table 1.2). Our review suggests that the direction and strength of the modification depends on the species mixture (BELLO et al. 2019b; Grossiord 2019; Lebourgeois et al. 2013 and biomes (Grossiord et al., 2014c). We define effect as positive when the drought sensitivity is reduced by species diversity and negative when drought sensitivity is enhanced by species diversity. Five studies showed 
Table 1.2: List of studies reporting the effect of species diversity on the drought responses of the forest. Species mixture are the names of species reported in the study. The conclusion column categorized study conclusion as negative (drought sensitivity increased with the increase in species diversity), neutral (no clear effect of species mixing on drought sensitivity), positive (drought sensitivity was reduced by increasing species diversity), and both (effect of structure were different from site to site, positive in some sites and negative in others).

\begin{tabular}{|c|c|c|c|}
\hline Study & Region/Forests & Species mixture & Conclusion \\
\hline BELLO et al. (2019b) & $\begin{array}{l}\text { Orléans forest, } \\
\text { France }\end{array}$ & Quercus petraea and Pinus sylvestris & Negative \\
\hline Tö̈GO et al. (2015) & $\begin{array}{l}\text { Orléans forest, } \\
\text { France }\end{array}$ & Quercus petraea and Pinus sylvestris & Negative \\
\hline $\begin{array}{l}\text { GROSSIORD et al. } \\
(2014 \mathrm{~b})\end{array}$ & $\begin{array}{l}\text { South-central Tus- } \\
\text { cany, Italy }\end{array}$ & Quercus cerris and Quercus petraea & Negative \\
\hline $\begin{array}{l}\text { Grossiord et al. } \\
(2014 \mathrm{~d})\end{array}$ & Boreal forests & $\begin{array}{l}\text { Betula pendula, Pinus sylvestris, and Picea } \\
\text { abies }\end{array}$ & Negative \\
\hline $\begin{array}{l}\text { VANHELLEMONT et al. } \\
(2019)\end{array}$ & Northern Belgium & $\begin{array}{l}\text { Fagus sylvatica, Quercus robur, and } Q \text {. } \\
\text { rubra }\end{array}$ & Neutral \\
\hline ZALLONI et al. (2019) & $\begin{array}{l}\text { Vesuvio National } \\
\text { Park, Italy }\end{array}$ & Quercus ilex L. and Pinus pinea & Neutral \\
\hline $\begin{array}{l}\text { DĂNESCU et al. } \\
(2018)\end{array}$ & $\begin{array}{l}\text { South-western Ger- } \\
\text { many }\end{array}$ & Spruce and fir & Neutral \\
\hline BELLO et al. (2019a) & Orléans state forest & Quercus petraea and Pinus sylvestris & Positive \\
\hline SidOR et al. (2018) & $\begin{array}{l}34 \text { forest sites in Ro- } \\
\text { mania }\end{array}$ & $\begin{array}{l}\text { Pinus sylvestris L. mixed with other } \\
\text { species. }\end{array}$ & Plus \\
\hline $\begin{array}{l}\text { SOUSA-SiLVA et al. } \\
\text { (2018) }\end{array}$ & Belgium & $\begin{array}{l}\text { Fagus sylvatica, Quercus petraea, and Quer- } \\
\text { cus robur }\end{array}$ & Positive \\
\hline $\begin{array}{l}\text { KOTLARZ et al. } \\
(2018)\end{array}$ & Poland & Pinus sylvestris L. and Quercus robur $L$. & Positive \\
\hline $\begin{array}{l}\text { ANDEREGG et al. } \\
(2018)\end{array}$ & Fluxnet sites & Species were different in each forest types & Positive \\
\hline GrandA et al. (2018) & $\begin{array}{l}\text { Agüero, northeast } \\
\text { Spain }\end{array}$ & $\begin{array}{l}\text { Pinus halepensis, Pinus nigra subsp. Salz- } \\
\text { mannii and Pinus sylvestris L. }\end{array}$ & Positive \\
\hline METZ et al. (2016) & $\begin{array}{l}\text { Three major geo- } \\
\text { graphic regions of } \\
\text { Germany }\end{array}$ & Fagus sylvatica with other species & Positive \\
\hline MÖLDER et al. (2014) & $\begin{array}{l}\text { Hainich National } \\
\text { Park, Germany }\end{array}$ & Fagus sylvatica with five other species & Positive \\
\hline $\begin{array}{l}\text { LEBOURGEOIS et al. } \\
(2013)\end{array}$ & $\begin{array}{l}\text { crystalline Vosges } \\
\text { Mountains, France }\end{array}$ & $\begin{array}{l}\text { Abies alba with Fagus sylvatica and with } \\
\text { Picea abies }\end{array}$ & Positive \\
\hline $\begin{array}{l}\text { PRETZSCH et al. } \\
(2013)\end{array}$ & South Germany & $\begin{array}{l}\text { Picea abies, Fagus sylvatica, and Quercus } \\
\text { petraea }\end{array}$ & Positive \\
\hline ViTALI et al. (2018) & Black Forest & Norway spruce, silver fir and Douglas fir & Both \\
\hline $\begin{array}{l}\text { FORRESTER et al. } \\
(2016)\end{array}$ & $\begin{array}{l}\text { Major European for- } \\
\text { est types }\end{array}$ & Species were different in each forest types & Both \\
\hline $\begin{array}{l}\text { GROSSIORD et al. } \\
(2014 \mathrm{c})\end{array}$ & $\begin{array}{l}\text { Five forest types of } \\
\text { Europe }\end{array}$ & Many & Both \\
\hline
\end{tabular}


negative effects of species diversity on the drought sensitivity of forests, three did not find any relationship, three reported positive and negative effects which differed from one site to another, and nine reported positive effects. In order to understand these differences in the results, we have tried to understand the effect of forest structural heterogeneity on carbon dioxide.

In order to estimate effect of structural heterogeneity of forests on drought response, we require an appropriate tool to quantify drought. In next section, we discuss different types of models that have been used to calculate soil water in the forests, a key parameter reflecting water availability to the trees.

\subsection{Soil water models}

Soil water availability is one of the major factors that limits productivity and decomposition or mineralisation of soil organic matter in forests (PAUL et al., 2003). Recently, there has been an increasing reports on severe effects of water shortage on forests around the world (Allen et al., 2015). These impacts include episodes of large-scale diebacks, sudden drops in productivity after extreme droughts (BRESHEARs et al., 2005) and chronic increases in tree mortality and growth decline (BussotTi et al., 2017). Understanding the effects of droughts on forest productivity and tree mortality is crucial to formulate adaptive forest management strategies (LINDNER et al., 2014). Modelling forest production, drainage and turnover of organic matter and nutrients all need accurate predictions of soil water content (PAUl et al., 2003).

Measurement of soil water content can be expensive, requires a lot of time, and is a complex process due to its inherent temporal and spatial variability. Therefore, a number of soil water simulation models have been developed during the last several decades with a wide range of sophistication (JoNG et al., 1996). One of the earliest model was developed by Thornthwaite (1948). The model simulates soil water using a simple water balance approach in which mean monthly precipitation and soil water storage is balanced against estimated potential evapotranspiration. The budgeting procedures have slowly become more complicated by utilizing daily time steps, multi-layering of the soil profile and variable rates of extraction and movement of water from the various zones (JoNG et al., 1996). In addition, several models simulate three interconnected components namely (i) the atmosphere (i.e. potential evapotranspiration), (ii) the crop (i.e. plant phenology) and (iii) the soil (i.e. root-zone water) such as models developed by RADDATZ 1993.

Many of them are used to estimate soil water availability for forest growth which predict water content within the root zone of stands and water content within surface soil layers under forests PAUL et al. (2003). Recently, many improvements have been made in soil water models for more accurate predictions and more suitable application. Here, we briefly describe a few recent soil water models used in the context of forest soils. First we describe few simple bucket models like simple water balance model (SWBM), Simple process-led algorithms for simulating habitats model (SPLASH), lumped water balance model (BILJOU), and soil water under forest (SWUF) followed by more complex vegetation models like Simulator for Mediterranean landscapes (SIERRA), coupled heat and mass transfer model for soil-plant-atmosphere systems (CoupModel), Lund-Potsdam-Jena Dynamic Global Vegetation Model (LPJ), and CASTANEA. 
OrTH et al. (2013) modified simple water balance model (SWBM) proposed by Koster et al. (2012). The model considers evapotranspiration and run-off ratios as simple functions of soil moisture. The model shows that simple water balance model can be utilized together with precipitation, net radiation, and measurements to predict soil moisture and its controls even in the situation where direct soil moisture measurements are not present.

Simple process-led algorithms for simulating habitats (SPLASH) model offers robust estimations of key quantities at ecologically relevant time-scales. The model can be used to produce driving datasets for ecological and land-surface models (e.g., monthly carbon and water fluxes or seasonal plant functional trait distributions) from more readily available meteorological observations. The model shows promising results in spite of the model's simplifications and limited climatic drivers (DAvis et al., 2017).

A lumped water balance model (BILJOU) was developed to quantify drought intensity and duration in forest stands (GRANIER et al., 1999). The information needed by the model includes daily potential evapotranspiration and rainfall as input climatic data. The site and stand parameters needed include maximum extractable soil water and leaf area index, the latter controlling (i) stand transpiration; (ii) forest floor evapotranspiration; and (iii) rainfall interception. Other informations such as root distribution and soil porosity can also be utilized if available. The robustness of the model and its easy parametrisation for a large range of species and soil types make it suitable for many ecological applications on both inter- and intra-annual basis (GRANIER et al., 1999).

Soil water under forest (SWUF) model was developed by PAUL et al. (2003) which is used to predict daily water content within both surface soil layers and the sub-soil under a range of forest types. It is a simple cascading water bucket model which was mainly derived by combining algorithms from well-tested models for prediction of soil water under agriculture and extend them to account for interception by, and evaporation from, the dense canopy and litter layer, and the influence of site mounding, and weeds or understorey of forests, on soil water. The model can also be integrated in models of mineralisation of soil organic matter as well as models of forest production. The model was intentionally developed for simple and easy use. Therefore, it only requires easily obtainable data such as leaf area index, litter layer mass, irrigation applied, bulk density, and the upper and lower limit of water content.

Simulator for Mediterranean landscapes (SIERRA) was developed for particular use in Mediterranean-type communities subjected to large recurrent fires. The main property of the model is to utilize explicit functional processes to simulate vegetation dynamics based on fluxes of water and carbon. A spatial representation of the annual course of vertical structure of biomass and carbon fluxes coupled with the weekly soil water budget and evapotranspiration rates can be obtained using the model. The model shows that a weekly water budget is the main driver for primary production and inter-specific competition according to water availability, and at the same time simulates seasonal water stress of species. So far, the model has no limitation towards the species composition and it can be used as a practical tool for a large range of water limited ecosystems (MouiLLOT et al., 2001).

Coupled heat and mass transfer model for soil-plant-atmosphere systems (CoupModel) can be used to explain many problems regarding hydrological and/or thermal processes in 
the soil-plant-atmosphere system. Examples of the model application include simulation of regulating factors for biological and chemical processes in the soil, simulation of coupled biological and abiotic processes, simulation of coupled atmosphere and soil processes, generalisation of results to new soils, climates and time periods, and prediction of the influence of management e.g. soil heat extraction, mulching, drainage, irrigation and plant husbandry (JANSSON et al., 2011).

The Lund-Potsdam-Jena Dynamic Global Vegetation Model (LPJ) incorporates processbased large-scale representations of terrestrial vegetation dynamics and land-atmosphere carbon and water exchanges in a modular framework. The property of the model include feedback through canopy conductance between photosynthesis and transpiration and interactive coupling between these 'fast' processes and other ecosystem processes such as resource competition, tissue turnover, population dynamics, soil organic matter and litter dynamics and fire disturbance (SiTch et al., 2003).

DAVI et al. (2005a) developed a new hybrid model, CASTANEA, described in DAVI et al. (2005b), to simulate the carbon balance and the water cycle. The purpose of the model is to obtain net carbon and water fluxes of deciduous forest from half-hourly to multi-annual time scales and to accurately simulate ecosystem changes in biomass and soil organic matter from season to decades. The carbon balance input data includes canopy photosynthesis, autotrophic and heterotrophic respirations, net ecosystem exchange, wood and root growth. The water fluxes includes transpiration, soil evaporation, interception, drainage and soil water status. The model results simulates all the measured individual processes well, except the root respiration, which was underestimated during summer (DAVI et al., 2005a). Therefore, the model suggests that more effort is needed on studying and modelling both root respiration and root turnover.

The described models are either not standalone soil water model but part of the land surface models (e.g. LPJ, CASTANEA, SIERRA, coupModel), or simple that does not take into account the soil and vegetation characteristics (e.g. SWBM, SPLASH). Models like SWUF and BILJOU are standalone model that takes into soil and vegetation characteristics. However, SWUF is built on MS-excel platform and BILJOU is online. Running these model for a single site or few years work excellently. But when we require the model to run for many sites with different sets of parameters both models become impractical. Additionally, modifying or improving the process is not possible in BILJOU as it is not open source and complicated in SWUF. Thus, an multi-layer soil model that can easily be used without many parameters and is open access is still missing.

\subsection{Aims and organization of the thesis}

Increase in anomalous events including droughts are predicted for future (BARRIOPEDRO et al., 2011; GREve et al., 2015). In this context, understanding adaptation and mitigation strategies for forests to cope with changing climate is essential. Forest structure can affect forest functions through niche complementarity, vertical and horizontal size diversity, etc. The effect of forest structure on drought sensitivity on forest functions are however not clear with different studies pointing to different directions. To understand the response of ecosystems to environmental and biotic disturbances, we can look at temporal stability and resistance of the ecosystems. Temporal stability of any ecosystem function (annual 
net ecosystem productivity and light saturated photosynthetic capacity in our case) is a measure of how much these functions fluctuate around its long-term mean between years (Tilman, 1999) and is related to ecosystem resilience (Holling, 1973). The resistance is the capacity of an ecosystem to remain unchanged after a disturbance (GRIMM et al., 1997). In this thesis, we used the difference between observed values during an anomalous year and long-term mean of an ecosystem function, normalized by long-term mean to allow inter site comparison, to estimate resistance of forest ecosystem. The four major aims of this thesis are to:

- investigate the annual and seasonal carbon dioxide fluxes in two differently structured forest.

- assess the implications of forest structure on temporal stability of carbon dioxide fluxes.

- examine the effect of forest structure on resistance of carbon dioxide fluxes during droughts.

- report the flexible open source forest soil water model (FWSM).

This work, 'The effect of forest structures on carbon dioxide fluxes', provide insights on how forest heterogeneity modulates the temporal stability and resistance of carbon dioxide fluxes during droughts. We investigated the effects of forest structure on temporal variability of carbon dioxide fluxes and anomalies of photosynthetic capacity during droughts, and additionally reported a flexible soil water model (FWSM). Here we have made an first attempt to calculate the structural indices for forests for which the carbon dioxide fluxes are readily available in fluxnet dataset (https://fluxnet.fluxdata.org/ data/fluxnet2015-dataset/). Using inventory data along with the fluxnet data provides an unique opportunity to study the impact of forest structure on carbon dioxide fluxes using multiple sites when most of the studies use only few sites (see Table 1.1 and 1.2). Thus we combined approaches from two scientific community, i.e. forest structure from forestry and carbon dioxide fluxes from micrometeorology. Also the availability of meteorological data at different time-scales (half-hourly, daily, monthly and yearly), allows quantifying droughts at different temporal scales. Here, we took an opportunity to develop a open source soil water model capable of estimating drought at daily scale.

I start this thesis describing the background on structural indices, how forest structure modifies forest functions, and different soil water models available in present days in chapter 1 . The introduction is followed by three scientific chapters presented as manuscript. After that in appendix I present two more scientific papers with a short description of the contribution I made. The five scientific studies are as following:

- Implications of structural diversity for seasonal and annual carbon dioxide fluxes in two temperate deciduous forests (chapter 2 of this thesis)

Rijan Tamrakar, Mark B. Rayment, Fernando Moyano, Martina Mund, and Alexander Knohl

published in Agriculture and forest meteorology (TAMRAKAR et al., 2018) 
In this paper we studied two forests of similar mean stand age near-identical site conditions, and dominated by beech trees (Fagus sylvatica), but with a very different stand structure (including age, diameter distribution, stocks of dead wood and species composition) because of different management regimes. We observed higher annual net ecosystem productivity (NEP) in the managed, even-aged, and homogeneous forest, than in the unmanaged, uneven-aged, and structurally diverse forest. On the other hand, inter-annual variation was lower in the structurally diverse forest than homogeneous managed forests. The higher variability of NEP in the homogeneous forest was attributed to biotic factors such as fruit production and a time-dependent growth trend.

- Effect of forest structure on drought response of forest canopy photosynthetic capacity (chapter 3 of this thesis)

Rijan Tamrakar, Mark B. Rayment, Fernando Moyano, and Alexander Knohl Manuscript to be submitted to Biogeosciences

We expanded our analysis from the first paper (chapter 2) and included 19 more sites across temperate region to understand the effect of structural diversity on carbon fluxes. We looked at photosynthetic capacity $\left(\mathrm{GPP}_{1000}\right)$ instead of absolute fluxes in order to normalize the climate differences among the sites. We asked two questions in this paper, (a) Do structurally diverse forests have lower variation in annual GPP $\mathrm{G}_{1000}$ ?

(b) Are structurally diverse forests more resistant to drought events?

\section{- A flexible forest soil water model (FWSM) in R}

Rijan Tamrakar, Mark B. Rayment, Fernando Moyano, and Alexander Knohl (chapter 4 of this thesis)

Manuscript to be submitted to Environmental modelling and software

We have looked at annual carbon fluxes in chapter 2 and annual photosynthetic capacity in chapter 3 . The signal of droughts might be lost at annual scale due to seasonality within a year. It is also important to understand how forest would respond to droughts at shorter time-scales (daily) and how these responses will be modulated by forest structure. However, an multi-layer soil model that can easily be used and is open access is still missing. Thus, we developed a flexible open source dynamic soil water model in R (forest soil water model, FWSM) which can also be translated to any other programming languages. In this chapter we describe a flexible open source soil water model for forests in R. We investigate how it performs in different fluxnet sites.

- Difference in carbon uptake and water use between a managed and an unmanaged beech forest in central Germany

Mathias Herbst, Martina Mund, Rijan Tamrakar, Alexander Knohl (Appendix A of this thesis) 
Published in Forest ecology and management (HERBST et al., 2015)

This paper assessed the net atmospheric carbon dioxide exchange (NEE), total evapotranspiration and net primary production of two neighbouring beech(Fagus sylvatica L.)forests in central Germany differing in site management. Though the inter-annual variability was higher in managed, even-aged stand, the unmanaged forest was weaker sink of carbon dioxide during a dry year. The study discusses the relative importance of tree and structural (age, size) diversity, leaf area index and regenerative growth as well as the temporal frame and extent of single weather extremes for the forest-atmosphere exchange. I supported in the preparation, analysis and discussions of figures A.2 and A.4 (section A.5.2) and contributed to the writing.

- Stand age and species richness dampen inter-annual variation of ecosystemlevel photosynthetic capacity

Talie Musavi, Mirco Migliavacca, Markus Reichstein, Jens Kattge, Christian Wirth, T. Andrew Black, Ivan Janssens, Alexander Knohl, Denis Loustau, Olivier Roupsard, Andrej Varlagin, Serge Rambal, Alessandro Cescatti, Damiano Gianelle, Hiroaki Kondo, Rijan Tamrakar and Miguel D. Mahecha (Appendix B of this thesis) Published in Nature ecology and evolution (Musavi et al., 2017)

The study looked at the inter-annual variability (IAV) of photosynthetic capacity at light saturation, a key ecosystem functional property determining gross primary productivity. The study found that the older and species rich forest had reduced IAV of photosynthetic capacity at light saturation. In this paper, I provided data from the Hainich site and edits to the manuscript.

Finally, we conclude this thesis with a synopsis (chapter 5) - findings from three chapters and appendix chapters. Here, I also include broader discussion on the implications of forest structure on carbon fluxes and in particularly during droughts. Finally, I give an outlook on the future direction of research on effect of forest structure on drought response. 


\section{CHAPTER 2}

Implications of structural diversity for seasonal and annual carbon dioxide fluxes in two temperate deciduous forests

Authors: Rijan Tamrakar, Mark Rayment, Fernando Moyano, Martina Mund, Alexander Knohl

Published in 'Agriculture and Forest Meteorology' (TAMrAKAR et al., 2018)

https://doi.org/10.1016/j.agrformet.2018.08.027 


\subsection{Abstract}

The effects of structural diversity on the carbon dioxide exchange $\left(\mathrm{CO}_{2}\right)$ of forests has become an important area of research for improving the predictability of future $\mathrm{CO}_{2}$ budgets. We report the results of a paired eddy covariance tower study with 11 years of data on two forest sites of similar mean stand age, near-identical site conditions, and dominated by beech trees (Fagus sylvatica), but with a very different stand structure (incl. age, diameter distribution, stocks of dead wood and species composition) because of different management regimes. Here we address the question of how management and related structural diversity may affect $\mathrm{CO}_{2}$ fluxes, and tested the hypothesis that more structurally diverse stands are less sensitive to variations in abiotic and biotic drivers. Higher annual net ecosystem productivity (NEP) was observed in the managed,even-aged, and homogenous forest $\left(585 \pm 57.8 \mathrm{~g} \mathrm{C} \mathrm{m}^{-2} \mathrm{yr}^{-1}\right)$, than in the unmanaged, uneven-aged, and structurally diverse forest ( $487 \pm 144 \mathrm{~g} \mathrm{C} \mathrm{m}^{2} \mathrm{yr}^{-1}$ ). About two-third of the difference in NEP between the sites was contributed by a higher annual gross primary productivity (GPP, $1627 \pm 164$ vs $1558 \pm 118 \mathrm{~g} \mathrm{C} \mathrm{m}^{2} \mathrm{yr}^{-1}$ ) and one-third by a lower annual ecosystem respiration (Reco, $1042 \pm 60$ vs $1071 \pm 96 \mathrm{~g} \mathrm{C} \mathrm{m}^{2} \mathrm{yr}^{-1}$ ) in the homogenous forest. Spring (April - May) and summer (June - July) were the two main seasons contributing to the overall annual differences between the sites, also, the sensitivities of seasonal NEP and GPP to environmental variables were stronger in the homogenous forest during those periods. Inter-annual variation of NEP was higher in the homogenous forest (coefficient of variation $(\mathrm{CV})=25 \%)$ compared to the heterogeneous forest $(\mathrm{CV}=12 \%)$. At annual time scale, the higher variability of NEP in the homogenous forest is attributed to biotic factors such as fruit production and a time-dependent growth trend, outweighing differences in environmental sensitivities.

\subsection{Introduction}

The carbon uptake of forests is affected by changes in both abiotic and biotic factors (Chen et al., 2015; Ciais et al., 2005). The former includes temperature, radiation, water and nutrient availability, and their intra and inter-annual variability. Biotic factors include plant functional traits such as nutrient status, structure, phenology, etc., that govern photosynthesis and respiration process (JENSEN et al., 2017) as well as inter- and intra-specific competition. Identifying and under- standing the factors that contribute to the variability in net carbon dioxide $\left(\mathrm{CO}_{2}\right)$ uptake, i.e. net ecosystem productivity (NEP), between forest ecosystems and the atmosphere is crucial for understanding how forests will respond to and affect future climate (BALDOCCHI et al., 2001; LuO et al., 2015)as well as for answering questions relevant to forest management and ecology.

Many eddy covariance (EC) flux studies (e.g. BARR et al. 2007; Dragoni et al. 2011; Hui et al. 2017; Humphreys et al. 2011; JENSEN et al. 2017; Kitamura et al. 2012; Richardson et al. 2009; Shao et al. 2015; Shao et al. 2016; Wu et al. 2013; YUAN et al. 2009) have attributed the inter-annual variability (IAV) of NEP variously to climatic variables, to phenological changes induced by climatic variables and to biotic changes, with RICHARDSON et al. (2009) contending that, on an annual scale, variation in NEP is more strongly dominated by changes in biotic factors than by climate. To date, most studies have 
focused on under- standing effects of climate and biotic changes on $\mathrm{CO}_{2}$ fluxes at single sites (Granier et al., 2008; PilegaArd et al., 2011; Wilkinson et al., 2012) or across contrasting ecosystem types (BALDOCCHI et al., 2005; Chu et al., 2016; JEnsEn et al., 2017; Ma et al., 2007; Novick et al., 2015; Pereira et al., 2007; Shao et al., 2014; Shao et al., 2015; ShaO et al., 2016; Wu et al., 2012). Other studies have used multiple sites from across global and regional networks to understand the variability of $\mathrm{CO}_{2}$ fluxes from different plant functional types and/or climatic zones (BEER et al., 2010; ChEN et al., 2015; LAW et al., 2002; Musavi et al., 2017). Such studies have been beneficial for understanding the underlying causes of variability in $\mathrm{CO}_{2}$ uptake, but because flux stations are not closely located, there are typically very large differences in the environmental conditions be- tween sites, making it challenging to disentangle the effects of abiotic vs biotic factors. The short period of time analysed is also a limitation found in some studies (ANTHONI et al., 2004; Hommeltenberg et al., 2014; Jensen et al., 2017). Only a few have investigated how structure and management scheme affect $\mathrm{CO}_{2}$ fluxes (HERBST et al., 2015; Musavi et al., 2017) even though it is reasonable to suppose that these are important drivers of $\mathrm{CO}_{2}$ fluxes and that they may interact with climate and biotic variables (LUYSSAERT, 2014). Here we present a case study that, in contrast, focuses on two forest sites that a) are characterized by similar site conditions, b) have a si- milar mean age, and c) are both dominated by beech trees (Fagus sylvatica) but differ in management regime and structure. We thus tackle the question of how management and related structural diversity may affect $\mathrm{CO}_{2}$ fluxes, and directly test the hypothesis that more structurally diverse stands are less sensitive to variations in abiotic and biotic dri- vers. This study builds on the work of HERBST et al. (2015), which was done at the same sites and showed their difference in carbon uptake and water use. We seek to identify the major drivers of seasonal and inter-annual variability of net ecosystem productivity (NEP), gross primary productivity (GPP) and ecosystem respiration (Reco) of a structurally diverse and a structurally-homogeneous temperate broadleaf forest. We test two hypotheses: 1) The annual NEP and GPP of the homogeneous forest is more sensitive to variation in climate variables compared to the hetero- geneous forest. A study utilizing tree rings has shown that pro- ductivity of diverse temperate beech forests exhibited higher temporal stability than monoculture forests mainly due to lower inter-annual variation as well as due to overyielding because of asynchronous behaviour of different tree species and their interactions (JUCKER et al., 2014). Grossiond et al. (2014c) observed higher water availability in mixed temperate beech forests than in single species forests during drought, which they speculate as result of niche partitioning and/or facilitation processes among the inter- acting species. 2) NEP and GPP of the homogeneous forest is more sensitive to in- trinsic species-determined characteristics such as fruit production. Synchronous fruit production, also known as masting, is a sink for plant resources that may compete with vegetative growth (OBESO, 2002) and a negative correlation between fruit production and ra- dial stem increment has been observed (DitTmar et al., 2003; SelÅs et al., 2002). Herbst et al. (2015) reported higher fruit production in the homogenous forest and here we will also quantify the effect of fruit production on annual NEP and GPP. 


\subsection{Material and methods}

\subsubsection{Site description}

Data were obtained from two forest sites, Hainich (DE-Hai) and Leinefelde (DE-Lnf), located in central Germany (Figure 2.1). The two sites are ca. $30 \mathrm{~km}$ apart both at an altitude of $450 \mathrm{~m}$ mean above sea level. Soil at both sites is composed of Triassic limestone covered with variable Pleistocene loess deposits. The climate is suboceanic-submontane with a long-term annual mean air temperature of ca. $8{ }^{\circ} \mathrm{C}$. General site characteristics are given in Table 2.1. The phenology of both sites is similar, with the dormant season lasting typically from November to March and growing season lasting from April to October.

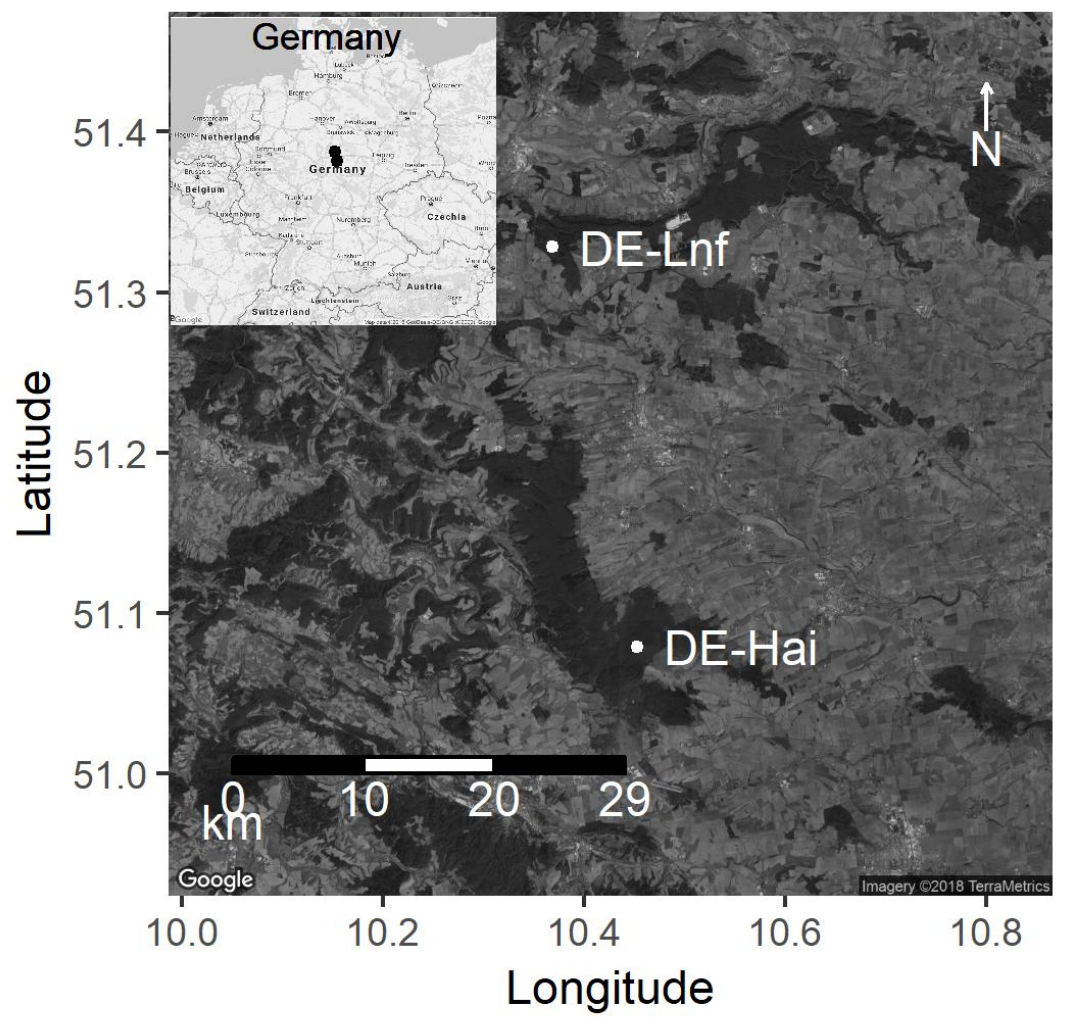

Figure 2.1: Map showing the location of the two study sites in the central Germany. Darker patches are forests and white dots show the positions of the eddy covariance flux towers at each site. Map of Germany in inset is not to scale.

Hainich: The Hainich site (DE-Hai) is an unmanaged forest with a heterogeneous structure, located in the central part of the Hainich National Park. Site details can be found in Anthoni et al. (2004) and KNOHL et al. (2003). Until the end of the 19th century, it was managed as a coppice-with-standards system and was subjected to selective cutting until 1965. From 1965 to 1997, the area was used as a military training base and a large part of the forest was left untouched, with only single and very valuable trees being cut. The forest has never been clear felled and, as a result, it exhibits characteristics of 
Table 2.1: Instrumentation and stand characteristics for the research sites. Hainich

\begin{tabular}{|c|c|c|}
\hline Characteristics & Hainich (DE-Hai) & Leinefelde (DE-Lnf) \\
\hline Latitude & $51^{\circ} 04^{\prime} 45,36^{\prime \prime} \mathrm{N}$ & $51^{\circ} 19^{\prime} 41,58^{\prime \prime} \mathrm{N}$ \\
\hline Longitude & $10^{\circ} 27^{\prime} 07,20 ” \mathrm{E}$ & $10^{\circ} 22^{\prime} 04,08^{\prime \prime} \mathrm{E}$ \\
\hline Altitude $[\mathrm{m}]$ & 440 & 450 \\
\hline Soil & $\begin{array}{l}\text { Pleistocene loess deposits with dom- } \\
\text { inance of Cambisols }\end{array}$ & $\begin{array}{l}\text { Pleistocene loess deposits with } \\
\text { dominance of Luvisols }\end{array}$ \\
\hline \multicolumn{3}{|l|}{ Instrumentation } \\
\hline EC measuring height $[\mathrm{m}]$ & 44 & 44 \\
\hline Displacement height $[\mathrm{m}]$ & 22 & 22 \\
\hline Sonic anemometer & Gill Sonic Model R3 & Gill Sonic Model R3 \\
\hline Infra-red gas analyser (IRGA) & Li6262 & Li6262 \\
\hline \multicolumn{3}{|l|}{ Stand characteristics } \\
\hline Primary species & $\begin{array}{l}\text { Fagus sylvatica } L(64) ., \text { Fraxinus ex- } \\
\text { celsior } L .(28), \text { Acer pseudoplatanus } \\
L(7) \text {. and other species }\end{array}$ & $\begin{array}{l}\text { Fagus sylvatica L. (single Quer- } \\
\text { cus petraea) }\end{array}$ \\
\hline Biomass $\left[\mathrm{t} \mathrm{Cha}^{-1}\right]$ & 212 & 237 \\
\hline Plant density [trees ha ${ }^{-1}$ ] & 334 & 224 \\
\hline Canopy height $[\mathrm{m}]$ & 35 & 35 \\
\hline $\mathrm{LAI}\left[\mathrm{m}^{2} \mathrm{~m}^{2}\right]$ & 5.1 & 4.2 \\
\hline Age [years] & $\begin{array}{l}\text { Maximum up to } 265 \text {, biomass } \\
\text { weighted average }=140\end{array}$ & $130 \pm 8$ \\
\hline
\end{tabular}

an unmanaged, old-growth forest with highly diverse horizontal and vertical structure, trees covering a wide range of age classes, up to a maximum of around 265 years, and large amounts of dead wood (both standing dead wood and coarse woody debris). The main tree species in the forest are beech (Fagus sylvatica, ca. 64\% of tree biomass), ash (Fraxinus excelsior, ca. 28\%), and sycamore (Acer pseudoplatanus, ca. 7\%), with some single trees of European hornbean (Carpinus betulus), elm (Ulmus glabra), maple (Acer platanoides) and other deciduous species. The main ground vegetation in the forest includes Allium ursinum, Mercurialis perennis and Anemone nemorosa (Mund, 2004). The Hainich flux tower site is located on a gentle north facing slope (2-3 inclination) surrounded by forest for more than $3 \mathrm{~km}$ in the prevailing wind direction. The only change in the surface land use is a small clearing located about $800 \mathrm{~m}$ perpendicular to the prevailing wind, with only $5 \%$ contribution to the overall wind direction (KNOHL et al., 2003).

Leinefelde The Leinefelde site (DE-Lnf) is an even-aged, about 130 years old, pure beech forest that was established and thinned as part of a regular shelterwood system with a rotation period of about 120-140 years. In recent years the management starts to transfer the shelterwood system towards a system of target diameter harvesting. Crown thinning - thinning of dominant trees to reduce crowding within the main canopy - is carried out regularly every 5-10 years. The thinning activity in the footprint area of the flux tower is presented in Figure 2.10. The ground vegetation includes Galium odoratum, Melica nutans, Milium ef fusum, Oxalis acetosella, and Stellaria holostea. The eddy covariance flux tower has been in operation since April 2002. No measurements were carried out in this site from 2007 to 2009 due to access limitation. 


\subsubsection{Eddy covariance and meteorological measurements}

Fluxes of carbon dioxide, water vapor, sensible heat, and momentum along with standard meteorological variables were measured at the two study sites. The two sites had identical eddy covariance instrumental setup and data acquisition techniques. The eddy covariance measurement system consisted of a three-dimensional sonic anemometer (Solent R3, Gill Instruments Ltd., Lymington, UK) and a fast response closed-path $\mathrm{CO}_{2} / \mathrm{H}_{2} \mathrm{O}$ infrared gas analyser in absolute mode (LI-6262, LI-COR Inc., Lincoln, NE, USA). The tube connecting the gas inlet and gas analyser was $50 \mathrm{~m}$. Data were collected on a field computer using the "EddySoft" software developed by O. Kolle from MPI-Biogeochemistry, Jena, Germany (Kolle and Rebmann, 2010). Detailed information about the instrumentation can be found in ANTHONi et al. (2004) and KNOHL et al. (2003). The turbulent fluxes were calculated using "EddyPro" software with same settings for both sites and all years. We followed AUBinet et al. (1999) and FoKEn et al. (2004) for quality control of the data collection and analyses. We used the "Fluxnet" online-tool (http://www.bgc-jena.mpg.de/bgi/index . php/Services/REddyProcWeb) and the REddyProc package in R (WUTZLER et al., 2018) based on REICHSTEIN et al. (2005) to obtain a continuous dataset of net ecosystem exchange and for partitioning this into gross primary production (GPP) and ecosystem respiration (Reco). Standard meteorological data were measured at both the sites. AnTHONI et al. (2004) and KNOHL et al. (2003) describe the details of the meteorological variables and instrumentation. We used the BILJOU model to calculate a water availability index (WAI). Details of this model are available in Granier et al. (1999).

\subsubsection{Fruit production data}

Periodical fruit production is an important characteristic of beech forests. In this study, we included fruit production as a biotic variable that is assumed to affect annual carbon fluxes. The fruits (seed and pericarp) were collected in litter traps (DE-Hai 25, DE-Lnf 21 traps of $0.25 \mathrm{~m}^{2}$ ) distributed within the main footprint, dried at $70{ }^{\circ} \mathrm{C}$ and weighed. The traps were closed plastic funnels with a small sieve at the bottom for retaining fruits while allowing drainage. The funnels were fixed on a pillar about $50 \mathrm{~cm}$ above the ground so that herbivores (mostly mice) were kept out.

\subsubsection{Statistical analysis}

Data from April 2002 to 2006 and from 2010 to 2016, the period with complete flux and meteorological data, was used to investigate the effect of meteorological variables on seasonal fluxes. We calculated zero-order correlations and slopes of the simple linear regressions between seasonal fluxes and meteorological variables. We also tested the differences of the sensitivities of seasonal $\mathrm{CO}_{2}$ fluxes to meteorological variables between sites (LENTH, 2017).

At annual scale, we used data from 2003 to 2006 and 2010 to 2016 (no fruit production data was available for 2002). Paired T-tests were applied to test for significant differences in annual $\mathrm{CO}_{2}$ fluxes and meteorological variables between the sites. For selecting which predictor explained annual NEP, GPP and Reco, we conducted stepwise multiple linear regression (MLR) using the Akaike Information Criteria (AIC) (FIELD et al., 2012). The predictor variables considered for the study were mean annual air temperature $\left(\mathrm{T}_{\text {air }}\right)$, soil 
temperature $\left(\mathrm{T}_{\text {soil }}\right)$, global radiation $\left(\mathrm{R}_{\mathrm{g}}\right)$, vapor pressure deficit (VPD), water availability index (WAI), spring air temperature, spring soil temperature, fruit production, growing season length, and time. The variable time was represented by calendar year. Thus, it integrates the effects of factors that vary and correlate with time, such as growth, effects of $\mathrm{CO}_{2}$ fertilization (FERnÁndEZ-MARTínez et al., 2017), phenology (BALDOCCHI, 2018; Froelich et al., 2015; Granier et al., 2008; PilegaArd et al., 2011; Urbanski et al., 2007), and changes in nutrient deposition (FERnÁndez-MARTínez et al., 2017). To create a model applicable to both sites, we defined a MLR model using all the variables selected as significant during the per-site fits and fitted it again, this time to the combined data from both sites. To estimate the relative effects of model predictor variables on response variables, we calculated the 'product measure' which distributes the overall model $\mathrm{R}^{2}$ to each of the predictors (NATHANs et al., 2012). Product measure is the product of a predictor's $\beta$-coefficient (standardized slope) in a MLR model and its zero-order correlation. We also conducted simple regressions of predictors against the model residuals, i.e. after having removed the effects of other predictor variables via multiple linear regression. $\mathrm{R}$ version 3.4.3 was used for analyses (R Development Core Team, 2018).

\subsection{Results}

\subsubsection{Meteorological characteristics}

The two sites were meteorologically similar (Figure 2.2). Averaged yearly global radiation $\left(\mathrm{R}_{\mathrm{g}}\right)$ from 2002 to 2016 was $122.4 \pm 6.5 \mathrm{~W} \mathrm{~m}^{-2}$ (mean $\pm \mathrm{sd}$ ) in DE-Hai and $124.0 \pm$ $7.2 \mathrm{~W} \mathrm{~m}^{-2}$ in DE-Lnf (Figure 2.2a). Mean annual temperature $\left(\mathrm{T}_{\mathrm{air}}\right)$ during the study period was $8.34 \pm 0.72{ }^{\circ} \mathrm{C}$ and $8.30 \pm 0.7{ }^{\circ} \mathrm{C}$ for DE-Hai and DE-Lnf, respectively. This similarity was consistent for all years with no statistically significant differences between the sites. The mean annual soil temperature $\left(\mathrm{T}_{\text {soil }}\right)$ was $7.61 \pm 0.36{ }^{\circ} \mathrm{C}$ and $8.23 \pm 0.38$ ${ }^{\circ} \mathrm{C}$ for DE-Hai and DE-Lnf, respectively. A systematically higher value of $0.62{ }^{\circ} \mathrm{C}$ was measured in DE-Lnf $(\mathrm{p}<0.001)$, possibly resulting from differences in the measurement depth between the sites (5 vs $4 \mathrm{~cm}$ in DE-Hai and DE-Lnf, respectively, Figure 2.11). Mean annual vapor pressure deficit (VPD) was $3.45 \pm 0.56 \mathrm{hPa}$ and $3.28 \pm 0.41 \mathrm{hPa}$ at DE-Hai and DE-Lnf, respectively, with no statistical difference between the sites. Mean annual precipitation - based on a single pluviometer per site - was significantly lower $(\mathrm{p}<0.001)$ in DE-Lnf $(601 \pm 154 \mathrm{~mm})$ than in DE-Hai $(744 \pm 152 \mathrm{~mm})$. Although DE-Lnf received less rainfall, the mean annual water availability index (WAI) was similar between the sites in most years, with average values of 0.86 and 0.84 in DE-Hai and DE-Lnf, respectively. We didn’t observe temporal trend in any meteorological variables (Table 2.4).

\subsubsection{Fruit production (masting) in the study sites}

Figure 2.3 shows the fruit production (masting) data for DE-Hai and DE-Lnf from 1999 to 2016. Data for 2001 and 2002 was not available due to technical issues. The average fruit production for the entire period was $73.2 \pm 77.9 \mathrm{~g} \mathrm{C} \mathrm{m}^{2} \mathrm{yr}^{-1}$ and $91.2 \pm 113.1$ $\mathrm{g} \mathrm{C} \mathrm{m}^{2} \mathrm{yr}^{-1}$ in DE-Hai and DE-Lnf, respectively. We define masting years as those when fruit production is more than $50 \mathrm{~g} \mathrm{C} \mathrm{m}^{2} \mathrm{yr}^{-1}$. Masting years occurred every two or three years. Average fruit production during such years was $151 \pm 46.3 \mathrm{~g} \mathrm{C} \mathrm{m}^{2} \mathrm{yr}^{-1}$ and 197 $\pm 91.8 \mathrm{~g} \mathrm{C} \mathrm{m}^{2} \mathrm{yr}^{-1}$ for DE-Hai and DE-Lnf, respectively, with the former being $76 \%$ of 
the latter. The significant differences between DE-Lnf und DE-Hai are restricted to the extraordinarily high mast years (fruit production $>200 \mathrm{~g} \mathrm{C} \mathrm{m}^{-2}$ ).

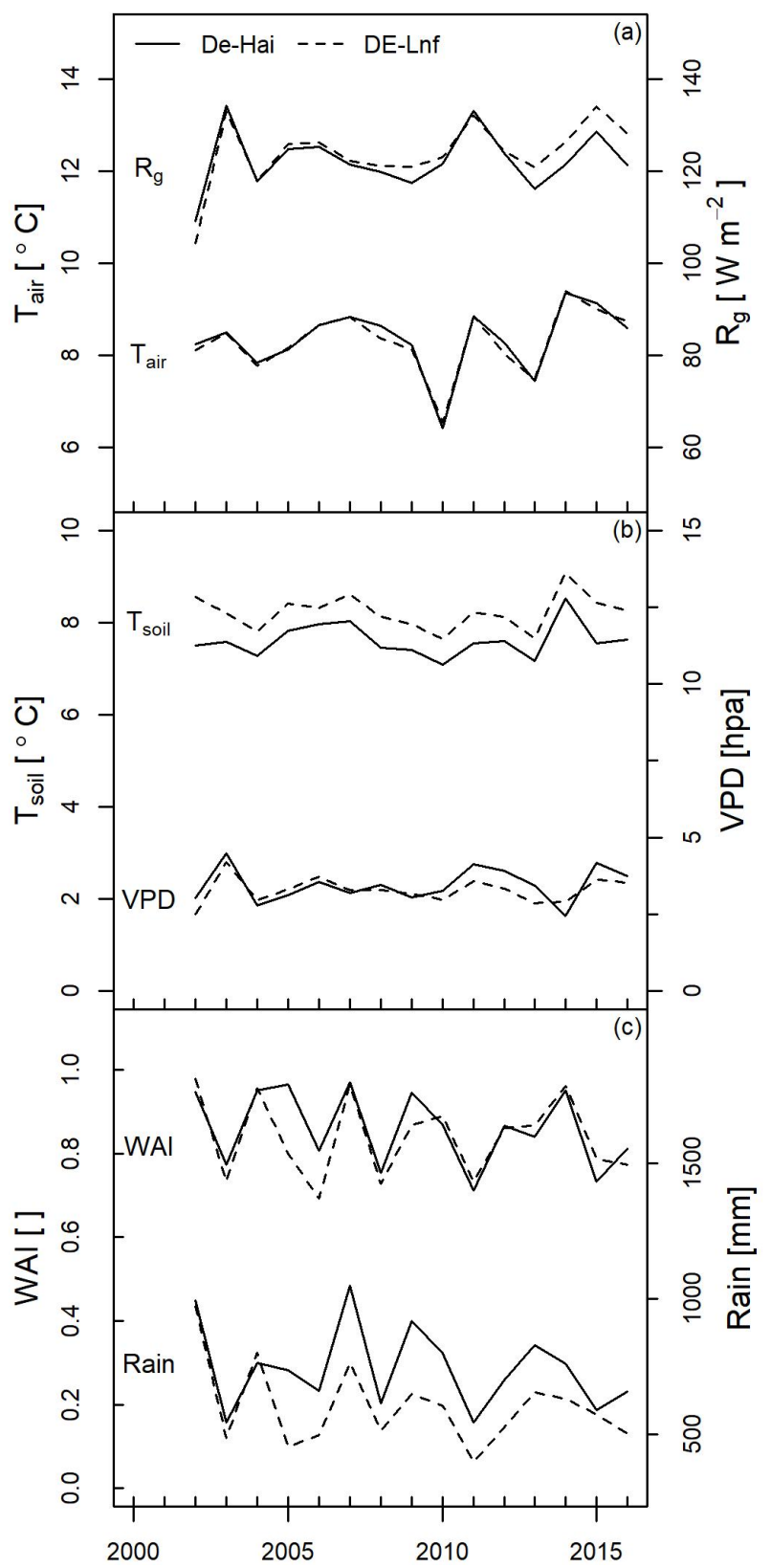

Figure 2.2: Mean annual values of (a) global radiation $\left(\mathrm{R}_{\mathrm{g}}\right)$ and air temperature $\left(\mathrm{T}_{\text {air }}\right)$; $(\mathrm{b})$ soil temperature $\left(\mathrm{T}_{\text {soil }}\right)$ and vapor pressure deficit (VPD); and (c) water availability index (WAI) and rainfall are shown from 2002 to 2016 . $\mathrm{T}_{\text {soil }}$ was measured at $5 \mathrm{~cm}$ for DE-Hai and $4 \mathrm{~cm}$ for DE-Lnf.

\subsubsection{Cumulative net ecosystem productivity (NEP)}

Figure 2.4 shows gap-filled cumulative net ecosystem productivity (NEP) data calculated from eddy covariance measurements of fluxes. Positive values correspond to a cumulative net uptake of $\mathrm{CO}_{2}$ by the vegetation (atmospheric sink) and negative values a net loss (atmospheric source). At the beginning of each year, both forests are sources of $\mathrm{CO}_{2}$. The 


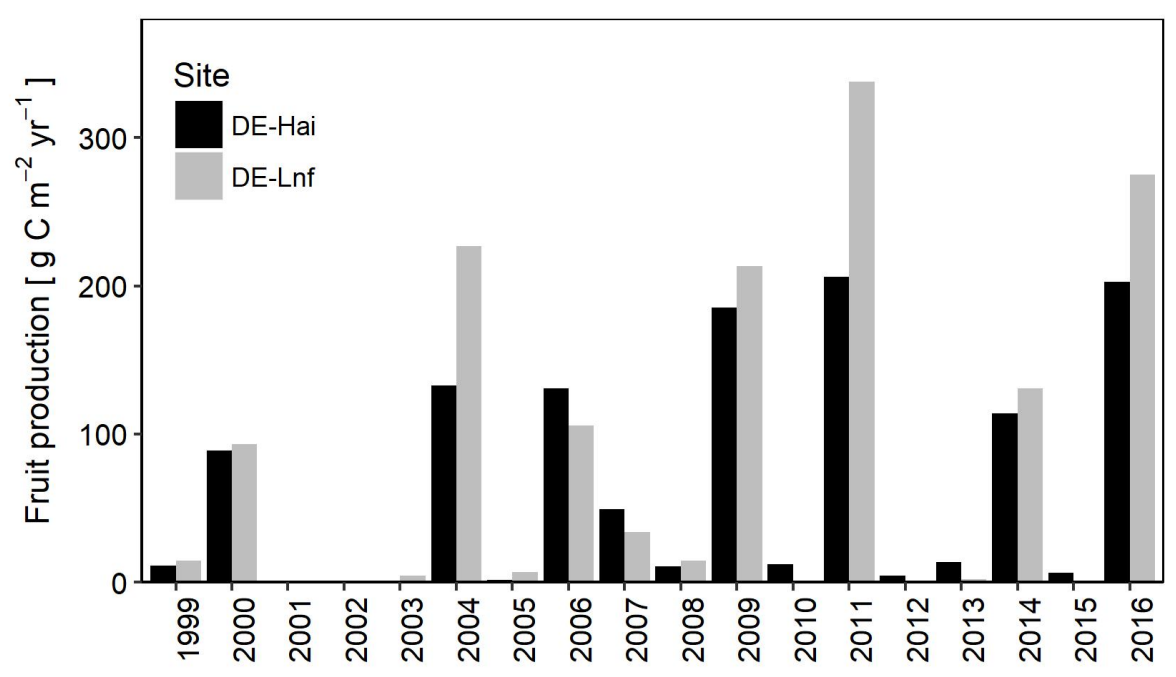

Figure 2.3: Total annual fruit production $\left(\mathrm{g} \mathrm{C} \mathrm{m}^{2} \mathrm{yr}^{-1}\right)$ in DE-Hai and DE-Lnf from 1999 to 2016. No data was recorded in 2001 and 2002.

average day of the year (doy) at which the net daily NEP switches from source to sink (i.e. shortly after leaf-out when the rate of change in the cumulative NEP goes from negative to positive) was 125 and 121 for DE-Hai and DE-Lnf, respectively (Table 2.5). But this was observed as early as doy 111 in DE-Hai and 112 in DE-Lnf in 2014, and as late as doy 134 in DE-Hai in 2010 and doy 130 in DE-Lnf in 2013. The forests continued to act as an overall $\mathrm{C}$ sink in average for 164 days and 168 days for DE-Hai and DE-Lnf, respectively. This

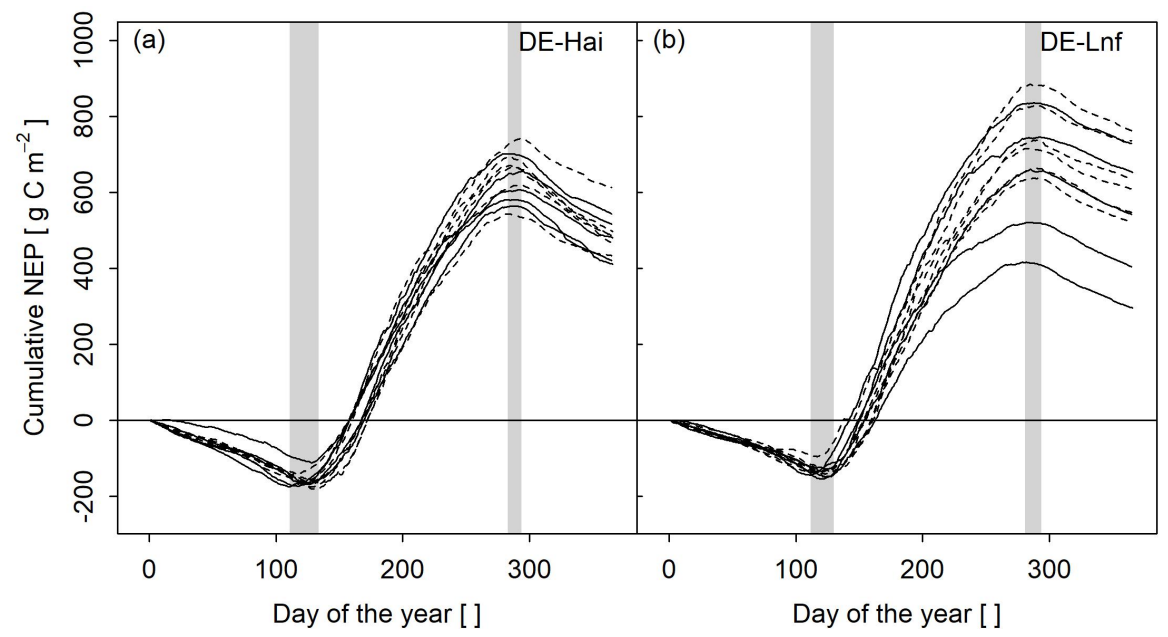

Figure 2.4: Cumulative net ecosystem productivity for (a) DE-Hai and (b) DE-Lnf. The solid lines indicate masting years and the dashed lines indicate remaining years. The vertical grey bars indicate the time of leaf out and leaf fall. The positive values of NEP indicate a cumulative carbon uptake by the ecosystem. 
growing season length was significantly correlated with mean annual temperature (Figure 2.12). Longer growing season length and earlier start of growing season corresponded to higher annual carbon fluxes (Figure 2.13c, f, i).

Most of the variation in annual cumulative NEP occurred between the period of leaf out and leaf fall. The inter-annual variability in NEP during the growing season was larger in DE-Lnf compared to DE-Hai. On average, NEP in masting years was lower than in other years, with this difference being particularly visible in DE-Lnf (black solid lines in Figure 2.4b). The lowest cumulative NEP for both sites was measured in 2004, a year characterized by high fruit production but not the highest value observed during the study period.

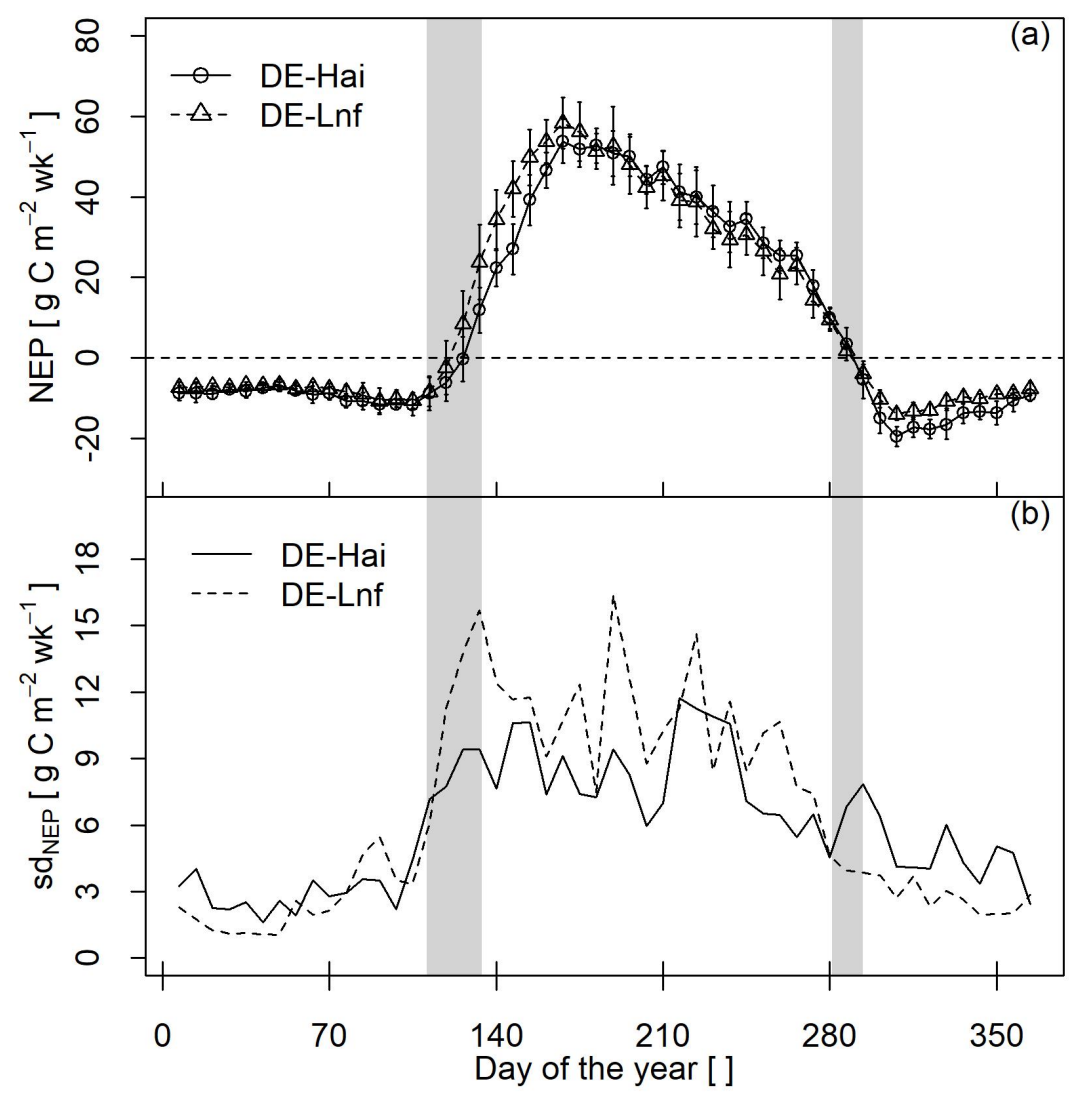

Figure 2.5: (a) The average annual NEP cycle, bar represents $95 \%$ confidence interval at $5 \%$ significance level and (b) standard deviation of weekly NEP. The grey horizontal bars show the range of the leaf out and leaf fall days of the two sites.

\subsubsection{Seasonal variability of the $\mathrm{CO}_{2}$ fluxes}

Both sites have a similar average annual cycle of NEP (Figure 2.5a). Each point corresponds to the mean across years of weekly sums of NEP. Both forests reached the highest carbon uptake rate between doy 165 and 175. DE-Lnf showed a higher positive NEP at the start of the growing season, and DE-Hai was a stronger carbon source (black solid lines in Figure 2.5) from November to December. 


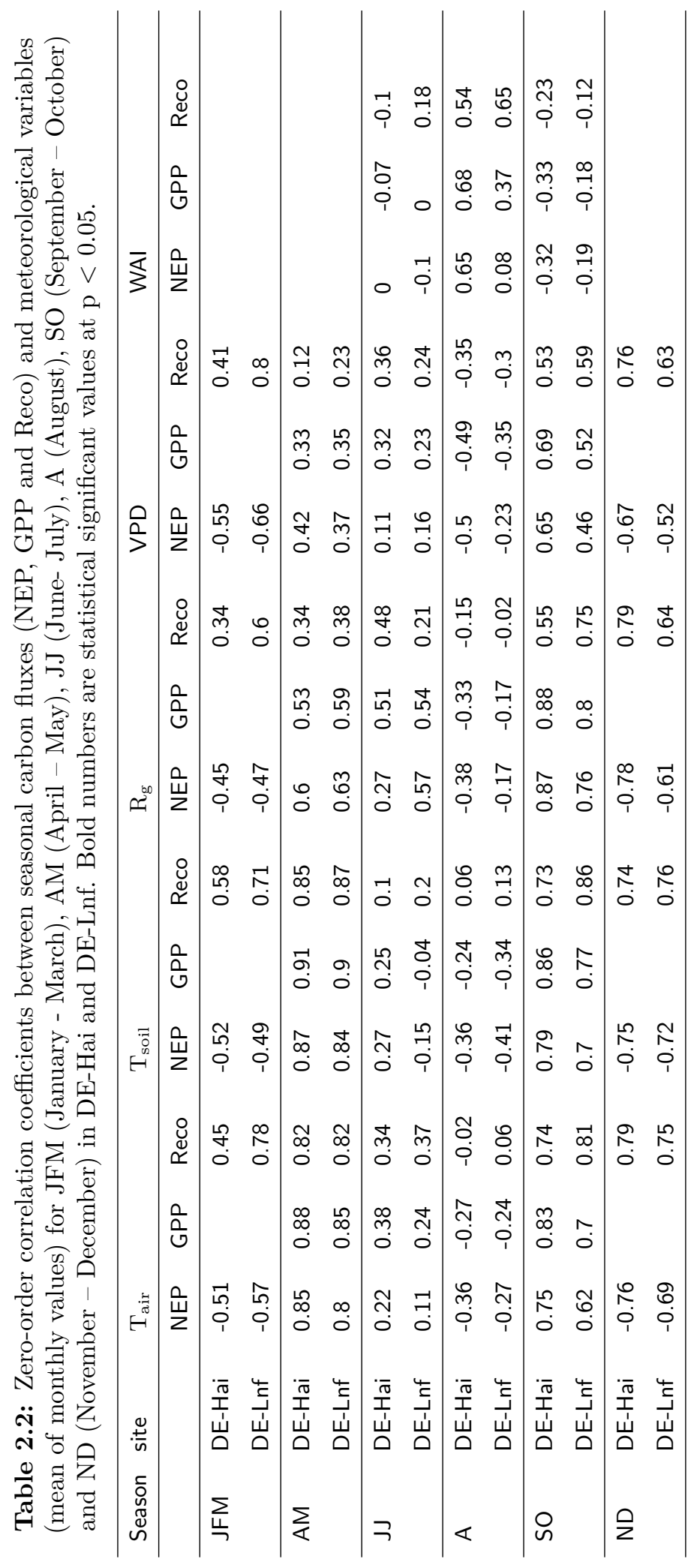




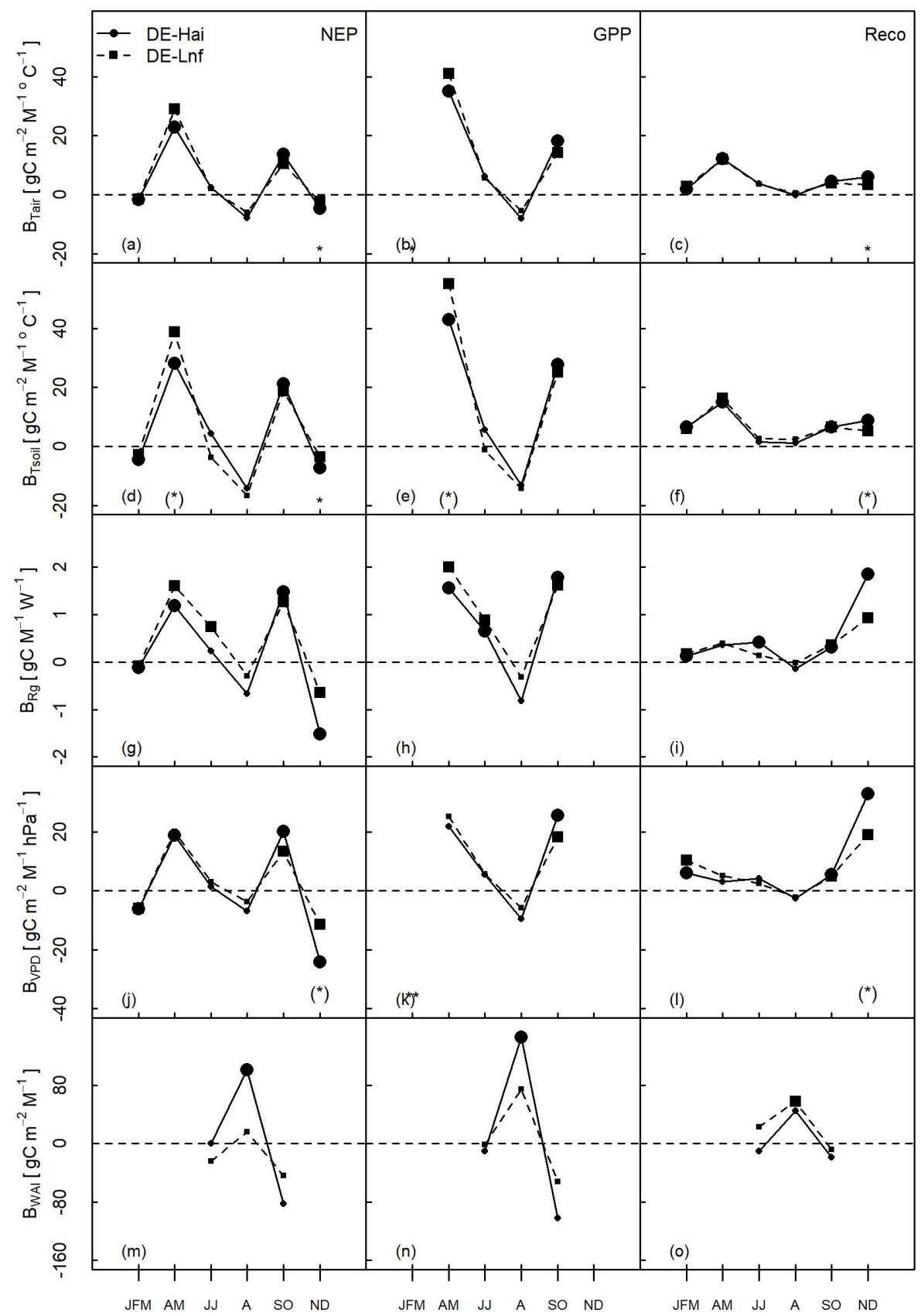

Figure 2.6: Slopes (B) between seasonal $\mathrm{CO}_{2}$ fluxes (NEP - column 1, GPP - column 2 and Reco - column 3) and meteorological variables (mean of monthly values) for JFM (January March), AM (April - May), JJ (June - July), A (August), SO (September - October) and ND (November - December). The larger circles and squares indicate slopes, which are significantly different from zero. ${ }^{* * *}$ indicate statistical significant difference of slopes between two sites at $\mathrm{p}<0.001 ;{ }^{* *}$ at $\mathrm{p}<0.01{ }^{*}$ at $\mathrm{p}<0.05$; and $\left({ }^{*}\right)$ at $\mathrm{p}<0.1$ at bottom of each figure (if any).

The first letter of each month is used in the timescale. 
Figure 2.5b shows the standard deviation of weekly NEP across years. The standard deviation of the early weeks of the year was low at both sites, and increased with the start of the growing season. A higher standard deviation in NEP was observed in DE-Lnf (dashed lines in Figure 2.5b) over the entire growing season. In DE-Hai (black solid lines in Figure 2.5b), the highest standard deviation was observed between doy 215 and 230 . During the last days of the year, DE-Hai exhibited a higher standard deviation compared to DE-Lnf. For further analysis, we separated the year into different seasons, winter months (November - December: ND, January - March: JFM), spring (April - May: AM), summer (June- July: JJ), August (A) and fall (September - October: SO), to account for the different drivers and dynamcs of NEP in these periods. August was treated separately from the main growing season as it is a particularly dry month and large variability observed in this period (see Figure 2.5b and Table 2.2).

\subsubsection{Meteorological factors controlling seasonal variability in $\mathrm{CO}_{2}$ fluxes}

For each site, Table 2.2 (correlation coefficients) and Figure 2.6 (absolute slopes) show the effect of measured meteorological factors on $\mathrm{CO}_{2}$ fluxes for different seasons of the year (see section 2.4.4). In winter, NEP was correlated with $\mathrm{T}_{\text {air }}, \mathrm{T}_{\text {soil }}, \mathrm{R}_{\mathrm{g}}$, and VPD at both sites with stronger correlation in ND than JFM (Table 2.2). In ND, NEP was significantly sensitive (higher absolute slopes) to $\mathrm{T}_{\text {air }}, \mathrm{T}_{\text {soil }}$ and VPD in DE-Hai than in DE-Lnf (Figure 2.6).

With the arrival of spring (April May, AM), $\mathrm{T}_{\text {soil }}$ became the most important factor controlling spring NEP, GPP and Reco in both sites, followed in importance by $\mathrm{T}_{\text {air }}$, and $\mathrm{R}_{\mathrm{g}}$. A $1{ }^{\circ} \mathrm{C}$ change in spring $\mathrm{T}_{\text {soil }}$ changed the NEP by $28.07 \pm 6.92$ and $38.74 \pm 11.19$ mathrmg $C \mathrm{~m}^{-2}$ month $^{-1}$ in DE-Hai and DE-Lnf, respectively. NEP was driven mainly by GPP, as seen by comparing $\mathrm{B}_{\text {TsoilGPP }}$ (slope between $\mathrm{T}_{\text {soil }}$ and GPP, Figure 2.6e) and $\mathrm{B}_{\text {TsoilReco }}$ (slope between $\mathrm{T}_{\text {soil }}$ and Reco, Figure 2.6f) for this period. NEP and GPP of DE-Lnf was more sensitive to $\mathrm{T}_{\text {soil }}$ than DE-Hai with significantly higher $\mathrm{B}_{\text {Tsoil }} \mathrm{NEP}$ (Figure 2.6d) and $\mathrm{B}_{\text {Tsoil }}$ GPP (Figure 2.6e).

In summer (June - July, JJ), $\mathrm{R}_{\mathrm{g}}$ remained a significant factor while other relationships weakened. In DE-Hai, $\mathrm{R}_{\mathrm{g}}$ showed a weak relationship with NEP but significantly correlated with both GPP and Reco, while in DE-Lnf it was significantly correlated with NEP and GPP. The sensitivity of NEP and GPP to $\mathrm{R}_{\mathrm{g}}$ was higher in DE-Lnf compared to DE-Hai. A change in $1 \mathrm{~W} \mathrm{~m}^{-2}$ of $\mathrm{R}_{\mathrm{g}}$ increased NEP by $0.74 \pm 0.47(\mathrm{p}<0.01) \mathrm{g} \mathrm{C} \mathrm{m}^{2} \mathrm{month}^{-1}$ in DE-Lnf and about $0.23 \pm 0.37(\mathrm{p}=0.11) \mathrm{g} \mathrm{C} \mathrm{m}^{2} \mathrm{month}^{-1}$ in DE-Hai and the difference between the sites is significant $(\mathrm{p}<0.1)$. In August $(\mathrm{A})$, only the soil water availability index (WAI) correlated significantly with $\mathrm{CO}_{2}$ fluxes, specifically with NEP, GPP and Reco in DE-Hai and only with Reco in DE-Lnf. In fall (September - October, SO), $\mathrm{T}_{\text {air }}$, $\mathrm{T}_{\text {soil }}, \mathrm{R}_{\mathrm{g}}$ and VPD, again became significantly correlated with NEP, GPP and Reco in both sites, with high correlation values for the first three and slightly lower ones for VPD.

\subsubsection{Seasonal differences in $\mathrm{CO}_{2}$ fluxes between the two sites}

In addition to slopes, we also looked at differences of average seasonal sums of NEP, GPP and Reco between sites (Figure 2.7). Significantly higher NEPs observed in DE-Lnf than in DE-Hai in JFM and ND (5.48 and $17.79 \mathrm{~g} \mathrm{C} \mathrm{m}^{-2} \mathrm{month}^{-1}$, Figure 2.7a) was due to lower 
Reco in DE-Lnf (Figure 2.7c). DE-Lnf also acted as a stronger carbon sink in the spring $\left(26 \mathrm{~g} \mathrm{C} \mathrm{m}^{-2}\right.$ month $^{-1}$ ) which was mostly due to higher GPP of $24 \mathrm{~g} \mathrm{C} \mathrm{m}^{-2}$ month $^{-1}$. In JJ, difference between NEP in two sites were insignificant because both GPP and Reco in DE-Lnf were significantly higher by $19.08 \mathrm{~g} \mathrm{C} \mathrm{m}^{-2}$ month $^{-1}$ and $10.94 \mathrm{~g} \mathrm{C} \mathrm{m}^{-2}$ month $^{-1}$, respectively. During August, NEP and GPP were similar in both sites, however, a higher Reco was observed in DE-Lnf $\left(10.04 \mathrm{~g} \mathrm{C} \mathrm{m}^{-2} \mathrm{month}^{-1}\right)$. In the fall, NEP, GPP and Reco were lower in DE-Lnf but differences were insignificant.

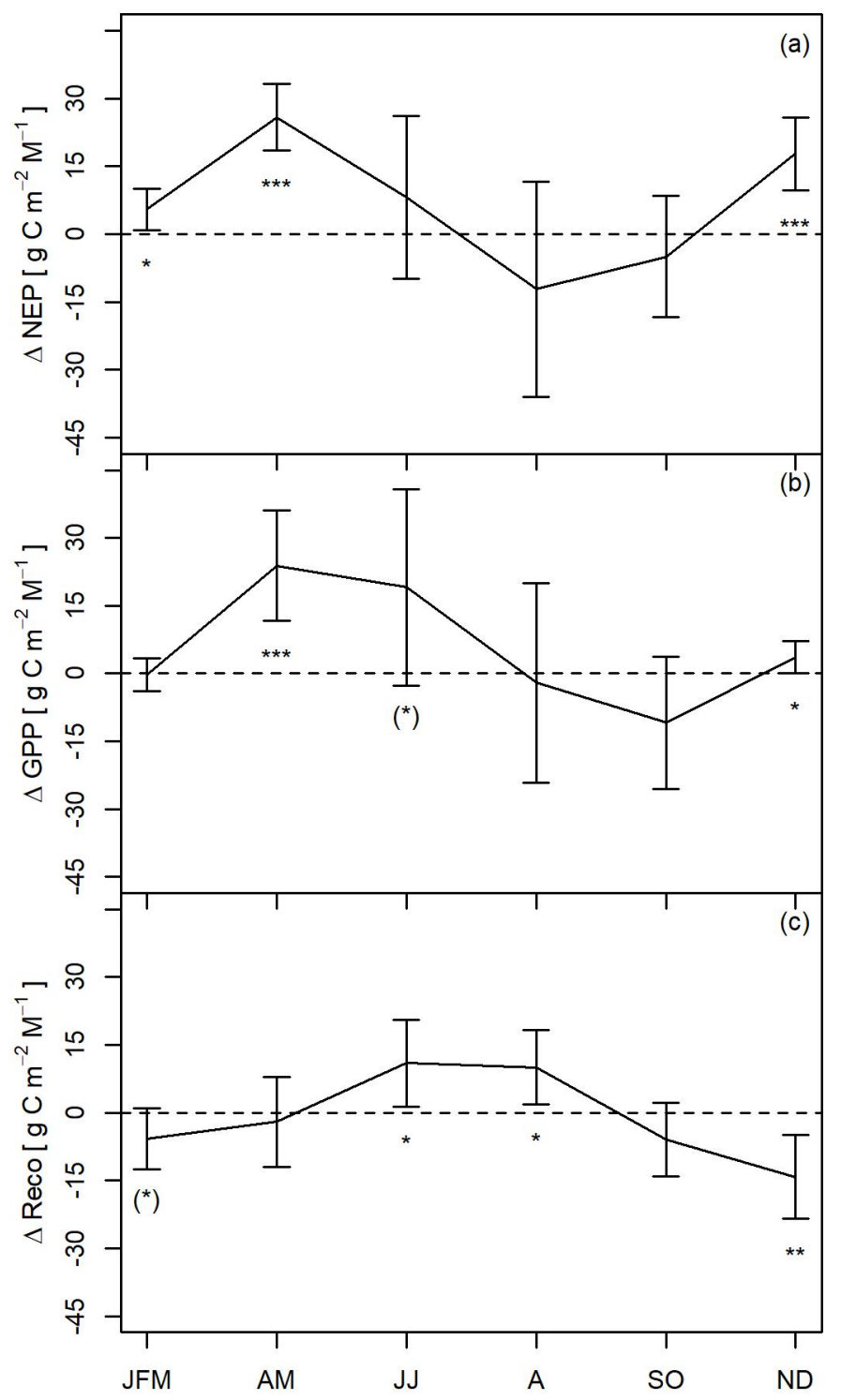

Figure 2.7: Difference in sum of (a) NEP, (b) GPP and (c) Reco between the two sites for JFM (January - March), AM (April - May), JJ (June- July), A (August), SO (September - October) and ND (November - December). The Yaxis represents $\mathrm{X}=\mathrm{XDE}-\mathrm{Lnf}-$ XDE-Hai (X being seasonal NEP, GPP or Reco). Bars represent 95\% confidence interval. The dashed line marks the zero line (indicates no difference between the sites). *** indicate statistical significance at $\mathrm{p}$ $<0.001 ;{ }^{* *}$ at $\mathrm{p}<0.01 ;{ }^{*}$ at $\mathrm{p}<$ $0.05 ;$ and $(*)$ at $\mathrm{p}<0.1$.

\subsubsection{Annual estimates of NEP, GPP and Reco}

Annual gap-filled NEP, GPP and Reco for both sites are presented in Figure 2.8. Mean Annual NEP was $487 \pm 57.8$ (mean \pm SD for the mean of all years) and $585 \pm 144$ 
$\mathrm{g} \mathrm{C} \mathrm{m}^{-2} \mathrm{yr}^{-1}$ in DE-Hai and DE-Lnf, respectively. A paired t-test showed that difference between the sites was significant $\left(98 \mathrm{~g} \mathrm{C} \mathrm{m}^{-2} \mathrm{yr}^{-1}, \mathrm{p}<0.05\right)$. We observed the largest differences in NEP between the two sites from 2010 (Table 2.6). Annual NEP was significantly more variable in DE-Lnf (Levene's test with $\mathrm{p}<0.05$ ), with coefficients of variation (CV) being $12 \%$ and $25 \%$ in DE-Hai and DE-Lnf, respectively. A significant temporal trend of NEP was observed only for DE-Lnf, with an increase of $21.8 \mathrm{~g} \mathrm{C} \mathrm{m}^{-2} \mathrm{yr}^{-1}$ $(\mathrm{p}<0.05)$. The mean of annual GPP values at DE-Hai and DE-Lnf was $1559 \pm 118$ and $1627 \pm 164 \mathrm{~g} \mathrm{C} \mathrm{m}^{-2} \mathrm{yr}^{-1}$ respectively, with the difference being statistically significant ( $\mathrm{p}$ $=0.07$ ). Like NEP, significantly higher annual GPP was again observed in DE-Lnf from 2010 (Table 2.6). The variability in annual GPP was not significantly different between the two sites, with coefficients of variation (CV) equalling $7.5 \%$ and $10 \%$ in DE-Hai and DE-Lnf, respectively. As for annual NEP, no temporal trend in annual GPP was observed in DE-Hai, whereas a significant trend of $25.5 \mathrm{~g} \mathrm{C} \mathrm{m}^{-2} \mathrm{yr}^{-1}(\mathrm{p}<0.05)$ was observed in DE-Lnf. The mean annual ecosystem respiration (Reco) was $1071 \pm 96$ and $1042 \pm 60$ $\mathrm{g} \mathrm{C} \mathrm{m}^{-2} \mathrm{yr}^{-1}$ in DE-Hai and DE-Lnf, respectively with no significant difference between sites. In contrast to annual NEP and GPP, annual Reco was lower in DE-Lnf with no significant difference. Annual Reco showed a positive temporal trend at both sites but it was statistically insignificant (Table 2.4).

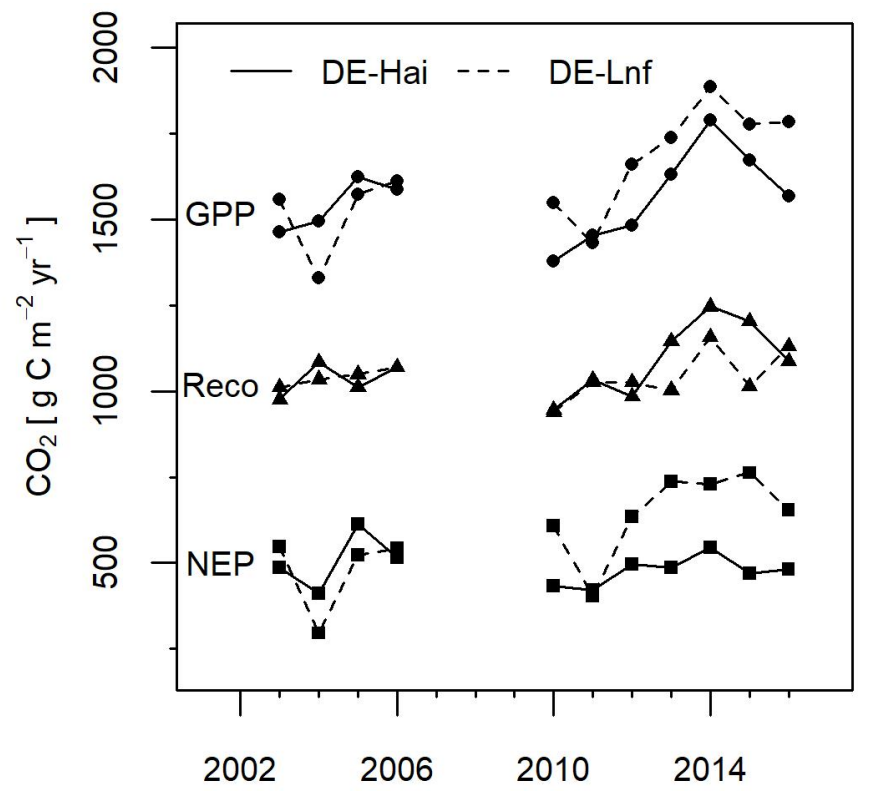

Figure 2.8: Annual sums of GPP, Reco and NEP from 2003 to 2016. Data from 2007 to 2009 was not measured in DE-Lnf.

\subsubsection{Factors contributing to annual variability of NEP, GPP and Reco}

Together, fruit production (FP), time (see the section 2.3.4) and mean annual soil temperature $\left(\mathrm{T}_{\text {soil }}\right)$ explained ca. $65 \%$ and $92 \%$ of the variation in annual NEP in DE-Hai and DE-Lnf, respectively (Table 2.3). In DE-Hai, $\mathrm{T}_{\text {soil }}$ was the most important factor, followed by FP (negative correlation). In the case of DE-Lnf, time and FP explained most of the variation. Results were similar for annual GPP, with a total $\mathrm{R}^{2}$ of 0.62 and 0.88 in DE-Hai and DE-Lnf, respectively. $\mathrm{T}_{\text {soil }}$ was the only significant variable for DE-Hai, 
explaining most of the variation in GPP. In DE-Lnf, time was the strongest predictor variable, followed by $\mathrm{T}_{\text {soil }}$ and $\mathrm{FP}$ (negative correlation). A significant relationship between annual Reco was found only for DE-Lnf with $\mathrm{T}_{\text {soil }}$ as the only significant variable. Figure 2.9 shows the relationship between each of the three significant driving variables $\left(\mathrm{T}_{\text {soil }}, \mathrm{FP}\right.$, time) and the three flux quantities (NEP, GPP, Reco) in terms of the residual variance remaining after the effects of the other two driving variables (e.g. FP and time, in the case of $T_{\text {soil }}$ ) have been removed. This analysis increased the amount of variation in NEP and GPP explained by $\mathrm{T}_{\text {soil }}$. We tested the difference between the slopes of two sites obtained in Figure 2.9 (Table 2.7). The sensitivities of NEP on $\mathrm{T}_{\text {soil }}$ were similar between the sites when the effect of fruit production and time is removed. The result was similar for GPP. Similarly, fruit production was significantly correlated with residuals of NEP after removing effect of $\mathrm{T}_{\text {soil }}$ and time (Figure $2.9 \mathrm{~b}$ ) in both sites. We observed that residuals of GPP decreased with increased fruit production, but significant only for DE-Lnf and with a more than twice as large slope (Figure 2.9e and Table 2.7). Slope between residuals of annual Reco and fruit production was not significantly different from zero for both sites but had a positive slope for DE-Lnf. Only in DE-Lnf, we observed positive slope between time and residuals of NEP after removing the effect of $\mathrm{T}_{\text {soil }}$ and $\mathrm{FP}$ (2.9c and Table 2.7). We also observed higher slope of residuals of GPP (Figure 2.9f) compared to residuals of Reco (Figure 2.9i) to time. In DE-Hai, positive slope between time and residuals of GPP was negated by Reco, thus showing no effect in residuals of NEP.

Table 2.3: Major factors contributing to the variation of annual NEP, GPP and Reco. Var is the contribution of each predictor to total $\mathrm{R}^{2}$ calculated with the product measure metric.

\begin{tabular}{|c|c|c|c|c|c|c|c|}
\hline Flux & Predictors & $\begin{array}{l}\text { DE-Hai } \\
\text { R2 }\end{array}$ & Coefficients & Var & $\begin{array}{l}\text { DE-Lnf } \\
\text { R2 }\end{array}$ & Coefficients & Var \\
\hline \multirow{4}{*}{ NEP } & & 0.65 & & & 0.92 & & \\
\hline & Tsoil + & & $110.48^{*}$ & 0.49 & & $79.94(*)$ & 0.07 \\
\hline & $\mathrm{FP}+$ & & $-0.34(*)$ & 0.15 & & $-0.74 * * *$ & 0.34 \\
\hline & Time & & -0.99 & 0 & & $22.30 * * *$ & 0.51 \\
\hline \multirow[t]{4}{*}{ GPP } & & 0.62 & & & 0.88 & & \\
\hline & Tsoil + & & $208.08 *$ & 0.49 & & $189.95 *$ & 0.28 \\
\hline & $\mathrm{FP}+$ & & -0.23 & 0 & & $-0.60 * *$ & 0.13 \\
\hline & Time & & 8.93 & 0.13 & & $22.57 *$ & 0.46 \\
\hline \multirow[t]{4}{*}{ Reco } & & 0.45 & & & 0.79 & & \\
\hline & Tsoil + & & 97.61 & 0.19 & & $109.90 * *$ & 0.65 \\
\hline & $\mathrm{FP}+$ & & 0.02 & 0 & & 0.14 & 0.14 \\
\hline & Time & & 9.92 & 0.25 & & 0.27 & 0 \\
\hline
\end{tabular}




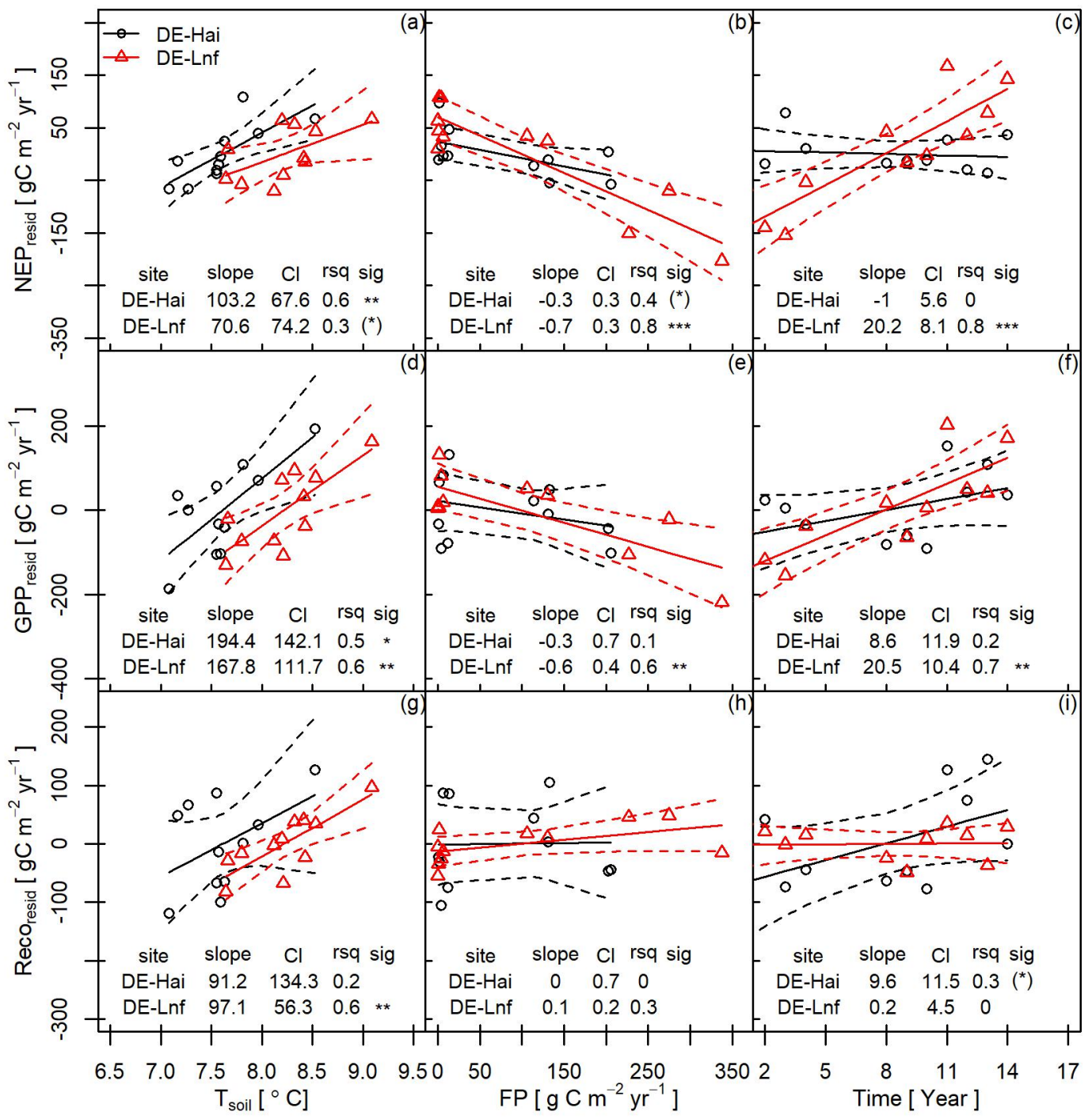

Figure 2.9: Simple linear regressions between residuals of different carbon fluxes after removing effect of fruit production and time (1st column, a, d, g), $\mathrm{T}_{\text {soil }}$ and time (2nd column, $\mathrm{b}, \mathrm{e}, \mathrm{h}$ ) or $\mathrm{T}_{\text {soil }}$ and fruit production (3rd column, c, f, i). Here time is represented by number plus 2000 for clean graph. The solid lines represent linear regression lines and dashed lines confidence interval at $5 \%$ significance level. $* * *$ indicate statistical significance at $\mathrm{p}<0.001$; $* *$ at $\mathrm{p}<0.01$; ${ }^{*}$ at $\mathrm{p}<0.05$; and $(*)$ at $\mathrm{p}<0.1$. 


\subsection{Discussions}

\subsubsection{Meteorological controls of seasonal $\mathrm{CO}_{2}$ fluxes}

We observed stronger sensitivity of winter Reco to $\mathrm{T}_{\text {soil }}$ (Figure 2.6) resulting in higher Reco in DE-Hai than in DE-Lnf, thus, higher winter NEP in DE-Lnf (Figure 2.7). Higher ecosystem respiration is most likely driven by higher stocks of decaying dead wood and by higher rates of leaf litter decomposition caused by higher leaf litter quality (proportion of litter from ash and maple trees) and a higher biological activity in the soil (MUND, 2004). In spring, NEP, GPP and Reco strongly correlated with $\mathrm{T}_{\text {air }}$ and $\mathrm{T}_{\text {soil }}$ with higher correlation values for $T_{\text {soil }}$ in both sites. The change of NEP with $T_{\text {soil }}$ was mostly driven by the sensitivity of GPP to $\mathrm{T}_{\text {soil }}$. Similar results were also observed in Borden forest, Canada, during the spring time (Froelich et al., 2015). Spring temperature is very important for leaf unfolding and we found that the growing season started earlier when spring air temperatures were higher (Figure 2.14). Also, warm soil means favourable growth conditions for roots (ALVAREZ-URIA et al., 2007), improving nutrient and water uptake and leading to increased photosynthesis. Along with GPP, Reco also increases with increased soil temperature, due to the increased activities of tree roots and microbes (Davidson et al., 1998; GonZalez-Meler et al., 2013). DE-Lnf was a significantly stronger sink during spring, primarily driven by GPP (Figure 2.7). We further observed higher sensitivity of GPP to $\mathrm{T}_{\text {soil }}$ in DE-Lnf than in DE-Hai $(\mathrm{p}<0.1)$. This could be explained by an earlier physiological activity in beech than in ash (COLE et al., 2017). DE-Lnf is a beech monoculture comprising mostly vital trees at their optimal age (optimal regarding wood growth and fruit production) whereas DE-Hai has $28 \%$ ash trees and includes many small, young, suppressed, very old, semi-dead and dead trees. In summer (June - July), $\mathrm{R}_{\mathrm{g}}$ was the most important abiotic environmental factor controlling carbon fluxes of both sites. DE-Lnf was a stronger sink with higher GPP and Reco because it is full of optimally growing trees that may have capitalised the radiation more than DE-Hai. Similarly, the stronger sensitivity of summer GPP and Reco to $R_{g}$ of DE-Lnf can be attributed to optimally growing trees of similar size and age that react to weather conditions in same direction and magnitude. August is of interest for DE-Hai where soil water availability (WAI) influences its $\mathrm{CO}_{2}$ fluxes. DE-Hai is more affected than DE-Lnf by water availability because of ash trees that are still active when WAI drops below a critical value (e.g. 2003). Trees close their stomata as the soil water availability reduces to prevent water loss (CHAVEs et al., 2002) also decreasing photosynthesis and respiration.

\subsubsection{Annual $\mathrm{CO}_{2}$ fluxes and its inter-annual variability}

Before comparing DE-Lnf with DE-Hai, it is useful to discuss site management and history. DE-Lnf is an example of a managed even-aged forest that was established and thinned as part of a regular shelterwood system with a rotation period of about 120-140 years. In recent years the management starts to transfer the shelterwood system towards a system of target diameter harvesting. Currently, DE-Lnf represents a mature forest at its optimum phase. If parts of the forest were not certified for seed production, and if the eddy tower were not there, the forest might have been thinned more heavily. This means under a different thinning regime or at another point in time living biomass and/or NEP might 
be different. For a comparison of managed, even-aged forests with unmanaged forests a chronosequence of several even-aged stands covering the entire rotation period would be needed. We thus note that the heterogeneous stand is not being compared with the average managed beech forest in the region, but rather with a mature and productive stand. This must be considered before concluding on the general impact of management on carbon sequestration in forest ecosystems. Both the sites were strong carbon sinks despite one site being in an advanced stage of growth with trees as old as 265 years. The ranges of annual NEP were comparable with Oak Ridge forest in Tennessee, US (577 $\pm 63 \mathrm{~g} \mathrm{C} \mathrm{m}^{-2} \mathrm{yr}^{-1}$, Wilson et al. 2001), Ozarks forest in Missouri, US (479 \pm 6563 $\mathrm{g} \mathrm{C} \mathrm{m}^{-2} \mathrm{yr}^{-1}$, ShaO et al. 2014), and Oak woodland forests, UK (486 $\pm 115 \mathrm{~g} \mathrm{C} \mathrm{m}^{-2} \mathrm{yr}^{-1}$ , WiLKInson et al. 2012) but slightly higher than average annual NEP for temperate forests (350 $\pm 100 \mathrm{~g} \mathrm{C} \mathrm{m}^{-2} \mathrm{yr}^{-1}$, Table 2.8). Average annual GPP and Reco of both sites also fell within the range average annual GPP $\left(1506 \pm 214 \mathrm{~g} \mathrm{C} \mathrm{m}^{-2} \mathrm{yr}^{-1}\right)$ and Reco $\left(1181 \pm 158 \mathrm{~g} \mathrm{C} \mathrm{m}^{-2} \mathrm{yr}^{-1}\right)$ of temperate deciduous forests. A previous study of the same sites using seven years of data (HERBST et al., 2015) reported small but non-significant difference between the sites for NEP. However, by including four more recent years we found a significant difference in NEP between the two sites. The absolute difference in mean annual NEP $\left(98 \mathrm{~g} \mathrm{C} \mathrm{m}^{-2} \mathrm{yr}^{-1}\right)$ results from a higher mean annual GPP of $69 \mathrm{~g} \mathrm{C}$ m-2yr-1 (2/3 of NEP) plus a lower mean annual Reco of $29 \mathrm{~g} \mathrm{C} \mathrm{m}^{-2} \mathrm{yr}^{-1}(1 / 3$ of NEP) in DE-Lnf. The higher mean annual values of NEP in DE-Lnf is due to higher annual NEP from 2010 than DE-Hai. From 2010, significantly higher GPP and lower Reco in DE-Lnf resulted in higher NEP. The higher carbon uptake in DE-Lnf was determined by the activities during winter, spring and summer (section 4.1). We observed lower coefficient of variation $(\mathrm{CV})$ of annual NEP for both the sites compared to average CV of annual NEP of temperate forests. Average CV of annual NEP for temperate forests is $35 \%$ (sd $= \pm 100 \mathrm{~g} \mathrm{C} \mathrm{m}^{-2} \mathrm{yr}^{-1}$, BALdoCCHI 2018 and Table 2.8) with the highest CV of $66 \%$ observed in the Borden forest (FROELICH et al., 2015) and Sorø forest (PILEGAARD et al., 2011). Interestingly, the CV of annual NEP in DE-Hai was the lowest among reported results for temperate deciduous forests and remained similar even after adding four years of data. Also, the CV of annual GPP and Reco of both sites were lower than the average for temperate deciduous forests. Like annual NEP, CV of annual GPP in DE-Hai was lowest among all the temperate deciduous broadleaved forests following the results of MusAvi et al., 2017 that reported older and diverse forests had less variation in saturated gross primary productivity (GPPsat). Between our sites, the managed, homogeneous forest showed a higher CV in NEP and GPP than the unmanaged, heterogeneous forest. Long-term studies conducted in temperate deciduous forests have identified many factors contributing to site-specific inter-annual variation of NEP. Some studies have found that growing season length explains inter-annual variation in NEP: the Borden forest in Canada (Froelich et al., 2015), Sorø forest in Denmark (PilegaArd et al., 2011), Hesse forest (Granier et al., 2008), Morgan-Monroe State Forest in Indiana (Dragoni et al., 2011). In our case, we observed positive correlation between growing season length and NEP and GPP (Figure 2.13e, f and g), and at the same time positive correlation between growing season length and temperatures (Figure 2.12). Among $\mathrm{T}_{\text {air }}$ and $\mathrm{T}_{\text {soil }}$, we found stronger relationship of $\mathrm{T}_{\text {soil }}$ with NEP and GPP (Figure 2.15 and Figure 2.16), this could have led 
to selection of $\mathrm{T}_{\text {soil }}$ in multiple linear model selection using AIC criteria. At an annual scale, we found that sensitivities of $\mathrm{T}_{\text {soil }}$ to NEP and GPP were similar based on residual analysis conducted after removing effect of fruit production and time. Other two important factors that explained annual fluxes were fruit production and time. We will discuss them separately in section 4.3 and 4.4 .

\subsubsection{Effect of fruit production on $\mathrm{CO}_{2}$ fluxes}

Fruit production (FP) was negatively correlated with NEP at both sites (Figure 2.17). The negative slope of NEP vs fruit production was mostly the result of a reduction of GPP in high fruit production years, i.e. photosynthesis decreased with increasing fruit production. Many studies reported that tree ring growth was reduced in years of high fruit production (e.g. HolmsGaARD 1955; Mund et al. 2010). Different mechanisms have been reported for this reduced growth in trees, including reduced photosynthetic rates in reproductive branches due to $\mathrm{N}$ or P depletion in those branches (SALA et al., 2012), smaller leaves (INNES, 1992), reduced leaf area (FERRETTI et al., 1998), lower number of leaves during the mast year (HAN et al., 2008) which could be due to diminished shoot growth and increased foliar bud mortality (IsHIHARA et al., 2009) as foliar buds are replaced by seeds (INNES, 1994). It is important to note that the effect was stronger in DE-Lnf - a homogeneous forests with trees in a similar fruit-producing age class (150 -170 years) (HERBST et al., 2015). On the other hand, DE-Hai has a heterogeneous structure with different species and a wide range of tree age from 0 to 265 years. Thus, beech fruit production does not occur in all trees (Figure 2.3).

\subsubsection{Effect of time on $\mathrm{CO}_{2}$ fluxes}

Many studies report that $\mathrm{CO}_{2}$ fluxes in temperate forests have been increasing (FERNÁNDEZMartínez et al. 2017; Froelich et al. 2015; Granier et al. 2008; Pilegaard et al. 2011, etc). A significant increasing temporal trend in $\mathrm{CO}_{2}$ uptake has also been observed in ca. 80 year-old managed beech forest in Sor $\varnothing$, Denmark $\left(-23 \mathrm{~g} \mathrm{C} \mathrm{m}^{-2} \mathrm{yr}^{-1}\right.$, PileGaArd et al. 2011), ca. 40 year-old managed beech forest in Hesse, France $\left(-43 \mathrm{~g} \mathrm{C} \mathrm{m}^{-2} \mathrm{yr}^{-1}\right.$, GrANiER et al. 2008) and ca. 95 year-old managed maple, red oak and white oak Harvard forest in US (-16 $\mathrm{g} \mathrm{C} \mathrm{m}^{-2} \mathrm{yr}^{-1}$, URBANSKI et al. 2007). We observed a similar temporal trend in NEP in DE-Lnf, a managed homogeneous forest, which was not visible when HeRBST et al. (2015) reported 7 years' data. The NEP of DE-Hai was reported to be - 494 $\mathrm{g} \mathrm{C} \mathrm{m}^{-2}$ and $-490 \mathrm{~g} \mathrm{C} \mathrm{m}^{-2}$ for 2000 and 2001, respectively by KNoHL et al. (2003) and the capacity remained in the same range for all 12 years described here, exhibiting no significant temporal trend. However, we observed positive trends in annual GPP and Reco at DE-Hai which might have cancelled resulting in no trend in NEP. The normal temporal trend in forest productivity is to follow a sigmoidal growth curve as individuals age. Overlaid on this, however, are the impacts of increasing atmospheric $\mathrm{CO}_{2}$ concentration, decreasing sulphur deposition (FERNÁNDEZ-MARTíNEZ et al., 2017), increasing nitrogen deposition, as well as management activities such as thinning. Here we used time as a variable because it is hard to disentangle these effects. Thus, our observed temporal trend in DE-Lnf needs a careful interpretation because the trend appears to reflect an increase in $\mathrm{CO}_{2}$ uptake starting from 2012 (Figure 2.8), and there was no significant temporal trend in any of the 
observed meteorological variables that could explain this increase (Table 2.4). We observed a positive trend in growing season length $(0.75$ days per year, $\mathrm{p}<0.05)$ which explained about $19 \%$ variability in NEP $(\mathrm{p}=0.16)$ but not as high as it has been reported for Hesse (Granier et al., 2008), Sorø (PilegaArd et al., 2011), Borden forest (Froelich et al., 2015), and Morgan Monroe state forest (Dragoni et al., 2011). As an alternate hypothesis, we note that thinning operations were carried out in the main flux footprint area of DE-Lnf, and we speculate that because thinning has the effect of increasing productivity in the remaining trees, this might have impacted NEP subsequently. About $2850 \mathrm{~g} \mathrm{C} \mathrm{m}^{-2}$ of biomass was thinned from the footprint area from 2002 to 2006 (Figure 2.10) with the largest thinning carried out in $2004\left(782 \mathrm{~g} \mathrm{C} \mathrm{m}^{-2}\right)$. For comparison, NEP in the period 2010 - 2016 was, in average, $171 \mathrm{~g} \mathrm{C} \mathrm{m}^{-2} \mathrm{yr}^{-1}$ higher than in the period $2003-2006$ (Table 2.6), amounting to $1197 \mathrm{~g} \mathrm{C} \mathrm{m}^{-2}$ of additional carbon in this period. Thus, it is likely that management is a strong driver of inter-annual variability in productivity, with the changes we observed being a response to thinning extended over several years. We note that Sorø was thinned about $20 \%$ every 10 years (PILEGAARD et al., 2011) and Hesse was thinned every five years (GRANIER et al., 2008), yet these authors did not report any significant effect of thinning on $\mathrm{CO}_{2}$ fluxes. This could be due to the effects of thinning being seen only gradually over the following years as trees adjust to the new conditions, thus making the connection between $\mathrm{C}$ fluxes and thinning difficult to perceive or quantify.

\subsection{Conclusions}

We compared two temperate deciduous forest types with similar site and meteorological conditions but with different structure in terms of diameter distribution, age and species composition. We found that the homogeneous forest had a higher mean annual NEP than the heterogeneous forest due to lower respiration rates in winter and higher carbon uptake rates in spring and summer. $\mathrm{CO}_{2}$ uptake by the homogeneous forest has increased in recent years playing a key role in determining differences between the forests. We identified an overall time-effect but could not disentangle possible contributing factors such as increasing atmospheric $\mathrm{CO}_{2}$ concentrations or effects of silvicultural management. In the introduction section, we put forward two hypotheses. Regarding hypothesis one, i.e. higher sensitivity of carbon fluxes of homogenous forests to abiotic environmental variables, we concluded that the homogenous forest showed a stronger sensitivity to abiotic environmental variables during spring $\left(\mathrm{T}_{\text {soil }}\right)$ and summer $\left(\mathrm{R}_{\mathrm{g}}\right)$ causing inter-annual differences between sites. At annual scale, however, the sensitivities of $\mathrm{CO}_{2}$ fluxes to abiotic environment variables are similar due to stronger control by biotic factors. In case of the second hypothesis, i.e. a higher negative sensitivity of $\mathrm{CO}_{2}$ fluxes of the homogenous forest to fruit production, we see that the NEP of the homogenous forest showed a stronger sensitivity to fruit production due to a higher negative sensitivity of GPP and higher positive sensitivity of Reco to fruit production. The relationships are weak; thus, we suggest that more data are required to confirm the hypothesis. Even though both forests are of same average age, structures of these forests vary. This leads to different responses of the $\mathrm{CO}_{2}$ fluxes to abiotic and biotic factors. Thus, it is necessary that we include structural information along with species traits (fruiting characteristics) and management activities to be able to predict the $\mathrm{CO}_{2}$ fluxes in response to future climate. 


\subsection{Supplementary materials}

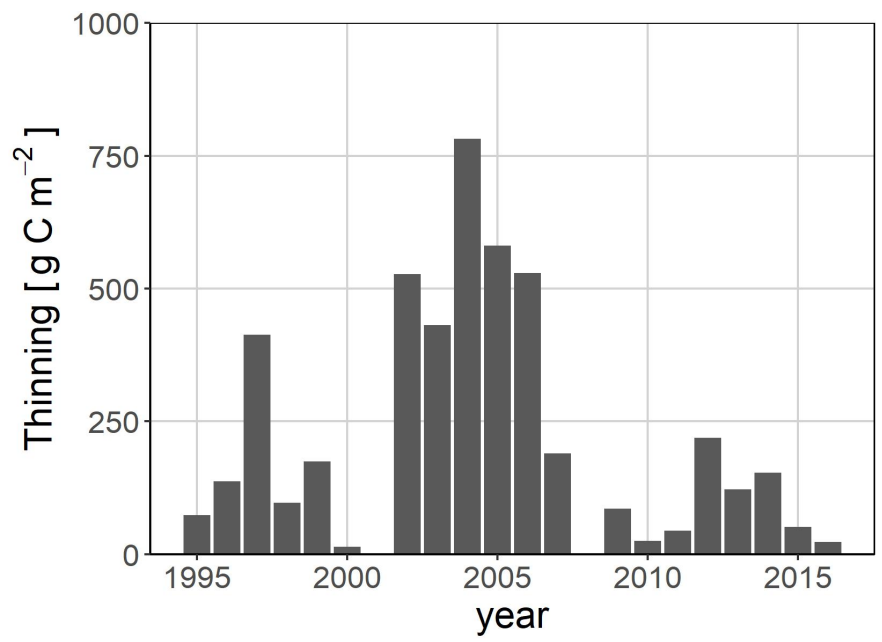

Figure 2.10: Annual footprint weighted thinning in eddy flux footprint area (calculated using Kljun et al., 2015) of DE-Lnf from 1995 to 2016. The highest thinning of $995 \mathrm{~g} \mathrm{C} \mathrm{m-2} \mathrm{was}$ conducted in 2005 from the footprint area.

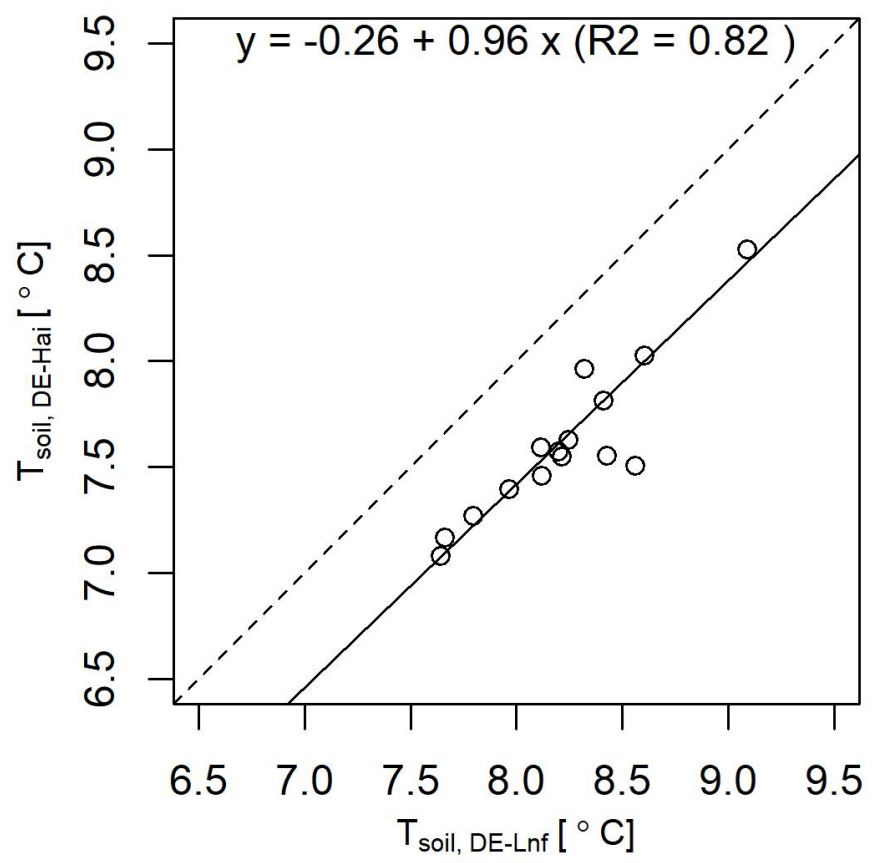

Figure 2.11: Linear regression between mean annual $T_{\text {soil }}$ of DE-Lnf and DE-Hai. Dashed line represents a line with slope 1 . Systematic difference between sites is due to difference in measurement depths (5 vs $4 \mathrm{~cm}$ in DE-Hai and DE-Lnf, respectively). 
Table 2.4: Average Annual values (mean and sd) and the temporal trend during the study period for all dependent and selected predictor variables for both sites. Units for GSS (growing season start day), and GSE (growing season end day) is doy yr-1 where doy indicates Julian day of the year. Trend is the temporal trend and * indicates the statistically significant values at $5 \%$ significance level.

\begin{tabular}{|c|c|c|c|c|c|}
\hline Variables & Units & $\begin{array}{l}\text { DE-Hai } \\
\text { mean } \pm \text { sd }\end{array}$ & trend & $\begin{array}{l}\text { DE-Lnf } \\
\text { mean } \pm \text { sd }\end{array}$ & trend \\
\hline $\mathrm{R}_{\mathrm{g}}$ & $\mathrm{W} \mathrm{m}{ }^{-2}$ & $122 \pm 6.5$ & 0.18 & $124 \pm 7.2$ & 0.62 \\
\hline $\mathrm{T}_{\text {air }}$ & ${ }^{\circ} \mathrm{C}$ & $8.34 \pm 0.72$ & 0.03 & $8.3 \pm 0.7$ & 0.05 \\
\hline $\mathrm{T}_{\text {soil }}$ & ${ }^{\circ} \mathrm{C}$ & $7.61 \pm 0.36$ & 0.01 & $8.23 \pm 0.38$ & 0.02 \\
\hline VPD & $\mathrm{hPa}$ & $3.45 \pm 0.56$ & 0.02 & $3.28 \pm 0.48$ & 0 \\
\hline Rain & $\mathrm{mm}$ & $744 \pm 152$ & -6.76 & $601 \pm 154$ & -9.12 \\
\hline WAI & - & $0.86 \pm 0.09$ & -0.01 & $0.84 \pm 0.1$ & 0 \\
\hline NEP & $\mathrm{g} \mathrm{C} \mathrm{m}^{-2} \mathrm{yr}^{-1}$ & $487 \pm 57.8$ & -3.14 & $585 \pm 144$ & $21.8^{*}$ \\
\hline GPP & $\mathrm{g} \mathrm{C} \mathrm{m}^{-2} \mathrm{yr}^{-1}$ & $1558 \pm 118$ & 4.25 & $1627 \pm 164$ & $25.5^{*}$ \\
\hline Reco & $\mathrm{g} \mathrm{C} \mathrm{m}^{-2} \mathrm{yr}^{-1}$ & $1071 \pm 96$ & 0.28 & $1042 \pm 60$ & 0.08 \\
\hline GSS & doy & $125 \pm 7$ & -0.42 & $121 \pm 5$ & -0.29 \\
\hline GSE & doy & $289 \pm 4$ & -0.35 & $288 \pm 5$ & 0.45 \\
\hline GSL & day & $164 \pm 7$ & 0.07 & $168 \pm 6$ & $0.75^{*}$ \\
\hline
\end{tabular}

Table 2.5: Growing season start day (GSS), end day (GSE) and length (GSL) for DE-Hai and DE-Lnf during the study period.

\begin{tabular}{lllllll}
\hline Year & $\begin{array}{l}\text { DE-Hai } \\
\text { GSS (doy) }\end{array}$ & GSE (doy) & GSL (days) & GE-Lnf \\
& GSS (doy) & GSE (doy) & GSL (days) \\
\hline 2003 & 125 & 292 & 167 & 123 & 290 & 167 \\
2004 & 123 & 288 & 165 & 121 & 281 & 160 \\
2005 & 125 & 293 & 168 & 122 & 291 & 169 \\
2006 & 127 & 294 & 167 & 126 & 294 & 168 \\
2010 & 134 & 283 & 149 & 123 & 283 & 160 \\
2011 & 117 & 288 & 171 & 114 & 285 & 171 \\
2012 & 129 & 289 & 160 & 124 & 290 & 166 \\
2013 & 131 & 288 & 157 & 130 & 292 & 162 \\
2014 & 111 & 284 & 173 & 112 & 288 & 176 \\
2015 & 114 & 284 & 170 & 117 & 293 & 176 \\
2016 & 130 & 292 & 162 & 117 & 292 & 175 \\
\hline Average & 125 & 289 & 164 & 121 & 289 & 168 \\
Sd & 7 & 4 & 7 & 5 & 4 & 6 \\
\hline
\end{tabular}




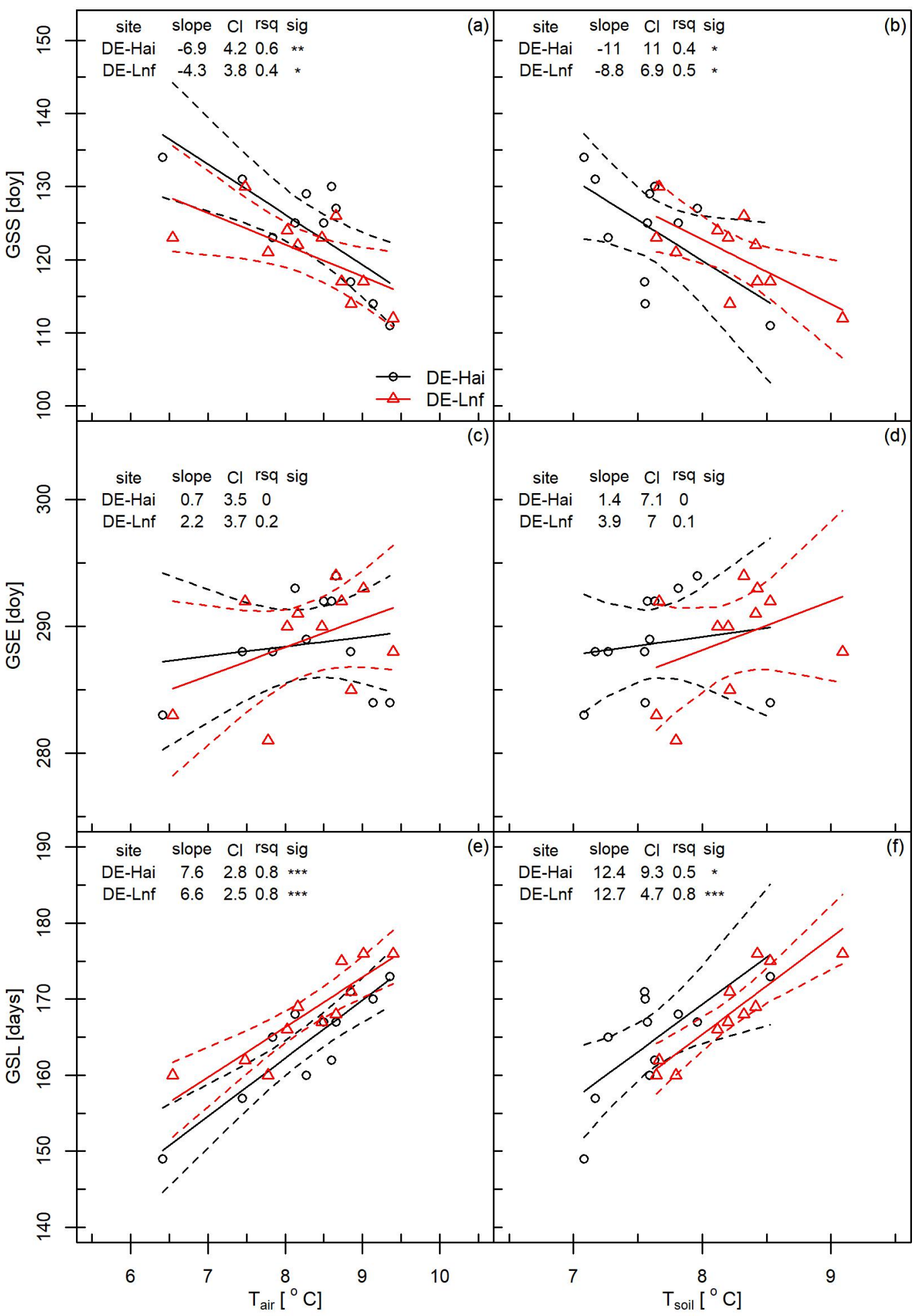

Figure 2.12: Relationship between $\mathrm{T}_{\text {air }}$ and $\mathrm{T}_{\text {soil }}$ with growing season matrix. GSS is growing season start day indicated by day of the year (doy), GSE is growing season end day indicated by day of the year (doy) and GSL is growing season length indicated by number of days. CI is $95 \%$ confidence interval of slope and rsq the coefficient of determination of linear regression, and sig its significance $\left(* * *\right.$ indicates statistical significance at $\mathrm{p}<0.001$; ** at $\mathrm{p}<0.01$; ${ }^{*}$ at $\mathrm{p}<0.05$; and $(*)$ at $\mathrm{p}<0.1)$. The solid lines represent linear regression lines and dashed lines $95 \%$ confidence interval. 


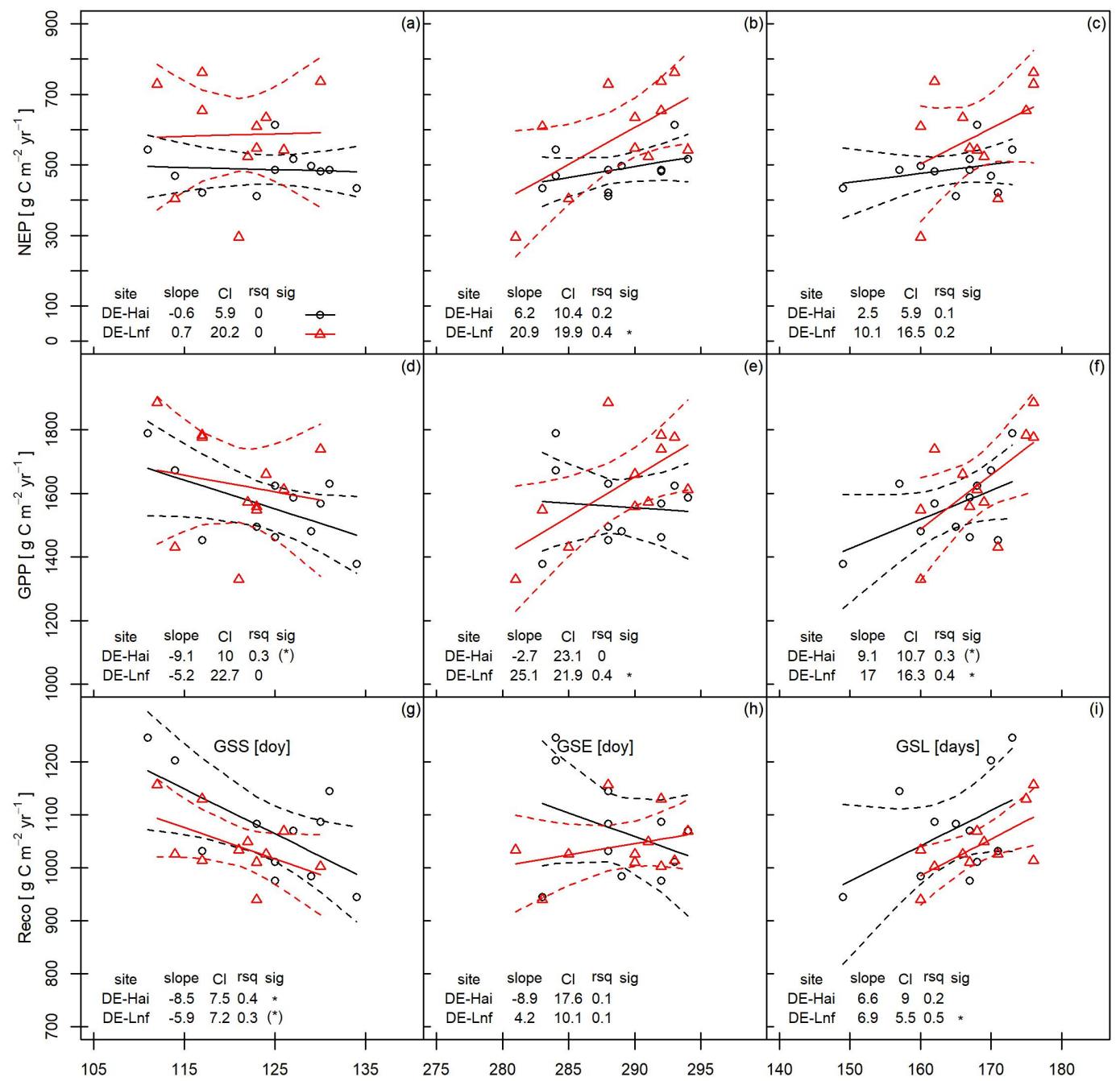

Figure 2.13: Simple linear regression between NEP, GPP and Reco with growing season start day (GSS), growing season end day (GSE) and growing season length day (GSL). CI is $95 \%$ confidence interval of slope and rsq the coefficient of determination of linear regression, and sig its significance $\left(* * *\right.$ indicates statistical significance at $\mathrm{p}<0.001 ;{ }^{* *}$ at $\mathrm{p}<0.01{ }^{*}$ at $\mathrm{p}<$ 0.05 ; and $(*)$ at $\mathrm{p}<0.1)$. The solid lines represent linear regression lines and dashed lines 95 $\%$ confidence interval. 
Table 2.6: Mean annual fluxes for two periods (2003-2006 and 2010-2016) and differences between two sites. Differences between sites were tested using paired t-test.

\begin{tabular}{lllll}
\hline period & Flux & DE-Hai (mean $\pm \mathrm{sd})$ & $\begin{array}{l}\text { DE-Lnf (mean } \pm \mathrm{sd}) \\
{\left[\mathrm{g} \mathrm{C} \mathrm{m}^{-2} \mathrm{yr}^{-1} 1\right]}\end{array}$ & $\begin{array}{l}\text { Diff } \\
{\left[\mathrm{g} \mathrm{C} \mathrm{m}^{-2} \mathrm{yr}^{-1}\right]}\end{array}$ \\
\hline \multirow{2}{*}{$2003-2006$} & NEP & $506 \pm 84$ & $476 \pm 122$ & 30 \\
& GPP & $1542 \pm 76$ & $1517 \pm 128$ & 25 \\
& Reco & $1035 \pm 50$ & $1040 \pm 25$ & 2 \\
$2010-2016$ & NEP & $476 \pm 41$ & $647 \pm 121$ & $171^{* *}$ \\
& GPP & $1568 \pm 142$ & $1689 \pm 156$ & $121^{* *}$ \\
& Reco & $1092 \pm 112$ & $1042 \pm 76$ & -50 \\
\hline
\end{tabular}

Table 2.7: Difference between the two sites with respect to slopes between each of the three significant driving variables $\left(\mathrm{T}_{\text {soil }}, \mathrm{FP}\right.$, time) and the three flux quantities (NEP, GPP, Reco) in terms of the residual variance remaining after the effects of the other two driving variables (e.g. FP and time, in the case of $\mathrm{T}_{\text {soil }}$ ) have been removed.

\begin{tabular}{llll}
\hline $\mathrm{CO}_{2}$ flux & Variable & $\begin{array}{l}\text { Slope difference } \\
\text { (DE-Hai }- \text { DE-Lnf) }\end{array}$ & $\mathrm{SE}$ \\
\hline $\mathrm{NEP}$ & $\mathrm{T}_{\text {soil }}$ & 32.6 & 44.5 \\
GPP & $\mathrm{T}_{\text {soil }}$ & 26.6 & 79.6 \\
Reco & $\mathrm{T}_{\text {soil }}$ & -5.9 & 63.4 \\
$\mathrm{NEP}$ & $\mathrm{FP}$ & $0.4^{*}$ & 0.2 \\
$\mathrm{GPP}$ & $\mathrm{FP}$ & 0.3 & 0.3 \\
Reco & $\mathrm{FP}$ & -0.1 & 0.3 \\
$\mathrm{NEP}$ & Time & $-21.2^{* *}$ & 4.3 \\
GPP & Time & $-11.9\left(^{*}\right)$ & 7 \\
Reco & Time & $9.3\left(^{*}\right)$ & 5.5 \\
\hline
\end{tabular}




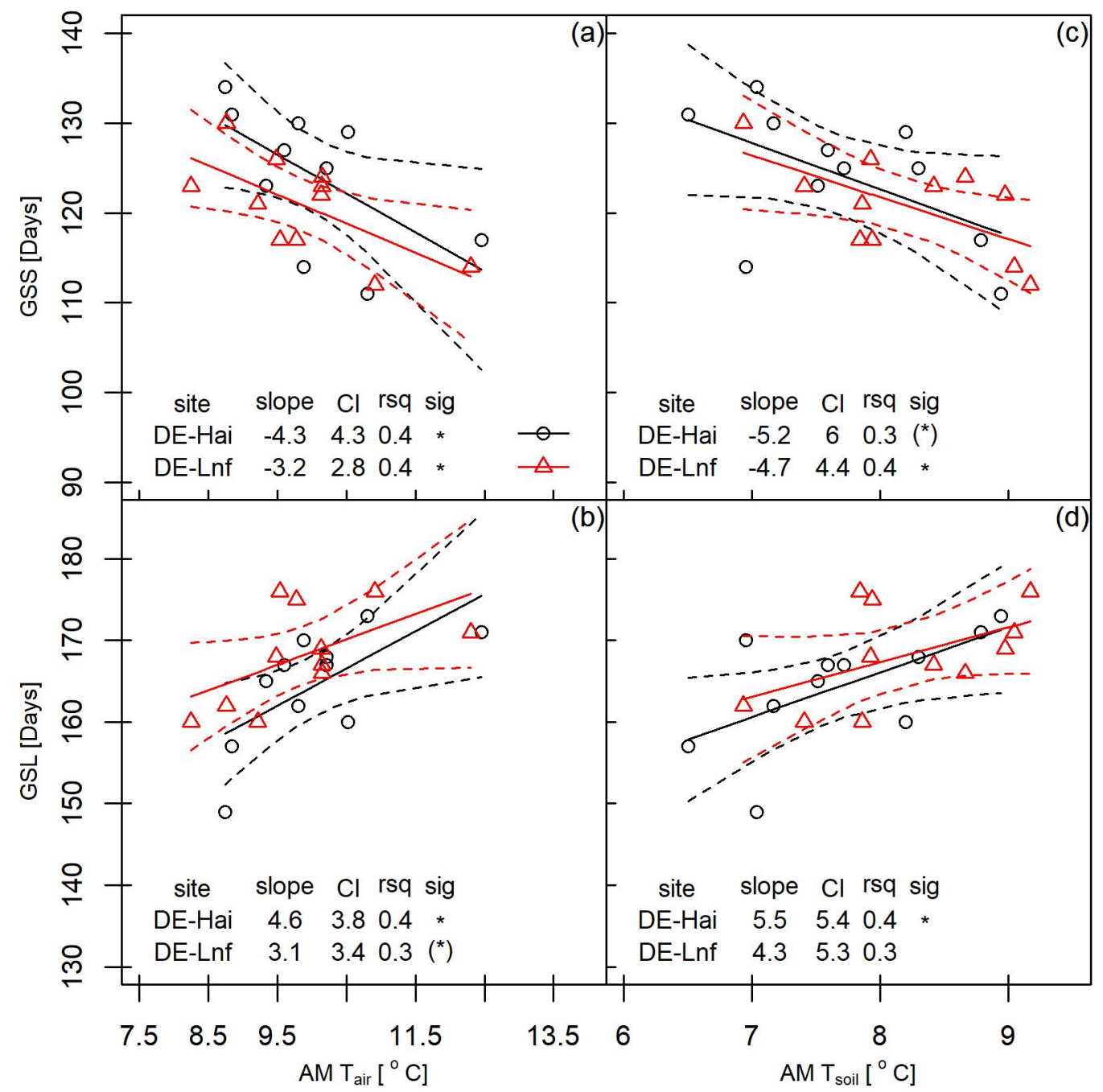

Figure 2.14: Relationship of growing season start day (GSS) and growing season length (GSL) with spring air (AM $\mathrm{T}_{\text {air }}$ ) and soil temperature (AM $\left.\mathrm{T}_{\text {soil }}\right)$. CI is $95 \%$ confidence interval of slope and rsq the coefficient of determination of linear regression, and sig its significance (*** indicates statistical significance at $\mathrm{p}<0.001$; ** at $\mathrm{p}<0.01$; ${ }^{*}$ at $\mathrm{p}<0.05$; and $\left(^{*}\right)$ at $\mathrm{p}$ $<0.1)$. The solid lines represent linear regressions and dashed lines $95 \%$ confidence interval. 

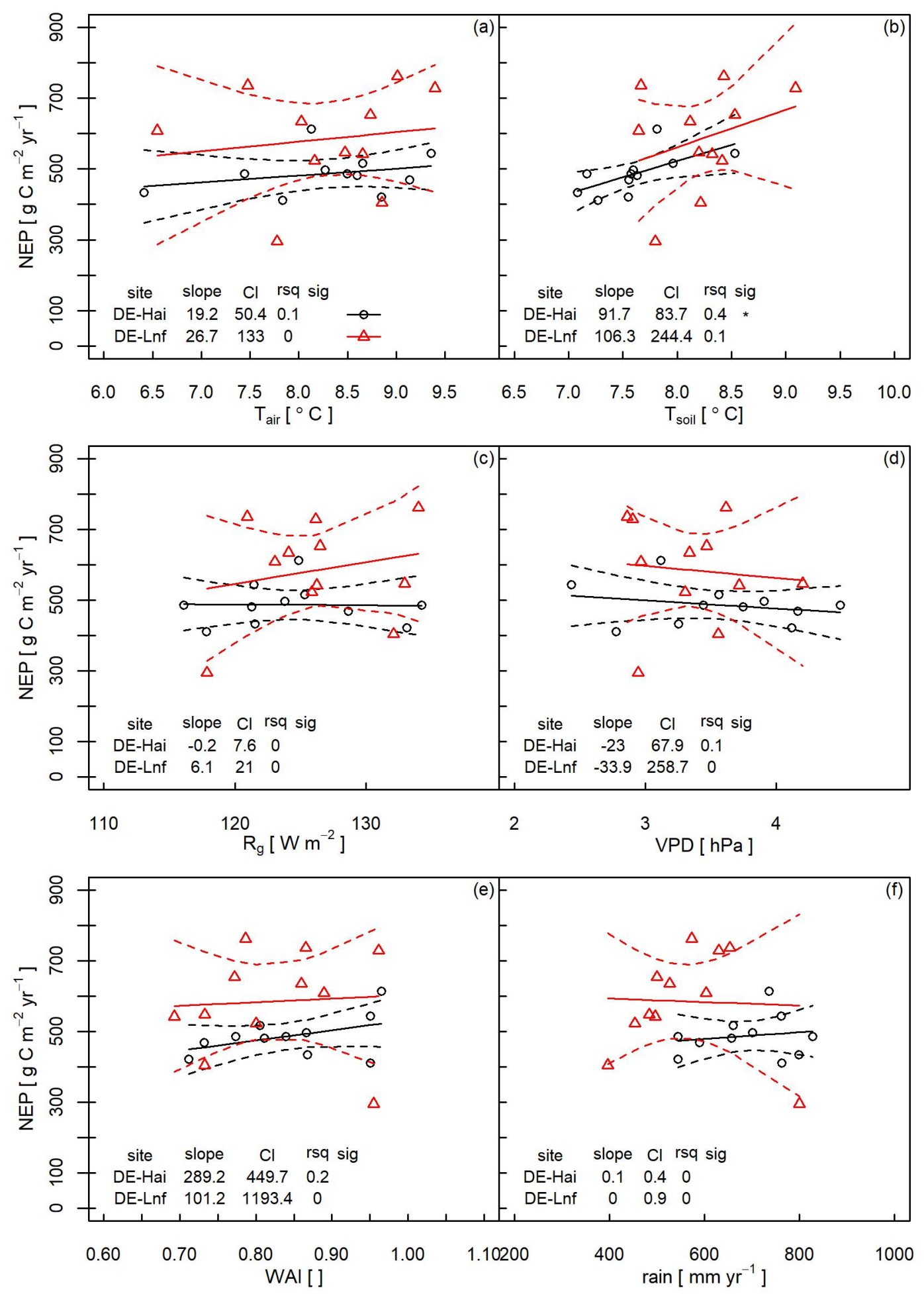

Figure 2.15: Regression between annual NEP and annual mean of meteorological variables (except for rain which was summed). CI is $95 \%$ confidence interval of slope and rsq the coefficient of determination of linear regression, and sig its significance (*** indicates statistical significance at $\mathrm{p}<0.001$; $* *$ at $\mathrm{p}<0.01$; ${ }^{*}$ at $\mathrm{p}<0.05$; and $(*)$ at $\mathrm{p}<0.1$ ). The solid lines represent linear regressions and dashed lines $95 \%$ confidence interval. 

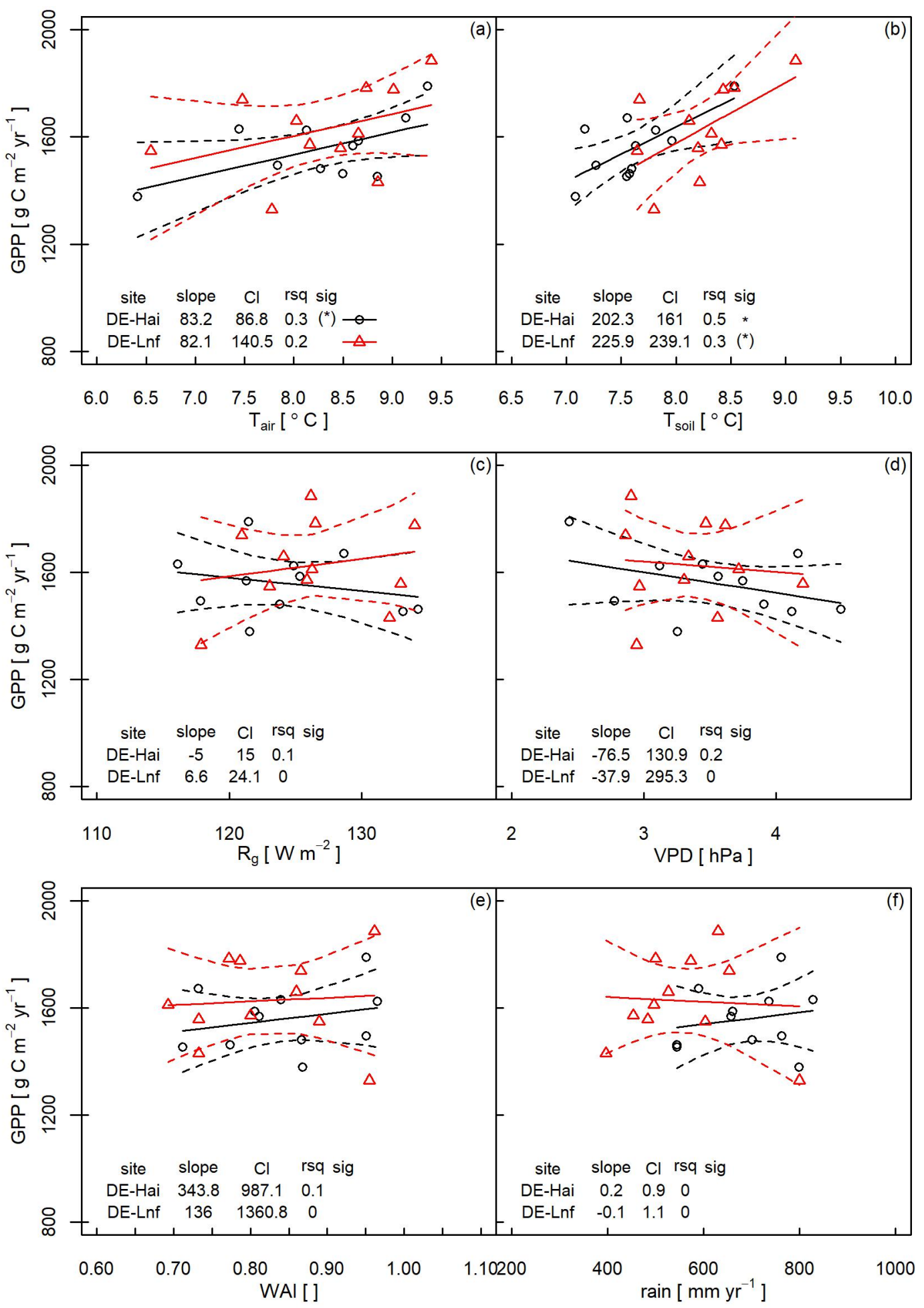

Figure 2.16: Regression between annual GPP and annual mean of meteorological variables (except for rain which was summed). CI is $95 \%$ confidence interval of slope and rsq the coefficient of determination of linear regression, and sig its significance $(* * *$ indicates statistical significance at $\mathrm{p}<0.001 ;{ }^{* *}$ at $\mathrm{p}<0.01{ }^{*}$ at $\mathrm{p}<0.05$; and $(*)$ at $\left.\mathrm{p}<0.1\right)$. The solid lines represent linear regressions and dashed lines $95 \%$ confidence interval. 


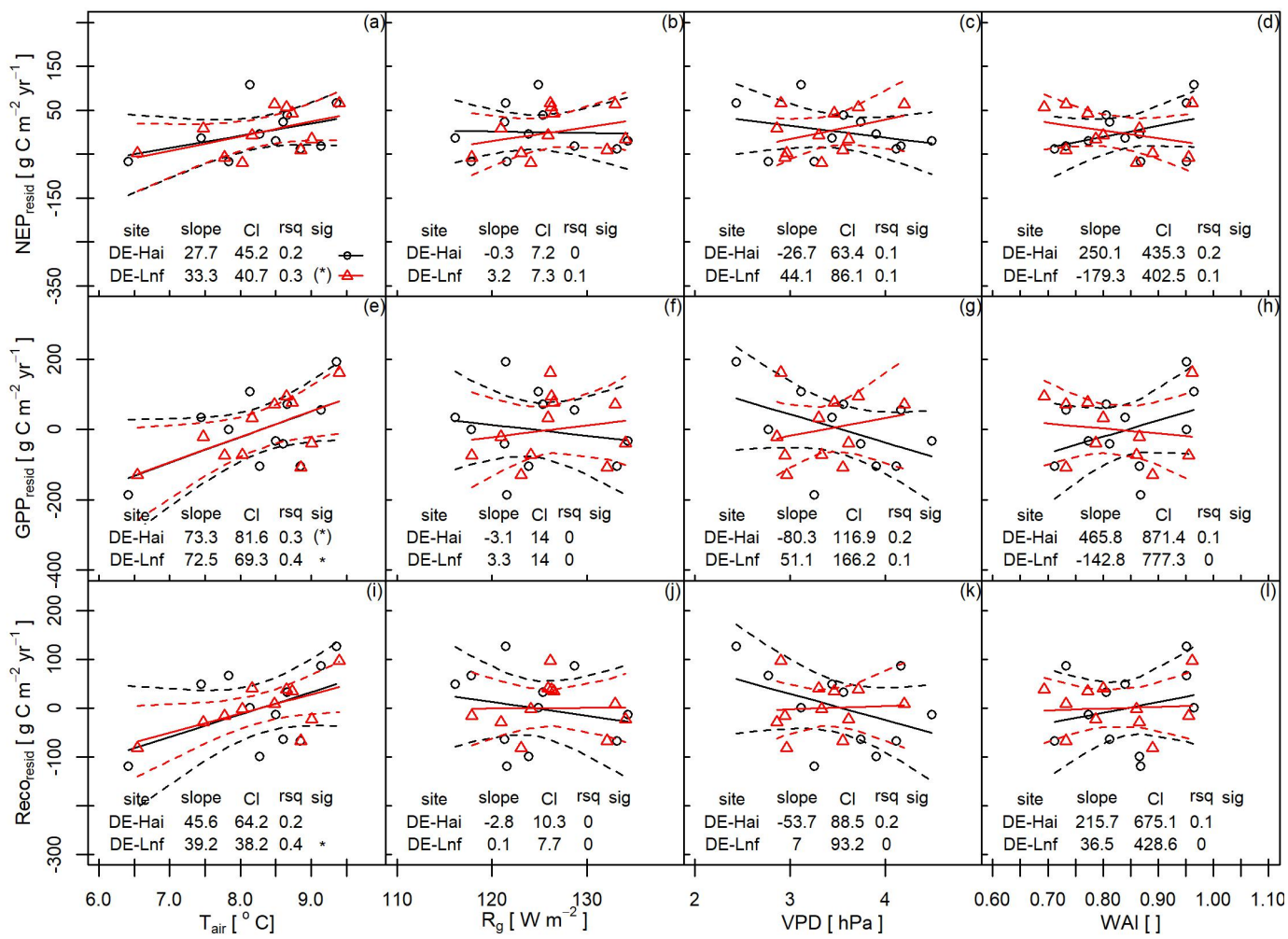

Figure 2.17: Linear regression between residual of NEP, GPP and Reco after removing the effect of time and fruit production (FP). CI is $95 \%$ confidence interval of slope and rsq the coefficient of determination of linear regression, and sig its significance (*** indicates statistical significance at $\mathrm{p}<0.001 ; * *$ at $\mathrm{p}<0.01 ; *$ at $\mathrm{p}<0.05$; and $(*)$ at $\mathrm{p}<0.1)$. The solid lines represent linear regression lines and dashed lines $95 \%$ confidence interval.

Table 2.8: Temperate broad-leaved deciduous forests with long term eddy covariance measurements. The table was modified after BALDOCCHI (2018). CV is coefficient of variation (standard deviation divided by mean).

\begin{tabular}{|c|c|c|c|c|c|c|c|c|c|}
\hline Site & Country & $\mathrm{n}$ & $\begin{array}{l}\text { NEP } \\
\text { mean } \pm \text { sd } \\
{\left[\mathrm{g} \mathrm{C} \mathrm{m}^{-2} \mathrm{yr}^{-1} \text { ] }\right.}\end{array}$ & $\mathrm{CV}$ & $\begin{array}{l}\text { GPP } \\
\text { mean } \pm \mathrm{sd} \\
{\left[\mathrm{g} \mathrm{C} \mathrm{m}^{-2} \mathrm{yr}^{-1}\right]}\end{array}$ & $\mathrm{CV}$ & $\begin{array}{l}\text { Reco } \\
\text { mean } \pm \mathrm{sd} \\
{\left[\mathrm{g} \mathrm{C} \mathrm{m}^{-2} \mathrm{yr}^{-1}\right]}\end{array}$ & $\mathrm{CV}$ & Reference \\
\hline Borden & Canada & 18 & $177 \pm 116$ & 0.66 & $1373 \pm 164$ & 0.12 & $1196 \pm 188$ & 0.16 & $\begin{array}{l}\text { FROELICH et al } \\
(2015)\end{array}$ \\
\hline Soroe & Denmark & 13 & $156 \pm 103$ & 0.66 & $1727 \pm 136$ & 0.08 & $1570 \pm 97$ & 0.06 & $\begin{array}{l}\text { PILEGAARD et al } \\
(2011)\end{array}$ \\
\hline Hesse & France & 10 & $386 \pm 171$ & 0.44 & $1397 \pm 192$ & 0.14 & $1011 \pm 137$ & 0.14 & GRANIER et al. (2008) \\
\hline Takayama & Japan & 9 & $237 \pm 98$ & 0.41 & $1110 \pm 409$ & 0.37 & $829 \pm 264$ & 0.32 & SAIGUSA et al. (2005) \\
\hline $\begin{array}{l}\text { Straights In- } \\
\text { closure }\end{array}$ & UK & 12 & $486 \pm 115$ & 0.24 & $1993 \pm 275$ & 0.14 & $1548 \pm 192$ & 0.12 & $\begin{array}{l}\text { PILEGAARD et al } \\
(2011)\end{array}$ \\
\hline $\begin{array}{l}\text { Morgan- } \\
\text { Monroe }\end{array}$ & US & 13 & $351 \pm 81$ & 0.23 & $1452 \pm 118$ & 0.08 & $1098 \pm 82$ & 0.07 & SULMAN et al. (2016) \\
\hline $\begin{array}{l}\text { Harvard } \\
\text { Forest, Peter- } \\
\text { sham }\end{array}$ & US & 13 & $245 \pm 100$ & 0.41 & $1400 \pm 164$ & 0.12 & $1153 \pm 105$ & 0.09 & $\begin{array}{l}\text { URBANSKI et al } \\
(2007)\end{array}$ \\
\hline Ozarks & US & 5 & $479 \pm 65$ & 0.14 & $1125 \pm 164$ & 0.15 & $646 \pm 121$ & 0.19 & SHAO et al. (2014) \\
\hline $\begin{array}{l}\text { Duke Forest, } \\
\text { Durham }\end{array}$ & US & 8 & $402 \pm 96$ & 0.24 & $1982 \pm 300$ & 0.15 & $1580 \pm 237$ & 0.15 & Novick et al. (2015) \\
\hline Oak Ridge & US & 5 & $577 \pm 63$ & 0.11 & $\mathrm{Na} \pm \mathrm{Na}$ & $\mathrm{Na}$ & $\mathrm{Na} \pm \mathrm{Na}$ & $\mathrm{Na}$ & WILSON et al. (2001) \\
\hline Average & & & $350 \pm 100$ & 0.35 & $1506 \pm 214$ & 0.15 & $1181 \pm 158$ & 0.14 & \\
\hline
\end{tabular}




\section{CHAPTER 3}

Effect of forest structure on drought response of ecosytem-level photosynthetic capacity

Manuscript to be submitted to 'Biogeosciences' 


\subsection{Abstract}

Understanding the effect of forest stand structure on the temporal stability of ecosystem functions and resistance during droughts is key to understanding how forests may respond to climate change. Whilst many studies have looked at the effect of species, few have studied the effect of horizontal and vertical structural diversity. Here, we look at the effect of nine structural parameters (including species richness) on the temporal stability of ecosystem-level light-saturated photosynthetic capacity $\left(\mathrm{GPP}_{1000}\right)$ and its resistance to changes in water availability during droughts, with the aim of answering two questions, (a) Do structurally diverse forests have lower variation in annual $\mathrm{GPP}_{1000}$ ? (b) structurally diverse forests more resistant to drought events? We found that unmanaged forests and forests managed as high forests with higher basal areas, which also tend to be older and more diverse in size, had more stable annual GPP $_{1000}$. Conversely, no structural parameters were found that explained $\mathrm{GPP}_{1000}$ anomalies during drought years. Instead, differences between sites in anomalies in $\mathrm{GPP}_{1000}$ were mostly explained by growing season air temperature. With relatively few flux sites having robust data on structural parameters, the statistical power of this type of analysis is limited, but we hope that with the availability of more canopy structural data from sites with long-term flux measurements we will be better able to understand the effect of structure on forest ecosystem functions.

\subsection{Introduction}

Forest structure - associated with the distribution of trees in space (both horizontally and vertically) and their variability in size - influences the local environmental conditions within stand (e.g. distribution of light and precipitation) affecting ecosystem functioning (e.g. ecosystem-level photosynthetic capacity). The changes in ecosystem functioning again modify the forest structure (see Figure 1 in Pretzsch et al. 2016). Forest structure plays thus an important role in determining ecosystem functioning and stand dynamics. Stand structural attributes like density, size distributions, size variation (of diameter and heights), spatial variation, age composition, species richness, canopy structure, etc. (McElHinNy et al., 2005; Pommerening, 2002; Río et al., 2016; Seidl et al., 2017) are used to quantify stand structure. There exist numerous indices to quantify stand structure either using a single stand structural attribute or a combination of them (see review by Río et al., 2016). Several advantages of structurally heterogeneous forests have been listed by ScHALL et al. (2018), like, increase in productivity, promotion of biodiversity, resistance and resilience against disturbances and equally profitable as structurally less heterogeneous forests. Hence, understanding the effect of forest stand structure on ecosystem productivity (FIRN et al., 2007; Gamfeldt et al., 2013; Lei et al., 2009; Liang et al., 2016; Mittelbach et al., 2001; Morin et al., 2011; Zhang et al., 2012) and stability (JUCKer et al., 2014; Morin et al., 2014) has been an important area of research in the recent years.

In many cases, stand structure is the result of management regime, for e.g., old growth forests with high heterogeneity results from cessation of management and young forests with low heterogeneity from clear cut. Pommerening et al. (2013) highlighted that management activities like thinnings led to a high number of pairs of large and small trees close to each other. 
Most studies have focused on the effect of tree species diversity (e.g. GAmFELDT et al., 2013; LIANG et al., 2016; ZHANG et al., 2012, etc) on ecosystem functions and few on other indices of stand structure (LEI et al., 2009; LEXERøD et al., 2006; LONG et al., 2010). In the case of temperate forests, where limited numbers of tree species grow (SCHULzE et al., 2016), understanding the effect of structural indices like age distribution, size distribution or canopy complexity may be key to understand the variability in stress response. The effect of structural diversity on ecosystem functions and its resistance or resilience to droughts have been less studied. But there are indications that increasing stand canopy complexity through a diverse age distribution improves the productivity of forest ecosystem (HARDiman et al., 2013). The forest structural indices based on diameter and height distribution had stronger positive effect on productivity than indices based on species diversity (DĂNESCU et al., 2016). LEI et al. (2009) have argued that structurally diverse could enhance resource use through niche complementaries, given the presence of different horizontal and vertical layers, both at the canopy and soil.

The biotic and abiotic factors that drive inter-annual variability of terrestrial $\mathrm{CO}_{2}$ exchange (CHEN et al., 2015; CiAIs et al., 2005) is important for understanding how forests will respond to future climate and improve the predictability of global $\mathrm{CO}_{2}$ budgets (BALDOCCHI et al., 2001; LUO et al., 2015). Biotic factors - functional traits of ecosystems such as nutrient status, phenology, maximum photosynthetic capacity etc., that govern photosynthesis and respiration process (JENSEN et al., 2017) - have been shown to explain the inter-annual variability of $\mathrm{CO}_{2}$ fluxes (MA et al., 2011; RICHARDSON et al., 2007). Maximum annual photosynthetic capacity of an ecosystem $\left(\mathrm{GPP}_{1000 \mathrm{p}}\right)$ - a biotic factor reflecting maximum ecosystem-level photosynthesis, is defined as the value of gross primary productivity (GPP) at saturating light under non-stressed conditions (MUSAVI et al., 2017). $\mathrm{GPP}_{1000 \mathrm{p}}$, estimate of $90^{\text {th }}$ percentile of daily maximum photosynthetic capacity, is a key variable in understanding the inter-annual variation in $\mathrm{CO}_{2}$ (Musavi et al., 2015). GPP $_{1000 p}$ highly correlates not only with annual GPP (XIA et al., 2015) but also with net $\mathrm{CO}_{2}$ flux of ecosystems (REICHSTEIN et al., 2014). The magnitude of inter-annual variability in $\mathrm{GPP}_{1000 \mathrm{p}}$ considerably varies across ecosystem (MUSAVI et al., 2016). MUSAVI et al. (2017) showed that the magnitude of inter-annual variability in $\mathrm{GPP}_{1000 \mathrm{p}}$ is strongly influenced by the age of the forest ecosystem - age is defined as the average tree age of the stand or the age of the stand since the last major disturbance that caused stand replacement. They reported lower magnitude of inter-annual variability $\mathrm{GPP}_{1000 \mathrm{p}}$ - indicating ecosystem functioning was not very sensitive to climatic variability - in older and diverse forests compared to younger forests. However, they do not offer a mechanistic explanation of their finding. Niche complementarity is driven by the forest structure and not just by age or species number. For example, light use among individual trees in a forest depends on tree architecture (YACHI et al., 2007). The niche partition of the light resource and the space in the forests are reflected by the correlation of the position and size of the tree canopy with light capture (IsHII et al., 2013).

In recent years climate warming has increased the frequency and severity of drought and heat-wave events. For the decade of 2006 to 2015, the observed global mean surface temperature was $0.87{ }^{\circ} \mathrm{C}\left(0.75{ }^{\circ} \mathrm{C}\right.$ to $\left.0.99{ }^{\circ} \mathrm{C}\right)$ higher than the average over the period of 1850 to 1900 and it is expected to reach $1.5^{\circ} \mathrm{C}$ between 2030 to 2052 (IPCC, 2018). This 
increase in average surface temperature also means an increase in extreme events (IPCC, 2012). SChLEussner et al. (2017) showed an increase in the number of hot days and warm nights from the period of 1960 - 1979 to 1991 - 2010. Some of the heat extremes in the last years (Coumou et al., 2013; HANSEN et al., 2012) include the European heat-waves of 2003 (CIAIs et al., 2005), 2006 (REBETEZ et al., 2009), and 2018, and the Russian heat-wave in 2010 (BARRIOPEDRO et al., 2011). BARRIOPEDRO et al. (2011) predicted a likelihood of an increase of extreme heatwaves by five to tenfold in Europe by the mid-21st century. These heatwaves are also intrinsically linked with drought, for example in 2003, the annual precipitation was $50 \%$ below average. Model results predict an increase in dryness in temperate regions of the US and Europe in the future (GREVE et al., 2015).

Under the drought conditions, the photosynthetic capacity of forests decrease due to combined effects of stomatal, mesophyll and biochemical limitations (Limousin et al., 2010; StPAul et al., 2012; ZHOU et al., 2015; Zhou et al., 2014). However, the response varies with climate, species, forest types and structure (Grossiord et al., 2014c; JuCKER et al., 2016). In temperate regions, the mixing of different tree species has shown to increase resistance and resilience of ecosystem functions to drought due to differentiated functions or asynchrony of various species (FORRESTER et al., 2010; LEBOURGEOIS et al., 2013; Pretzsch et al., 2013; Río et al., 2017). AnderegG et al. (2018) showed that the presence of diverse hydraulic traits decreases the drought sensitivity of forest ecosystems. In a forest with a mixture of beech and oak trees, the shallower rooting beech was relieved from drought stress by the hydraulic lift of water caused by the deep rooting oak (PRETzSCH et al., 2013; ZAPATER et al., 2011). A meta-analysis by Griess et al. (2011) showed that the mixing tree species dampened the lagged effect of drought (like secondary damages from insects, fungi and wind-throw). This means that on top of any positive effects of mixing on stress release and growth of trees, the reported avoidance or mitigation of secondary stress effects by species mixing can further improve the performance of mixed compared with pure stands. However, in Mediterranean and mountain climates, the mixing of tree species did not improve the resistance of forest ecosystems to drought (GROssiorD et al., 2014a; Grossiord et al., 2014d) and was negative in the case of a Boreal ecosystem (Grossiord et al., 2014d). ForRESTER et al. (2016) also concluded that a reduction of drought stress in mixed-species forests is not a general pattern and might vary between sites even for a given species combination. Thus, we need to take into account environment differences while looking at the effect of forest structure or species mixing on forest ecosystem functions, like, $\mathrm{GPP}_{1000 \mathrm{p}}$ or its anomalies.

In this paper, we go further than MusAvi et al. (2017) and look at the effects of diameterbased indices of forest structure on the $\mathrm{GPP}_{1000 \mathrm{p}}$. We are also interested in the effect of water limitation on ecosystem, thus we also calculated annual photosynthetic capacity of an ecosystem with the effect of hydrometeorological anomalies, represented by $\mathrm{GPP}_{1000 \mathrm{~m}}$, calculated as mean of all daily maximum photosynthetic capacity within a year. The lower magnitude of inter-annual variability of $\mathrm{GPP}_{1000 \mathrm{~m}}$ for an ecosystem indicated a very stable ecosystem functioning even during water limitation. Furthermore, we also investigated how the anomalies of $\mathrm{GPP}_{1000 \mathrm{p}}$ and $\mathrm{GPP}_{1000 \mathrm{~m}}$ during the droughts differ among different forests with varying structure. We examined how diameter based indices, tree species diversity, stand age and management affect the temporal stability of an ecosystem function 
(maximum photosynthetic capacity) and its resistance during droughts. We have tested two hypotheses in this paper:

(a) temporal stability of $\mathrm{GPP}_{1000}$ is higher in structurally diverse forests.

(b) resistance of $\mathrm{GPP}_{1000}$ during droughts is higher in structurally diverse forests.

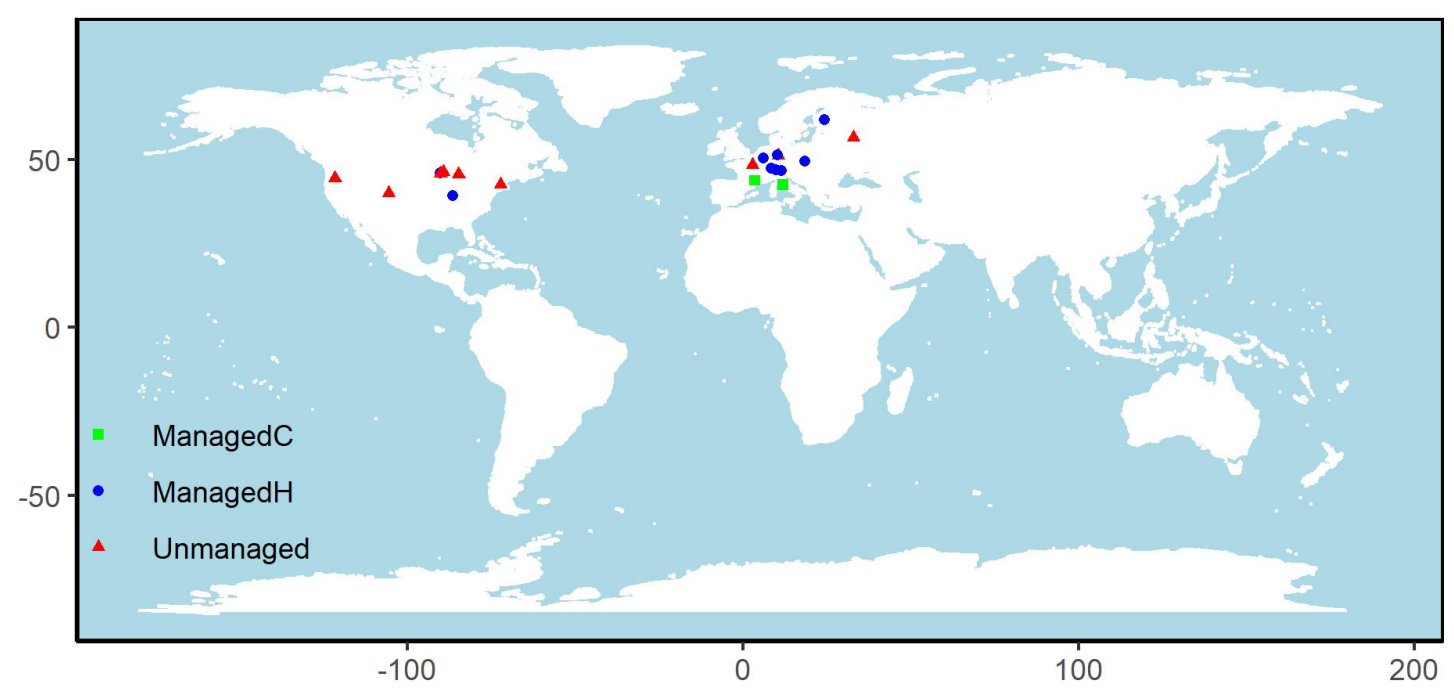

Figure 3.1: Map of the forest sites with flux tower used in this study. There were altogether 21 forest sites from temperate region. We included sites with inventory data and with at least 5 years of carbon dioxide flux data.

\subsection{Material and methods}

\subsubsection{Sites}

We requested inventory data from around 60 temperate eddy covariance flux sites. Finally, we had inventory data and carbon flux data from 21 temperate forest sites (Figure 3.1) with at least five years of flux data and that had forest inventory data. Details of the sites are given in Table 3.1. Flux data were retrieved from the ICOS 2019 (7 sites) and fluxnet 2015 database (14 sites) from https://fluxnet.fluxdata.org/data/fluxnet2015-dataset/. There were nine deciduous broad-leaved forests (DBF), six evergreen forests (ENF), five mixed forests $(\mathrm{MF})$, and one evergreen broad-leaved forest (EBF). Sites also represented a wide range of climatic zones. Sites were located between a latitude of 39.32 to 61.85 decimal degrees. IT-Ro1 had the shortest data on carbon flux from 2000 to 2008 and BE-Vie had the longest data from 1996 to 2018. Structure of a forest is usually the result of human intervention. We also collected data on history of management of each site (Table 3.8). Nine of the sites were unmanaged and twelve sites were managed. Out of 12 managed sites, three were managed as coppice forests (ManagedC) and nine as high forests (ManagedH).

\subsubsection{Forest structure indices}

We calculated nine stand structural indices from forest inventory data (Table 3.2). Age here refers to the age of forest stand since the last major disturbance that caused stand 
Table 3.1: List of sites. We included data from different forest types (FT), DBF - deciduous broad-leaved forests, ENF - evergreen needle-leaved forests, EBF - evergreen broad-leaved forests, and MF - mixed forests. Sites also represented wide climatic zones, Bor - Boreal, Tmp - temperate, TmpC - temperate-continental with hot or warm summers, Sba - sub-artic and STM - sub-tropical Mediterranean. Forests were also classified based on management regime, Unmanaged, ManagedH - managed as high forests, ManagedC - managed as coppice forests.

\begin{tabular}{|c|c|c|c|c|c|c|c|c|}
\hline Site & FT & Zone & Lat & Lon & Age & Years & Mgmt & References \\
\hline BE-Vie & $\mathrm{MF}$ & Tmp & 50.31 & 6.00 & 109 & 1996-2018 & ManagedH & HURDEBISE et al. (2017) \\
\hline CH-Dav & $\mathrm{MF}$ & Tmp & 46.82 & 9.86 & 244 & $1997-2018$ & ManagedH & ZWEIFEL et al. (2010) \\
\hline CH-Lae & MF & Tmp & 47.48 & 8.37 & 175 & 2004-2018 & ManagedH & ETzOLD et al. (2011) \\
\hline CZ-BK1 & ENF & TmpC & 49.50 & 18.54 & 34 & 2004-2018 & ManagedH & SEDLÁK et al. (2010) \\
\hline DE-Hai & $\mathrm{DBF}$ & $\mathrm{Tmp}$ & 51.08 & 10.45 & 260 & $2000-2018$ & Unmanaged & KNOHL et al. (2003) \\
\hline DE-Lnf & $\mathrm{DBF}$ & Tmp & 51.33 & 10.37 & 145 & 2002-2012 & ManagedH & HERBST et al. (2015) \\
\hline FI-Hyy & ENF & Bor & 61.85 & 24.29 & 53 & 1996-2018 & ManagedH & VESALA et al. (2005) \\
\hline FR-Fon & $\mathrm{DBF}$ & Tmp & 48.48 & 2.78 & 152 & 2005-2014 & Unmanaged & Отто et al. (2014) \\
\hline FR-Pue & $\mathrm{EBF}$ & STM & 43.74 & 3.60 & 74 & $2000-2014$ & ManagedC & AlLARD et al. (2008) \\
\hline IT-Ren & ENF & Tmp & 46.59 & 11.43 & 98 & $1998-2013$ & ManagedH & PAPALE et al. (2015) \\
\hline IT-Ro1 & $\mathrm{DBF}$ & STM & 42.41 & 11.93 & 16 & $2000-2008$ & ManagedC & PAPALE et al. (2015) \\
\hline IT-Ro2 & $\mathrm{DBF}$ & STM & 42.39 & 11.92 & 24 & 2002-2012 & ManagedC & HuRDEBISE et al. (2017) \\
\hline RU-Fyo & ENF & TmpC & 56.46 & 32.92 & 195 & $1998-2018$ & Unmanaged & MiLYUKOVA et al. (2002) \\
\hline US-Ha1 & $\mathrm{DBF}$ & TmpC & 42.54 & -72.17 & 92 & 1991-2012 & Unmanaged & URBANSKI et al. (2007) \\
\hline US-Me2 & ENF & STM & 44.45 & -121.56 & 100 & $2002-2014$ & Unmanaged & SchWARz et al. (2004) \\
\hline US-MMS & $\mathrm{DBF}$ & STM & 39.32 & -86.41 & 83 & 1999-2014 & ManagedH & EHMAN et al. (2002) \\
\hline US-NR1 & ENF & $\mathrm{SbA}$ & 40.03 & -105.55 & 103 & $1998-2014$ & Unmanaged & Monson et al. (2002) \\
\hline US-PFa & MF & TmpC & 45.95 & -90.27 & 47 & $1995-2014$ & ManagedH & DAVIS et al. (2003) \\
\hline US-Syv & MF & TmpC & 46.24 & -89.35 & 175 & 2001-2014 & Unmanaged & DEsAi et al. (2005) \\
\hline US-UMB & $\mathrm{DBF}$ & TmpC & 45.56 & -84.71 & 89 & $2000-2014$ & Unmanaged & Gough et al. (2007) \\
\hline US-WCr & $\mathrm{DBF}$ & TmpC & 45.81 & -90.08 & 75 & 1999-2014 & Unmanaged & DEsAi et al. (2005) \\
\hline
\end{tabular}

replacement normalized at the year 2015 - the year of release of fluxnet data. Further, we calculated the log of age. $\mathrm{DBH}$ is the mean tree diameter at breast height, but only counting those above $10 \mathrm{~cm}$. BA is the average basal area per unit hectare of all trees above $7 \mathrm{~cm} \mathrm{DBH}$. We collected data for the average height of the canopy trees from the literature.

The Shannon Size index (ShnSz), the Simpson size index (SimSz), and the shape parameter of the Weibull function (ShWb) were calculated from the diameter distribution (e.g. 3.2). The Shannon size (ShnSz) and the Simpson size (SimSz) diversity indices were calculated using eq. 3.1 and 3.2, respectively using Rpackage 'vegan' (OKSANEN et al., 2019).

$$
\begin{aligned}
\operatorname{Shn} S z & =-\sum_{i=1}^{R} p_{i} \ln p_{i} \\
\operatorname{Sim} S z & =\frac{1}{\sum_{i=1}^{R} p_{i}^{2}}
\end{aligned}
$$

$p_{i}$ in both equations is the proportion of trees in each diameter class, $\ln p_{i}$ is the natural 
$\log$ of $p_{i}$ and $\mathrm{R}$ is the number of diameter size classes. We used a diameter size class width of $5 \mathrm{~cm}$ for our analysis. Higher values of $\mathrm{ShnSz}$ and $\mathrm{SimSz}$ indicate trees distributed in many different size classes and lower values indicated the trees concentrated in few diameter size classes.

Table 3.2: List of structural variables used.

\begin{tabular}{lll}
\hline Structural parameters & Description & Units \\
\hline Age & Age of forest stand since the last major disturbance that & years \\
& caused stand replacement normalized at the year 2015 & \\
logAge & Log of age & - \\
BA & Total basal area & $\mathrm{m}^{2} \mathrm{ha}^{-1}$ \\
$\mathrm{DBH}$ & Diameter at breast height & $\mathrm{cm}$ \\
$\mathrm{Height}$ & The average height of canopy trees & $\mathrm{m}$ \\
ShnSz & Shannon size diversity index & - \\
SimSz & Simpson size diversity index & - \\
ShpWb & Shape Weibull parameter of the diameter distribution & - \\
SpNo & Number of species that makes up to $95 \%$ of basal area & - \\
\hline
\end{tabular}
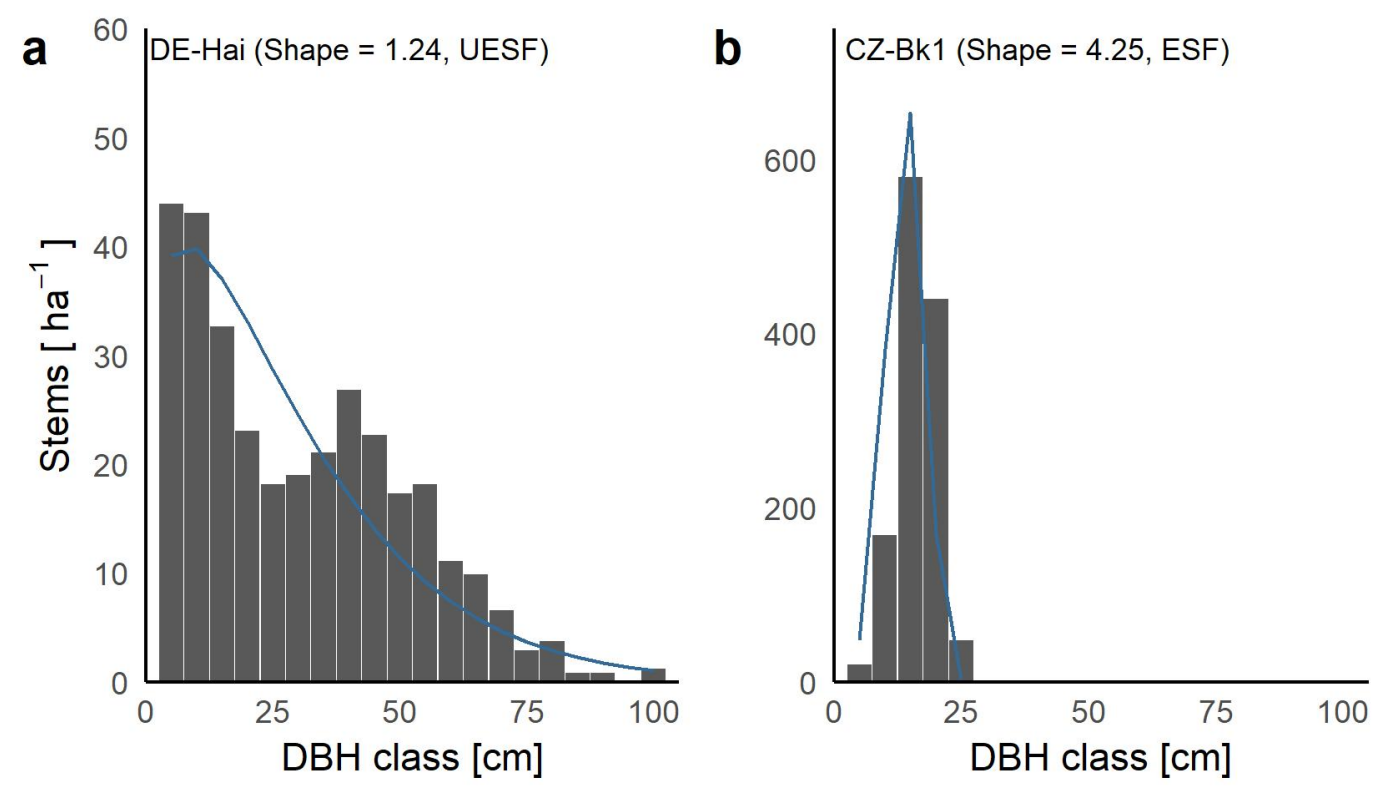

Figure 3.2: An example diameter distribution shown for (a) DE-Hai, an unevenly structured forest (ESF) and (b) CZ-Bk1, an evenly structured forest (ESF). The blue line represents the fitted Weibull function. 'Shape' is the shape parameter of the fitted Weibull function.

We calculated the shape parameter (k) of the Weibull function (eq. 3.3) fitted to the diameter distribution (the blue line in Figure 3.2). $\lambda$ is the scale parameter of the Weibull function.

$$
y=\frac{k}{\lambda}\left(\frac{x}{\lambda}\right)^{k-1} \exp ^{\left(-\frac{x}{\lambda}\right)^{k}}
$$


The sites were categorized as (a) unevenly structured forests (UESF) if the values of $\mathrm{k}$ were around one indicating a higher frequency of trees in smaller diameter size classes and a decreasing frequency of trees with increasing diameter size class (DE-Hai in Figure 3.2a), and (b) evenly structured forests (ESF) if the values were greater than one indicating uniform forests with trees concentrated in few diameter classes (CZ-Bk1 in Figure 3.2b).

Finally, species number (SpNo) is the number of tree species which add up to $95 \%$ of basal area.

\subsubsection{Environmental data}

We used average annual and growing season (May - September) values of five environmental variables, namely air temperature $(\mathrm{TA})$, global radiation $\left(\mathrm{R}_{\mathrm{g}}\right)$, vapour pressure deficit (VPD), precipitation $(\mathrm{P})$, and standardized precipitation and evapotranspiration index (SPEI). We obtained the data for the first four environmental variables from the fluxnet 2015 and ICOS 2019 databases. We downloaded the SPEI data for each site from SPEIbase, a new global database that covers the period 1901-2015 at a 0.5-degree resolution (BEGUERÍA et al., 2017). SPEI is the climatic water balance (precipitation minus potential evapotranspiration) over different timescales (from monthly to 24 monthly) expressed as a standardized Gaussian variate with a mean of zero and a standard deviation of one (BEGUERía et al., 2010) at a location. We used the R-codes provided by BEgueRía (2017) to extract the SPEI values for each site.

To present the environmental condition of the sites we estimated the mean and standard deviation of annual and growing season values across years for all environmental variables. The mean and standard deviation of annual values across years for each environmental variable is indicated by subscript mean and sd (for e.g. $\mathrm{TA}_{\text {mean }}$ and $\mathrm{TA}_{\mathrm{sd}}$ ), respectively. Similarly, the mean and values of growing season across years is indicated by $\mathrm{GS}_{\text {mean }}$ and $\mathrm{GS}_{\mathrm{sd}}$ (for e.g. $\mathrm{TA}_{\mathrm{GSmean}}$ and $\mathrm{TA}_{\mathrm{GSsd}}$ ), respectively. We included growing season values because photosynthesis mostly occur during this period of the year. Therefore, there were altogether 20 different environmental indicators for each site.

\subsubsection{Annual light-saturated gross primary productivity $\left(\mathrm{GPP}_{1000}\right)$}

First we investigated daily values of net ecosystem exchange (NEE) for all sites and removed all the periods when the data had problems.

Second, we quantified daily $\mathrm{GPP}_{1000}$ by fitting rectangular hyperbolic light-response curve (LRC) including the effect of vapour pressure deficit as suggested by LASSLOP et al. (2010) (eq. 3.4 and eq. 3.5).

$$
\begin{aligned}
& N E E=\frac{\alpha \beta R_{g}}{\alpha+\beta}+\gamma \\
& \beta= \begin{cases}\beta_{0} \exp \left(-k\left(V P D-V P D_{0}\right)\right) & \text { if } \mathrm{VPD}>V P D_{0} \\
\beta_{0} & \text { if } \mathrm{VPD}<V P D_{0}\end{cases}
\end{aligned}
$$

where NEE is net ecosystem exchange $\left(\mu \mathrm{mol} \mathrm{m}^{-2} \mathrm{yr}^{-1}\right), \alpha$ is the canopy light utilization 
efficiency and represents the initial slope of the light-response curve, $\beta\left(\mu \mathrm{mol} \mathrm{m}^{-2} \mathrm{yr}^{-1}\right)$ is the maximum $\mathrm{CO}_{2}$ uptake rate of the canopy at light saturation, $\gamma\left(\mu \mathrm{mol} \mathrm{m}^{-2} \mathrm{yr}^{-1}\right)$ is the ecosystem respiration and $\mathrm{R}_{\mathrm{g}}$ is the downward shortwave radiation $\left(\mathrm{W} \mathrm{m}^{-2}\right)$. The effect of high VPD on the LRC was included by replacing $\beta$ by an exponentially decreasing function as shown in eq. 3.4. We fixed the value of $V P D_{0}$ to $10 \mathrm{hPa}$ as in (LASSLOP et al., 2010).

We estimated $\alpha, \beta_{0}, k$ and $\gamma$ using 5 days of not gap-filled daytime $\left(\mathrm{R}_{\mathrm{g}}>4 \mathrm{~W} \mathrm{~m}^{2}\right)$ half-hourly data selected with a moving window approach. We used the R package 'FME' for fitting the LRC (SOETAERT et al., 2016). We then computed the GPP (the first part of eq. 3.4) at $1,000 \mathrm{~W} \mathrm{~m}^{2}$ of $\mathrm{R}_{\mathrm{g}}$ (corresponding to PAR of $2,110 \mu \mathrm{mol} \mathrm{m}^{-2} \mathrm{yr}^{-1}$ ) and 10 $\mathrm{hPa}$ of VPD, which is daily GPP 1000 . This $\mathrm{GPP}_{1000}$ was assigned to the day in the middle of the 5-day window. We did not use parameters of model fits with $\mathrm{R}^{2}$ lower than 0.6. We calculated GPP 1000 from May to September to include the most photosynthetically active period for all forest types. We calculated two types of annual $\mathrm{GPP}_{1000}, \mathrm{GPP}_{1000 \mathrm{p}}$ and $\mathrm{GPP}_{1000 \mathrm{~m}} \cdot \mathrm{GPP}_{1000 \mathrm{~m}}$ is the mean of all daily values of $\mathrm{GPP}_{1000}$ which includes effect of drought events if any occurred (see Figure 3.3). Similarly, GPP $1000 \mathrm{~m}$ is $90^{\text {th }}$ percentile of all daily values of $\mathrm{GPP}_{1000}$ which excludes any hydrometeorological anomalies, thus is the maximum photosynthetic capacity of the forests.

\subsubsection{Drought estimation}

We used the standardized precipitation-evapotranspiration index (SPEI) to identify and quantify drought events across flux tower sites at the annual scale. SPEI values are available for monthly to 24 monthly timescales, represented by a number after SPEI. For e.g. SPEI12

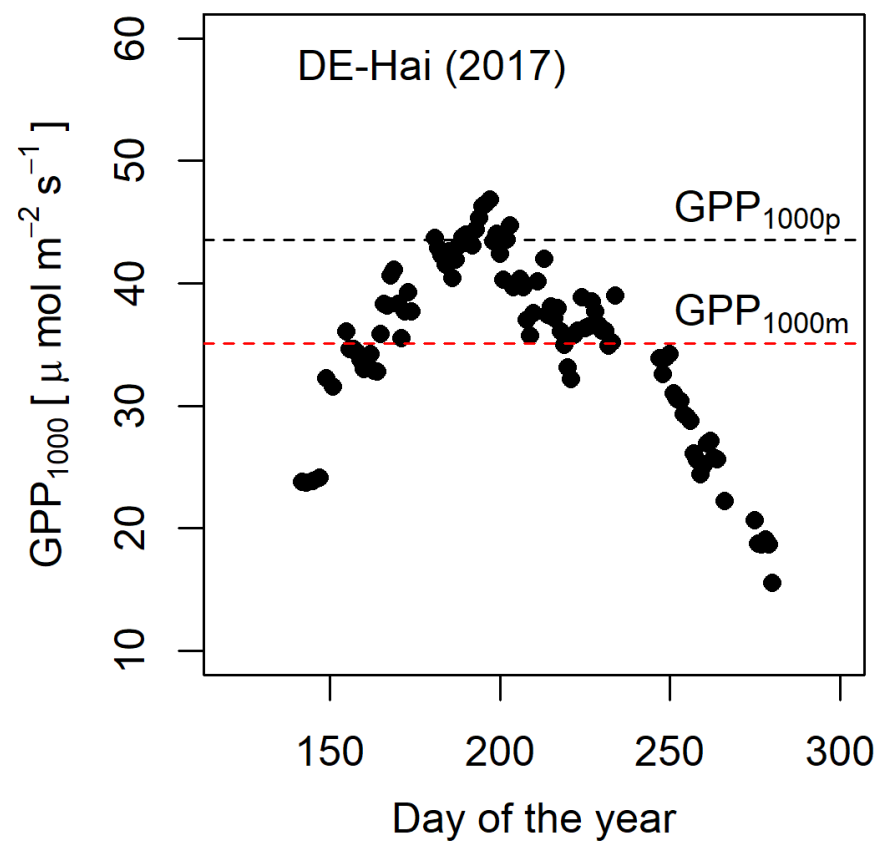

Figure 3.3: An example of timeseries for light-saturated GPP $\left(\mathrm{GPP}_{1000}\right)$ in DE-Hai for 2017. The black dashed line represents the annual $\mathrm{GPP}_{1000 \mathrm{p}}, 90^{\mathrm{th}}$ percentile , and the red dashed line $\mathrm{GPP}_{1000 \mathrm{~m}}$, the mean of all values. 
values represent SPEI value for a period accumulated over 12 months. In our case, we required annual SPEI spanning from January to December which is SPEI12 for December (hereafter, SPEI12).

Negative values of SPEI indicate drier conditions. For our study, we defined drought years as those when SPEI12 values lie below the lower 10 percentile of 115 years long SPEI data i.e. value less than or equal to -1.28. We present an example of DE-Hai in Figure 3.4. Here, SPEI12 in 2003 is -1.28 which means an annual drought (shown by the value of 12 and the water balance is accumulated from January 2003 to December 2003) with the probability of occurring once a decade has occurred. Altogether there were 24 events of droughts identified in 21 sites ( $2^{\text {nd }}$ row in Table 3.9).

\subsubsection{Statistical analysis}

We used software R-3.5.1 (R Development Core Team, 2018) for the analysis. The R codes and data for this chapter are available in https://doi.org/10.25625/KO7YTE.

\section{Coefficient of variation of $\mathrm{GPP}_{1000}$}

In order to better compare the temporal variability of forest ecosystem function, we calculated the coefficient of variation $(\mathrm{CV})$ of $\mathrm{GPP}_{1000 \mathrm{p}}\left(\mathrm{CV}_{\mathrm{GPP} 1000 \mathrm{p}}\right)$ and $\mathrm{GPP}_{1000 \mathrm{~m}}$ $\left(\mathrm{CV}_{\mathrm{GPP} 1000 \mathrm{~m}}\right)$ for each site, i.e. the standard deviation divided by the mean across years (eq. 3.6), thus obtaining a normalized measure for all sites. Additionally, we conducted an analysis using the standard deviation of $\mathrm{GPP}_{1000}$ across all years. Table 3.9 gives mean and standard deviation of different carbon dioxide fluxes across different years.

Ten of the sites showed temporal trends in $\mathrm{GPP}_{1000 \mathrm{p}}$ or $\mathrm{GPP}_{1000 \mathrm{~m}}$ (for e.g. see Figure 3.5 and last column in Table 3.9), likely due to tree growth or increasing atmospheric carbon dioxide concentrations (FERNÁNDEZ-MARTínez et al., 2017). Thus, we also the calculated

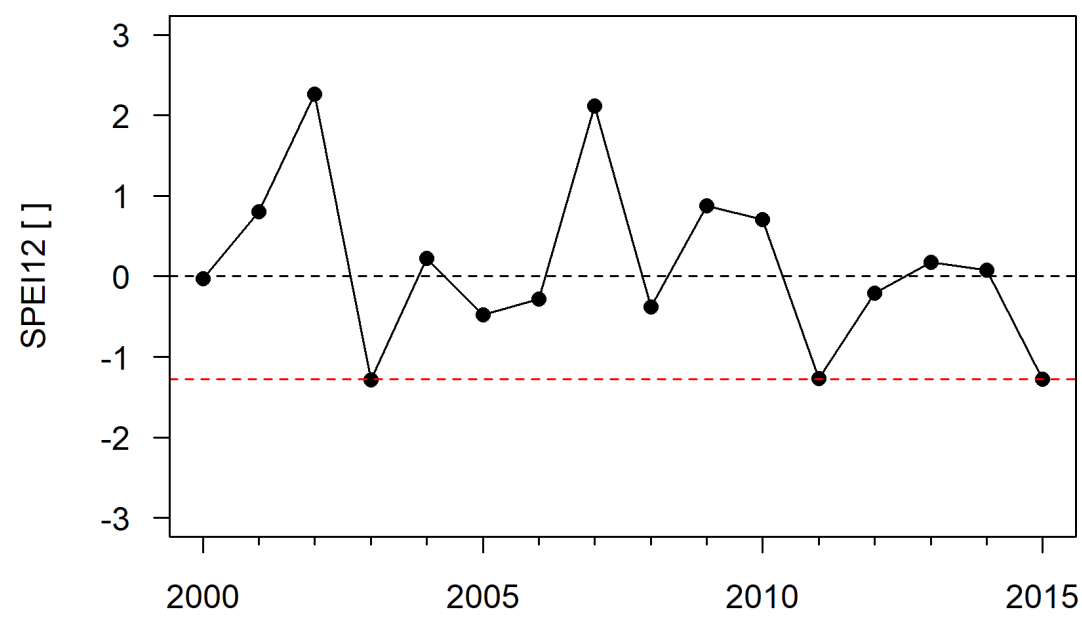

Figure 3.4: Annual standardized precipitation and evapotranspiration index (SPEI12) values for DE-Hai from 2000 to 2015. The positive values indicate wetter years and negative drier years. SPEI12 values at or below -1.28 , the red dashed line, indicate drought events as defined for this study and have a return period of ten years on average. 
coefficient of variation after removing any significant trends $(\mathrm{p}<0.05)$. As an example for sites with and without annual trend, we have plotted annual values of $\mathrm{GPP}_{1000 \mathrm{~m}}$ for US-MMS (without trend) and US-UMB (with trend) in Figure 3.5. We observed significant temporal trend in $\mathrm{GPP}_{1000 \mathrm{~m}}$ of $0.35 \mu \mathrm{mol} \mathrm{m}^{-2} \mathrm{yr}^{-1}$ in US-UMB (dashed line in the Figure 3.5). In such case, we detrended the data represented by the dotted line in the same figure.

Thus, there were four variation of $\mathrm{CV}$ of $\mathrm{GPP}_{1000}$ :- $\mathrm{CV}_{\mathrm{GPP} 1000 \mathrm{mWT}}$ - from mean with trend; $\mathrm{CV}_{\mathrm{GPP} 1000 \mathrm{mWoT}}$ - mean without trend; $\mathrm{CV}_{\mathrm{GPP} 1000 \mathrm{pWT}}$ - percentile with trend; $\mathrm{CV}_{\mathrm{GPP} 1000 \mathrm{pWoT}}$ - percentile without trend. We also calculated the coefficient of variation of growing season gross primary productivity (GPP) and ecosystem respiration (Reco).

$$
C V_{G P P 1000}=\frac{s d_{G P P 1000}}{m^{2} a n_{G P P 1000}}
$$

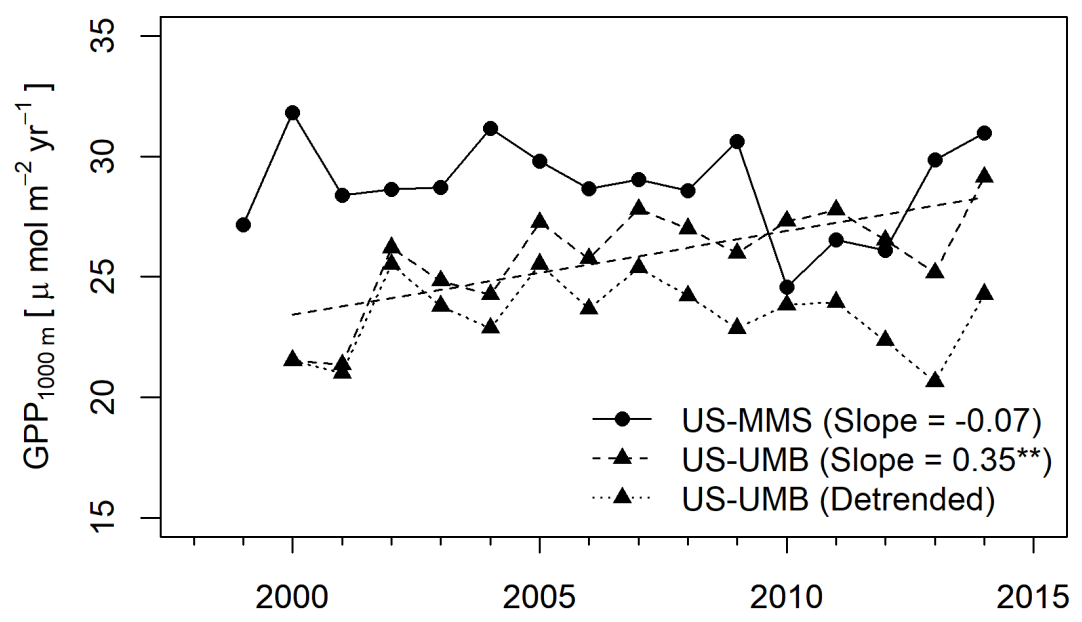

Figure 3.5: Example of annual GPP $1000 \mathrm{~m}$ for US-MMS and US-UMB. The straight lines represent annual trend for US-UMB for which the temporal trend is significant. Detrended $\mathrm{GPP}_{1000 \mathrm{~m}}$ is also shown for US-UMB. ${ }^{* *}$ is significant at $\mathrm{p}=0.01$.

\section{Anomalies of $\mathrm{GPP}_{1000}$}

For understanding the resistance of forest ecosystems to drought, we calculated the anomalies of $\mathrm{GPP}_{1000 \mathrm{p}}$ and $\mathrm{GPP}_{1000 \mathrm{~m}}$ for dry years as shown in eq. 3.7, where $\mathrm{GPP}_{1000 \mathrm{i}}$ is the $\mathrm{GPP}_{1000}$ for an $\mathrm{i}^{\text {th }}$ dry year of a site and mean ${ }_{\mathrm{GPP} 1000}$ is the mean across years for the same site. Like CV of $\mathrm{GPP}_{1000 \mathrm{p}}$, we also calculated anomalies after removing long term trends. Thus, there were also four variations of anomalies of $\mathrm{GPP}_{1000}$, Ano $\mathrm{GPP} 1000 \mathrm{mWT}$ - from mean with trend; Ano ${ }_{\mathrm{GPP} 1000 \mathrm{mWoT}}$ - from mean without trend; Ano GPP1000pWT from percentile with trend; and $\mathrm{Ano}_{\mathrm{GPP} 1000 \mathrm{pWoT}}$ - from percentile without trend.

$$
\text { Anomaly }_{G P P 1000}=\frac{G P P_{1000 i}-\text { mean }_{G P P 1000}}{\text { mean }_{G P P 1000}}
$$


Step-wise regression with meteorological and structural variables

We calculated the Pearson correlation of each $\mathrm{CV}_{\mathrm{GPP} 1000}$ and Anomaly $\mathrm{GPP} 1000$ with meteorological and structural variables. For each case, we then chose only the variables which were significant at the 0.05 level and management regime for including in a stepwise regression, which was performed without any interaction effect. All continuous predictors were standardized with mean and sd 1 before stepwise regression. Models were evaluated by sequential comparison (forward and backward selection) based on Akaike Information Criterion (AIC) and maximum likelihood likelihood (ML) estimation, using the stepAIC function in $\mathrm{R}$ ( $\mathrm{R}$ Development Core Team, 2018). We then calculated the variation inflation factor (VIF) for each explanatory variable selected by stepwise regression, using the vif function from car package (Fox et al., 2019). High values of VIF of an explanatory variable indicated a high correlation with other explanatory variables in the multiple linear regression. The final model was then established by discarding the variables with VIF values higher than 2 . The model result was also plotted with effect of single environmental variable and structure or management.

\subsection{Results}

\subsubsection{Structural characteristics of sites}

Table 3.3 shows the values of the structural parameters for all forest sites. The youngest forest was IT-Ro1, forest regenerating after clear cut via coppicing in December 1999. The site with oldest trees was DE-Hai, an unmanaged deciduous forest. BA was smallest in IT-Ro2 (a young forest managed as coppice-with-standards) and largest in US-NR1 (an unmanaged forest). FR-Pue, an evergreen broad-leaved coppice forest, and BE-Vie, a managed mixed forest, had the smallest and largest DBH, respectively. Tree height was lowest in FR-Pue and highest in DE-Hai and DE-Lnf. The coppice forests (FR-Pue, IT-Ro1 and IT-Ro2) had the lowest values ShnSz and SimSz, whereas BE-Vie had the highest. US-MMS and US-PFa have the highest species diversity, and seven sites have only one species. Based on ShWb values, ten forests were categorised as unevenly structured forests (UESF) and remaining as evenly structured forests (ESF). 
Table 3.3: Values of nine structural parameters for all sites. Mean and sd are the mean and standard deviation across sites, respectively. Based on the Shape of Weibull function (ShWb) forests are categorised as unevenly structured forests (UESF) or evenly structured forests (ESF) forests.

\begin{tabular}{|c|c|c|c|c|c|c|c|c|c|}
\hline Site & $\begin{array}{c}\text { Age } \\
\text { (Years) }\end{array}$ & $\begin{array}{c}\text { logAge } \\
-\end{array}$ & $\begin{array}{c}\text { BA } \\
\left(\mathrm{m}^{2} \mathrm{ha}^{-1}\right)\end{array}$ & $\begin{array}{l}\mathrm{DBH} \\
(\mathrm{cm})\end{array}$ & $\begin{array}{l}\text { Height } \\
\text { (m) }\end{array}$ & $\begin{array}{c}\mathrm{ShnSz} \\
-\end{array}$ & $\mathrm{SimSz}_{-}$ & $\begin{array}{c}\mathrm{SpNo} \\
-\end{array}$ & ShWb \\
\hline BE-Vie & 109 & 4.69 & 37.3 & 44.15 & 33 & 2.72 & 0.93 & 5 & UESF \\
\hline CH-Dav & 244 & 5.5 & 49.31 & 25.4 & 25 & 2.1 & 0.86 & 1 & $\mathrm{ESF}$ \\
\hline CH-Lae & 175 & 5.16 & 37.5 & 28.7 & 31 & 2.46 & 0.9 & 8 & UESF \\
\hline CZ-BK1 & 34 & 3.53 & 26.4 & 14.54 & 14 & 0.96 & 0.56 & 1 & $\mathrm{ESF}$ \\
\hline DE-Hai & 260 & 5.56 & 37.84 & 33.45 & 35 & 2.62 & 0.92 & 3 & UESF \\
\hline DE-Lnf & 145 & 4.98 & 36.03 & 44.06 & 35 & 1.77 & 0.79 & 1 & $\mathrm{ESF}$ \\
\hline FI-Hyy & 53 & 3.97 & 25.73 & 17.33 & 14 & 1.55 & 0.77 & 3 & $\mathrm{ESF}$ \\
\hline FR-Fon & 152 & 5.02 & 49.5 & 33.2 & 30 & 2.61 & 0.88 & 2 & UESF \\
\hline FR-Pue & 74 & 4.3 & 27.16 & 10.24 & 6 & 0.86 & 0.54 & 1 & $\mathrm{ESF}$ \\
\hline IT-Ren & 98 & 4.58 & 32 & 20.56 & 29 & 2.1 & 0.83 & 3 & UESF \\
\hline IT-Ro1 & 16 & 2.77 & 23.69 & 11.81 & 18 & 1.18 & 0.63 & 1 & $\mathrm{ESF}$ \\
\hline IT-Ro2 & 24 & 3.18 & 11.73 & 11.97 & 16 & 1.33 & 0.66 & 1 & UESF \\
\hline RU-Fyo & 195 & 5.27 & 30.5 & 24.29 & 28 & 1.95 & 0.84 & 2 & $\mathrm{ESF}$ \\
\hline US-Ha1 & 92 & 4.52 & 37.31 & 25.61 & 23 & 2.06 & 0.85 & 9 & UESF \\
\hline US-Me2 & 100 & 4.61 & 41.27 & 31.82 & 18 & 1.7 & 0.76 & 1 & $\mathrm{ESF}$ \\
\hline US-MMS & 83 & 4.42 & 41.23 & 33.1 & 31 & 2.46 & 0.9 & 14 & $\mathrm{ESF}$ \\
\hline US-NR1 & 103 & 4.63 & 54.77 & 14.76 & 12 & 1.56 & 0.75 & 3 & UESF \\
\hline US-PFa & 47 & 3.85 & 22.02 & 19.87 & 20 & 1.68 & 0.76 & 14 & UESF \\
\hline US-Syv & 175 & 5.16 & 23.29 & 25.6 & 27 & 2.31 & 0.88 & 4 & UESF \\
\hline US-UMB & 89 & 4.49 & 24.87 & 19.24 & 26 & 1.95 & 0.83 & 7 & UESF \\
\hline US-WCr & 75 & 4.32 & 31.82 & 19.84 & 24 & 1.86 & 0.83 & 4 & $\mathrm{ESF}$ \\
\hline Mean & 111.57 & 4.5 & 33.39 & 24.26 & 23.57 & 1.89 & 0.79 & 4.19 & - \\
\hline $\mathrm{Sd}$ & 68.05 & 0.73 & 10.47 & 9.81 & 8.15 & 0.54 & 0.11 & 4.03 & - \\
\hline
\end{tabular}

Figure 3.6 shows the histogram (diagonal plots) of six selected structural parameters and correlation between them except for ShWb. We plotted boxplots for ShWb against other variables (the last row of Figure 3.6). Distributions of most of the structural parameters were non-uniform and skewed (diagonal plots in Figure 3.6). Study sites belonged to a wide range of ages (16-260) with $90 \%$ sites below 200 years. In the case of BA, the sites were mostly between 20 to $40 \mathrm{~m}^{2} \mathrm{ha}^{-1}$. The DBH of sites were uniformly distributed between 10 to $35 \mathrm{~cm}$ and two sites with DBH higher than $40 \mathrm{~cm}$. The SimSz values of sites were mostly between 0.7 and 0.9 . Ten sites i.e. about $47 \%$ of total sites had a maximum of 2 species.

Age, BA, DBH and SimSz are significantly correlated with each other (figures on the left side of diagonal plots of Figure 3.6 and corresponding correlation values on the right side of the diagonal plots). For example, the correlation between SimSz and DBH is 0.71 $(\mathrm{p}<0.001)$ meaning that the forests with thicker stems also have trees distributed in more size classes. SpNo did not correlate with any other structural parameter. The boxplots of $\mathrm{ShWb}$ with other structural parameter showed that unevenly structured and evenly forests did not differ (last column of Figure 3.6) in age, BA, DBH, SimSz or SpNo, though the median values were always slightly higher for unevenly structured forests. 


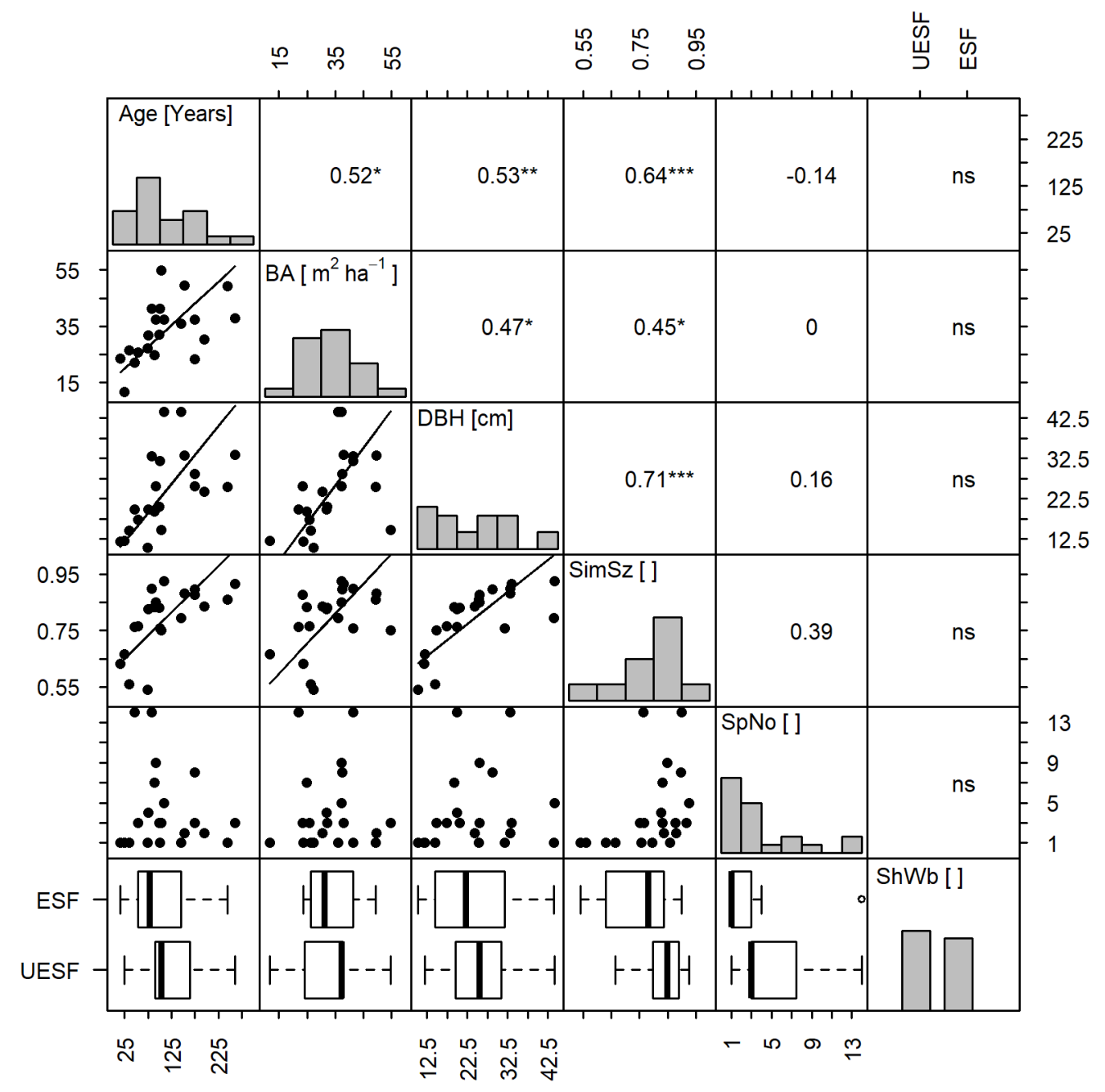

Figure 3.6: Chart showing histogram (barpot in the case of ShWb) and relationship between different structural parameters. Only six are included to increase the clarity of the figure. Histograms of each structural parameter are on the diagonal, with scatter plots between variables on one side and the respective correlation coefficients on the opposite side. The last row is presented as boxplot for categorical variable ShWb (UESF - unevenly structured forests, $\mathrm{ESF}$ - evenly structured forests). The stars represent the level of significance: $* * *$ for $\mathrm{p}=0.001$, $* *$ for $\mathrm{p}=0.01$, and $*$ for $\mathrm{p}=0.05$. The line in the scatter plots is the linear relationship of significant correlations. 

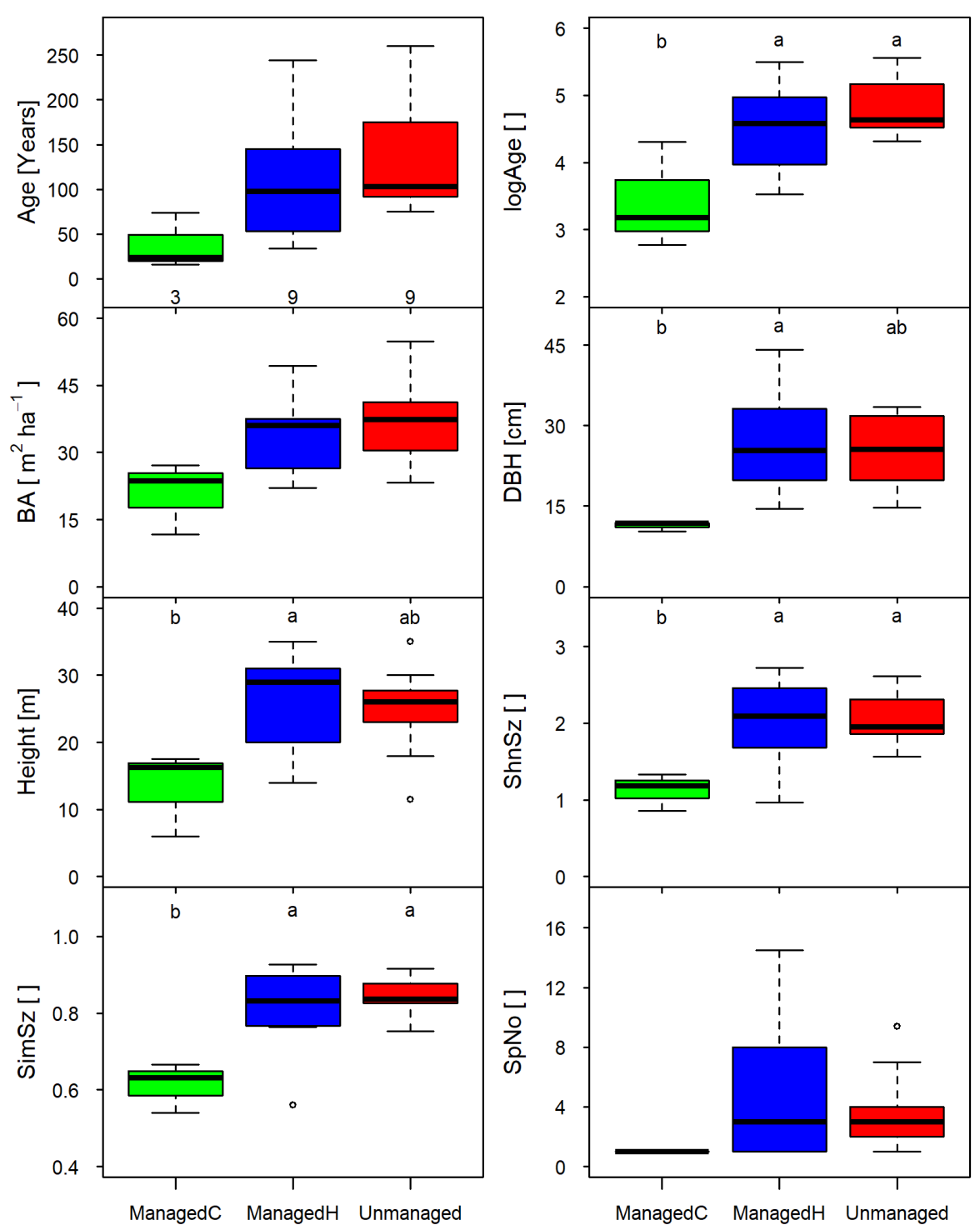

Figure 3.7: Effect of forest management on different structural parameters. The values on the bottom of first plot are the number of forests in each management regime. The different letters on top of each plot represent significant difference (at $\mathrm{p}<0.05$ ) between sites categorized by management regime.

The forest structure results from human intervention mostly via silvicultural operations. Figure 3.7 shows the effect of forest management on different structural parameters. Most of the structural parameters were lower for coppice forests (FR-Pue, IT-Ro1 and IT-Ro2) compared to forest managed as high forests and unmanaged forests. logAge, DBH, height, ShnSz and SimSz were significantly lower. The structural parameters for managed and unmanaged forests however did not differ. 


\subsubsection{Factors explaining inter-site variability in $\mathrm{CV}_{\mathrm{GPP} 1000}$}

Table 3.4: Zero-order correlation of environmental and structural variables with $\mathrm{CV}_{\mathrm{GPP} 1000}$ calculated from mean and percentile with (WT) and without trend (WoT). ${ }^{* * *}$ is significant at $\mathrm{p}<0.001,{ }^{* *} \mathrm{p}<0.01$, and $* \mathrm{p}<0.05$.

\begin{tabular}{|c|c|c|c|c|}
\hline \multirow{3}{*}{ Variables } & \multicolumn{3}{|c|}{ Correlation of } & \\
\hline & \multicolumn{2}{|c|}{$\mathrm{CV}_{\mathrm{GPP} 1000 \mathrm{~m}}$} & \multicolumn{2}{|c|}{$\mathrm{CV}_{\mathrm{GPP} 1000 \mathrm{p}}$} \\
\hline & WT & WoT & WT & WoT \\
\hline \multicolumn{5}{|l|}{ Environmental parameters } \\
\hline $\mathrm{TA}_{\text {mean }}$ & 0.41 & $0.51^{*}$ & 0.26 & 0.27 \\
\hline $\mathrm{R}_{\text {gmean }}$ & 0.37 & 0.34 & 0.41 & 0.4 \\
\hline $\mathrm{VPD}_{\text {mean }}$ & $0.46^{*}$ & $0.49 *$ & $0.45^{*}$ & 0.39 \\
\hline $\mathrm{P}_{\text {mean }}$ & 0.18 & 0.18 & 0.12 & 0.03 \\
\hline $\mathrm{SPEI}_{\text {mean }}$ & -0.41 & -0.39 & -0.39 & -0.36 \\
\hline $\mathrm{TA}_{\mathrm{GSmean}}$ & 0.38 & $0.46^{*}$ & 0.27 & 0.28 \\
\hline $\mathrm{R}_{\mathrm{gGSmean}}$ & 0.42 & 0.37 & $0.45^{*}$ & 0.41 \\
\hline VPDGSmean & $0.43^{*}$ & $0.44^{*}$ & 0.42 & 0.35 \\
\hline $\mathrm{P}_{\text {GSmean }}$ & -0.06 & -0.11 & -0.06 & -0.07 \\
\hline $\mathrm{SPEI}_{\mathrm{GSmean}}$ & -0.41 & -0.31 & $-0.45^{*}$ & -0.39 \\
\hline $\mathrm{TA}_{\mathrm{sd}}$ & 0.17 & 0.16 & 0.14 & 0.25 \\
\hline $\mathrm{R}_{\mathrm{gsd}}$ & $0.52^{*}$ & 0.33 & 0.39 & 0.34 \\
\hline $\mathrm{VPD}_{\mathrm{sd}}$ & 0.37 & 0.34 & 0.21 & 0.29 \\
\hline $\mathrm{P}_{\mathrm{sd}}$ & $0.52^{* * *}$ & $0.44^{*}$ & $0.46^{*}$ & 0.41 \\
\hline $\mathrm{SPEI}_{\mathrm{sd}}$ & 0.06 & -0.07 & 0.16 & 0 \\
\hline $\mathrm{TA}_{\mathrm{GSsd}}$ & -0.16 & -0.15 & -0.19 & -0.16 \\
\hline $\mathrm{R}_{\mathrm{gGSsd}}$ & 0.25 & 0.13 & 0.2 & 0.16 \\
\hline $\mathrm{VPD}_{\mathrm{GSsd}}$ & 0.22 & 0.25 & 0.08 & 0.14 \\
\hline$P_{\text {GSsd }}$ & $0.61^{* * *}$ & $0.61^{* * *}$ & $0.58^{* * *}$ & $0.61^{* * *}$ \\
\hline $\mathrm{SPEI}_{\mathrm{GSsd}}$ & 0.06 & 0 & 0.04 & -0.08 \\
\hline \multicolumn{5}{|l|}{ Structural parameters } \\
\hline Age & -0.26 & -0.23 & -0.29 & -0.27 \\
\hline logAge & -0.35 & -0.35 & -0.33 & -0.37 \\
\hline $\mathrm{BA}$ & $-0.57 * * *$ & $-0.48^{*}$ & $-0.5^{*}$ & $-0.47^{*}$ \\
\hline DBH & $-0.44^{*}$ & $-0.44^{*}$ & $-0.54^{* * *}$ & $-0.5^{*}$ \\
\hline $\mathrm{DBH}_{\mathrm{sd}}$ & -0.18 & -0.18 & -0.3 & -0.26 \\
\hline Height & -0.35 & -0.33 & $-0.52^{* * *}$ & -0.4 \\
\hline ShnSz & $-0.43^{*}$ & $-0.43^{*}$ & $-0.54^{* * *}$ & $-0.45^{*}$ \\
\hline $\mathrm{SimSz}$ & $-0.47^{*}$ & $-0.47^{*}$ & $-0.56^{* * *}$ & $-0.44^{*}$ \\
\hline SpNo & -0.15 & -0.1 & -0.16 & -0.07 \\
\hline
\end{tabular}

Table 3.4 lists the zero-order correlation of $\mathrm{CV}_{\mathrm{GPP} 1000 \mathrm{mWT}}, \mathrm{CV}_{\mathrm{GPP} 1000 \mathrm{mWoT}}, \mathrm{CV}_{\mathrm{GPP} 1000 \mathrm{pWT}}$ and $\mathrm{CV}_{\mathrm{GPP} 1000 \mathrm{pWoT}}$ with environmental and structural variables. Among environmental variables, the standard deviation of growing season rainfall sum $\left(\mathrm{P}_{\mathrm{GSsd}}\right)$ showed the strongest significant correlation and in the case of structural variables, BA, DBH, ShnSz and $\mathrm{SimSz}$ correlated in similar magnitude with all metrics of $\mathrm{CV}_{\mathrm{GPP} 1000}$. The positive correlation of $\mathrm{CV}_{\mathrm{GPP} 1000}$ with $\mathrm{P}_{\mathrm{GSsd}}$ means that sites with a higher inter-annual variation in their growing season rainfall have higher variability in $\mathrm{GPP}_{1000}$. On the other hand, the BA, DBH, ShnSz and SimSz were negatively correlated with $\mathrm{CV}_{\mathrm{GPP} 1000}$ meaning denser 
forests with thick stems and higher size diversity showed less variability in GPP ${ }_{1000}$.

We also looked at the correlation of standard deviation of annual $\operatorname{GPP}_{1000}\left(\operatorname{Sd}_{\mathrm{GPP} 1000}\right)$ with environmental and structural variables (Table 3.10). $\mathrm{Sd}_{\mathrm{GPP} 1000}$ correlated positively with the standard deviation of growing season rainfall $\left(\mathrm{P}_{\mathrm{GSsd}}\right)$ and negatively with basal area (BA) for $\mathrm{CV}_{\mathrm{GPP} 1000}$. Furthermore, we also looked at the correlation of coefficient of variation of GPP ( $\left.\mathrm{CV}_{\mathrm{GPP}}\right)$ and Reco $\left(\mathrm{CV}_{\text {Reco }}\right)$ with all structural and environmental parameters (Table 3.11). $\mathrm{CV}_{\mathrm{GPP}}$ correlated with $\mathrm{P}_{\mathrm{GSsd}}$, and Simpson size diversity index (SimSz).

Table 3.5: Stepwise regression coefficients for four metrics of $\mathrm{CV}_{\mathrm{GPP} 1000}$ with environmental and structural parameters. Predictor estimates were normalized with mean 0 and standard deviation 1 , hence their magnitude is proportional to the effect size. Note that the intercept (a) indicates the response of unmanaged forests, while managedH indicates forests managed as high forests and managedC as coppice. ${ }^{* * *}$ is significant at $\mathrm{p}<0.001,{ }^{* *} \mathrm{p}<0.01,{ }^{*} \mathrm{p}<0.05$ and $\left(^{*}\right) \mathrm{p}<0.1$.

\begin{tabular}{|c|c|c|c|c|}
\hline Model & Fixed effects & $\mathrm{R}^{2}$ & $\operatorname{adj}^{2}$ & Estimate \pm se \\
\hline 1. $\mathrm{CV}_{\mathrm{GPP} 1000 \mathrm{mWT}}=$ & $\begin{array}{l}\mathrm{a}+ \\
\mathrm{b} \text { ManagedH }+ \\
\mathrm{c} \text { ManagedC }+ \\
\mathrm{d} \mathrm{P}_{\text {GSsd }}+ \\
\mathrm{e} \mathrm{BA}+\end{array}$ & 0.66 & 0.58 & $\begin{array}{l}-0.25 \pm 0.23 \\
0.14 \pm 0.32 \\
1.32 \pm 0.54^{*} \\
0.33 \pm 0.17\left(^{*}\right) \\
-0.24 \pm 0.17\end{array}$ \\
\hline 2. $\mathrm{CV}_{\mathrm{GPP} 1000 \mathrm{mWoT}}=$ & $\begin{array}{l}\mathrm{a}+ \\
\mathrm{b} \text { ManagedH }+ \\
\mathrm{c} \text { ManagedC }+ \\
\mathrm{d} \mathrm{P}_{\text {GSsd }}+ \\
\mathrm{e} \mathrm{P}_{\text {sd }}+\end{array}$ & 0.71 & 0.64 & $\begin{array}{l}-0.4 \pm 0.21\left(^{*}\right) \\
0.26 \pm 0.3 \\
2.04 \pm 0.49^{* * *} \\
0.47 \pm 0.19^{*} \\
-0.25 \pm 0.2\end{array}$ \\
\hline 3. $\mathrm{CV}_{\mathrm{GPP} 1000 \mathrm{pWT}}=$ & $\begin{array}{l}\mathrm{a}+ \\
\mathrm{b} \text { ManagedH }+ \\
\mathrm{c} \text { ManagedC }+ \\
\mathrm{d} \text { PGSsd }_{\text {G }} \\
\text { e Height }+\end{array}$ & 0.61 & 0.51 & $\begin{array}{l}-0.29 \pm 0.25 \\
0.29 \pm 0.34 \\
1.13 \pm 0.59\left(^{*}\right) \\
0.35 \pm 0.18\left(^{*}\right) \\
-0.29 \pm 0.19\end{array}$ \\
\hline 4. $\mathrm{CV}_{\mathrm{GPP} 1000 \mathrm{pWoT}}=$ & $\begin{array}{l}\mathrm{a}+ \\
\mathrm{b} \text { ManagedH }+ \\
\mathrm{c} \text { ManagedC }+ \\
\mathrm{d} \mathrm{P}_{\mathrm{GSsd}}+\end{array}$ & 0.56 & 0.48 & $\begin{array}{l}-0.37 \pm 0.25 \\
0.36 \pm 0.35 \\
1.52 \pm 0.54^{*} \\
0.36 \pm 0.18\left(^{*}\right)\end{array}$ \\
\hline
\end{tabular}

Table 3.5 shows the result of stepwise regression of four metrics of $\mathrm{CV}_{\mathrm{GPP} 1000}$ with environmental and structural variables. Model 1 and 2 use $\mathrm{CV}_{\mathrm{GPP} 1000 \mathrm{~m}}$ with and without trend, respectively. Similarly, model 3 and 4 use $\mathrm{CV}_{\text {GPP1000p }}$ with and without trend, respectively. $\mathrm{P}_{\mathrm{GSsd}}$ and management regime were selected as predictors in all four models. The effect of unmanaged stand on $\mathrm{CV}_{\mathrm{GPP} 1000}$ (intercepts in Table 3.5) was negative indicating that inter-annual variation of $\mathrm{GPP}_{1000}$ was lowest in unmanaged stands (also see Figure 3.8). The higher $\mathrm{CV}_{1 \mathrm{GPP} 000}$ was observed in forests growing in climates with higher variation in growing season rainfall (Figure 3.8). The coppice forests (ManagedC) had significantly higher $\mathrm{CV}_{1 \mathrm{GPP} 000}$ compared to the forests managed as high forests and unmanaged forests in every case (Figure 3.8). The unmanaged forests had the lowest $\mathrm{CV}_{1 \mathrm{GPP} 000}$ but did not differ from forests managed as high forests. 


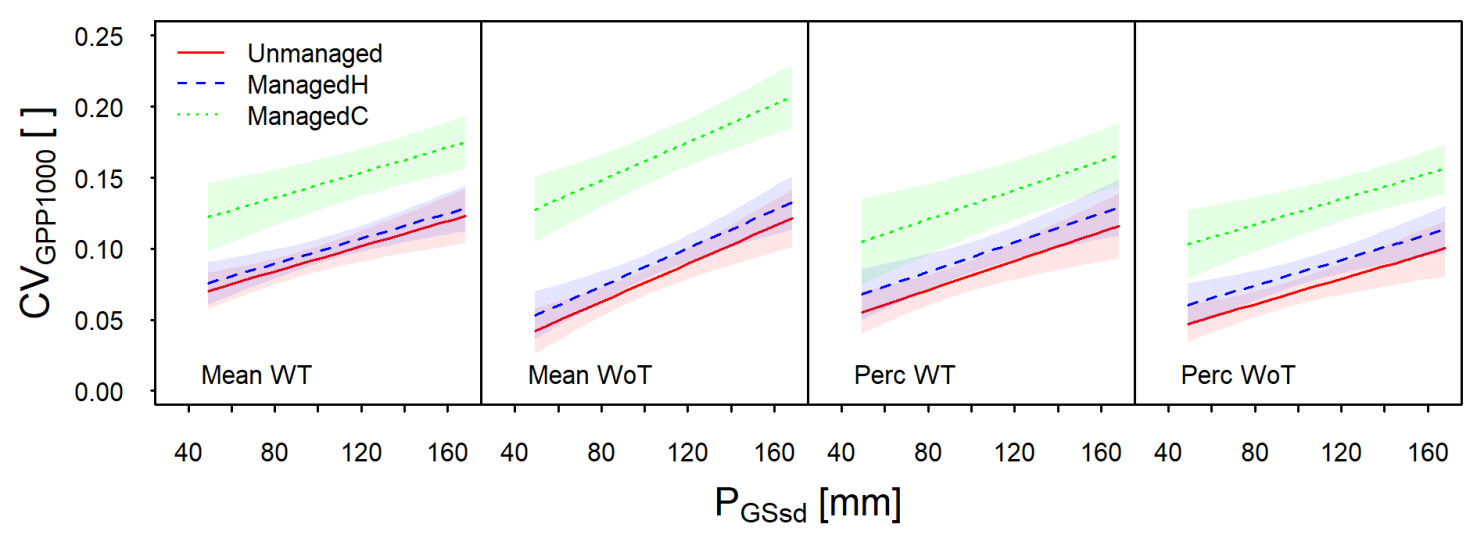

Figure 3.8: Effect of different forest management regimes on four metrics of $\mathrm{CV}_{\mathrm{GPP}} 1000 \mathrm{~m}$. Lines correspond to the predicted response based on mixed-effects models presented in Table 3.5) and shaded areas indicate the $95 \%$ confidence interval. The remaining predictors estimate were fixed at their mean values.

\subsubsection{Factors affecting $\mathrm{GPP}_{1000}$ anomalies during droughts}

Like in section 3.4.2, we looked at the zero-order correlation of environmental and structural variables with the four metrics of $\mathrm{GPP}_{1000}$ anomaly (Ano $\mathrm{GPP}_{1000}$, Table 3.6). The negative anomaly means large drought effect. The correlation was significant with two structural parameters (BA and logAge) and numerous environmental variables (also see Figure 3.10). We observed the highest correlation $(0.67$ - 0.74$)$ with mean growing season air temperature $\left(\mathrm{TA}_{\mathrm{GSmean}}\right)$ among environmental variables and with the basal area $(0.60-0.67)$ among structural variables. A positive correlation generally denotes a less negative AnoGPP1000 with an increase in the explanatory variable. For example, the positive relationship between basal area and Ano GPP1000 indicates that a higher basal area correlates with a less pronounced decrease in $\mathrm{GPP}_{1000}$. The positive significant relationship between logAge and Ano $_{\text {GPP1000 }}$ is driven by coppice forests (leftmost plot in Figure 3.10). The relationship is however opposite for unmanaged forests.

We also looked at the correlation of GPP and Reco anomalies with all independent variables. GPP anomalies strongly correlated with the basal area (0.52), the standard deviation of annual and the growing season radiation (-0.52 and -0.53), and mean growing season temperature (-0.46) as shown in Table 3.12.

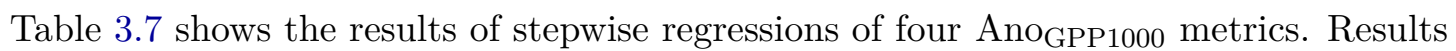
show that the mean growing season air temperature $\left(\mathrm{TA}_{\mathrm{GSmean}}\right)$ is the most important variable. Other explanatory variables differed from model to model. In the case of model 1 , management was selected as an explanatory variable. The intercept in model 1 indicates the effect of unmanaged forest. The effect is negative indicating that reduction in GPP $\mathrm{F}_{1000 \mathrm{mWT}}$ was more pronounced in unmanaged forests during droughts (Figure 3.9). However, when the effects of any other predictors is not considered, we observed more negative values of Ano $_{\mathrm{GPP} 1000}$ in coppice forests during drought events compared to unmanaged forests (the last plot in Figure 3.10). 
Table 3.6: Zero-order correlation of environmental and structural variables with AnoGPP1000 calculated from mean and percentile with (WT) and without trend (WoT). ${ }^{* * *}$ is significant at $\mathrm{p}<0.001,{ }^{* *} \mathrm{p}<0.01$, and ${ }^{*} \mathrm{p}<0.05$.

\begin{tabular}{|c|c|c|c|c|}
\hline \multirow{3}{*}{ Variables } & \multicolumn{4}{|c|}{ Correlation of } \\
\hline & \multicolumn{2}{|c|}{ AnOGPP1000m $_{\text {G }}$} & \multicolumn{2}{|c|}{ AnoGPP1000P } \\
\hline & WT & WoT & WT & WoT \\
\hline \multicolumn{5}{|l|}{ Environmental parameters } \\
\hline $\mathrm{TA}_{\text {mean }}$ & $-0.59 * * *$ & $-0.62^{* * *}$ & $-0.69 * * *$ & $-0.66^{* * *}$ \\
\hline $\mathrm{R}_{\text {gmean }}$ & -0.15 & -0.14 & -0.31 & -0.26 \\
\hline $\mathrm{VPD}_{\text {mean }}$ & $-0.49 *$ & $-0.51^{* * *}$ & $-0.55^{* * *}$ & $-0.5^{* * *}$ \\
\hline $\mathrm{P}_{\text {mean }}$ & 0.1 & 0.03 & -0.12 & -0.17 \\
\hline $\mathrm{SPEI}_{\text {mean }}$ & 0.15 & 0.23 & 0.13 & 0.17 \\
\hline $\mathrm{TA}_{\mathrm{GSmean}}$ & $-0.67^{* * *}$ & $-0.7^{* * *}$ & $-0.74^{* * *}$ & $-0.7^{* * *}$ \\
\hline $\mathrm{R}_{\mathrm{gGSmean}}$ & -0.35 & -0.34 & $-0.48^{*}$ & $-0.41^{*}$ \\
\hline $\mathrm{VPD}_{\mathrm{GSmean}}$ & $-0.51^{* * *}$ & $-0.54^{* * *}$ & $-0.54^{* * *}$ & $-0.5^{* * *}$ \\
\hline $\mathrm{P}_{\mathrm{GSmean}}$ & $0.46^{*}$ & $0.46^{*}$ & 0.32 & 0.27 \\
\hline $\mathrm{SPEI}_{\mathrm{GSmean}}$ & 0.38 & $0.48^{*}$ & 0.26 & 0.32 \\
\hline $\mathrm{TA}_{\mathrm{sd}}$ & -0.19 & -0.16 & -0.24 & -0.23 \\
\hline $\mathrm{R}_{\mathrm{gsd}}$ & $-0.66^{* * *}$ & $-0.64^{* * *}$ & $-0.66^{* * *}$ & $-0.61^{* * *}$ \\
\hline $\mathrm{VPD}_{\mathrm{sd}}$ & $-0.63^{* * *}$ & $-0.68^{* * *}$ & $-0.62^{* * *}$ & $-0.65^{* * *}$ \\
\hline $\mathrm{P}_{\mathrm{sd}}$ & -0.11 & -0.21 & -0.3 & -0.35 \\
\hline $\mathrm{SPEI}_{\mathrm{sd}}$ & 0.2 & 0.2 & 0.21 & 0.21 \\
\hline $\mathrm{TA}_{\mathrm{GSsd}}$ & -0.31 & -0.24 & -0.3 & -0.24 \\
\hline $\mathrm{R}_{\mathrm{gGSsd}}$ & $-0.63^{* * *}$ & $-0.62^{* * *}$ & $-0.64^{* * *}$ & $-0.61 * * *$ \\
\hline $\mathrm{VPD}_{\mathrm{GSsd}}$ & $-0.64^{* * *}$ & $-0.7 * * *$ & $-0.56^{* * *}$ & $-0.58 * * *$ \\
\hline$P_{\text {GSsd }}$ & 0.05 & -0.01 & -0.13 & -0.16 \\
\hline $\mathrm{SPEI}_{\mathrm{GSsd}}$ & -0.26 & -0.24 & -0.31 & -0.29 \\
\hline \multicolumn{5}{|l|}{ Structural parameters } \\
\hline Age & 0.36 & 0.37 & 0.38 & 0.37 \\
\hline logAge & $0.42^{*}$ & $0.47^{*}$ & $0.46^{*}$ & $0.49^{*}$ \\
\hline $\mathrm{BA}$ & $0.67^{* * *}$ & $0.66^{* * *}$ & $0.63^{* * *}$ & $0.6^{* * *}$ \\
\hline $\mathrm{DBH}$ & 0.19 & 0.23 & 0.28 & 0.28 \\
\hline $\mathrm{DBH}_{\mathrm{sd}}$ & -0.11 & -0.05 & -0.18 & -0.14 \\
\hline Height & 0.07 & 0.15 & 0.14 & 0.16 \\
\hline $\mathrm{ShnSz}$ & 0.11 & 0.19 & 0.13 & 0.16 \\
\hline $\mathrm{SimSz}$ & 0.17 & 0.26 & 0.2 & 0.24 \\
\hline ShWb & 0.32 & 0.24 & 0.4 & 0.31 \\
\hline
\end{tabular}

While structural parameters were not selected in stepwise regression, Table 3.4) shows positive correlations between $\mathrm{Ano}_{\mathrm{GPP} 1000}$ and age, logAge and BA, with BA being the strongest. However, the relationship between logAge and Ano GPP1000 is caused by a very young site and two old sites (on the leftmost plot of Figure 3.10), and most of the remaining points forms a cloud without any distinct pattern. The effect of basal area looks convincing (the middle plot of Figure 3.10) however, we see that BA and TA $\mathrm{GSmean}_{\text {have reciprocal }}$ effects (size of the dots in the figure). 
Table 3.7: Stepwise regression coefficients for four metrics of Ano GPP1000 with environmental and structural parameters. Predictor estimates were normalized with mean 0 and standard deviation 1 , hence their magnitude is proportional to the effect size. Note that the intercept a in model 1 indicates the response of unmanaged forests, while managedH indicates forests managed as high forests and managedC as coppice. $* * *$ is significant at $\mathrm{p}<0.001,{ }^{*} \mathrm{p}<$ $0.01,{ }^{*} \mathrm{p}<0.05$ and $(*) \mathrm{p}<0.1$.

\begin{tabular}{|c|c|c|c|c|}
\hline Model & & $\mathrm{R}^{2}$ & $\operatorname{adj}^{2}$ & Estimate \pm se \\
\hline 1.AnoGPP1000mWT $=$ & 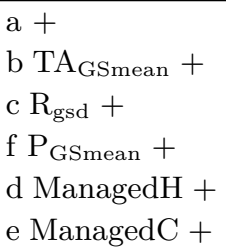 & 0.78 & 0.71 & $\begin{array}{l}-0.31 \pm 0.19 \\
-0.49 \pm 0.16^{* *} \\
-0.59 \pm 0.13^{* * *} \\
0.25 \pm 0.17 \\
0.41 \pm 0.32 \\
0.73 \pm 0.42\left(^{*}\right)\end{array}$ \\
\hline 2.Ano $\mathrm{GPP}_{1000 \mathrm{mWoT}}=$ & $\begin{array}{l}\mathrm{a}+ \\
\mathrm{b} \mathrm{TA}_{\mathrm{GSmean}}+ \\
\mathrm{c} \mathrm{R}_{\mathrm{gGSsd}}+ \\
\mathrm{d} \mathrm{P}_{\mathrm{GSmean}}+\end{array}$ & 0.73 & 0.69 & $\begin{array}{l}0 \pm 0.11 \\
-0.38 \pm 0.14^{*} \\
-0.49 \pm 0.13^{* * *} \\
0.33 \pm 0.13^{*}\end{array}$ \\
\hline 3.Ano ${ }_{\mathrm{GPP} 1000 \mathrm{pWT}}=$ & $\begin{array}{l}\mathrm{a}+ \\
\mathrm{b} \mathrm{TA}_{\mathrm{GSmean}}+ \\
\text { c R RGSmean }+ \\
\mathrm{d} \mathrm{R}_{\mathrm{gGSsd}}+\end{array}$ & 0.75 & 0.71 & $\begin{array}{l}0 \pm 0.11 \\
-0.47 \pm 0.13^{* *} \\
-0.25 \pm 0.12\left(^{*}\right) \\
-0.45 \pm 0.12^{* *}\end{array}$ \\
\hline 4. $\mathrm{Ano}_{\mathrm{GPP} 1000 \mathrm{pWoT}}=$ & $\begin{array}{l}\mathrm{a}+ \\
\mathrm{b} \mathrm{TA}_{\mathrm{GSmean}}+ \\
\mathrm{c} \mathrm{R}_{\mathrm{gGSsd}}+ \\
\mathrm{d} \mathrm{R}_{\mathrm{gGSmean}}+\end{array}$ & 0.66 & 0.61 & $\begin{array}{l}0 \pm 0.13 \\
-0.46 \pm 0.15^{* *} \\
-0.42 \pm 0.14^{* *} \\
-0.2 \pm 0.14\end{array}$ \\
\hline
\end{tabular}

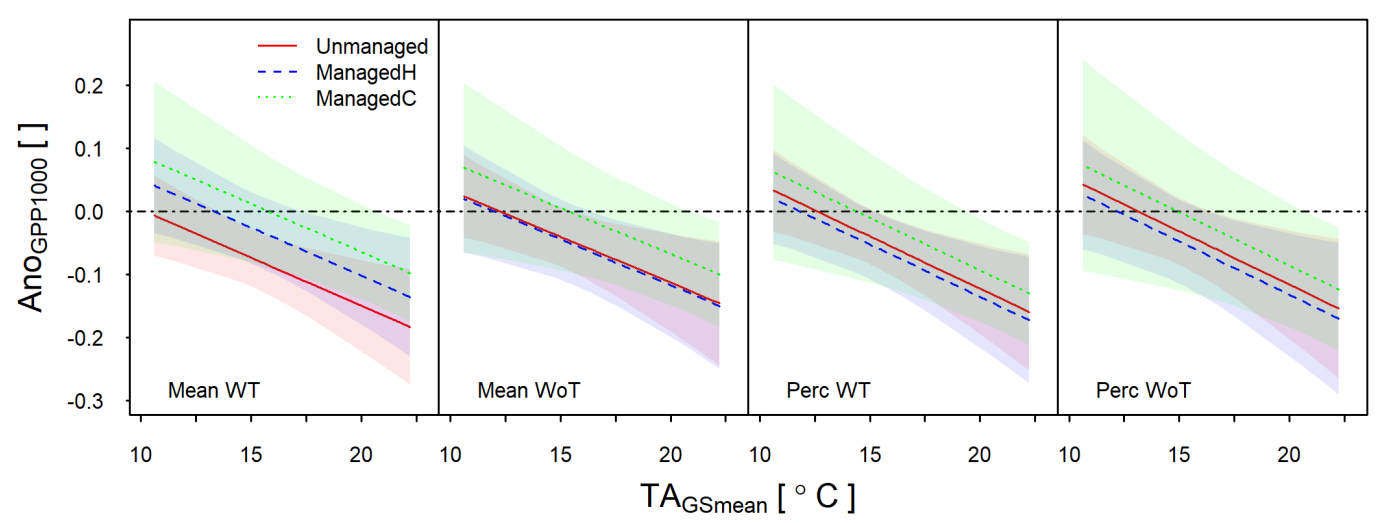

Figure 3.9: Effect of different forest management regimes on four metrics of Ano ${ }_{\mathrm{GPP} 1000 \mathrm{~m}}$. Lines correspond to the predicted response based on models presented in Table 3.7 (we added management as an additional predictor when it was not selected) and shaded areas indicate the $95 \%$ confidence interval. The remaining predictors estimate were fixed at their mean values. 


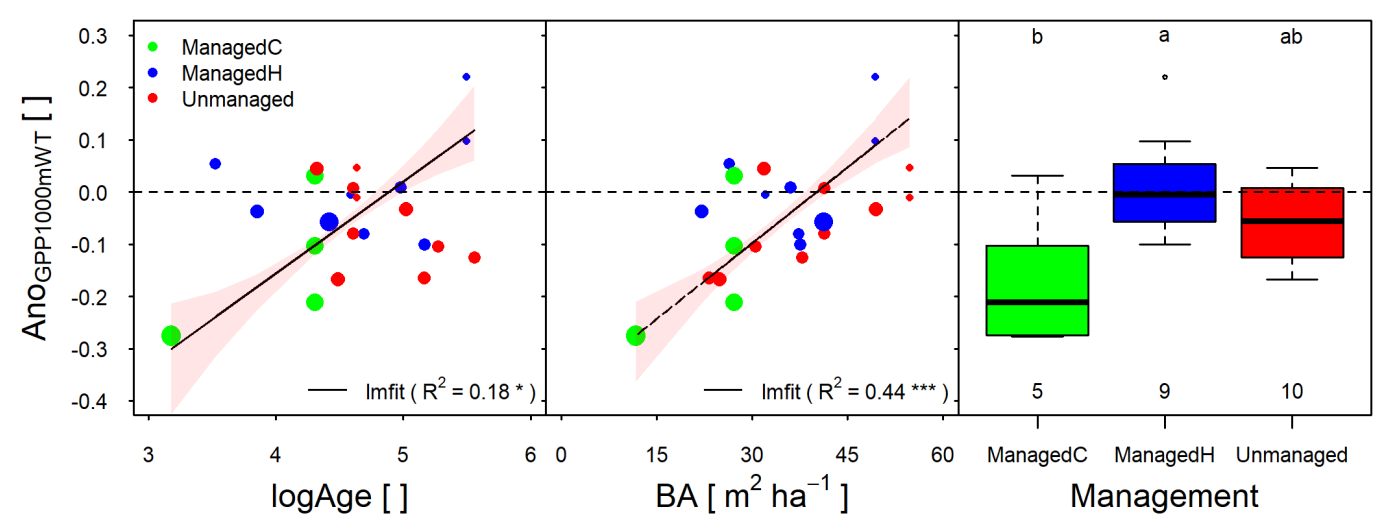

Figure 3.10: The first and second plot shows the relationship of logAge and basal area

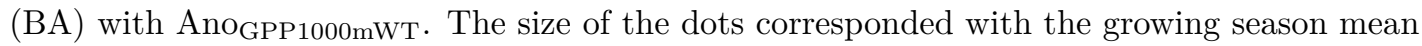
temperature $\left(\mathrm{TA}_{\mathrm{GSmean}}\right)$. The last plot shows the effect of management on Ano $\mathrm{GPP}_{1000 \mathrm{mWT}}$ without removing effect of any other predictor variables. The different letters on the top of the last plot indicates the significant differences at $\mathrm{p}<0.05$.

\subsection{Discussion}

\subsubsection{Temporal stability of $\mathrm{GPP}_{1000}$}

We found that forests from climates with low variability in growing season rainfall and unmanaged forests had stable $\mathrm{GPP}_{1000}$ i.e. lower inter-annual variation in $\mathrm{GPP}_{1000}$. Our results differ from those of (MUSAVI et al., 2017) which showed higher stability in older

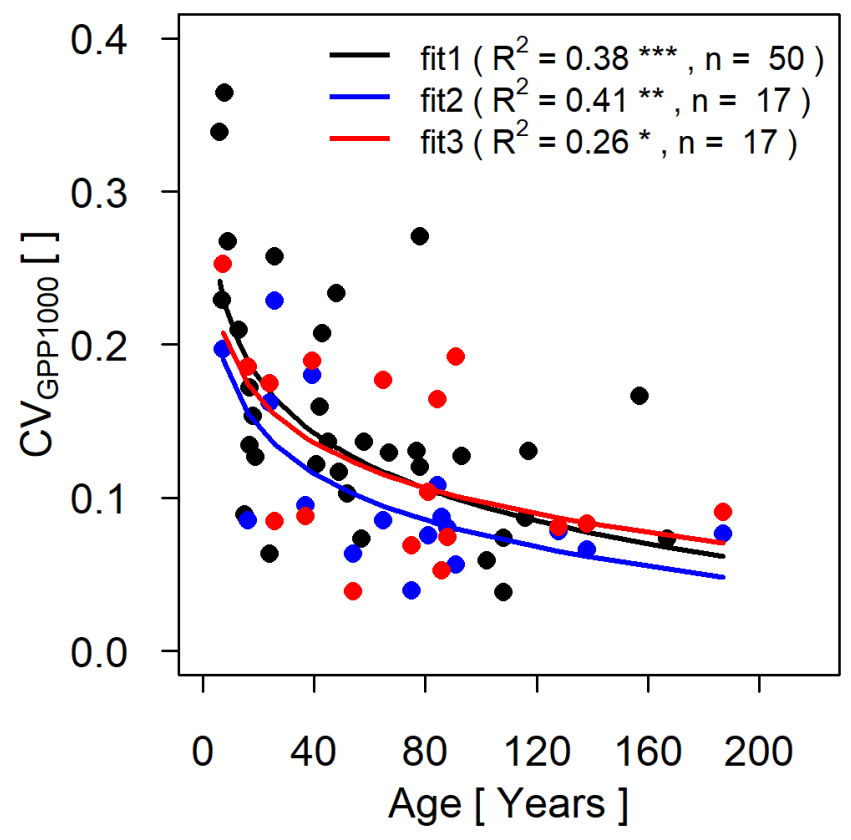

Figure 3.11: Relationship between age and $\mathrm{CV}_{\mathrm{GPP} 1000}$ using a subset of sites from Musavi et al. (2017) but using an extended time period. fit1 is the line as published by MusAvi et al. (2017), fit2 is a subset of data from fit1 for which extended data was available and fit3 uses longer time series data. 
and species diverse forests. They showed that stand age was the strongest predictor of $\mathrm{CV}_{\mathrm{GPP} 1000 \mathrm{p}}$. Forest age itself results from human intervention or cessation of human intervention mostly via silvicultural operations, the unmanaged forests are older than managed forests and significantly older than coppice forests (Figure 3.7). On the other hand, the relationship between age and $\mathrm{CV}_{\mathrm{GPP} 1000 \mathrm{p}}$ strengthens or weakens based on the number of sites and length of data available. We had fewer sites (50 v 21) but a longer time series for each site. Figure 3.11 shows the change in the strength of the relationship between stand age and $\mathrm{CV}_{\mathrm{GPP} 1000}$ when using fewer sites (blue) and longer time-series data (red). When taking a subset of 17 sites, the relationship improved from $\mathrm{R}^{2}$ of 0.38 to 0.41 (from black to blue). However, when longer time series of those same sites were used, $\mathrm{R}^{2}$ decreased from 0.41 to 0.26 (from blue to red). We used different sites than those used in their paper (due to inventory data availability), our relationship was in the same direction but weaker. Additionally, we see the effect of variability in growing season rainfall on $\mathrm{CV}_{\mathrm{GPP} 1000 \mathrm{p}}$ because $\mathrm{GPP}_{1000}$ is normalized for radiation and vapour pressure deficit but without taking into account effect of water limitation (see eq. 3.4). The change in rainfall amount during growing season thus affect the photosynthetic capacity (see Table 3.13).

BA, logAge, ShnSz and SimSz negatively correlated with $\mathrm{CV}_{\mathrm{GPP} 1000}$ indicating lower inter-annual variation in $\mathrm{GPP}_{1000}$ and thus more stable $\mathrm{GPP}_{1000}$. EHBRECHT et al. (2017) showed that structurally more forests had lower daily fluctuations in temperature and vapour pressure deficit which could be the result of higher enhanced stand transpiration in such forests (Forrester, 2015; GeBAUER et al., 2012). Thus, more stable climate conditions in the structurally complex could have contributed to more stable $\mathrm{GPP}_{1000}$.

The management regime had significant effect on these structural parameters (Figure 3.7). (SCHALL et al., 2018) also showed that forest management controlled forest structure. Coppice forests usually had lower values for all different structural parameters because they are usually recently created via clear cut. These forests also show higher interannual variation in $\mathrm{GPP}_{1000}$ (Figure 3.8) indicating that their functioning sensitive to environmental conditions. On the other hand, we note that the unmanaged forests and managed high forests (ManagedH) are older, have higher DBH and size diversity. In terms of structural diversity managed high forests (ManagedH) and unmanaged forests are not different (Figure 3.7).

With time, the forest adapts to their habitat by widening their size distribution, increasing the inequality of tree sizes, extending the canopy space occupation, increasing stand density and diversifying the boundaries between crowns of different species (PRETzSCH et al., 2016). Larger trees also have higher root mass (Bolte et al., 2004; DrexhaGe et al., 1999) that facilitates absorbing nutrients and soil water. Since the forests with the higher basal area also have more diverse sizes of trees, we can assume a higher variation in root distribution as well as in canopy distribution. The higher variation in root distribution will increase the complementary use of nutrients and water. Similarly, higher horizontal differentiation can lead to better use of light resources. Thus, the ecosystem-level photosynthetic capacity $\left(\mathrm{GPP}_{1000}\right)$ was more stable in unmanaged forests than which structurally diverse forests which are also 


\subsubsection{Effect of forest structure on $\mathrm{GPP}_{1000}$ anomalies}

The stepwise regression results showed that Ano GPP1000 was mostly driven by environmental conditions, $\mathrm{TA}_{\text {mean }}$ being the most important. The sites with lower temperatures have shown positive anomalies during droughts meaning that, under drier conditions, these forests actually increase their $\mathrm{CO} 2$ uptake. Environmental and site conditions have been reported to modulate the relationship between forest productivity and species diversity (JuCker et al., 2016; PotTer et al., 2014).

Though the regression analysis did not choose logAge and BA as a predictor variable, simple correlation showed that BA and logAge significantly correlated with Ano GPP1000mWT, with more positive Ano ${ }_{\text {GPP1000mWT }}$ in the forests with higher basal area. MAUSOLF et al. (2018) reported that forests that are unmanaged for more than 50 years were less sensitive to spring drought compared to managed forests. Older forests could have deeper and heterogeneously distributed roots. One of the most effective strategies for plants to deal with drought is to have deep, ramified and dense root system as it provides trees with access to larger soil water reserves (BRÉDA et al., 2006). Since, in our case effect of $\mathrm{TA}_{\text {mean }}$ and $\mathrm{BA}$ are reciprocal, we can not confirm that forests with higher basal area have lower values of $\mathrm{GPP}_{1000}$ during droughts.

We have looked at the direct effect of droughts on forest ecosystems, i.e. we have analysed the disturbances in ecosystem-level photosynthetic capacity during the year when droughts have occurred. Ten drought events did not affect $\mathrm{GPP}_{1000}$, we speculate that these droughts could have occurred without temperature stress. The effect of drought is strong when drought co-occurred with temperature stress (CIAIS et al., 2005; VON Buttlar et al., 2018). Light use efficiency of temperate forests were less or non sensitive to droughts (STOCKER et al., 2018). But the GPP 1000 of coppice forests in Sub-tropical Mediterranean region (IT-Ro2 and FR-Pue) show strong response to drought and listed as drought sensitive forests by STOCKER et al. (2018).

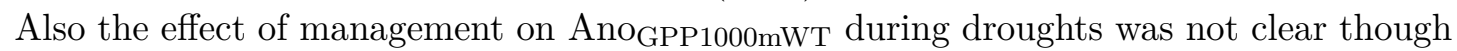
management was selected in case of Ano GPP1000mWT only. The coppice forests had more

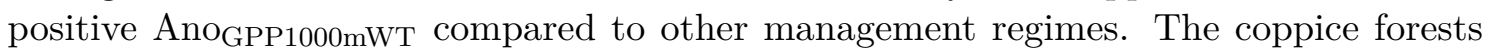
in our case were from the relatively warmer regions (indicated by dots in Figure 3.10). Thus we arrive to this result after removing the effect of climate which was stronger than management. The effect of droughts on $\mathrm{GPP}_{1000}$ was higher in unmanaged forests than managed high forests but statistically insignificant (Figure 3.10 when we did not remove effect any other factor. The managed forests are regularly thinned, the thinning has shown to increase the resistance against drought in the forests (MAGRUDER et al., 2013; SOHN et al., 2016). It hint us towards the point that forests management, particularly appropriate thinning activities, can decrease the effect of drought on forests. More studies can aid us in comfirming this, studies including droughts in 2018 and 2019 in Europe will give us further hint.

\subsubsection{Limitations of the study}

The main question addressed here is if the response of photosynthetic $\mathrm{C}$ fluxes to climate variation and drought is affected by the structural characteristics of forests. An ideal situation to understand the effect of structural parameters on any functional parameter of 
forests (e.g. $\mathrm{GPP}_{1000}$ ) would be to have uniformly distributed sites over a wide range of structural parameter values, i.e. an equal number of sites in each structural parameter classes. For example, the effect of age on $\mathrm{GPP}_{1000}$ can be best understood if we have an equal number of forests in a wide range of age classes. In our case, our sites were not equally distributed across structural parameter classes. Similarly, this study is limited by the lower number of samples but high number of predictors. Regressions using this kind of data (independent variable concentrated in some parameter classes) could be biased or otherwise unreliable.

\subsubsection{Outlook}

Here, we have used only the structural parameter calculated from single structural attributes. However, to classify different forest along the axes of stand structures we need to have indices that combine multiple structural attributes (Gossner et al., 2014; SCHALl et al., 2018). Use of these more complex stand structural indices to understand the relationship between stand structure and forest resistance/resilience could be an interesting area of research in future. Recently, new and promising methods have been developed to characterize three-dimensional forest structure, such as terrestrial laser scanning (TSL)(EHBRECHT et al., 2016). Using the structural data from these techniques can further hint us on the effect of forest structure on resilient and resilience of forest ecosystem functions.

\subsection{Conclusions}

Our findings suggests that in addition to the effects of structural and environmental parameters on the stability of ecosystem functioning, inclusion of management activities is necessary. Here, we find that management regimes dominates the structural indices. Regarding our two hypotheses presented in the introduction section, we could confirm our first hypothesis. The unmanaged forests which had more diverse stand structure had higher temporal stability of ecosystem functioning (here measured in the response of inter-annual variation of $\left.\mathrm{GPP}_{1000}\right)$. Whereas we could not confirm second hypothesis regarding the higher resistant of photosynthetic capacity $\left(\mathrm{GPP}_{1000}\right)$ of diverse forests during drought. However, we observe the indication that forests with higher basal area were more resistant during droughts.

\subsection{Competing interests}

We declare that we have no conflict of interest.

\subsection{Acknowledgements}

We would like to thank Erasmus Mundus Joint Doctorate Programme Forest and Nature for Society (EMJD FONASO) and University of Goettingen Scholarship for funding this research. We are grateful to all the PIs for providing inventory data. 


\subsection{Supplementary materials}

Table 3.8: Brief management history of the sites.

\begin{tabular}{|c|c|}
\hline Site & Management Regime \\
\hline BE-Vie & $\begin{array}{l}\text { Forest was thinned at the beginning of } 2001 \text {, in mid- } 2003 \text { and at } \\
\text { the end of } 2004 \text {. }\end{array}$ \\
\hline CH-Dav & $\begin{array}{l}\text { From } 1987 \text { to } 2008 \text {, only seven of } 500 \text { trees on the } 0.6 \text { ha long-term } \\
\text { ecosystem monitoring plot were removed from the site, mostly } \\
\text { following a severe storm in } 1990 \text {. In October } 2006 \text {, an area of } \\
1750 \mathrm{~m}^{2} \text { within the north-east part of the eddy covariance (EC) } \\
\text { footprint was harvested. }\end{array}$ \\
\hline CH-Lae & $\begin{array}{l}\text { The southern part of the EC footprint has been managed accord- } \\
\text { ing to the forest stewardship council (FSC) since } 1998 \text { and the } \\
\text { northern part is left unmanaged as a nature reserve since } 2001\end{array}$ \\
\hline CZ-BK1 & Norway spruce planted in 1981. \\
\hline DE-Hai & The old-growth beech forest. \\
\hline DE-Lnf & $\begin{array}{l}\text { The pure beech forest and thinned under regular shelterwood } \\
\text { system with a rotation period of about } 120-140 \text { years. }\end{array}$ \\
\hline FI-Hyy & Scots pine planted in 1962 and thinned in early 2002. \\
\hline
\end{tabular}

FR-Fon Forest stand located in protected reserve.

FR-Pue This forest has been managed as a coppice for centuries and the last clear cut was performed in 1942 .

IT-Ren The site is of natural origin and is used for wood production.

IT-Ro1 The site is in the initial developmental stages after the forest cut via coppicing in December 1999

IT-Ro2 The forest is managed as coppice-with-standards with a rotation cycle ranging 15-20 years and arranged in 15 sequentially aged compartments.

RU-Fyo The site is located in reserve without any commercial disturbance since 1960s.

ETZOLD et al.

(2011)

SEDLÁK et al. (2010)

KnOHL et al. (2003)

TAMRAKAR et al. (2018)

ILVESNIEMI et al. (2009) and Vesala et al. (2005)

Koop et al. (1987) and Отто et al. (2014)

Allard et al. (2008) and PITA et al. (2013)

Papale et al. (2015)

PAPAle et al. (2015)

HuRdebise et al. (2017)

MiLyukova et al. (2002)

US-Ha1 Some selective harvesting in site was done $300 \mathrm{~m}$ to the S-SE but not in a direction sampled by EC tower.

US-Me2 The site was clear-cut in 1914 and then allowed to regenerate naturally.

US- $\quad$ The forest is a secondary successional broadleaf forest. Timber

MMS has been harvested around EC tower based on selection and seed tree methods on a 20-25 years rotation for several decades

US-NR1 The sub-alpine forest is recovering from early twentieth century logging.

URBANSKI et al. (2007)

SCHWARZ et al. (2004)

EHMAN et al. (2002)

MONSON et al. (2002)

US-PFa The parts of forest has been thinned and clear-cut within the past few decades.

US-Syv It is unmanaged old-growth site which has never been logged.

US- $\quad$ The stand was disturbed by harvest and fire once in the early

UMB 20th century and was not disturb later.

US-WCr The site is mature upland forest. The forests were harvested Desai et al. (2005) extensively in early 1990s. 
Table 3.9: Dry years, and annual mean \pm sd values of different fluxes (NEE, GPP, Reco, $\mathrm{GPP}_{1000 \mathrm{p}}$ and trend of $\left.\mathrm{GPP}_{1000 \mathrm{p}}-\mathrm{T}_{\mathrm{GPP} 100}\right)$ for sites.

\begin{tabular}{llccccc}
\hline Site & Dry years & NEE & GPP & Reco & $\mathrm{GPP}_{1000}$ & $\mathrm{~T}_{\mathrm{GPP} 100}$ \\
\hline- & - & $\mathrm{g} \mathrm{C} \mathrm{m}^{-2} \mathrm{yr}^{-1}$ & $\mathrm{~g} \mathrm{C} \mathrm{m}^{-2} \mathrm{yr}^{-1}$ & $\mathrm{~g} \mathrm{C} \mathrm{m}^{-2} \mathrm{yr}^{-1}$ & $-\mathrm{mol} \mathrm{m}^{-2} \mathrm{yr}^{-1}$ & ${ }^{-} \mathrm{mol} \mathrm{m}^{-2} \mathrm{yr}^{-1}$ \\
BE-Vie & 2003 & $-477 \pm 157$ & $1816 \pm 186$ & $1385 \pm 242$ & $27.41 \pm 2.41$ & $0.26^{* * *}$ \\
CH-Dav & 2003,2015 & $-78 \pm 183$ & $1055 \pm 92$ & $853 \pm 157$ & $16.91 \pm 2.08$ & -0.1 \\
CH-Lae & 2015 & $-673 \pm 395$ & $1867 \pm 177$ & $1678 \pm 315$ & $32.19 \pm 3.12$ & $0.4^{*}$ \\
CZ-BK1 & 2015 & $-858 \pm 120$ & $1914 \pm 155$ & $968 \pm 169$ & $29.18 \pm 2.68$ & $0.45^{* *}$ \\
DE-Hai & 2003 & $-544 \pm 84$ & $1541 \pm 143$ & $1153 \pm 104$ & $29.3 \pm 2.92$ & -0.19 \\
DE-Lnf & 2003 & $-597 \pm 167$ & $1659 \pm 107$ & $1127 \pm 78$ & $29.21 \pm 2.6$ & 0.03 \\
FI-Hyy & & $-227 \pm 55$ & $1106 \pm 109$ & $924 \pm 92$ & $21.15 \pm 1.5$ & $0.18^{* * *}$ \\
FR-Fon & 2005 & $-633 \pm 91$ & $1678 \pm 178$ & $1026 \pm 242$ & $30.15 \pm 1.51$ & 0.01 \\
FR-Pue & $2005,2006,2012$ & $-232 \pm 86$ & $1224 \pm 257$ & $970 \pm 240$ & $14.65 \pm 2.96$ & -0.33 \\
IT-Ren & 2005 & $-678 \pm 143$ & $1503 \pm 248$ & $991 \pm 243$ & $24.42 \pm 3.3$ & $0.59^{* *}$ \\
IT-Ro1 & & $-226 \pm 194$ & $1646 \pm 122$ & $1352 \pm 178$ & $21.53 \pm 2.59$ & 0.87 \\
IT-Ro2 & 2007,2012 & $-682 \pm 258$ & $1631 \pm 163$ & $1011 \pm 195$ & $23.29 \pm 4.38$ & -0.31 \\
RU-Fyo & 2002 & $105 \pm 127$ & $1351 \pm 133$ & $1413 \pm 102$ & $23.86 \pm 1.54$ & $0.11^{*}$ \\
US-Ha1 & & $-226 \pm 208$ & $1551 \pm 232$ & $1274 \pm 268$ & $26.72 \pm 2.54$ & $0.21^{*}$ \\
US-Me2 & 2002,2013 & $-550 \pm 265$ & $1656 \pm 152$ & $1190 \pm 271$ & $19.93 \pm 1.82$ & $0.37^{* *}$ \\
US-MMS & 1999 & $-427 \pm 73$ & $1644 \pm 114$ & $1231 \pm 133$ & $28.79 \pm 1.97$ & -0.07 \\
US-NR1 & 2002,2012 & $-170 \pm 29$ & $910 \pm 49$ & $766 \pm 55$ & $16.1 \pm 0.82$ & 0.01 \\
US-PFa & 2006 & $-12 \pm 114$ & $903 \pm 236$ & $810 \pm 149$ & $20.39 \pm 2.59$ & 0.04 \\
US-Syv & 2006 & $-74 \pm 113$ & $1184 \pm 266$ & $947 \pm 146$ & $21.59 \pm 2.53$ & $0.64^{* *}$ \\
US-UMB & 2000 & $-269 \pm 65$ & $1319 \pm 138$ & $1071 \pm 114$ & $25.86 \pm 2.19$ & $0.35^{* *}$ \\
US-WCr & 2006 & $-260 \pm 153$ & $1272 \pm 139$ & $1043 \pm 171$ & $25.58 \pm 3.15$ & 0.13 \\
\hline
\end{tabular}


Table 3.10: The zero-order correlation of environmental and structural variables with $\mathrm{Sd}_{\mathrm{GPP} 1000}$ calculated from mean and $90^{\text {th }}$ percentile with and without trend. $* * *$ is significant at $\mathrm{p}=0.001,{ }^{* *} \mathrm{p}=0.01$, and ${ }^{*} \mathrm{p}=0.05$.

\begin{tabular}{|c|c|c|c|c|}
\hline \multirow{3}{*}{ Variables } & \multicolumn{4}{|c|}{ Correlation of } \\
\hline & \multicolumn{2}{|c|}{$\mathrm{Sd}_{\mathrm{GPP} 1000 \mathrm{~m}}$} & \multicolumn{2}{|c|}{$\mathrm{Sd}_{\mathrm{GPP} 1000 \mathrm{p}}$} \\
\hline & WT & WoT & WT & WoT \\
\hline \multicolumn{5}{|l|}{ Environmental parameters } \\
\hline $\mathrm{TA}_{\text {mean }}$ & $0.43^{*}$ & $0.56^{* * *}$ & 0.33 & $0.43^{*}$ \\
\hline $\mathrm{R}_{\text {gmean }}$ & 0.12 & 0.15 & 0.3 & 0.3 \\
\hline $\mathrm{VPD}_{\text {mean }}$ & 0.2 & 0.3 & 0.3 & 0.34 \\
\hline $\mathrm{P}_{\text {mean }}$ & 0.27 & 0.17 & 0.22 & 0.06 \\
\hline $\mathrm{SPEI}_{\text {mean }}$ & -0.31 & -0.29 & -0.34 & -0.3 \\
\hline $\mathrm{TA}_{\mathrm{GSmean}}$ & 0.4 & $0.52^{*}$ & 0.39 & $0.46^{*}$ \\
\hline $\mathrm{R}_{\mathrm{gGSmean}}$ & 0.2 & 0.2 & 0.37 & 0.34 \\
\hline $\mathrm{VPD}_{\mathrm{GSmean}}$ & 0.18 & 0.26 & 0.29 & 0.31 \\
\hline $\mathrm{P}_{\text {GSmean }}$ & 0.11 & -0.05 & 0.07 & -0.09 \\
\hline $\mathrm{SPEI}_{\mathrm{GSmean}}$ & -0.3 & -0.22 & $-0.45^{*}$ & -0.32 \\
\hline $\mathrm{TA}_{\mathrm{sd}}$ & 0.35 & 0.34 & 0.38 & 0.41 \\
\hline $\mathrm{R}_{\mathrm{gsd}}$ & $0.57^{* * *}$ & 0.31 & $0.51^{*}$ & 0.32 \\
\hline $\mathrm{VPD}_{\mathrm{sd}}$ & $0.49^{*}$ & $0.44^{*}$ & 0.36 & 0.35 \\
\hline $\mathrm{P}_{\mathrm{sd}}$ & $0.43^{*}$ & 0.33 & $0.46^{*}$ & 0.3 \\
\hline $\mathrm{SPEI}_{\mathrm{sd}}$ & -0.2 & -0.34 & -0.07 & -0.28 \\
\hline $\mathrm{TA}_{\mathrm{GSsd}}$ & 0.05 & 0.06 & -0.04 & 0.02 \\
\hline $\mathrm{R}_{\mathrm{gGSsd}}$ & 0.31 & 0.18 & 0.33 & 0.2 \\
\hline $\mathrm{VPD}_{\mathrm{GSsd}}$ & 0.29 & 0.33 & 0.16 & 0.23 \\
\hline$P_{\text {GSsd }}$ & $0.46^{*}$ & $0.47^{*}$ & $0.55^{* * *}$ & $0.48^{*}$ \\
\hline $\mathrm{SPEI}_{\mathrm{GSsd}}$ & 0 & -0.12 & 0 & -0.17 \\
\hline \multicolumn{5}{|l|}{ Structural parameters } \\
\hline Age & -0.2 & -0.11 & -0.35 & -0.28 \\
\hline logAge & -0.31 & -0.27 & -0.42 & -0.39 \\
\hline $\mathrm{BA}$ & $-0.61^{* * *}$ & $-0.44^{*}$ & $-0.66^{* * *}$ & $-0.52^{*}$ \\
\hline $\mathrm{DBH}$ & -0.17 & -0.16 & $-0.45^{*}$ & -0.38 \\
\hline $\mathrm{DBH}_{\mathrm{sd}}$ & -0.01 & -0.01 & -0.21 & -0.17 \\
\hline Height & 0.06 & 0.04 & -0.28 & -0.19 \\
\hline ShnSz & -0.14 & -0.15 & -0.42 & -0.33 \\
\hline $\mathrm{SimSz}$ & -0.21 & -0.2 & $-0.44^{*}$ & -0.33 \\
\hline $\mathrm{SpNo}$ & -0.03 & 0.02 & -0.07 & 0.01 \\
\hline
\end{tabular}


Table 3.11: The zero-order correlation of environmental and structural variable with mean annual GPP and Reco calculated with and without trend. *** is significant at $\mathrm{p}=0.001,{ }^{*} \mathrm{p}$ $=0.01$, and $* \mathrm{p}=0.05$.

\begin{tabular}{|c|c|c|c|c|}
\hline \multirow{3}{*}{ Variables } & \multicolumn{4}{|c|}{ Correlation of } \\
\hline & \multicolumn{2}{|c|}{ GPP } & \multicolumn{2}{|c|}{ Reco } \\
\hline & WT & WoT & WT & WoT \\
\hline \multicolumn{5}{|l|}{ Environmental parameters } \\
\hline $\mathrm{TA}_{\text {mean }}$ & 0.41 & $0.55^{* * *}$ & 0.29 & 0.19 \\
\hline $\mathrm{R}_{\text {gmean }}$ & 0.19 & 0.2 & 0.26 & 0.18 \\
\hline $\mathrm{VPD}_{\text {mean }}$ & 0.38 & $0.47^{*}$ & 0.19 & 0.01 \\
\hline $\mathrm{P}_{\text {mean }}$ & 0.23 & 0.21 & 0.31 & 0.34 \\
\hline $\mathrm{SPEI}_{\text {mean }}$ & -0.41 & -0.39 & -0.23 & -0.11 \\
\hline $\mathrm{TA}_{\mathrm{GSmean}}$ & 0.37 & $0.44^{*}$ & 0.19 & 0.08 \\
\hline $\mathrm{R}_{\mathrm{gGSmean}}$ & 0.28 & 0.28 & 0.3 & 0.17 \\
\hline $\mathrm{VPD}_{\mathrm{GSmean}}$ & 0.4 & $0.46^{*}$ & 0.16 & -0.04 \\
\hline $\mathrm{P}_{\mathrm{GSmean}}$ & -0.02 & -0.14 & 0.15 & 0.29 \\
\hline $\mathrm{SPEI}_{\text {GSmean }}$ & -0.38 & -0.23 & -0.09 & 0.06 \\
\hline $\mathrm{TA}_{\mathrm{sd}}$ & 0.11 & -0.09 & 0.09 & 0.09 \\
\hline $\mathrm{R}_{\mathrm{gsd}}$ & $0.43^{*}$ & 0.38 & 0.05 & 0.02 \\
\hline $\mathrm{VPD}_{\mathrm{sd}}$ & 0.2 & 0.25 & 0.03 & 0.08 \\
\hline $\mathrm{P}_{\mathrm{sd}}$ & 0.38 & 0.39 & 0.19 & 0.15 \\
\hline $\mathrm{SPEI}_{\mathrm{sd}}$ & 0.1 & 0.02 & 0.05 & -0.02 \\
\hline $\mathrm{TA}_{\mathrm{GSsd}}$ & -0.23 & -0.24 & -0.2 & -0.14 \\
\hline $\mathrm{R}_{\mathrm{gGSsd}}$ & 0.19 & 0.24 & -0.01 & 0.03 \\
\hline $\mathrm{VPD}_{\mathrm{GSsd}}$ & 0.15 & 0.27 & -0.1 & -0.09 \\
\hline$P_{\text {GSsd }}$ & $0.45^{*}$ & $0.48^{*}$ & 0.2 & 0.15 \\
\hline $\mathrm{SPEI}_{\mathrm{GSsd}}$ & 0.18 & 0.07 & 0.18 & 0.18 \\
\hline \multicolumn{5}{|l|}{ Structural parameters } \\
\hline Age & -0.3 & -0.17 & -0.06 & 0.01 \\
\hline logAge & -0.35 & -0.26 & -0.07 & -0.04 \\
\hline BA & $-0.54^{* * *}$ & -0.39 & 0.03 & 0.13 \\
\hline $\mathrm{DBH}$ & $-0.44^{*}$ & -0.36 & -0.16 & -0.1 \\
\hline $\mathrm{DBH}_{\mathrm{sd}}$ & -0.1 & 0 & $0.47^{*}$ & $0.56^{* * *}$ \\
\hline Height & -0.42 & -0.32 & -0.17 & 0 \\
\hline ShnSz & $-0.47^{*}$ & -0.38 & 0 & 0.13 \\
\hline $\mathrm{SimSz}$ & $-0.58 * * *$ & $-0.49^{*}$ & -0.16 & 0.01 \\
\hline $\mathrm{SpNo}$ & -0.18 & -0.34 & -0.07 & -0.09 \\
\hline
\end{tabular}


Table 3.12: The zero-order correlation of GPP and Reco anomalies of dry years with environmental and structural variables. Anomalies were also estimated with trend and after removing trend. ${ }^{* * *}$ is significant at $\mathrm{p}=0.001,{ }^{* *} \mathrm{p}=0.01$, and ${ }^{*} \mathrm{p}=0.05$.

\begin{tabular}{|c|c|c|c|c|}
\hline \multirow{3}{*}{ Variables } & \multicolumn{4}{|c|}{ Correlation of } \\
\hline & \multicolumn{2}{|c|}{$\mathrm{Ano}_{\mathrm{GPP}}$} & \multicolumn{2}{|c|}{ Anoreco } \\
\hline & WT & WoT & WT & WoT \\
\hline \multicolumn{5}{|l|}{ Environmental parameters } \\
\hline $\mathrm{TA}_{\text {mean }}$ & -0.3 & -0.33 & -0.06 & -0.05 \\
\hline $\mathrm{R}_{\text {gmean }}$ & -0.32 & -0.22 & -0.06 & 0.07 \\
\hline $\mathrm{VPD}_{\text {mean }}$ & $-0.44^{*}$ & -0.39 & -0.07 & 0.02 \\
\hline $\mathrm{P}_{\text {mean }}$ & 0.03 & -0.15 & -0.15 & -0.34 \\
\hline $\mathrm{SPEI}_{\text {mean }}$ & 0.02 & 0.13 & -0.15 & -0.15 \\
\hline $\mathrm{TA}_{\mathrm{GSmean}}$ & $-0.46^{*}$ & $-0.45^{*}$ & -0.18 & -0.18 \\
\hline $\mathrm{R}_{\mathrm{gGSmean}}$ & $-0.43^{*}$ & -0.34 & -0.09 & 0.05 \\
\hline $\mathrm{VPD}_{\mathrm{GSmean}}$ & $-0.44^{*}$ & $-0.41^{*}$ & -0.06 & 0.02 \\
\hline $\mathrm{P}_{\mathrm{GSmean}}$ & 0.28 & 0.19 & -0.1 & -0.27 \\
\hline $\mathrm{SPEI}_{\mathrm{GSmean}}$ & 0.34 & $0.43^{*}$ & 0.05 & 0.09 \\
\hline $\mathrm{TA}_{\mathrm{sd}}$ & -0.08 & -0.07 & -0.22 & -0.24 \\
\hline $\mathrm{R}_{\mathrm{gsd}}$ & $-0.53^{* * *}$ & $-0.51^{* * *}$ & -0.35 & -0.32 \\
\hline $\mathrm{VPD}_{\mathrm{sd}}$ & $-0.45^{*}$ & $-0.49 * * *$ & -0.19 & -0.25 \\
\hline $\mathrm{P}_{\mathrm{sd}}$ & -0.21 & -0.35 & -0.17 & -0.29 \\
\hline $\mathrm{SPEI}_{\mathrm{sd}}$ & -0.14 & -0.11 & -0.02 & -0.08 \\
\hline $\mathrm{TA}_{\mathrm{GSsd}}$ & -0.18 & -0.16 & -0.3 & -0.24 \\
\hline $\mathrm{R}_{\mathrm{gGSsd}}$ & $-0.51^{* * *}$ & $-0.54^{* * *}$ & -0.35 & -0.37 \\
\hline $\mathrm{VPD}_{\mathrm{GSsd}}$ & $-0.41^{*}$ & $-0.46^{*}$ & -0.13 & -0.16 \\
\hline$P_{\text {GSsd }}$ & -0.09 & -0.14 & -0.13 & -0.25 \\
\hline $\mathrm{SPEI}_{\mathrm{GSsd}}$ & -0.36 & -0.33 & -0.16 & -0.3 \\
\hline \multicolumn{5}{|l|}{ Structural parameters } \\
\hline Age & 0.37 & 0.38 & 0.2 & 0.21 \\
\hline logAge & 0.38 & $0.43^{*}$ & 0.19 & 0.26 \\
\hline $\mathrm{BA}$ & $0.53^{* * *}$ & $0.51^{* * *}$ & 0.32 & 0.37 \\
\hline $\mathrm{DBH}$ & 0.33 & 0.34 & 0.11 & 0.19 \\
\hline $\mathrm{DBH}_{\text {sd }}$ & 0.11 & 0.17 & 0.19 & 0.27 \\
\hline Height & 0.24 & 0.29 & 0.01 & 0.05 \\
\hline ShnSz & 0.24 & 0.31 & 0.06 & 0.15 \\
\hline $\mathrm{SimSz}$ & 0.24 & 0.33 & 0.03 & 0.14 \\
\hline $\mathrm{SpNo}$ & -0.03 & 0.02 & -0.18 & -0.15 \\
\hline
\end{tabular}


Table 3.13: The distance correlation values of $\mathrm{GPP}_{1000 \mathrm{~m}}$ and $\mathrm{GPP}_{1000 \mathrm{p}}$ with yearly growing season rainfall $\left(\mathrm{TA}_{\mathrm{GSmean}}\right.$.

\begin{tabular}{lcc}
\hline site & GPP $_{1000 \mathrm{~m}}$ VsTA $_{\text {GSmean }}$ & GPP $_{1000 \mathrm{p}}$ VsTA $_{\text {GSmean }}$ \\
\hline BE-Vie & 0.43 & 0.45 \\
CH-Dav & 0.45 & 0.39 \\
CH-Lae & 0.32 & 0.38 \\
CZ-BK1 & 0.45 & 0.50 \\
DE-Hai & 0.57 & 0.36 \\
DE-Lnf & 0.38 & 0.45 \\
FI-Hyy & 0.37 & 0.28 \\
FR-Fon & 0.53 & 0.37 \\
FR-Pue & 0.64 & 0.65 \\
IT-Ren & 0.37 & 0.37 \\
IT-Ro1 & 0.58 & 0.53 \\
IT-Ro2 & 0.71 & 0.43 \\
RU-Fyo & 0.34 & 0.35 \\
US-Ha1 & 0.43 & 0.41 \\
US-Me2 & 0.62 & 0.48 \\
US-MMS & 0.59 & 0.52 \\
US-NR1 & 0.35 & 0.37 \\
US-PFa & 0.52 & 0.32 \\
US-Syv & 0.53 & 0.52 \\
US-UMB & 0.35 & 0.43 \\
US-WCr & 0.52 & 0.42 \\
\hline
\end{tabular}





\section{CHAPTER 4}

A flexible forest soil water model (FWSM) in R

Manuscript to be submitted to 'Environmental modelling and software' 


\subsection{Abstract}

Soil water availability is one of the most important determinants of vegetation characteristics. To estimate soil water in forest soils, a new model (forest soil water model - FSWM), suitable for a range of forest soils, is developed in the $\mathrm{R}$ environment. This new open-source model incorporates the Gash model for interception, the Ritchie model for soil evaporation and the Richards equation for soil water movement. Model performance, evaluated against soil water measurements at 12 sites, was good for deciduous broadleaf forests $\left(\mathrm{R}^{2}=0.68\right)$, moderate for mixed forests $\left(\mathrm{R}^{2}=0.57\right)$ and evergreen needle leaf forests $\left(\mathrm{R}^{2}=0.45\right)$. Performance when simulating evapotranspiration was better, with $\mathrm{R}^{2}$ from values 0.52 to 0.88. FSWM is also flexible for simulating soil horizons with different depths and helps when comparing modeled with observed values at different soil depths. The above characteristics make FSWM a flexible and freely available tool for the ecosystem and hydrological research.

\subsection{Introduction}

Soil water availability is one of the most important determinants of vegetation characteristics (Clark et al., 2016; Stephenson, 2002), including vegetation health (Hu et al., 2017; LANTSChner et al., 2019; LiU et al., 2018), and productivity (HuANG et al., 2012; REICHSTEIN et al., 2007; WANG et al., 2016). The increasing frequency of drought events in recent years (SPINONI et al., 2019) has increased interest within the scientific community towards better understanding the associated impacts on terrestrial ecosystems.

Various drought indices have been proposed to quantify droughts (see review by SPEICH, 2019). Some indices use precipitation data alone (e.g. the standardized precipitation index - SPI by MCKEE et al., 1993; the standardized precipitation and evapotranspiration index - SPEI by VICENTE-SERRANO et al., 2010) while other use physiological parameters along with meteorological variables (e.g. the water stress integral - WSI by MYERS, 1988). Soil water in forests can be calculated either from sub-modules of process-based land surface models, as found in FORCLIM (Bugmann et al., 1998), FOREST-BGC (RunNing et al., 1988), SPA (Williams et al., 1996), FORSKA (Prentice et al., 1992), SIERRA (Mouillot et al., 2001), LPJ-DGVM (Sitch et al., 2003), CASTANEA (DAVI et al., 2005b), CoupModel (JANSSON et al., 2011), and others, or from soil water balance models like Site Water Balance - SWB (Grier et al., 1977), the Simple Water Balance Model - SWBM (OrTh et al., 2013), SPLASH (Davis et al., 2017), BILJOU (Granier et al., 1999), SWUF (PAUL et al., 2003), and others. Process-based land surface models usually involve a large number of parameters and the estimation of these parameters requires detailed field and experimental data. If soil water content or drought indices are required, water balance models using simple soil and stand parameters and climatic data are often adequate (GRANIER et al., 1999).

JoNG et al. (1996) categorized water balance models into budget models, semi-dynamic models and dynamic models and pointed out the main advantages and disadvantages of each. Most simple budget models consider the soil profile as a bucket into which water flows until it is full and surplus water is then either runoff or drainage beneath the root zone (DAvis et al., 2017). The advanced budget models have the soil profile divided into 
multiple layers (O'LEARY et al., 1985). In the case of semi-dynamic models, the rate of water movement of each layer varies as a function of infiltration amount, the relative water content, percolation coefficient, drainage rate coefficients, etc. (GRANIER et al., 1999; PAUL et al., 2003). In dynamic models, the physical factors governing water movement in soil - for example, the soil water potential, the differential water capacify, the hydraulic conductivity, etc. of each soil layer - control infiltration and redistribution of water (JONG et al., 1996).

STOCKER et al. (2018) used three different water budget models (SPLASH, SWBM and ET-driven bucket) and two different water holding capacities to quantify soil water content of many different ecosystem types. Their results showed that in most of the temperate forests analyzed (eg. Hainich, Tharandt, Soroe, Loobos, Hyytiala, etc) soil moisture had little to no influence on light use efficiency (LUE). Contrary to that, GrANIER et al. (2007), using the semi-dynamic soil water model (BILJOU), showed that soil moisture for the same temperate sites had a strong influence on gross primary productivity (GPP) in the heat-wave of 2003. We note that STOCKER et al. (2018) used longer-term data including 2003. Such inconsistencies in reported drought effects can arise from a number of factors, such as errors in the calculation of soil moisture indices, differences in the temporal data coverage (only one year in the case of GRANIER et al. (2007)), different types of models, and different functional properties of forest stands. Such uncertainties can make it difficult to address ecological questions about the sensitivity of functional properties (e.g. LUE) of temperate forests to drought or to derive meaningful drought indices.

One approach is to use semi-dynamic or dynamic models that allow calculating water dynamics of entire soil profiles over multiple years, spatial and temporal levels at which direct measurements are rarely available (and in any case prone to large errors). The resulting data can be more effectively used to test if functional properties of temperate forests have been more or less affected by soil moisture content in a given period. These models can utilize site-specific soil parameters and vegetation characteristics to quantify forest soil moisture indices.

Although there are many models (as listed above) that calculate soil water dynamics using a variety of approaches, it is difficult to find soil water models that are open source, easily accessible and practical to implement. The latter requires models that are standalone, meaning they are independent and can be run with a minimal set of vegetation, soil and climate data. Models also do not always have the structural flexibility to simulate different soil vertical resolutions, thus making them more easily comparable to the variety of site-level moisture data available.

The BILJOU model (GrANIER et al., 1999), a semi-dynamic model, is a useful tool for such purposes because it requires simple soil and stand parameters, in addition to climatic data. BILJOU can be run for single years using the online platform https: //appgeodb.nancy.inra.fr/biljou/. There are a few disadvantages of this model. First, running the model for multiple years in such a platform is impractical and quickly becomes tedious and time-demanding. Second, the model code is closed source, making it impossible to know precisely how calculations are performed or to modify the code if changes in parameter values or processes are desired. Thus, we recognized the need to build a model using a familiar and accessible platform, for which we chose $\mathrm{R}$ ( $\mathrm{R}$ Development Core 
TEAM, 2018). Making the code open-source facilitates the improvement and further development of the model by the research community.

Here we present the forest soil water model (FSWM) that runs at a daily time scale. Our model is based on the same general principles underlying BILJOU (GRANIER et al., 1999) while improving a number of processes and adding functionality for the quantification of soil water in temperate forests. These improvements include (1) the use of soil texture data, to estimate field capacity, wilting point and hydraulic conductivity (SAXTON et al., 2006); (2) the use of net radiation whenever possible instead of solar radiation; (3) an optional function to calculate root distribution in different soil layers (GALE et al., 1987); (4) the Ritchie formulation for soil evaporation (RITCHIE, 1972); (5) the Gash model of interception (GASH et al., 1995); and (6) the Richards equation to calculated soil water movement (RICHARDS, 1931).

\subsection{Materials and methods}

\subsubsection{Model description}

FSWM runs at a daily scale and calculates transpiration, interception, throughfall, soil evaporation, soil moisture and drought indices - relative extractable water (REW) at a daily scale and annual drought index (ADI) at an annual scale - using the input data shown in Table 4.1. Soil can be represented in multiple layers. Saturation point, field capacity, wilting point, and hydraulic conductivity of different soil layers are calculated using soil texture data following SAXTON et al. (2006). Field capacity, however, can also be given as input data by estimating it from the measured long-term soil moisture data. Changes in daily soil water content $(\Delta) \mathrm{SW}$, eq. 4.1 ) are calculated as the balance between total rainfall $(\mathrm{P})$, interception $(\mathrm{I})$, transpiration $(\mathrm{T})$, soil evapotranspiration $(\mathrm{E})$ and drainage (D). The model assume no run-off. Symbols and parameters used in the model are listed in Table 4.2 and 4.3 , respectively.

$$
\Delta S W=P-I-T-E-D
$$

\section{Distribution of roots}

We used the model presented by GALE (1987) for the vertical distribution of root. In this model, lower values of the parameter $\beta$ represent higher abundance of roots on the shallower soil layers. Jackson et al. (1996) listed $\beta$ values for different ecosystems between 0.914 and 0.975 ( $\beta=0.976$ and 0.966 for temperate coniferous and deciduous forests, respectively). Whenever data for root mass in different soil layers is available, we can calculate site-specific $\beta$ values.

$$
Y=1-\beta^{d}
$$

Here, $\mathrm{Y}$ is the cumulative root fraction from the surface to any depth (d) in centimeters. 
Table 4.1: List of inputs required for the model, site data, soil layer data, phenological, and climatic data.

\begin{tabular}{|c|c|}
\hline Symbols & Description \\
\hline \multicolumn{2}{|l|}{ Site data } \\
\hline Ele & site elevation $[\mathrm{m}]$ \\
\hline FT & forest type - Deciduous, Evergreen or Mixed \\
\hline Lat & latitude [decimal degrees] \\
\hline Site & name of the site \\
\hline TRD & total rooting depth $[\mathrm{cm}]$ \\
\hline $\mathrm{M}_{\mathrm{H}}$ & wind speed measurement height $[\mathrm{m}]$ \\
\hline \multicolumn{2}{|c|}{ Data for each soil layer } \\
\hline $\mathrm{BD}$ & bulk density $\left[\mathrm{g} \mathrm{cm}^{-3}\right]$ \\
\hline Clay & clay $\left[\mathrm{g} \mathrm{g}^{-1}\right]$ \\
\hline $\mathrm{DL}$ & depth of layer lower boundary $[\mathrm{cm}]$ \\
\hline DU & depth of layer upper boundary $[\mathrm{cm}]$ \\
\hline DUL & the volumetric water content of drained soil $\left[\mathrm{v} \mathrm{v}^{-1}\right]$ (optional) \\
\hline Gravel & gravel $\left[\mathrm{g}^{-1}\right]$ \\
\hline $\mathrm{RF}$ & root fraction (optional) \\
\hline Sand & sand $\left[\mathrm{g} \mathrm{g}^{-1}\right]$ \\
\hline SOM & soil organic matter content $\left[\mathrm{g} \mathrm{g}^{-1}\right]$ \\
\hline \multicolumn{2}{|c|}{ Phenological data } \\
\hline GSE & Julian day when the all the leaves fall \\
\hline GSS & Julian day when the first leaves appear \\
\hline Lai & maximum leaf area index for the year $\left[\mathrm{m}^{2} \mathrm{~m}^{-2}\right]$ \\
\hline \multicolumn{2}{|c|}{ Climatic data } \\
\hline $\mathrm{P}$ & daily sum of rainfall $[\mathrm{mm}]$ \\
\hline $\mathrm{R}_{\mathrm{g}}$ & daily short-wave radiation $\left[\mathrm{Mj} \mathrm{m}^{-2}\right.$ day $\left.^{-1}\right]$ (if $\mathrm{R}_{\mathrm{n}}$ not available) \\
\hline $\mathrm{RH}_{\max }$ & maximum daily relative humidity $[\%]$ \\
\hline $\mathrm{RH}_{\min }$ & minimum daily relative humidity [\%] \\
\hline $\mathrm{R}_{\mathrm{n}}$ & daily net radiation $\left[\mathrm{Mj} \mathrm{m}^{-2}\right.$ day $\left.^{-1}\right]$ \\
\hline $\mathrm{T}_{\max }$ & maximum daily temperature $\left[{ }^{\circ} \mathrm{C}\right]$ \\
\hline $\mathrm{T}_{\text {mean }}$ & mean daily temperature $\left[{ }^{\circ} \mathrm{C}\right]$ \\
\hline $\mathrm{T}_{\min }$ & minimum daily temperature $\left[{ }^{\circ} \mathrm{C}\right]$ \\
\hline $\mathrm{WS}_{\mathrm{MH}}$ & wind speed at measurement height $[\mathrm{m}]$ \\
\hline
\end{tabular}

\section{Temporal variation of leaf area index (LAI) and light reaching the ground}

Forests in the model can be either evergreen, deciduous or mixed. For evergreen forests, we maintain a constant LAI over the year. For deciduous forests, LAI is 0 during the non-leaved period and linearly increases after the start of leaf-out over the course of 45 days, after which it reaches a maximum. Based on our experience in a deciduous unmanaged Hainich forest, Germany, the underground vegetation starts growing nearly two weeks before the tree leaves start coming out and tree leaves took around thirty days to come out completely. For mixed forests, LAI is divided into an evergreen and a deciduous fraction, with the dynamics of each fraction being as described for each forest type. LAI for the evergreen part is constant over the entire year and we follow the same principle for the deciduous part as in the deciduous forest. LAI remains maximum for both deciduous and 
Table 4.2: Symbols of variables used in the model.

\begin{tabular}{|c|c|}
\hline Symbols & Description \\
\hline $\mathrm{C}$ & canopy cover ( 0 to 1$)$ \\
\hline $\mathrm{D}$ & sub-surface drainage $\left[\mathrm{mm} \mathrm{day}^{-1}\right]$ \\
\hline$\Delta$ & slope of the saturation vapour pressure curve $\left[\mathrm{kPa}{ }^{\circ} \mathrm{C}\right]$ \\
\hline Dep & depth of the soil layer $[\mathrm{cm}]$ \\
\hline$d z_{i}$ & thickness of soil layer i [mm] \\
\hline $\mathrm{E}$ & soil evaporation $\left[\mathrm{mm} \mathrm{day}^{-1}\right]$ \\
\hline $\mathrm{FC}$ & field capacity $[\mathrm{mm}]$ \\
\hline$\gamma$ & psychrommetric constant $\left[\mathrm{kPa}^{\circ} \mathrm{C}\right]$ \\
\hline I & rainfall interception $\left[\mathrm{mm} \mathrm{day}^{-1}\right]$ \\
\hline $\mathrm{K}$ & empirical unsaturated hydraulic conductivity function $\left[\mathrm{mm} \mathrm{s}^{-1}\right]$ \\
\hline LAI & leaf area index $\left[\mathrm{m}^{2} \mathrm{~m}^{-2}\right]$ \\
\hline$\lambda$ & latent heat of vaporization $\left[\mathrm{MJ} \mathrm{kg}{ }^{-1}\right]$ \\
\hline $\mathrm{L}_{\mathrm{g}}$ & proportion of light at canopy \\
\hline $\mathrm{L}_{\mathrm{g}}^{\circ}$ & proportion of light reaching ground \\
\hline $\mathrm{P}$ & daily sum of rainfall $\left[\mathrm{mm} \mathrm{day}^{-1}\right]$ \\
\hline PET & potential evapotranspiration $\left[\mathrm{mm} \mathrm{day}^{-1}\right]$ \\
\hline $\mathrm{P}_{\mathrm{s}}$ & canopy saturating rainfall $[\mathrm{mm}]$ \\
\hline$\psi$ & empirical soil hydraulic capillary head function [mm] \\
\hline $\mathrm{r}$ & ratio of $\mathrm{TR}_{\max }$ to $\mathrm{PET}$ \\
\hline REW & relative extractable water \\
\hline $\mathrm{T}$ & transpiration $\left[\mathrm{mm} \mathrm{day}^{-1}\right]$ \\
\hline $\mathrm{t}$ & time $[s]$ \\
\hline$\theta_{i}$ & volumetric soil water content of layer $\mathrm{i}\left[\mathrm{m}^{3} \mathrm{~m}^{-3}\right]$ \\
\hline $\mathrm{TR}_{\max }$ & transpiration without water stress $\left[\mathrm{mm} \mathrm{day}^{-1}\right]$ \\
\hline WP & Wilting point $[\mathrm{mm}]$ \\
\hline $\mathrm{WS}_{2 \mathrm{~m}}$ & wind speed at $2 \mathrm{~m}$ height $\left[\mathrm{m} \mathrm{s}^{-1}\right]$ \\
\hline $\mathrm{Y}$ & cumulative root fraction \\
\hline $\mathrm{z}$ & vertical coordinate (positive downward) [mm] \\
\hline
\end{tabular}

mixed forest until leaves start falling in autumn. LAI starts to decrease 45 days before all the leaves shed.

The proportion of light reaching the ground $\left(\mathrm{L}_{\mathrm{g}}\right)$ is estimated with the Beer-Lambert function using a light extinction coefficient $(\mathrm{k})$ and LAI as shown in eq. 4.3. The fraction of light intercepted by the canopy is the remaining fraction (eq. 4.4) and also considered as canopy cover $(\mathrm{C})$.

$$
\begin{gathered}
L_{g}=e^{-k * L A I} \\
L_{c}=C=1-L_{g}
\end{gathered}
$$

\section{Canopy interception}

We used the Gash model (GASH et al., 1995) for quantifying canopy interception (I) where daily rainfall is considered to fall in a single event. First, the minimum amount of rainfall required to saturate the canopy $\left(\mathrm{P}_{\mathrm{S}}\right)$ is calculated based on canopy storage $(\mathrm{S})$, rate of evaporation during the rainfall event (ER) and canopy cover (C) (eq. 4.5). Canopy storage 
Table 4.3: Symbols of parameters and their values used in model.

\begin{tabular}{|c|c|c|c|}
\hline Parameter & Description & Value & Reference \\
\hline$\beta$ & Root distribution parameter & $0.92-0.97$ & JACKSON et al., 1996 \\
\hline $\mathrm{CSC}$ & Canopy water storage capacity & $0.10-1\left[\mathrm{~mm} \mathrm{LAI}^{-1}\right]$ & $\begin{array}{l}\text { BitTNER et al., 2010; } \\
\text { CÁCERES et al., 2015; } \\
\text { KLAASSEN et al., } 1998\end{array}$ \\
\hline $\mathrm{ER}$ & $\begin{array}{l}\text { The ratio of the evaporation } \\
\text { rate to rainfall rate during the } \\
\text { rainfall event }\end{array}$ & $0.05-0.25$ & $\begin{array}{l}\text { BitTNER et al., 2010; } \\
\text { CÁCERES et al., } 2015\end{array}$ \\
\hline $\mathrm{g}$ & Desorptivity values & $2-8\left[\mathrm{~mm} \mathrm{day}^{-1 / 2}\right]$ & $\begin{array}{l}\text { Kustas, 2016; PAUL et } \\
\text { al., } 2003\end{array}$ \\
\hline $\mathrm{k}$ & Light extinction coefficient & 0.5 & \\
\hline
\end{tabular}

on a particular day is calculated as the product of canopy storage capacity (CSC) and LAI. Intercepted water is then calculated as shown in eq. 4.6.

$$
\begin{aligned}
& P_{s}=\frac{S}{C E R} \ln (1-E R) \\
& I= \begin{cases}C P_{s}+C E R\left(P-P_{s}\right) & \text { if } \mathrm{P}>P_{s} \\
C P & \text { if } \mathrm{P}<=P_{s}\end{cases}
\end{aligned}
$$

\section{Transpiration}

Transpiration is a function of PET, LAI and relative extractable water (REW). The model first calculates the potential evapotranspiration (PET) with the Penman-Monteith equation (ZOTARELLI et al., 2010) requiring daily net radiation $\left(\mathrm{R}_{\mathrm{n}}\right)$, mean temperature $\left(\mathrm{T}_{\text {mean }}\right)$, vapour pressure deficit (VPD), and wind speed at $2 \mathrm{~m}$ height $\left(\mathrm{WS}_{2 \mathrm{~m}}\right)$ as shown in eq. 4.7. If $\left(R_{n}\right)$ is not available it is estimated from the global radiation $\left(R_{g}\right)$. $W_{2 m}$ is calculated using eq. 4.8 .

$$
\begin{aligned}
P E T & =\frac{0.408 \Delta R_{n}+\gamma \frac{900}{T \text { Tean }+273} W S_{2 m} V P D}{\Delta+\gamma\left(1+0.34 W S_{2 m}\right)} \\
W S_{2 m} & =W S_{M H} \frac{4.87}{\ln \left(67.8 M_{H}-5.42\right)}
\end{aligned}
$$

Secondly, the model estimates $\mathrm{r}$, the ratio of maximum stand transpiration (transpiration without water limitation - $\mathrm{TR}_{\max }$ ) to PET as the function of LAI (eq. 4.9). A soil water limitation to transpiration is estimated by calculating REW, which is the ratio of available water (available soil water -SW minus wilting point - WP) to maximum available water (field capacity - FC minus wilting point - WP) for plants (eq. 4.10). Actual transpiration $(\mathrm{T})$ is then calculated as the product of $\mathrm{r}$ and PET when soil water is not limited or as a function dependent on r, REW and PET when soil water is limited (eq. 4.11). 


$$
\begin{aligned}
& r=\frac{T R_{\max }}{P E T}= \begin{cases}0.75 & \text { if } \mathrm{LAI}>=6 \\
0.125 L A I & \text { if } \mathrm{LAI}<6\end{cases} \\
& R E W=\frac{S W-W P}{F C-W P} \\
& T= \begin{cases}r P E T & \text { if REW }>0.4 \\
P E T \frac{r R E W+0.15(0.4-R E W)}{0.4} & \text { if REW }<=0.4\end{cases}
\end{aligned}
$$

\section{Understorey evapotranspiration}

Understorey evapotranspiration is the minimum between soil water supply $\left(\mathrm{S}_{\text {soil }}\right)$ from the topsoil layer and potential soil evaporation. $S_{\text {soil }}$ is based on Ritchie (1972). First, the time required to evaporate the water deficit (i.e. the difference between field capacity (FC1) and soil water (SW1) - $t_{\text {def }}$ ), from the topsoil layer is calculated (eq. 4.13) and is dependent on desorptivity parameter $(\gamma)$. Then, the soil water supply is calculated (eq. 4.14).

$$
\begin{aligned}
& E_{\text {soil }}=\min \left(S_{\text {soil }}, P E T_{s}\right) \\
& t_{\text {def }}=\left[\frac{F C_{1}-S W_{1}}{\gamma}\right]^{2} \\
& S_{\text {soil }}=\gamma\left(\sqrt{t_{\text {def }}+1}-\sqrt{t_{\text {def }}}\right)
\end{aligned}
$$

Potential evaporation from the understorey $\mathrm{PET}_{\mathrm{s}}$ is calculated using the same formulation as for the canopy (eq. 4.7). The net radiation reaching the ground was estimated as the product of fraction light reaching the ground (eq. 4.3 ) and net radiation at the canopy $R_{n}$. Wind speed under the canopy was estimated from eq. 4.15. During the non-leaved period, the $R_{n}$ reaching the ground was assumed to be 0.3 as used by BITTNER et al. (2010).

$$
W S_{2 m}=W S_{M H} \exp \left[a\left(\frac{2}{M_{H}}-1\right)\right]
$$

\section{Water movement in soil}

The model divides the soil into at least two layers: the top layer $(0-10 \mathrm{~cm})$ from where soil evaporation occurs and bottom layer(s). The number of soil layers (nsl) depends on the soil details available. The Richards equation (RICHARDS, 1931) is applied for vertical water flow through unsaturated porous medium to estimate the change in soil moisture in each soil layer (eq. 4.16). The unsaturated conductivity $\left(K_{\theta}\right)$ and tension $\left(\psi_{\theta}\right)$ at soil moisture $(\theta)$ is quantified following Saxton and Rawls (2006), and linearized about change in volumetric soil water content $\left(d_{\theta}\right)$. A tridiagonal system of equations is used to solve $d_{\theta}$, as implemented in the $\mathrm{R}$ package LimSolve(SOETAERT et al., 2016). The solution conserves 
water as shown in eq. 4.17 .

$$
\begin{aligned}
\frac{d \theta}{d t}=\frac{d}{d z}\left[-K_{\theta} \frac{d\left(\psi_{\theta}+z\right)}{d z}\right] & \begin{aligned}
{\left[\theta_{1} \cdot d z_{1}+\ldots \ldots . .+\theta_{n s l} d z_{n s l}\right]_{n+1}=} & {\left[\theta_{1} d z_{1}+\ldots \ldots . .+\theta_{n s l} d z_{n s l}\right]_{n}+} \\
& \left(q_{i n f l}-q_{E}-q_{T}-q_{D}\right) d t
\end{aligned}
\end{aligned}
$$

where, $\theta_{i}$ is volumetric soil water content of layer $\mathrm{i}\left[\mathrm{m}^{3} \mathrm{~m}^{-3}\right]$

$\mathrm{d}_{\mathrm{z}}$ is thickness of $\mathrm{i}^{\text {th }}$ soil layer $[\mathrm{mm}]$

$\mathrm{n}$ is the number of the timestep (day of the year in our case)

qinf is the infiltration rate $\left(\mathrm{mm} \mathrm{s}^{-1}\right)$

$\mathrm{q}_{\mathrm{E}}$ is the soil evaporation $\operatorname{rate}\left(\mathrm{mm} \mathrm{s}^{-1}\right)$

$\mathrm{q}_{\mathrm{T}}$ is the transpiration rate $\left(\mathrm{mm} \mathrm{s}^{-1}\right)$

$\mathrm{q}_{\mathrm{D}}$ is the drainage rate $\left(\mathrm{mm} \mathrm{s}^{-1}\right)$

$\mathrm{dt}$ is the number of seconds in a timestep (86400 seconds in our case)

The lower and upper boundaries for daily soil water content are given by wilting point (WP) and field capacity (FC), respectively. As a more reliable alternative to pedotransfer functions, FC can be directly taken from long-term measurement of soil moisture that captures maximum field values. Temperate forests typically show periods of stable high soil water levels, indicating a well-drained maximum (see Fig. 4.3). This value, also known as the drained upper limit (DUL), can be used as FC. WP, on the other hand, was estimated using the soil texture data following SAXTON et al. (2006). Water exceeding FC is percolated from a soil layer down to lower layers. Any excess water in the last soil layer is lost as sub-surface drainage.

\section{Drought indices}

REW is the index for daily drought. At the annual scale, we calculate annual drought days (ADD) and annual drought intensity as drought index (ADI). ADD is calculated as the numbers of days when REW is below 0.4 (based on threshold value given by GRANIER et al., 1999) and ADI as:

$$
A D I=\frac{\sum \max \left[\frac{0.4-R E W}{0.4}, 0\right]}{365}
$$

where ADI is dimensionless and ranges between 0 (when daily REW is always above 0.4) and 1 (when daily REW is 0 in all days of a year).

\subsubsection{Data}

We compiled data from twelve forest sites within the fluxnet2015 eddy covariance data set (FluXnet, 2017). Data consisted of daily climate (temperature, humidity, precipitation, radiation), latent energy fluxes, soil moisture and soil texture of four deciduous broad-leaved forests (DBF), four evergreen needle-leaved forests (ENF) and four mixed forests (MF)(Table 
4.4). Soil data (sand, clay, bulk density, gravel, soil organic material) were obtained from fluxnet2015, euroflux (http://www.europe-fluxdata.eu/) and from relevant literature. Data and model for this chapter are available at https://doi.org/10.25625/3DVVVN.

Table 4.4: Sites used in this study.

\begin{tabular}{llrrl}
\hline Site & Forest Type & Latitude & Elevation & Reference \\
\hline DE-Hai & DBF & 51.08 & 431 & KNOHL et al. (2003) \\
DE-Lnf & DBF & 51.33 & 450 & HERBST et al. (2015) \\
DK-Sor & DBF & 55.49 & 40 & PILEGAARD et al. (2001) \\
US-MMS & DBF & 39.32 & 293 & SchMid et al. (2000) \\
DE-Tha & ENF & 50.96 & 295 & GrÜNWALD et al. (2007) \\
IT-Lav & ENF & 45.96 & 1319 & PAPALE et al. (2015) \\
NL-Loo & ENF & 52.17 & 26 & SCHELHAAS et al. (2004) \\
US-Me2 & ENF & 44.45 & 1234 & IRVINE et al. (2004) \\
BE-Bra & MF & 51.31 & 16 & JANSSENS et al. (1999) \\
BE-Vie & MF & 50.31 & 495 & AUBINET et al. (2001) \\
CH-Lae & MF & 47.48 & 674 & ETzOLD et al. (2011) \\
US-Syv & MF & 46.24 & 533 & DESAI et al. (2005) \\
\hline
\end{tabular}

\subsubsection{Model parameterizations}

Four model parameters namely deabsorbity $(\gamma)$, canopy storage capacity (CSC), rate of canopy evaporation to rainfall rate $(\mathrm{ER})$ and the root distribution coefficient $(\beta)$ were optimized by minimizing the difference between modelled evapotranspiration and evapotranspiration calculated from the observed corrected latent energy (details on latent energy correction is detailed in FLUXNET, 2017). Parameters were separately optimized for each forest type by selecting four years of one randomly selected site from each forest type (DBF:DE-Hai, ENF:DE-Tha and MF:BE-Bra). Optimization was carried out with the R package FME (SoETAERT et al., 2016).

\subsubsection{Model evaluation}

We evaluated the model results with soil moisture and corrected evapotranspiration data from the 12 fluxnet sites, excluding the data used to estimate the parameters discussed in section 4.3.3. For evapotranspiration comparison, we used only the days with more than $80 \%$ non-filled half-hourly observed evapotranspiration data.

\subsection{Results and discussions}

\subsubsection{Field capacity (FC) and wilting point (WP)}

Using FC from field soil moisture measurements instead of approximating it with a pedotransfer function improved the model performance in all sites except in BE-Bra (Figure 4.1). The highest improvement was observed in US-Me2 (38 \% increase in $\left.\mathrm{R}^{2}\right) . \mathrm{R}^{2}$ of deciduous forests increased in average ca. $9 \%$. Different studies have used different soil water potential to estimate FC (e.g. KäTTERER et al., 2006; Le BAS et al., 1997; White, 2006 , etc.). Here we used a soil water potential of $-33 \mathrm{Kpa}$ and pedotransfer functions developed by SAXTON et al. (2006) for approximating FC from soil texture (RICHARDS, 
1944). Nemes et al. (2011) showed that FC estimated from -33 kPa can differ from the field measured FC.

Similarly, optimizing the texture (clay and sand \%) improved the model performance significantly in DBF sites (lower panels of Fig. 4.1). Texture vary spatially within a forest. In Figure 4.16, we show the texture reported in three different papers at DE-Hai (BITTNER et al., 2010; GuCKLAND et al., 2009; Kutsch et al., 2010). Even though KuTsCH et al. (2010) measured the soil texture in plots approximately three kilometers west of plots measured by BitTner et al. (2010) and GuCKLAND et al. (2009), the values of clay content vary considerably over short distances.

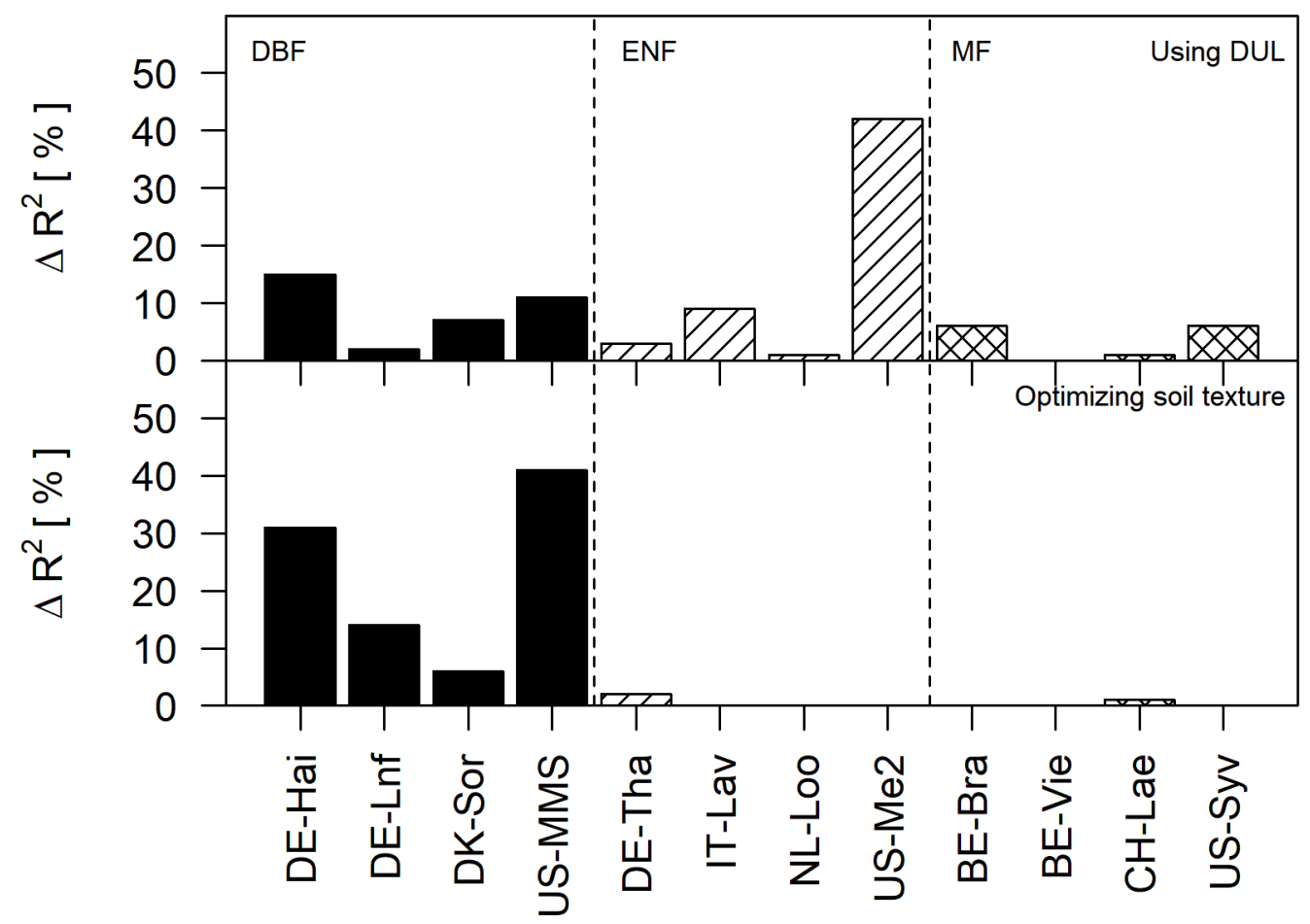

Figure 4.1: Improvement in performance by using FC from field measurements (top row) and by optimizing soil texture (bottom row).

\subsubsection{Model parameterizations}

Optimized values of parameters $\beta$, CSC, ER and g are presented in Table 4.5. $\beta$ for DBF and ENF are lower than suggested by JACKSON et al. (1996). However, the $\beta$ values are similar to estimates by BiTTNER et al. (2010) based on fine roots measurement.

CSC values were within the range estimated by different studies. BitTner et al. (2010) estimated CSC between 0.06 to $0.21 \mathrm{~mm} \mathrm{LAI}^{-1}$ during the foliated period and 0.08 to 0.13 mm LAI ${ }^{-1}$ during the non-foliated period for a beech forest. LINK et al. (2004) reviewed values of CSC and found them to lie between 0.1 to 0.22 for needle-leaved forests. However, estimated CSC values are lower than estimated by CÁCERES et al. (2015) for all forest types. 
Our estimates for ER (0.1 for all forest types) were similar to CÁCERES et al. (2015). They estimated ER equal to 0.2 in winter and 0.05 in summer. The parameters CSC and ER are highly correlated in all forest types (Table 4.9).

The desoptivity coefficients (g) values were within the range of other studies. KUSTAS (2016) reports the value of $g$ between 2.11 to 8 for different soil types. Here, we did not parameterize the value of $\mathrm{g}$ for different seasons although a seasonal dependency has been reported (JACKSON et al., 1976).

Table 4.5: Optimized values of root distribution parameter $(\beta)$, canopy water storage capacity $\left(\mathrm{CSC}, \mathrm{mm} \mathrm{LAI}^{-1}\right)$, the ratio of the evaporation rate to rainfall rate during the rainfall event (ER), and desorptivity values (g, mm day ${ }^{-1 / 2}$ ).

\begin{tabular}{|c|c|c|c|c|}
\hline Parameter & Estimate & Std. Error & $\mathrm{t}$ value & $\overline{\operatorname{Pr}(>|t|)}$ \\
\hline \multicolumn{5}{|l|}{$\mathrm{DBF}$} \\
\hline$\beta$ & 0.93 & 0.11 & 8.85 & 0.00 \\
\hline $\mathrm{CSC}\left[\mathrm{mm} \mathrm{LAI}^{-1}\right]$ & 0.11 & 0.01 & 8.19 & 0.00 \\
\hline $\mathrm{ER}$ & 0.10 & 0.02 & 6.54 & 0.00 \\
\hline $\mathrm{g}\left[\mathrm{mm} \mathrm{day}^{-1 / 2}\right]$ & 3.05 & 0.14 & 21.76 & 0.00 \\
\hline \multicolumn{5}{|l|}{ ENF } \\
\hline$\beta$ & 0.94 & 0.13 & 7.06 & 0.00 \\
\hline $\mathrm{CSC}\left[\mathrm{mm} \mathrm{LAI}^{-1}\right]$ & 0.25 & 0.02 & 11.19 & 0.00 \\
\hline $\mathrm{ER}$ & 0.10 & 0.02 & 5.63 & 0.00 \\
\hline $\mathrm{g}\left[\mathrm{mm} \mathrm{day}^{-1 / 2}\right]$ & 3.32 & 0.24 & 13.87 & 0.00 \\
\hline \multicolumn{5}{|l|}{ MF } \\
\hline$\beta$ & 0.97 & 0.06 & 17.01 & 0.00 \\
\hline $\mathrm{CSC}\left[\mathrm{mm} \mathrm{LAI}^{-1}\right]$ & 0.10 & 0.02 & 4.81 & 0.00 \\
\hline ER & 0.10 & 0.02 & 4.54 & 0.00 \\
\hline $\mathrm{g}\left[\mathrm{mm} \mathrm{day}{ }^{-1 / 2}\right]$ & 2.79 & 0.59 & 4.70 & 0.00 \\
\hline
\end{tabular}

\subsubsection{Model evaluation}

Table 4.6 shows the model performance against measured soil water for all sites. The timeseries of modelled and observed soil moisture data for all sites are presented in Appendix 4.6.1.

For DBF sites, the average $\mathrm{R}^{2}$ was 0.69 with the highest $\mathrm{R}^{2}$ in the managed beech forest site DE-Lnf and the lowest in DK-Sor after optimizing soil texture. The observed soil moisture time series for DK-Sor (Figure 4.5) shows numerous erratic periods (for e.g. 2007-2010 and 2016-2018). In the case of US-MMS, the new model performed better than for DK-Sor based on the top soil moisture data only (Figure 4.6).

Model performance was average for evergreen needle-leaved forests, with a mean $\mathrm{R}^{2}$ of 0.45 , with the lowest values for NL-Loo. The timeseries of observed data for NL-Loo (Figure 4.9), a sandy site, shows unrealistic constant values (ca. 0.06) from mid 2000 to mid 2002 (flat lines in top layer) and mid 2004 to 2007. Model performance in IT-Lav, though slightly better compared to NL-Loo, was poor. The observed and modelled data better matched for deeper depth than the top depth (Figure 4.8) and observed top soil data differed strongly between 2004-2008 and 2009-2015. In the case of DE-Tha, only data for top soil is available with high inter-annual variation (Figure 4.7). 
In the case of mixed forests, model performance was good for two sites (BE-Bra and CH-Lae) and poor for US-Syv. Soil moisture for only the top $10 \mathrm{~cm}$ is reported for US-Syv and shows unrealistic constant values from 2009 to 2011. Additionally, the observed soil moisture is higher from 2012 to 2015. There were also errors in the soil moisture data in BE-Vie starting from 2007 (Figure 4.12).

We have found data issues in numerous sites making our evaluation results poor. On top of that if data is only available for top soil, the results are poor. Measurement by soil moisture sensors are more prone to errors in upper soil layer than bottom layers (Mittelbach et al., 2012). Similarly, the soil measurements become more uncertain with time.

Table 4.6: Performance of FSWM tested against measured soil moisture.

\begin{tabular}{llccccc}
\hline Site & FT & $\mathrm{R}^{2}$ & RMSE & Slope & Intercept & Count \\
\hline DE-Hai & DBF & 0.75 & 0.04 & 1.05 & -0.03 & 5104 \\
DE-Lnf & DBF & 0.84 & 0.03 & 0.92 & 0.03 & 5344 \\
DK-Sor & DBF & 0.54 & 0.04 & 0.82 & 0.04 & 2557 \\
US-MMS & DBF & 0.64 & 0.06 & 0.96 & 0.03 & 5844 \\
DE-Tha & ENF & 0.43 & 0.08 & 0.69 & 0.12 & 7978 \\
IT-Lav & ENF & 0.37 & 0.03 & 0.53 & 0.20 & 3944 \\
NL-Loo & ENF & 0.29 & 0.05 & 3.26 & -0.13 & 2557 \\
US-Me2 & ENF & 0.72 & 0.07 & 1.14 & 0.00 & 4748 \\
BE-Bra & MF & 0.82 & 0.04 & 0.83 & 0.06 & 1461 \\
BE-Vie & MF & 0.52 & 0.02 & 1.16 & -0.04 & 2723 \\
CH-Lae & MF & 0.60 & 0.04 & 1.13 & 0.00 & 2192 \\
US-Syv & MF & 0.33 & 0.06 & 1.46 & -0.05 & 2616 \\
\hline
\end{tabular}

The model performed better when evaluated against measured evapotranspiration data than soil moisture data (Table 4.7). We observed $\mathrm{R}^{2}$ values between 0.52 to 0.87 with the highest values in DBF sites followed by MF and ENF. The slope between modelled and observed evapotranspiration for two DBF sites (DE-Hai and DE-Lnf) was close to one but lower for the other two sites (DK-Sor and US-MMS). The slope was around one for most ENF sites. For MF, the slope was lower with an average of 0.80 .

Underestimation of evapotranspiration, reflected in a slope that is lower than one, can be due to an underestimation of PET, low values of LAI or REW, as in our model transpiration is a function of PET, LAI and REW. Here, we have used the FAO-56 Penman-Monteith equation to evaluate potential evapotranspiration. An earlier version of BILJOU used the Penman equation (Granier et al., 1999), and CÁCEREs et al. (2015) used a formulation given by PRENTICE et al. (1992). The choice of the equation makes large differences in potential evapotranspiration (XU et al., 2002). We used the Priestly-Taylor formulation (PRIESTLEY et al., 1972) to see if the evapotranspiration data for four sites with low predicted values improved (Figure 4.15). The slope improved by about $10 \%$ (0.76 to 0.90 in DK-Sor, 0.74 to 0.88 in US-MMS, 0.83 to 0.94 in BE-Bra and 0.79 to 0.85 in BE-Vie) with small changes in RMSE.

In Figure 4.2, we compared the FWSM model results for DE-Hai with results from the online BILJOU Model (UMR EEF, 1999). BILJOU model was run using the same parameter values for soil as used in FWSM. It was only possible to check the results of 
Table 4.7: Evaluating the model against measured evapotranspiration data.

\begin{tabular}{ccccccc}
\hline Site & FT & $\mathrm{R}^{2}$ & RMSE & Slope & Intercept & Count \\
\hline DE-Hai & DBF & 0.87 & 0.48 & 0.95 & 0.05 & 4193 \\
DE-Lnf & DBF & 0.88 & 0.45 & 0.94 & 0.06 & 2777 \\
DK-Sor & DBF & 0.82 & 0.67 & 0.76 & 0.16 & 5032 \\
US-MMS & DBF & 0.87 & 0.81 & 0.74 & 0.31 & 5633 \\
DE-Tha & ENF & 0.76 & 0.56 & 0.87 & 0.19 & 8033 \\
IT-Lav & ENF & 0.61 & 0.76 & 1.09 & -0.45 & 3905 \\
NL-Loo & ENF & 0.52 & 1.00 & 0.91 & -0.24 & 6392 \\
US-Me2 & ENF & 0.67 & 0.70 & 1.02 & -0.13 & 4246 \\
BE-Bra & MF & 0.76 & 0.55 & 0.83 & 0.22 & 5995 \\
BE-Vie & MF & 0.83 & 0.56 & 0.79 & 0.18 & 6027 \\
CH-Lae & MF & 0.72 & 1.06 & 0.77 & -0.13 & 5479 \\
US-Syv & MF & 0.80 & 0.61 & 0.79 & 0.16 & 1843 \\
\hline
\end{tabular}

the BILJOU Model against evapotranspiration as this model does not return results for individual soil layers. The performance of both models was very similar. Our model, however, had a slightly higher $\mathrm{R}^{2}$ and lower RMSE. Major differences in two models were the interception (Gash model instead of Rutter model), soil evaporation (Ritchie model instead of simple dependence on topsoil REW) and root water movement (used Richards equation instead of simply distributing the infiltration to different soil layers).

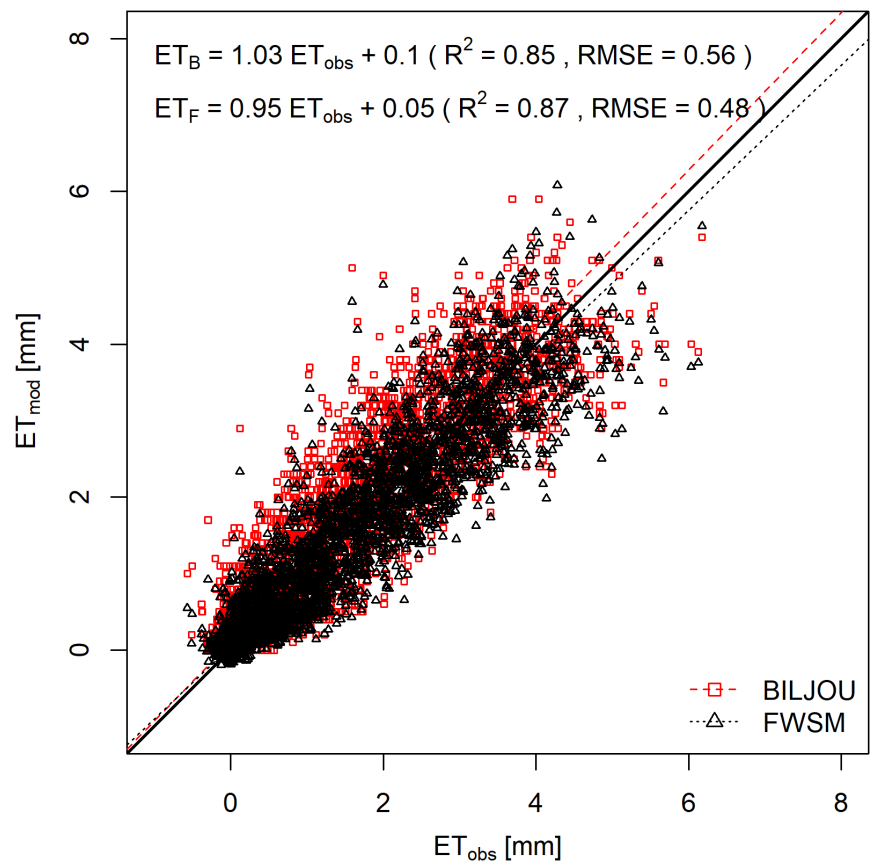

Figure 4.2: Evaluating the results of FWSM against BILJOU Model. ET B $_{\mathrm{B}}$ (black triangles) and $\mathrm{ET}_{\mathrm{F}}$ (red squares) represent values of evapotranspiration values from FWSM and BILJOU model respectively. 


\subsubsection{Average annual values of different ET components}

Here, we report the average annual ET components namely transpiration, interception, and soil evapotranspiration (Table 4.8). Transpiration was about $40 \%, 45 \%$ and $36 \%$ of the total gross rainfall in DBF, ENF and MF, respectively. Interception was about $9 \%$, $15 \%$ and $11 \%$ of the gross rainfall in DBF, ENF and MF, respectively. Soil evaporation was very similar to interception with $10 \%, 8 \%$ and $9 \%$ of total gross rainfall in DBF, ENF and MF. The interception for DE-Hai in our case is much lower than that reported by BITTNER et al. (2010) for the same site, where they reported interception values of 21 to $41 \%$ for different plots during 2005-2007. However, they did not include the canopy interception as part of evapotranspiration while comparing it with eddy flux tower data from the same site. Since interception is evaporated back to the atmosphere, their total sum of evapotranspiration is much larger than the evapotranspiration measurement. Our results for DE-Hai was closer to the results from the online BILJOU model (Table 4.10).

Table 4.8: Annual rainfall (mean $\pm \mathrm{sd}$ ) and different evapotranspiration components (mean \pm sd) namely transpiration (TR), interception (In), soil evaporation (Esoil) for all study sites.

\begin{tabular}{llrclr}
\hline $\begin{array}{l}\text { Site } \\
(-)\end{array}$ & $\begin{array}{l}\text { FT } \\
(-)\end{array}$ & $\begin{array}{r}\text { Rain } \pm \text { sd } \\
(\mathrm{mm})\end{array}$ & $\begin{array}{c}\text { TR } \pm \text { sd } \\
(\mathrm{mm})\end{array}$ & $\begin{array}{l}\text { In } \pm \text { sd } \\
(\mathrm{mm})\end{array}$ & $\begin{array}{r}\text { Esoil } \pm \text { sd } \\
(\mathrm{mm})\end{array}$ \\
\hline DE-Hai & DBF & $689 \pm 170$ & $292 \pm 23$ & $62 \pm 13$ & $71 \pm 9$ \\
DE-Lnf & DBF & $614 \pm 157$ & $296 \pm 15$ & $69 \pm 12$ & $62 \pm 3$ \\
DK-Sor & DBF & $837 \pm 299$ & $260 \pm 24$ & $63 \pm 12$ & $74 \pm 9$ \\
US-MMS & DBF & $1083 \pm 194$ & $427 \pm 31$ & $69 \pm 8$ & $119 \pm 11$ \\
DE-Tha & ENF & $820 \pm 137$ & $284 \pm 32$ & $130 \pm 16$ & $67 \pm 5$ \\
IT-Lav & ENF & $1283 \pm 300$ & $238 \pm 13$ & $130 \pm 26$ & $122 \pm 3$ \\
NL-Loo & ENF & $829 \pm 214$ & $329 \pm 49$ & $147 \pm 29$ & $26 \pm 2$ \\
US-Me2 & ENF & $486 \pm 158$ & $416 \pm 23$ & $84 \pm 18$ & $47 \pm 4$ \\
BE-Bra & MF & $819 \pm 134$ & $249 \pm 30$ & $88 \pm 12$ & $74 \pm 9$ \\
BE-Vie & MF & $952 \pm 201$ & $263 \pm 22$ & $89 \pm 11$ & $64 \pm 4$ \\
CH-Lae & MF & $832 \pm 120$ & $388 \pm 22$ & $93 \pm 10$ & $60 \pm 3$ \\
US-Syv & MF & $665 \pm 174$ & $265 \pm 26$ & $78 \pm 14$ & $88 \pm 11$ \\
\hline
\end{tabular}

\subsection{Conclusions}

Soil water availability is one of the most important determinants of vegetation characteristics. To estimate soil water dynamics in forest soils, the forest soil water model or FSWM, suitable for a wide range of forest soils, was developed in $\mathrm{R}$. This new open-source model improves over similar models (such as the BILJOU model) by incorporating the Gash model for interception, the Ritchie model for soil evaporation and the Richards equation for soil water movement. Model users can directly input texture data to the model instead of providing available soil water in each layer. We have included pedotransfer functions given by SAXTON et al. (2006). Model performance was variable, being better in deciduous broad-leaved forests and worse in needle-leaved forests. It is likely that some of this poor fit is the result of poorly constrained soil moisture data at some of the Fluxnet sites. However, we are also not confident about the soil data available in the fluxnet site as there are straight lines or very low soil water content. 
4.6 Supplementary materials 
4.6.1 Model evaluation other sites

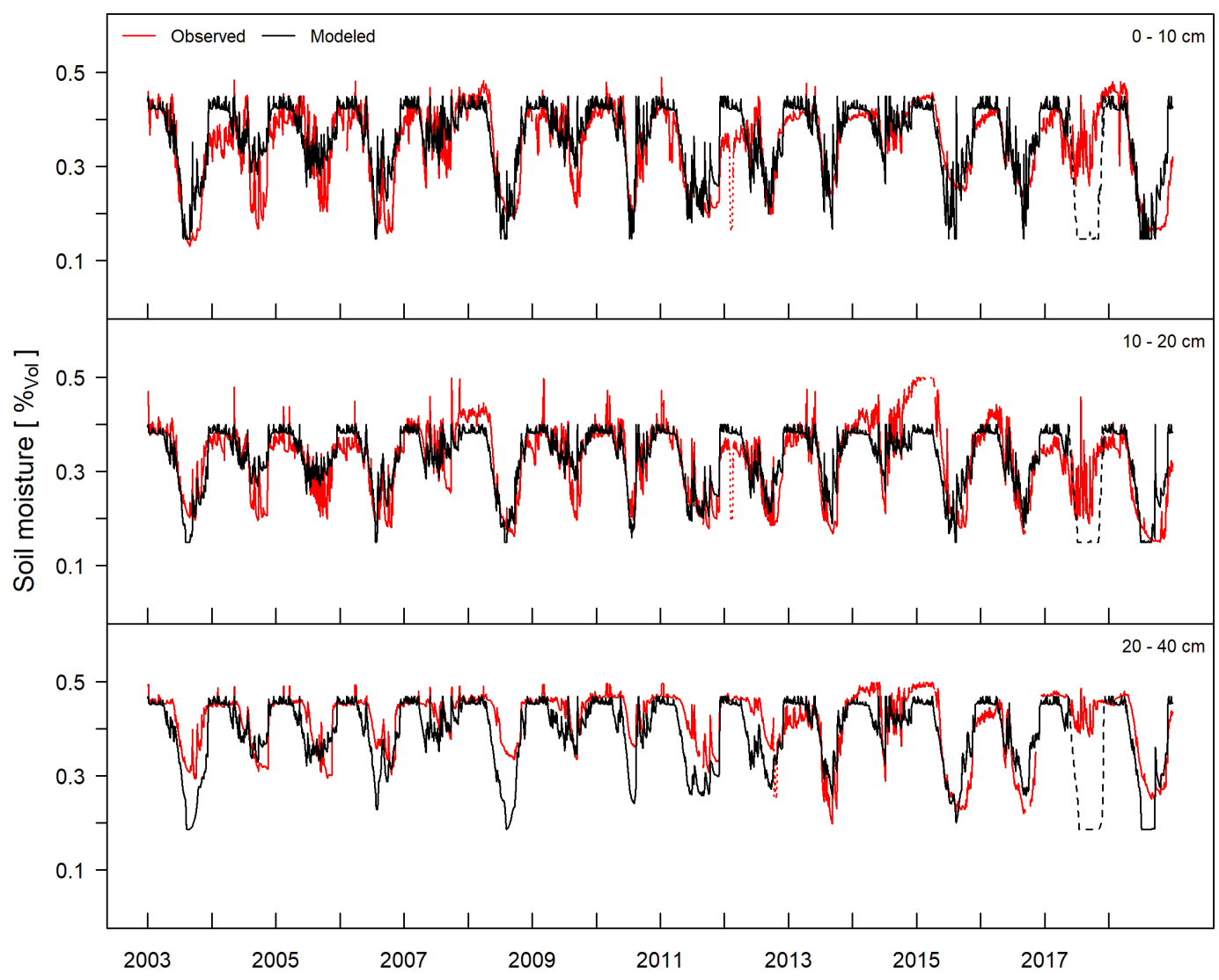

Figure 4.3: The observed and modelled soil moisture data for three layers at DE-Hai site. In 2017, the precipitation data was unrealistic with numerous zero values this led to very low soil moisture prediction. 


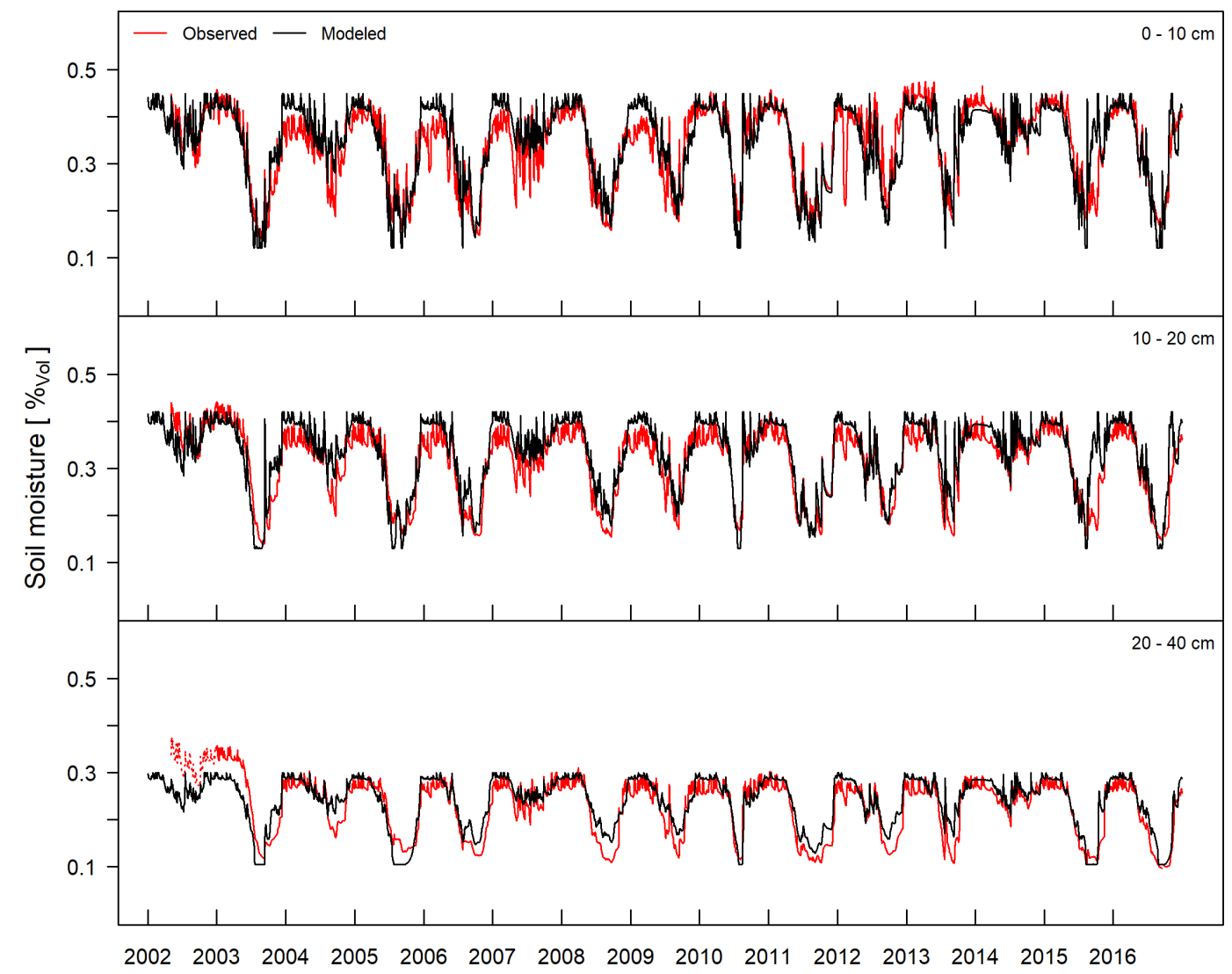

Figure 4.4: The observed and modelled soil moisture data for three layers at DE-Lnf site. The observation and modelled values fit quite well for this site. 


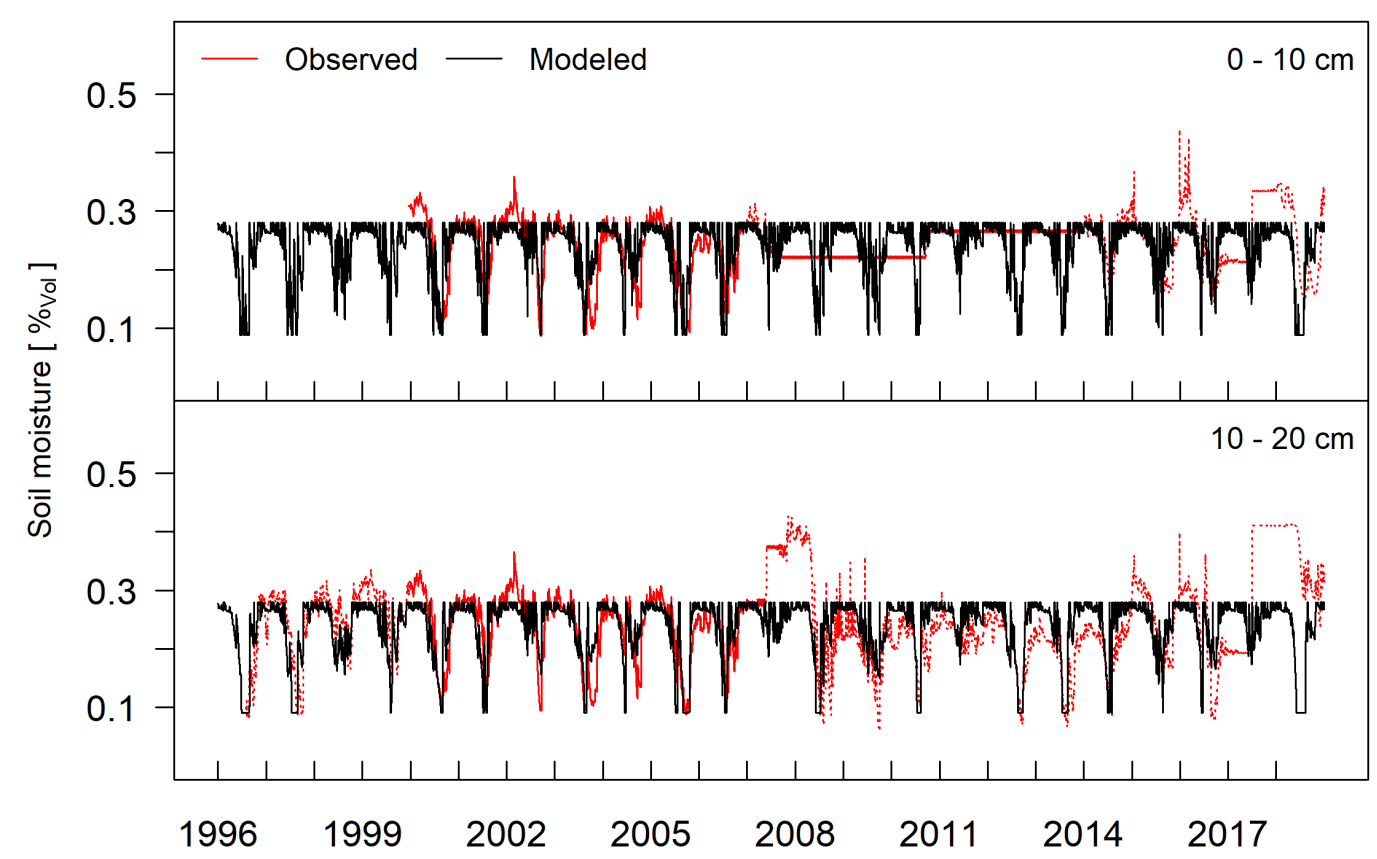

Figure 4.5: The observed and modelled soil moisture data for two layers at DK-Sor site. We observed some unrealistic values for this site in both layers (for example the flat line from mid 2007 to end of 2010 in $0-10 \mathrm{~cm}$ layer).

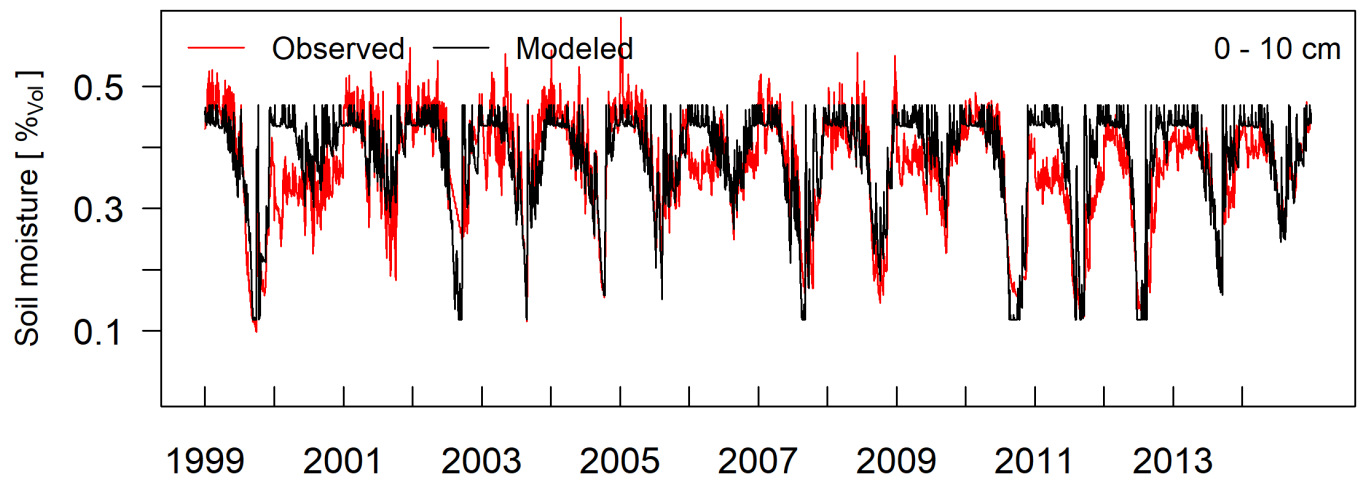

Figure 4.6: The observed and modelled soil moisture data for top layer at US-MMS site. The site reported the data only for top layer. 


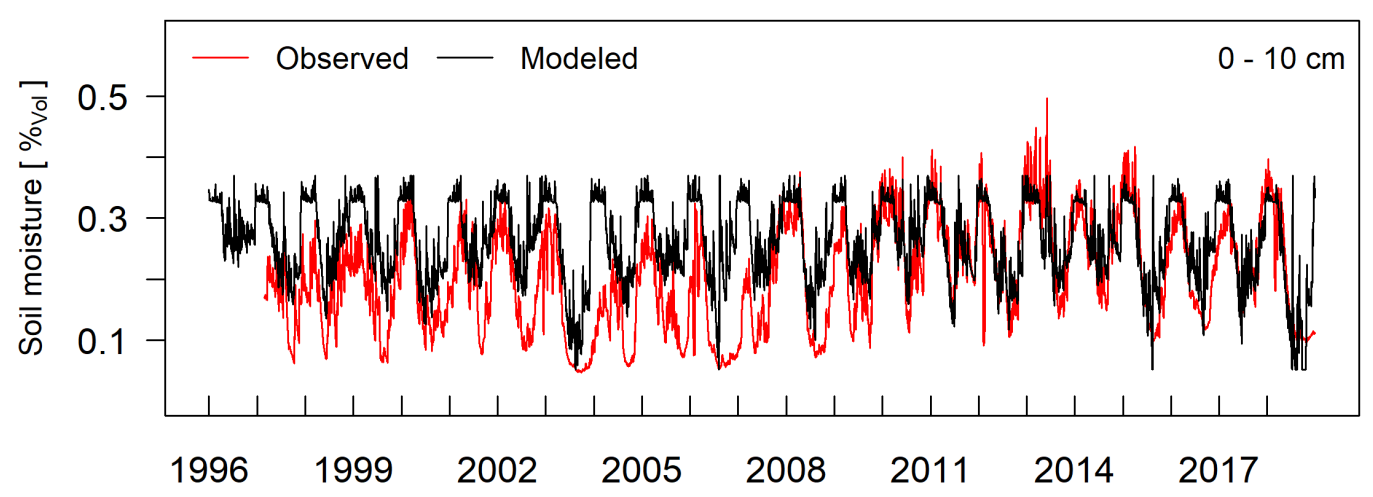

Figure 4.7: The observed and modelled soil moisture data for top layer at DE-Tha site. The site reported the data only for top layer.

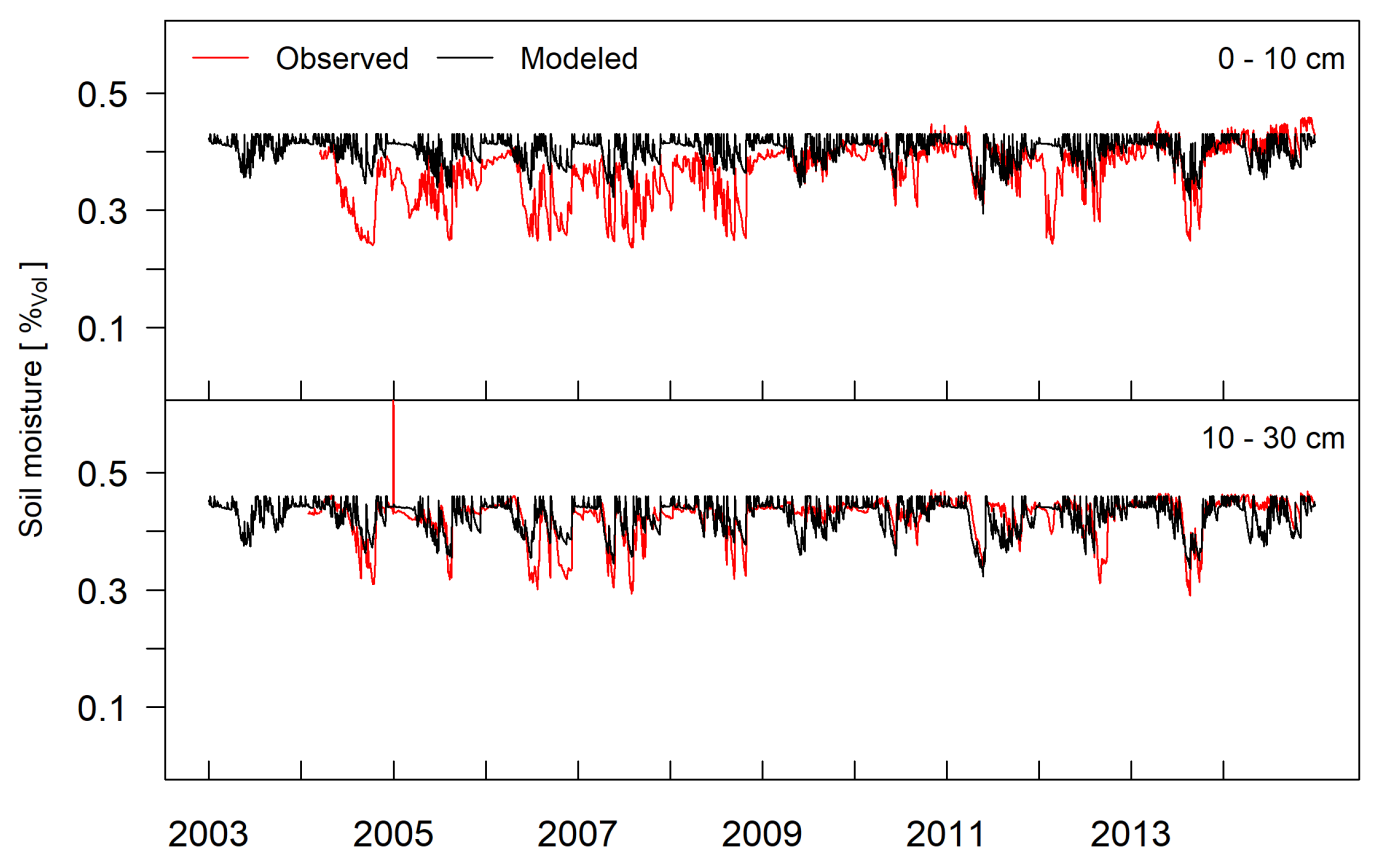

Figure 4.8: The observed and modelled soil moisture data for two layers at IT-Lav site. 


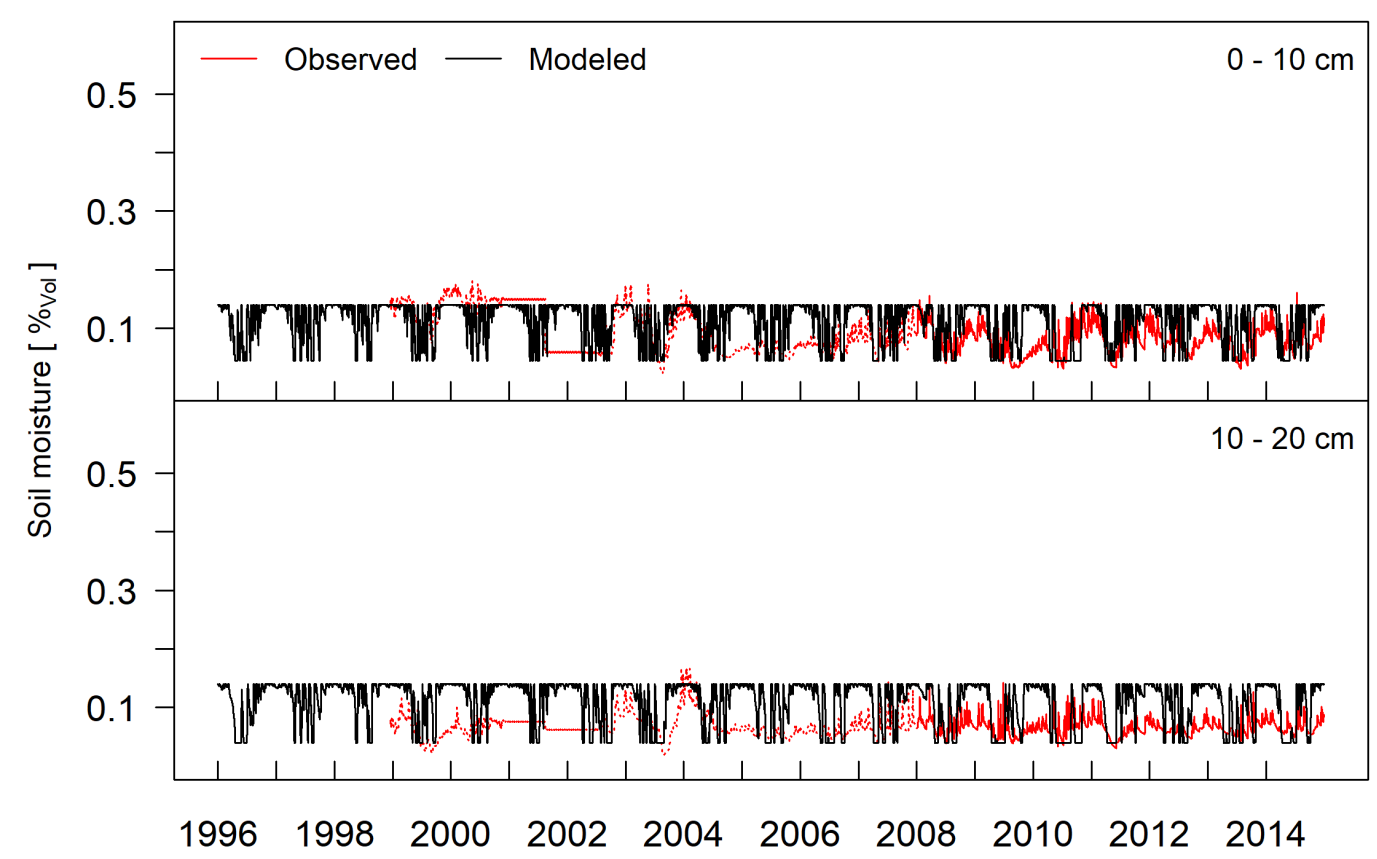

Figure 4.9: The observed and modelled soil moisture data for two layers at NL-Loo site. The values are unrealistic for some periods for this site (for example the values from mid 2000 to end of 2002 .

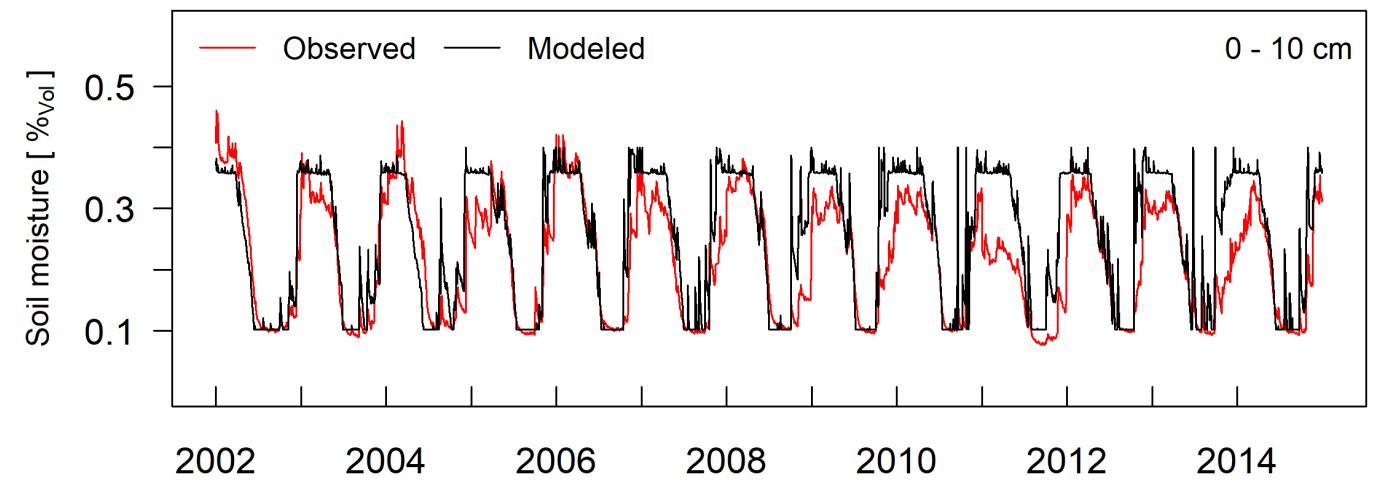

Figure 4.10: The observed and modelled soil moisture data US-Me2 site. 


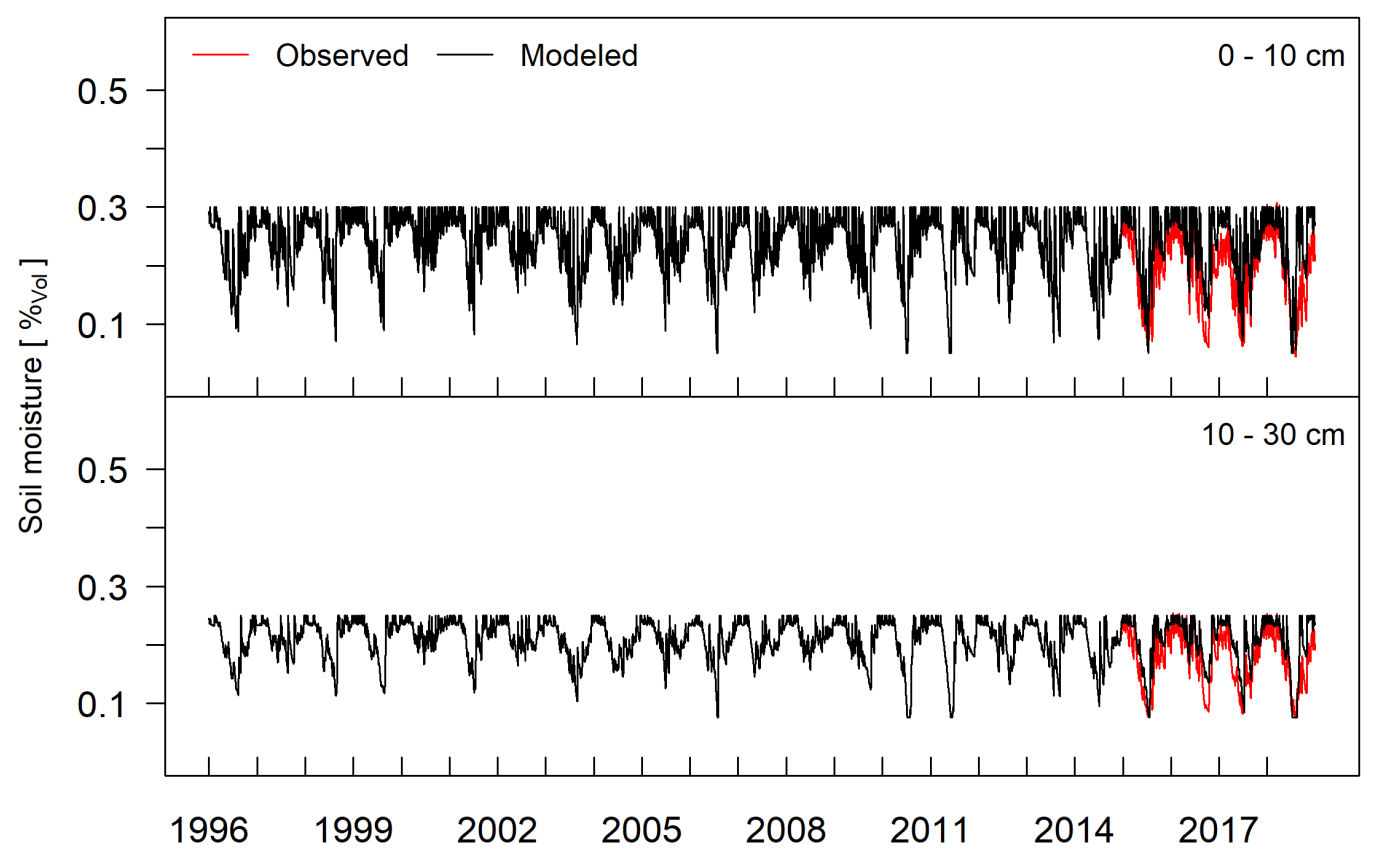

Figure 4.11: The observed and modelled soil moisture data for two layers at BE-Bra site. The measurement data were available only from 2015. 


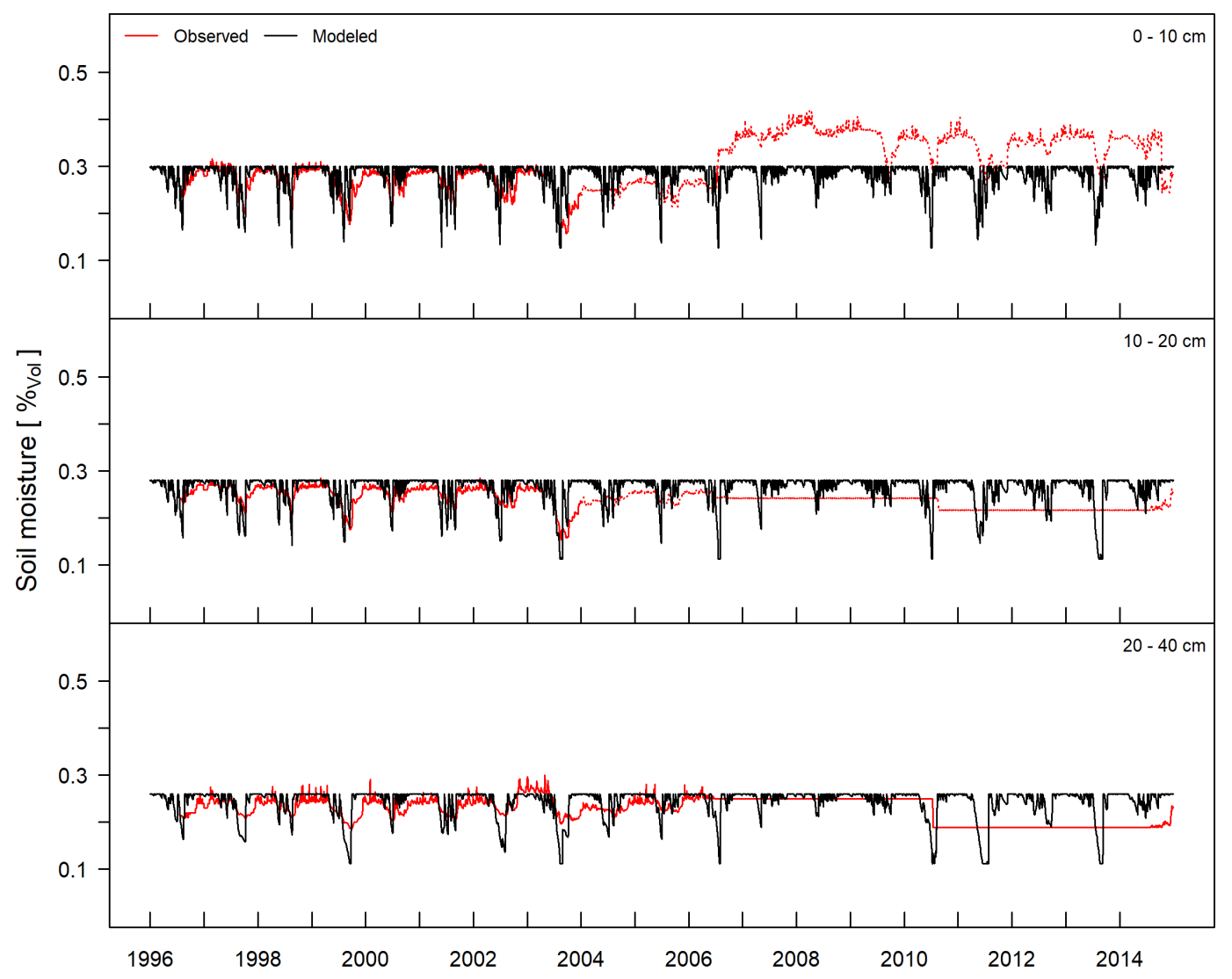

Figure 4.12: The observed and modelled soil moisture data for three layers at BE-Vie site. The reported data were unrealistic for this site from 2006 to 2014. 


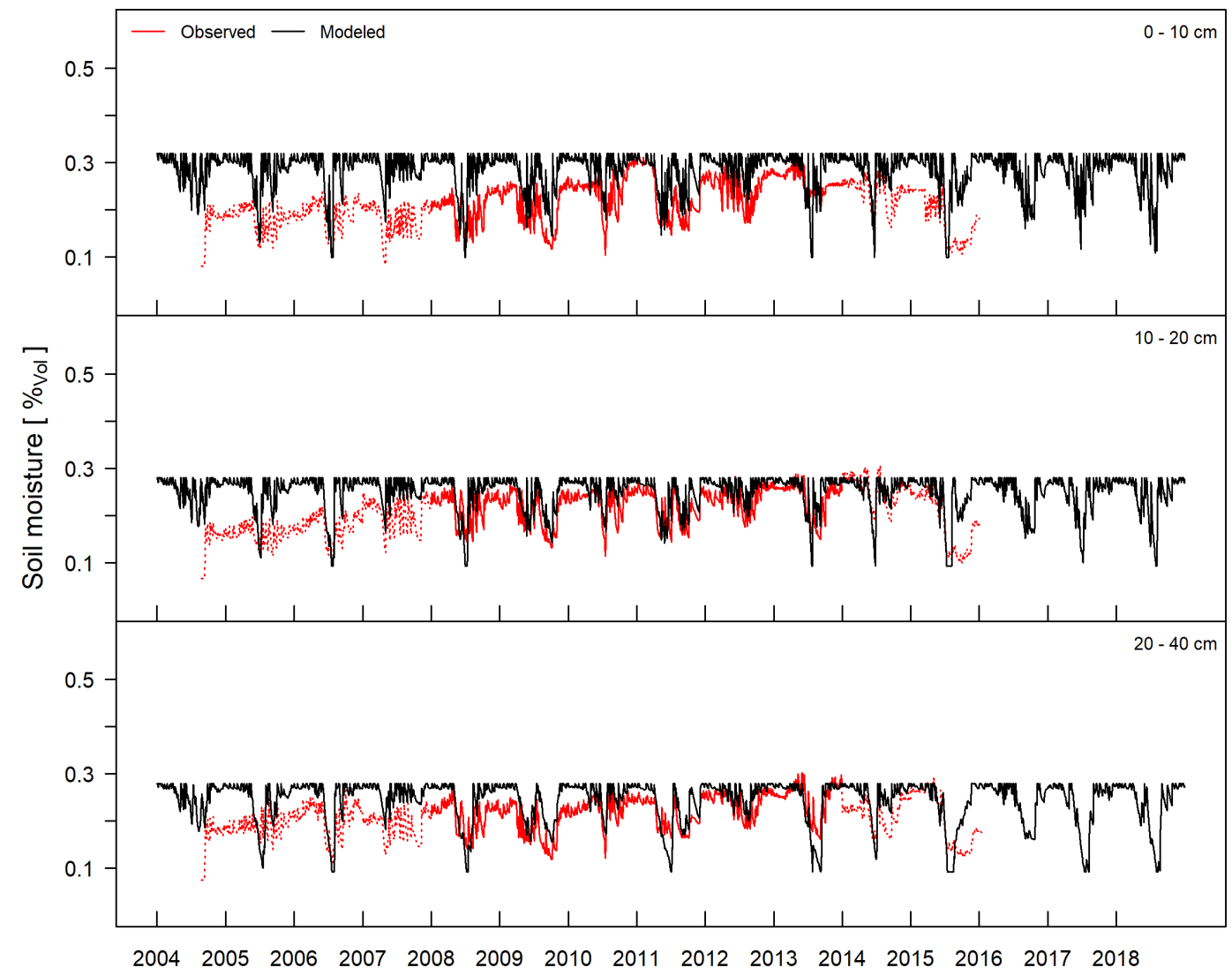

Figure 4.13: The observed and modelled soil moisture data for three layers at CH-Lae site.

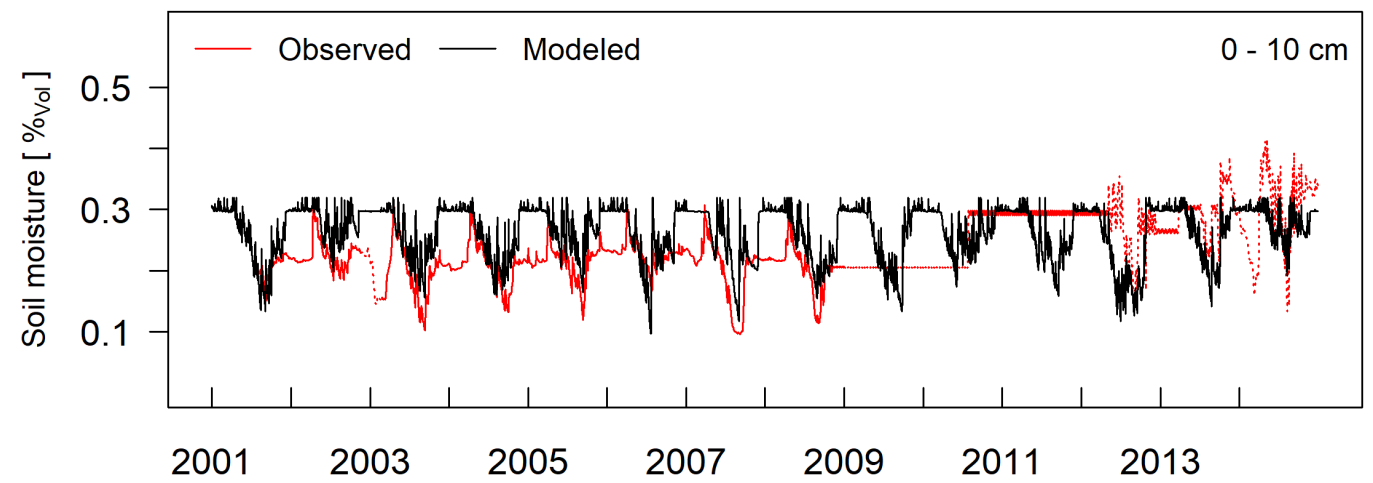

Figure 4.14: The observed and modelled soil moisture data for a layer at US-Syv site. 


\subsubsection{Model Parameter correlation}

Table 4.9: Model parameter correlation

\begin{tabular}{lllll}
\hline DBF & & & & \\
\hline & RDb & CSC & ER & gamma \\
\hline RDb & 1.00 & 0.06 & -0.02 & -0.25 \\
CSC & 0.06 & 1.00 & -0.73 & -0.01 \\
ER & -0.02 & -0.73 & 1.00 & -0.00 \\
gamma & -0.25 & -0.01 & -0.00 & 1.00 \\
\hline MF & & & & \\
\hline RDb & 1.00 & 0.07 & -0.10 & -0.72 \\
CSC & 0.07 & 1.00 & -0.65 & -0.02 \\
ER & -0.10 & -0.65 & 1.00 & 0.05 \\
gamma & -0.72 & -0.02 & 0.05 & 1.00 \\
\hline ENF & & & & \\
\hline RDb & 1.00 & -0.01 & -0.04 & -0.69 \\
CSC & -0.01 & 1.00 & -0.66 & -0.07 \\
ER & -0.04 & -0.66 & 1.00 & -0.01 \\
gamma & -0.69 & -0.07 & -0.10 & 1.00 \\
\hline
\end{tabular}


4.6.3 Using Priestley Taylor formulation of evapotranspiration

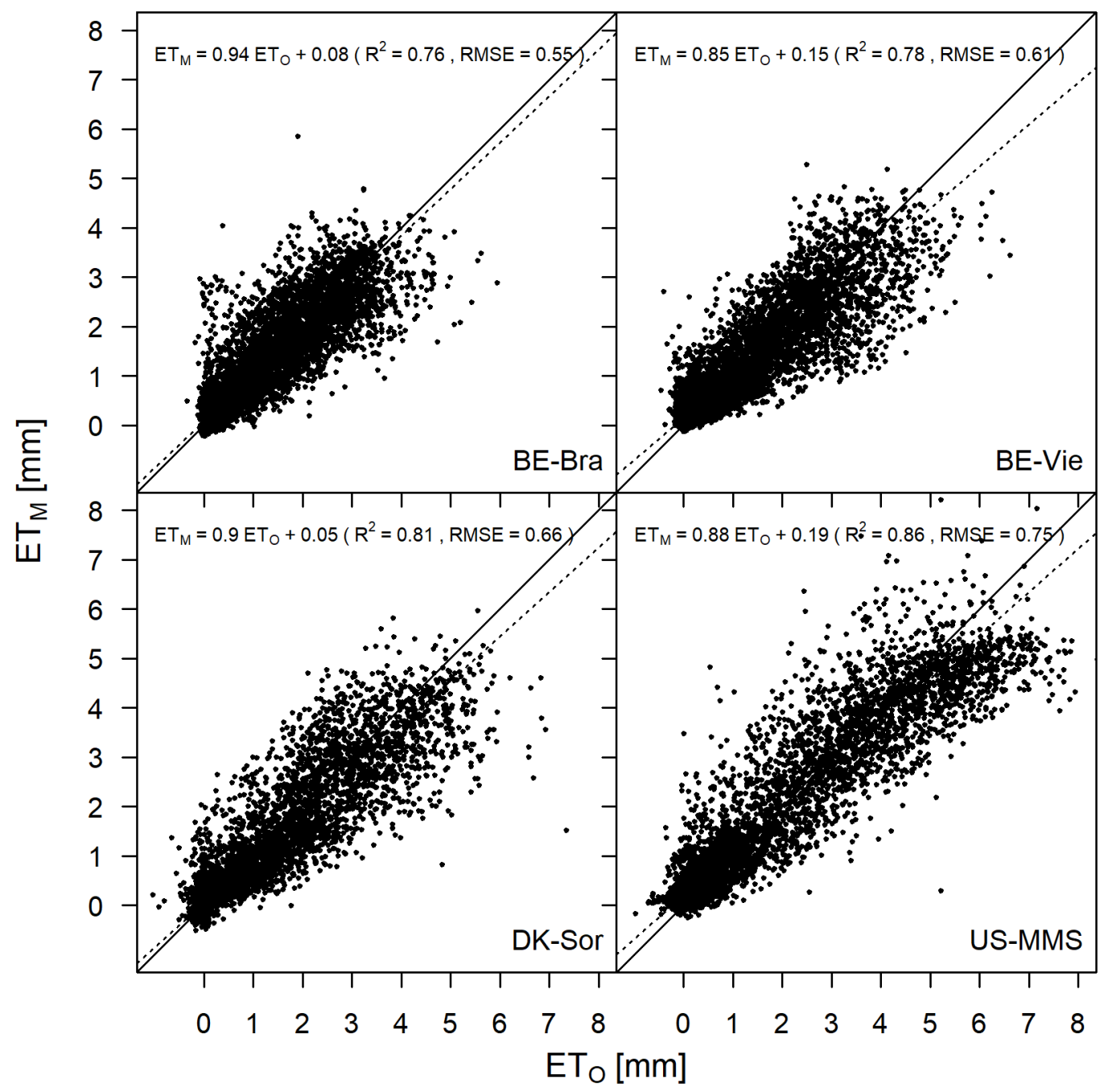

Figure 4.15: Modelled evapotranspiration $\left(\mathrm{ET}_{\mathrm{M}}\right)$ versus observed evapotranspiration $\left(\mathrm{ET}_{\mathrm{O}}\right)$ for randomly selected four sites using Priestley Taylor formulation of evapotranspiration. The solid line represent 1:1 line and the dotted line represent the linear regresssion line between $\mathrm{ET}_{\mathrm{M}}$ and $\mathrm{ET}_{\mathrm{O}}$. 
4.6.4 Evapotranspiration component for DE-Hai from BILJOU model

Table 4.10: Average evapotranspiration components namely transpiration (TR), interception (IN) and soil evaporation (Esoil) from BILJOU for 2003 - 2018.

\begin{tabular}{rrrrr}
\hline $\begin{array}{r}\text { Site } \\
(-)\end{array}$ & $\begin{array}{r}\text { Year } \\
(-)\end{array}$ & $\begin{array}{r}\text { TR } \\
(\mathrm{mm})\end{array}$ & $\begin{array}{r}\text { IN } \\
(\mathrm{mm})\end{array}$ & $\begin{array}{r}\text { Esoil } \\
(\mathrm{mm})\end{array}$ \\
\hline DE-Hai & 2003 & 370 & 78 & 35 \\
DE-Hai & 2004 & 313 & 111 & 36 \\
DE-Hai & 2005 & 330 & 104 & 42 \\
DE-Hai & 2006 & 355 & 102 & 34 \\
DE-Hai & 2007 & 310 & 119 & 45 \\
DE-Hai & 2008 & 330 & 95 & 33 \\
DE-Hai & 2009 & 298 & 120 & 43 \\
DE-Hai & 2010 & 352 & 102 & 37 \\
DE-Hai & 2011 & 374 & 101 & 42 \\
DE-Hai & 2012 & 374 & 112 & 35 \\
DE-Hai & 2013 & 346 & 106 & 36 \\
DE-Hai & 2014 & 300 & 122 & 39 \\
DE-Hai & 2015 & 355 & 94 & 39 \\
DE-Hai & 2016 & 370 & 84 & 38 \\
DE-Hai & 2017 & 291 & 55 & 32 \\
DE-Hai & 2018 & 343 & 59 & 37 \\
\hline
\end{tabular}


4.6.5 Variation of texture in DE-Hai

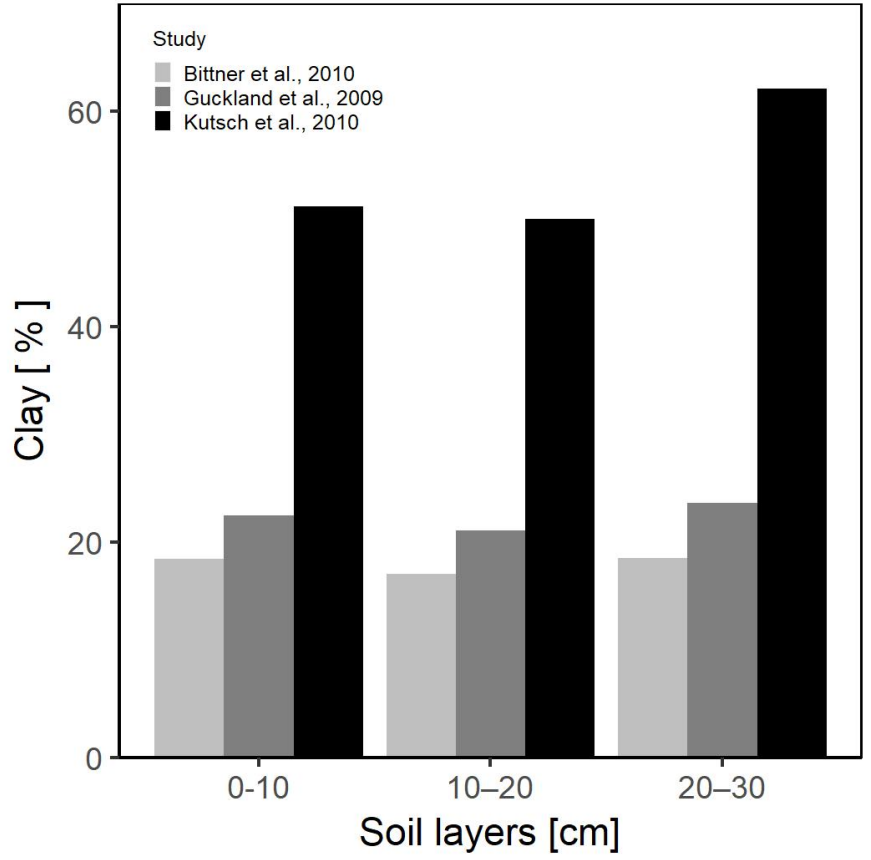

Figure 4.16: Soil clay data for DE-Hai from three different studies (BITTNER et al., 2010; GuCKLAND et al., 2009; Kutsch et al., 2010). The results from KuTsch et al. (2010) is different from other two studies. 
CHAPTER 5

Synopsis 
Climate change poses a threat to many forest ecosystems (SEIDL et al., 2017; STEvensRumann et al., 2018). Warmer and drier conditions may increase fire, drought and insect disturbances, while warmer and wetter conditions may intensify disturbances from wind and pathogens (SEIDL et al., 2017). It has been suggested (FELTON et al., 2016; Hardiman et al., 2011; Puettmann et al., 2015; Pukkala, 2016; Yousefpour et al., 2016) that creating heterogeneous forest stand structures through different management approaches can enhance forest stability, adaptability and resilience. Forest structure can be diversified either by mixing different tree species and/or increasing horizontal and vertical heterogeneity. It is important to understand how such changes in forest structure might impact forest ecosystem functions during both normal and stressful conditions. Many studies have focused on the effect of tree species diversity on forest stand productivity (JACTEL et al., 2018; LiAng et al., 2016; Pretzsch et al., 2015; ZHANG et al., 2012, etc), ecosystem services (tree biomass production, soil carbon storage, berry production and game production potential - GAMFELDT et al., 2013; RUIZ-BENITO et al., 2014), and forest resistance to natural disturbances (GROSSIORD et al., 2014c; JaCtel et al., 2017; JaCtel et al., 2007; Lebourgeois et al., 2013; Merlin et al., 2015; Silva Pedro et al., 2015, etc). Few studies, however, have examined the effect of other forest structural characteristics such as stem size heterogeneity, crown structure, age-related diversity, tree height diversity, etc. Some of the studies that have looked at the effect of forest structural characteristics (other than tree species diversity) on different ecosystem functions (e.g. timber volume, timber volume growth, basal area increment, above-ground carbon storage, etc) are listed in Table 1.1. Apart from a study by MusAvi et al. (2017), none of the studies used widely available eddy covariance tower data from Fluxnet (https://fluxnet.fluxdata.org/data/fluxnet2015-dataset/). Of all of these studies, only two have looked at the implication of structural attribute on ecosystem functions during drought (BELLO et al., 2019b; MERLiN et al., 2015).

We took the opportunity to capitalise on the data available from fluxnet and amalgamate these with forest inventory data. With this rich dataset, we aimed to understand how forest structure influences annual and seasonal carbon dioxide fluxes, temporal variability of carbon dioxide fluxes and resistance of carbon dioxide fluxes during drought. This thesis attempts to fulfill these objectives through three major scientific studies and two co-authored papers. The first study (TAMRAKAR et al., 2018) investigates the abiotic and biotic factors controlling annual and seasonal carbon dioxide fluxes of two forests in Germany that are structurally different due to differing management regimes. This chapter builds on the first co-author chapter (HERBST et al., 2015) where we compared the annual carbon dioxide and water fluxes between these forests and discussed the limitations of the methods. The second study (chapter 3) examined the effect of structure on the temporal variability of ecosystem-level photosynthetic capacity and its resistance to drought across 21 Fluxnet sites. This chapter expanded the analysis of the second co-author paper (MUSAVI et al., 2017) - which focused on the temporal variability of ecosystem-level photosynthetic capacity but used only species number, tree height, and age - by including basal area, management, DBH, DBH variation (Shannon size index and Simpson size index) and evenness. The third study (chapter 4) was developed in response to the need to derive a consistent soil moisture dataset in order to examine the effect of drought on forest $\mathrm{CO}_{2}$ 
fluxes at shorter timescales (i.e. at a daily scale in our case). We have presented a robust and flexible new soil water model, which we believe has a high potential to be used in further research.

In the following sections, we will discuss the major outcome of the objectives listed in section 1.5 with its limitations and wider implications.

\subsection{Higher average long-term net ecosystem productivity (NEP) in a structurally homogeneous forest.}

Our results suggest that managed forests with homogenous structure with single species (Fagus sylvatica) have a significantly higher mean annual NEP than the unmanaged heterogenous forests (TAMRAKAR et al., 2018). This is in contrast to the assumption that forest with complex stand structure and/or higher tree species diversity are more productive (DĂNEscu et al., 2016; HARdiman et al., 2011; JACtel et al., 2018; LiAng et al., 2016; PRETZSCH et al., 2015; ZhANG et al., 2012) and in particular, that mixing complementary tree species improves productivity (Pretzsch et al., 2015; Pretzsch et al., 2010). The effect of tree species biodiversity on productivity, however, varies spatially (JUCKER et al., 2014; LIANG et al., 2016; RATCLIFFE et al., 2016) and depends on environmental conditions (JuCKER et al., 2016; RATCLIFFE et al., 2017). The forests in our case are located very close to each other with similar environmental conditions (Figure 2.2). The difference in NEP was not significant with a shorter dataset of 7 years (HERBST et al., 2015) but differed when we included 4 more years of data. The heterogeneous forest, an old-growth forest, is unmanaged (MUND et al., 2010) whereas thinning activities have been carried out in the homogeneous forest (TAMRAKAR et al., 2018). Thinning is a silvicultural operation managing inter-tree competition to the benefit of retained trees (BoncINA et al., 2007). Thinning periods were followed by periods with a steady increase in carbon uptake, presumably due to a greater availability of resources per tree. For example, soil water availability improved in the thinned plot compared to unthinned plot enhancing the tree growth in the thinned plot (BREDA et al., 1995). Thinning, however, did not impact the carbon uptake of a Sitka spruce forest (SAUNDERS et al., 2012) and a boreal forest (VESALA et al., 2005). Both the studies looked at the impact immediately after the year of thinning. Canopy photosynthesis was reduced due to a decrease in leaf area index (LAI) but at the same time ground-vegetation photosynthesis may have increased as a result increasing light penetration to overcast situation. Soil respiration did not differ between pre and post-thinning (VESALA et al., 2005). In our study, we investigated three years after the major thinning and the final year of the study was nine years after thinning. The areas previously thinned may have been colonised by new plants improving the carbon uptake.

Differences in carbon uptake between the forests were strongly driven by higher winter respiration rates and lower spring and summer carbon uptake rates in the heterogeneous forest. The heterogeneous forest, an old-growth forest, is characterized by large amounts of standing dead trees and woody debris in the forest floor (KUTSCH et al., 2010) which may have led to the higher winter heterotrophic respiration. However, an important thing to note is that carbon uptake capacity of this heterogeneous old-growth forest was similar to other temperate deciduous forests (SHAO et al., 2014; WILKInSON et al., 2012; WiLSON et al., 2001), and it still continued to sequester carbon in line with the finding that ageing 
forests continue to accumulate carbon (LUYSSAERT et al., 2008). In addition to carbon uptake, this forest also provided the biodiversity conservation benefit associated with high plant diversity (MÖLDER et al., 2006), addressing two major of the pressing issues of our generation: biodiversity conservation and climate change (MEA, 2005). The managed forest provided greater climate-mitigation benefits but a heterogeneous forest with trees of different ages, standing and fallen dead wood and multiple species provides the additional benefit of biodiversity conservation. Achieving both the targets of biodiversity conservation and climate change mitigation harmoniously in a single forest is challenging (FERREIRA et al., 2018; Sabatini et al., 2019). Particularly in a temperate forest, attempting to pursue both biodiversity conservation and climate change mitigation goals simultaneously requires comprimise (SABATINI et al., 2019).

Management rather than tree species diversity positively affected forest productivity (TAMrakar et al., 2018). However, this result was based on two sites only, thus it might be context specific and might not be generally applicable. We suggest using more eddy covariance sites to confirm the hypothesis that the effect of management on carbon uptake is stronger than tree species diversity. Combining the results from eddy covariance measurement with biometric data will generate a more precise quantification of this result, therefore we recommend forest sites in the Fluxnet network conduct regular inventories and record details of the management (e.g. thinning) for future research activities.

\subsection{Lower interannual variability of net ecosystem productivity (NEP) in a heterogeneous forest.}

In addition to comparing average values of ecosystem functions of forest (section 5.1), stability of the ecosystem function over the period of time (IvEs et al., 2007) is important. We have used the interannual variability, specifically the ratio of standard deviation and mean of ecosystem function (i.e. the coefficient of variation of NEP), as a measure of ecosystem stability (TILMAN, 1999). Our study suggests that the NEP of heterogeneous forests is more stable than that of homogeneous forests (TAMrAKAR et al., 2018). An ecosystem is considered to be stable when it is able to preserve its functioning and structure over time (HolLING, 1973), i.e. low interannual variability of ecosystem functions or, in our case, a low coefficient of variation. Mechanistically, three processes - overyielding, species asynchrony, and niche complementarity have been suggested to stabilise forest ecosystem functions in mixed forests (JUCKER et al., 2014; Río et al., 2017). Overyielding (i.e. higher productivity but similar standard deviation among the compared sites, Río et al., 2017; Tilman, 1999) was not the cause of the higher stability in the heterogeneous forest because the heterogeneous forest had lower productivity compared to the homogeneous forest (section 5.1). We did not observe asynchrony in species responses to environmental fluctuation in our sites but to masting. The higher standard deviation of NEP of homogeneous forest, caused by the time-related growth and the masting, increased the coefficient of variation. As a result of the similar size and age of the trees in the homogenous forest, all the trees had the same and simultaneous reaction during masting whereas in the case of the heterogeneous forest, not all trees (not even all beech trees because of their young age) showed masting (HERBST et al., 2015). That is the structural synchrony or lack of structural heterogeneity in the homogeneous forest led all the trees of the forests to react 
similarly when masting.

\subsection{Lower interannual variability of ecosystem-level photosynthetic capacity in unmanaged forests.}

When comparing sites from different climates, it is best to use normalized functional parameters (such as light-saturated ecosystem-level photosynthetic capacity) - which take into account variations in local environment. The interannual variation of such normalized functional parameters is thus caused by management activities, site or climatic-response characteristics. Here, we have identified the factors affecting the interannual variation of light-saturated ecosystem-level photosynthetic capacity $\left(\mathrm{CV}_{\mathrm{GPP} 1000}\right)$ in MusAVI et al. 2017 and chapter 3) using data from multiple Fluxnet sites. Forest stand age explained most of the inter-site variation of $\mathrm{CV}_{\mathrm{GPP} 1000}$ (MUSAVI et al., 2017). Forest stand age itself does not offer a mechanistic explanation for the difference in $\mathrm{CV}_{\mathrm{GPP} 1000}$. In chapter 3 we went further and calculated structural parameters using the forest inventory data. The forests with higher structural diversity (higher Simpson and Shannon size diversity index) had lower interannual variability. The forests with higher Simpson and Shannon size diversity index were also older. Structural heterogeneity typically results from management activities (Pommerening et al., 2013; Schall et al., 2018). Unmanaged forests had a lower interannual variability of $\mathrm{CV}_{\mathrm{GPP} 1000}$ but were not significantly different from the managed high forest. The managed high forests are mostly managed to resemble old-growth forests (Messier et al., 2013; Puettmann et al., 2015) and none of the managed high forests in our case had been clear cut recently. Thus, managed forests that resemble natural forests are able to dampen their physiological response to environmental conditions. In our case, one of the limitations comparing the interannual variability of an ecosystem function from different sites is the difference in dataset duration, time frame and coverage of drought events. Three sites did not experience drought at all during the data measurement period and one site experienced three drought years. Comparing the interannual variability of site with and without drought years (there was no drought during measurement period and not that site have not experienced drought) biases our reults. Thus, this analysis should be repeated again when longer time series data become available, ideally when all sites have experienced at least one drought event.

\subsection{The impact of drought on the ecosystem-level light-saturated photosynthetic capacity of forests.}

The interannual variation of ecosystem-level light saturated photosynthetic capacity $\mathrm{GPP}_{1000}$ of forests informs us about the response of forests to the interannual variation of environmental drivers and plant physiology. It does not tell us directly about the response of forests to drought events. In the face of changing climate with increasing probability of droughts (SPINONI et al., 2019), it is critical to understand the effects of droughts alongside the effects of interannual variation in other of environmental parameters.

CiAIs et al. (2005) reported a $30 \%$ reduction in GPP in Europe during the 2003 European heatwave and drought, but other studies estimated a lower reduction (VETTER et al., 2008; Von ButTlar et al., 2018). We observed a maximum of $27 \%$ reduction of $\mathrm{GPP}_{1000}$ in Mediterranean forests and much less in other forests (Chapter 3). The two 
Mediterranean forests in our study are coppice forests. The repeated vegetative propagation in coppice forests may cause genetic stagnation reducing the adaptive capacity to the climate change(Marko Stojanović, 2017). Another interesting point to note is that $\mathrm{GPP}_{1000}$ of managed high forests were not affected by droughts (Chapter 3 - Figure 3.10). In our two-site study, we found that NEP and GPP of managed forest (composed of Fagus) was less affected by 2003 drought than the unmanaged forest (mostly composed of Fraxinus and Fagus, Herbst et al., 2015). The leaf-out and leaf fall in Fraxinus occurs later than in Fagus. The drought in 2003 occurred in later summer affecting the GPP of Fraxinus which alone still had leaves. The managed forest is thinned regularly, the thining can reduce the transpiration and increase the water availability during droughts (SoHn et al., 2013; SoHN et al., 2016). One of the strategies to improve the resistance of forest to drought could be to plant the appropriate mix of trees (for example mixing beech, spruce and oak in Central Europe, Pretzsch et al. 2013 and manage (thin) them.

Three of the sites did not experience any drought events during the period analyzed and 14 sites experienced only one drought. European sites experienced strong droughts in 2018 (BurAs et al., 2019) and 2019, years that were not part of this analysis. Adding data for these years may improve our understanding of the impact of droughts on forests.

In some cases, the effect of drought was not captured at the annual scale because of compensation by higher productivity in non-drought periods within a year. For example in DE-Lnf during the 2003 drought, higher net ecosystem productivity was observed in the warm spring and summer, compensating the reduction of net ecosystem productivity in the late growing season period (HERBST et al., 2015). We lose important information by only conducting analysis using annual ecosystem productivity or annual tree ring data. The Fluxnet data allows us to conduct analysis down to half-hourly timescales. A full understanding of the effects of droughts on ecosystem productivity requires analysis at with at multiple timescales.

We limited ourselves to look at direct effects of the droughts on $\mathrm{GPP}_{1000}$, i.e. the response of $\mathrm{GPP}_{1000}$ during drought years. Any lagged effects of the droughts (BRÉDA et al., 2006; Thabeet et al., 2009; Vennetier et al., 2007) were not captured in our study. A further analysis would include looking at tree mortality or insect infestation in the years following drought in order to identify any carryover effect of previous droughts.

\subsection{Development of an open-source soil water model.}

The development of an open-source, flexible, forest soil water model-FSWM in R offers a new freely available tool to estimate soil water dynamics in forest soils. Open-source models help in improving the chances of collaboration among scientists, increasing productivity through collaborative burden-sharing, and making them available for public scrunity (Pfenninger et al., 2017).

The model can be applied to a range of forest soils and offers flexibility to simulate different numbers of soil layers, and is thus adaptable to the available soil data. The model performance varied across forest types, being best in deciduous broad-leaved forests and less good in needle-leaved forests. We noted sometimes significant deviations between modelled and measured data, and we suggest that this is not always because the model predictins are poor, but that sometimes the practical difficulties of measureing soil moisture 
are significant. We suggest regular and spatially comprehensive monitoring of soil moisture.

\subsection{Outlook}

This thesis has resulted in a useful database of structural stand parameters not currently included in the Fluxnet database, and a practical approach to quantify the effect of forest structure on ecosystem function during droughts. Significant questions are raised in this thesis and should be addressed in future research.

- Extending the structural indices database: As a large repository of data, the Fluxnet database provides a unique opportunity for exploring and understanding numerous different ecosystems. Currently, data for many ecosystem fluxes (carbon dioxide, water and heat fluxes) and meteorology are available in the Fluxnet database with some general site characteristics and biological data. However typical forest inventory data e.g. on DBH distribution is not included. Forest inventory data can be integrated with Fluxnet data to further understand these ecosystems. In the case of forestry, inventory of stands has been an important tool to understand forest dynamics. In our work, we have combined the inventory data and ecosystem fluxes and calculated numerous structural indices. This work can be extended to more sites creating an increasingly useful dataset for understanding the effect of forest structure on forest ecosystem processes.

- The use of the forest soil water model (FWSM). Here, we looked at the effect of forest structure on the annual responses of forests to climate variation and drought. The effect of drought is often not detectable at annual scales, therefore, it is important to assess the effects on shorter timescales. The FWSM is able to simulate soil moisture at daily time scales, yet it can also easily be used for multiple sites and years. This provides a unique tool to understand soil moisture dynamics within and between years and during droughts. Additionally, FWSM is open-source and can also be used and improved by other scientists.

- Extending the analysis with more data: Our findings, particularly those on the effect of forest structure on ecosystem functioning during drought, are inconclusive. To reach more robust results, the analysis should be extended with more sites that include forest structural indices. Increasing the number of sites will increase the statistical power and confidence in the results. The summer of 2018 was unusually dry in Europe (Buras et al., 2019). Including the data from this year might provide more insight into the modulation of drought effects by forest structure.

- Looking at the response of other forest functions: The Fluxnet database offers a unique opportunity tfor studying forest functions beyond those analysed in this thesis, e.g. water use efficiency (WUE) and microclimate. WUE is the rate of carbon uptake per unit water loss (KEENAN et al., 2013), and is affected by tree size and stand density (FORRESTER, 2015). More research can be done on how the WUE is modified by forest structure. Another research direction involves looking for vegetation effects on local climate. For example TANG et al. (2018) reported that forests generally cool the land surface and lower air temperatures. By assessing this, 
we could investigate if differences in land surface temperatures (also during droughts) vary across forests of varying structural complexity.

Finally, we conclude that this thesis presents a complete analysis of the available data, focusing on understanding the effect of forest structure on ecosystem functions. Next to our results and conclusions, the new model tool and dataset provide significant support for further investigations into the role of forest structure in modifying ecosystem function during drought. 


\section{A Difference in carbon uptake and water use between a managed and an unmanaged beech forest in central Germany}

Authors: Mathias Herbst, Martina Mund, Rijan Tamrakar, Alexander Knohl Published in 'Forest ecology and management' (HerBST et al., 2015)

http://dx.doi.org/10.1016/j.foreco.2015.05.034

I supported in the preparation, analysis and discussions of figures A.2 and A.4 (section A.5.2). Further, I read and reviewed the manuscript. 


\section{A.1 Abstract}

Net atmospheric carbon dioxide exchange, total evapotranspiration and net primary production of two neighbouring beech (Fagus sylvatica L.)forests in central Germany differing in site management were measured using the eddy covariance technique and biometric methods. The unmanaged site was an old-growth forest with admixtures of ash (Fraxinus excelsior L.) and sycamore (Acer pseudoplatanus $L$.) trees whereas the managed site was a regularly thinned, even-aged (about 130 years old), pure beech stand. Average carbon fluxes measured over seven years did not differ significantly between the two forests. Evapotranspiration was slightly higher (and consequently water use efficiency lower) at the unmanaged site. The maximum rates as well as the interannual variability of both net ecosystem exchange and net primary production were considerably larger at the managed, even-aged stand. The lowest annual carbon sequestration rates were observed in years with high fruit production in beech combined with cold and dry spells during leaf development which affected the carbon balance of the managed forest more than that of the unmanaged forest. In contrast, an extraordinarily dry period in late summer 2003 caused a stronger reduction in net carbon uptake in the old-growth forest which can probably be attributed to the contribution of ash to the ecosystem fluxes. Ash has a different phenology which madeit more susceptible to the late summer drought. The relative importance of tree and structural (age, size) diversity, leaf area index and regenerative growth as well as the temporal frame and extent of single weather extremes for the forest-atmosphere exchange is discussed and it is concluded that site management and forest structure needs to be included in soil-vegetation-atmosphere-transfer models as it can often override effects of land use or plant functional type.

\section{A.2 Introduction}

Changes in land cover and their biophysical and biogeochemical effects have been investigated much more thoroughly so far than differences in land management within a single land cover type (LUYSSAERT, 2014). Forest management can alter species and structural diversity as well as ecophysiological traits. Their influence on the carbon cycle and the water use efficiency of forest ecosystems and their interannual variability are as yet not well understood. This hampers any robust assessment of the impact of management practices on the greenhouse gas balance. Many recent studies about the effect of land cover type on the ecosystem carbon budget and the water use efficiency are based on the increasing number of canopy gas exchange measurements by means of the eddy covariance technique (KeEnAn et al., 2013; LuyssaerT et al., 2007). However, it has also been noted that a large variability in gas exchange is caused by species-specific traits within one land use type (GroenENDIJK et al., 2011; LAw, 2014) which can make it difficult to transfer general trends to specific sites. Inhomogeneous instrumentation and data analysis often amplifies the problem.

Therefore we present a case study of paired measurements of ecosystem carbon and water fluxes in two neighbouring forests that are characterised by the same site conditions and are dominated by European beech (Fagus sylvatica), and where identical instrumentation and data analysis were used, to investigate the effect of structural diversity and the admixture 
of other tree species, caused by different historical and recent forest management, on canopy gas exchange. In terms of recent trends in forest management, beech is considered as "pillar of close-to-nature forestry in the central European lowland" (PRETZSCH, 2014). Understanding its responses to natural and anthropogenic changes and disturbances is thus of high relevance and significance. With this study, which combines eddy covariance measurements with more traditional biometric methods to assess the forests' primary production, we try to test the following two hypotheses:

(1) Forest management in terms of establishing and maintaining an even-aged, monospecific stand improves the carbon gain and the water use efficiency compared to an unmanaged forest. (2) Structural diversity as encountered in the unmanaged forest decreases the interannual variability of growth and water use as well as the susceptibility to disturbances.

\section{A.3 Material and methods}

\section{A.3.1 Sites}

The two forests sites are located in Thuringia in centralGermany, ca. $30 \mathrm{~km}$ apart from each other. Both stands grow at an altitude of $450 \mathrm{~m}$ a.s.l. and face similar soil conditions (Triassic limestone covered with variable Pleistocene loess deposits) and climatic conditions (suboceanic-submontane climate with long-term means of about $8{ }^{\circ} \mathrm{C}$ for annual air temperature and $750 \mathrm{~mm}$ precipitation). Annual air temperature and precipitation sums during the study period are given in Table A.1.

Table A.1: Mean annual air temperature $\left(\mathrm{t}_{\mathrm{a}}\right)$ and annual precipitation $(\mathrm{P})$ during the study period.

\begin{tabular}{lll}
\hline Year & $\mathrm{t}_{\mathrm{a}}\left({ }^{\circ} \mathrm{C}\right)$ & $\mathrm{P}(\mathrm{mm})$ \\
\hline 2003 & 8.50 & 544 \\
2004 & 7.83 & 763 \\
2005 & 8.13 & 736 \\
2006 & 8.66 & 660 \\
2010 & 6.71 & 756 \\
2011 & 8.85 & 544 \\
2012 & 8.27 & 701 \\
\hline
\end{tabular}

The Hainich site is an unmanaged stand in the central part of Hainich National Park. The area was never clear-cut but used as a coppice-with-standards system until the end of the 19th century and then for selective cutting by the local population until 1965. From 1965 to 1997 it was part of a military training area and only single, very valuable trees were cut. Since December 1997 no management activities at all have taken place. Regarding to its highly diverse horizontal and vertical structure the forest can be characterised as an old-growth forest with tree ages varying between 0 and 250 years (Figure A.1, KNOHL et al., 2003; Mund, 2004). Beech (F. sylvatica L.) is the dominating tree species, accounting for ca. $64 \%$ of tree biomass, and ash (Fraxinus excelsior L.) and sycamore (Acer pseudoplatanus L.) make up most of the remaining biomass with a share of $28 \%$ and $7 \%$, respectively (Table A.2). Single trees of Carpinus betulus (L.), Ulmus glabra (L.), Acer platanoides (L.) and A. campestre (L.) are admixed as remnants of the historical forest management regime (Mund et al., 2010). 

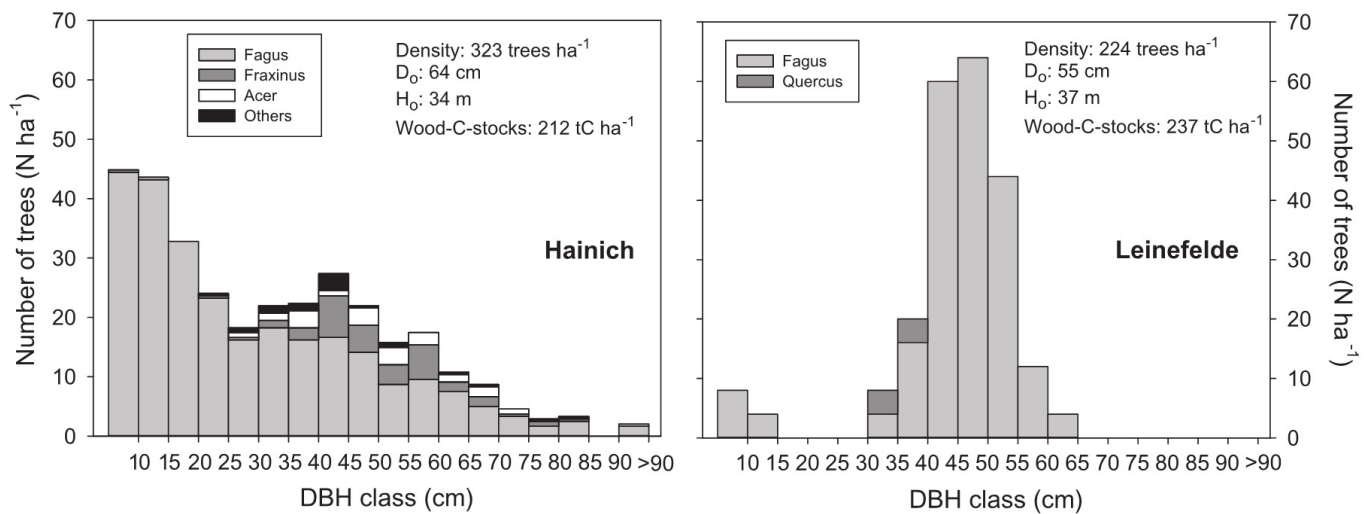

Figure A.1: Frequency distribution of stem diameter (DBH, diameter at breast height) and key stand characteristics of the study sites Hainich and Leinefelde. Do: quadratic mean of $\mathrm{DBH}$ of the $20 \%$ largest trees per study plot; Ho: tree height predicted for Do (dominant stand height).

Table A.2: Some stand characteristics of the two forests.

\begin{tabular}{|c|c|c|}
\hline & Hainich (unmanaged) & Leinefelde (managed) \\
\hline Soil & $\begin{array}{l}\text { Pleistocene loess deposits with domi- } \\
\text { nance of Cambisols }\end{array}$ & $\begin{array}{l}\text { Pleistocene loess deposits with domi- } \\
\text { nance of Luvisols }\end{array}$ \\
\hline $\begin{array}{l}\text { Most abundant tree } \\
\text { species (\%biomass) }\end{array}$ & $\begin{array}{l}\text { Fagus sylvatica }(64 \%) \text { Fraxinus excelsior } \\
(28 \%) \text { Acer pseudoplatanus }(7 \%)\end{array}$ & Fagus sylvatica $(99 \%)$ \\
\hline Tree age (years) & $0-250$ & 130 \\
\hline Mean canopy height $(\mathrm{m})$ & 35 & 35 \\
\hline $\begin{array}{l}\text { Stand density (stems } \\
\mathrm{ha}^{-1} \text { ) }\end{array}$ & 323 & 224 \\
\hline Leaf area index $(-)$ & 5.1 & 4.2 \\
\hline
\end{tabular}

The Leinefelde site is an even-aged, pure beech stand managed as a shelterwood system for maximum wood production. Thinning was carried out regularly every 10-20 years (ANTHONi et al., 2004). The measurement site consists of a 130 year-old stand which is surrounded by other even-aged beech stands. The site at Leinefelde is characterised by a slightly thicker loess cover, associated with a dominance of Luvisols, than the Hainich site where Cambisols are the dominant soil type (Mund, 2004). The herbaceous ground vegetation differs in species composition between the two forests (ANTHONI et al., 2004).

The maximum annual effective leaf area index as measured with an LAI-2000 plant canopy analyser (LI-COR Inc., Lincoln, NE, USA) was on average 5.1 at the unmanaged site and 4.2 at the managed site (Table A.2). The latter had a lower stand density (224 $\mathrm{m}^{-2}$ vs. $323 \mathrm{~m}^{-2}$ ) but a higher wood biomass (above- and belowground; $237 \mathrm{t} \mathrm{C} \mathrm{ha-1}$ vs. $212 \mathrm{t} \mathrm{C} \mathrm{ha}^{-1}$ ). The leaf area was concentrated more towards the canopy top than it was the case at the unmanaged site. The maximum canopy height as determined by visual inspection from the respective tower was about $35 \mathrm{~m}$ at both sites. 


\section{A.3.2 Eddy covariance data}

The eddy covariance measurements at the two sites were carried out at $44 \mathrm{~m}$ above the ground with identical instrumentation and data acquisition techniques. Each measurement system consisted of a three-dimensional sonic anemometer (Solent R3, Gill Instruments Ltd., Lymington, UK) and a closed-path $\mathrm{CO}_{2} / \mathrm{H}_{2} \mathrm{O}$ infrared gas analyser (LI-6262, LI-COR Inc., Lincoln, NE, USA) placed at the bottom of the instrument tower and connected to the gas inlet close to the anemometer by a $50 \mathrm{~m}$ long tube. Technical details about the installation can be found in KNOHL et al. (2003). Data were synchronised and stored on a field computer using the "EddySoft" data acquisition software by O. Kolle (Max-PlanckInstitute for Biogeochemistry, Jena, Germany). The turbulent fluxes were recalculated in 2013 with version 4.1 of the "EddyPro" software (LI-COR Inc., Lincoln, NE, USA).

The data collection and quality control followed the methodology of AUBINET et al. (2000) and FoKEN et al. (2004). The gap filling and the partitioning of the net ecosystem CO2 exchange (NEE) into gross primary production (GPP) and ecosystem respiration (Reco) was carried out using the 'Fluxnet' online-tool based on REICHSTEIN et al. (2005). Evapotranspiration was calculated as the residual of net radiation and sensible heat flux (GASH et al., 1999) in terms of the annual totals. Direct eddy covariance measurements of ET based on the water vapour concentrations recorded by the LI-6262 were rejected because of a large underestimation of the flux caused by attenuation of the water vapour fluctuations in the long tubing. For details about standard meteorological variables recorded at the sites we refer once again to earlier descriptions of the two measurements stations (Anthoni et al., 2004; Knohl et al., 2003). Due to a lack of funding, no flux data could be obtained at the managed site from 2007 to 2009.

\section{A.3.3 Biometric data}

The estimates for annual wood NPP of the study sites resulted from continuous measurements of stem diameter at breast height (1.3 m above ground level) in combination with stand inventories. At the tree scale stem diameter increment was measured with dendrometers distributed over different diameter size classes and at Hainich also over different tree species. At the homogenous stand Leinefelde up to 22 trees were equipped with a dendrometer and at the unmanaged stand Hainich up to 96 trees. The exact number of measurement trees in each year of the study period varied because of damages to single dendrometers, and at Hainich also because of the natural dieback of individual trees that had to be replaced with new trees. For 2003 and 2004 also data from stem increment cores taken at the Hainich site were available (KAHL et al., 2012, M. Bryukhanova, Institute of Forest SB RAS, Akademgorodok, Krasnoyarsk, Russia, unpublished) and included in this study.

To scale up stem growth from the tree level to the stand level site- and species-specific regression functions describing the annual relationship between initial basal area (crosssectional area of a stem at breast height) and basal area increment were developed and applied to stand inventories of the study sites. The extent of the stand inventories represent the different stand structure of the study sites. At the homogenous, pure beech stand Leinefelde stem diameter and tree height of all trees $\mathrm{P} 7 \mathrm{~cm}$ in diameter of one plot (25 / $25 \mathrm{~m}$ ) located within the main footprint of the eddy-covariance-tower (ANTHONI et al., 
2004) was measured. At the diverse Hainich site the regression functions were applied to repeated stand inventories. The first inventory (2000) comprised 14 plots (radius of each plot: $15 \mathrm{~m}$ ) that were located along a transect within the centre of the main footprint. The second inventory included 20 additional plots distributed over the entire footprint. The distribution of these plots was based on an "importance sampling design" (ANDERSON, 1999). This means that a predefined number of locations for the plots were randomly chosen according to a probability distribution that defines the probabilities of the source areas of the carbon fluxes detected by the eddy-covariance-measurements (GöCKEDE et al., 2008; GöcKede et al., 2004; ReBmann et al., 2005). At each plot stem diameter of all trees P7 $\mathrm{cm}$ in diameter and in 2005 also tree height was measured. Above- and belowground woody biomass per tree and year were calculated via biomass regression functions (F. sylvatica: Wutzler et al. (2008); all other species: FEHRMann (2006) (aboveground woody biomass) and Wutzler et al. (2008) (coarse roots)). For the conversion of woody biomass into carbon stocks a mean carbon concentration of $50 \%$ was assumed.

The annual net primary production (NPP) of leaves, buds and fruits was derived from litter sampling within the main footprint. The samples were separated, dried and weighed. Growth, ripening and dropping of the fruits occur during one year. Thus, fruit NPP can be estimated directly from annual fruit fall, similar to leaf NPP. However, in mast years we observed a substantial premature as well as delayed dropping of beech fruits. Thus, in mast years all fruits sampled between early summer of the current year and spring of the following year were summed up to fruit NPP of the respective mast year. Mean carbon concentration of beech leaves was $48 \%$, of leaves from the other species $46 \%$, and that of fruits $54 \%$ (nuts and shells).

For the comparison between the inter-annual variability of NEP and wood NPP it is assumed that by far the largest proportion of annual NEP results from carbon accumulation in living, aboveand belowground woody biomass. This assumption is based on the following features of the study sites: (1) the natural mortality of trees was close to zero at Leinefelde and very low $(<1 \%$ vol.) at Hainich, (2) because of the low mortality rates and the lack of any major disturbances at Hainich, more or less constant rates of dead wood decomposition can be expected at the stand scale, (3) during the study period no tree harvesting occurred within the main footprint of the managed site Leinefelde, and (4) the largest proportion of carbon allocated to leaves, fine roots, fruits and the ground vegetation is respired within 1-2 years, and, except for the fruits, the inter-annual variability of their production is low compared to that of wood NPP (Mund, 2004; Mund et al., 2010). The largest source of uncertainty results from the net uptake or release of carbon by the soil. SchrumpF et al. (2014) showed that at the Hainich site and during the period 2004-2009 on average $65 \pm 29 \mathrm{~g} \mathrm{C} \mathrm{m}^{-2} \mathrm{a}^{-1}$ ) were accumulated in the soil. The accumulation rates of single years most likely differ from this mean value, but because of the high spatial heterogeneity of soil carbon stocks it is extremely difficult to detect their changes in single years (SchrumpF et al., 2011). For Leinefelde, only one soil inventory was available (Mund, 2004). Consequently, for the present study we assumed that the inter-annual variability of soil carbon accumulation can be neglected. 


\section{A.4 Results}

Over the seven year period of simultaneous eddy covariance measurements the annual net carbon exchange, i.e. net ecosystem productivity (NEP), with the atmosphere varied less from year to year at the unmanaged forest stand (standard deviation (SD) $=70$ $\left.\mathrm{g} \mathrm{C} \mathrm{m}^{-2} \mathrm{a}^{-1}\right)$ than it did at the managed site ( $\mathrm{SD}=119 \mathrm{~g} \mathrm{C} \mathrm{m}^{-2} \mathrm{a}^{-1}$; Figure A.2). The lowest annual NEP was observed in 2004 and the second lowest in 2011 in both forests. The largest net uptake occurred in 2012 at the managed site and in 2005 at the unmanaged site. Most of the interannual variation in NEP resulted from changes in GPP by up to 400 $\mathrm{g}$ carbon per square metre ground area between different years indicating a surprisingly constant ecosystem respiration $\left(\mathrm{R}_{\mathrm{e}} \mathrm{co}\right)$, which indeed varied only by less than $200 \mathrm{~g}$ carbon per square metre at both sites. The lowest Reco was calculated for 2010 which was on average the coldest year of the studied seven years (Figure A.2). The only, weak exception of the close relationship between GPP and NEP was observed at the Hainich site in 2004, where GPP was less reduced compared to the other years than NEP.

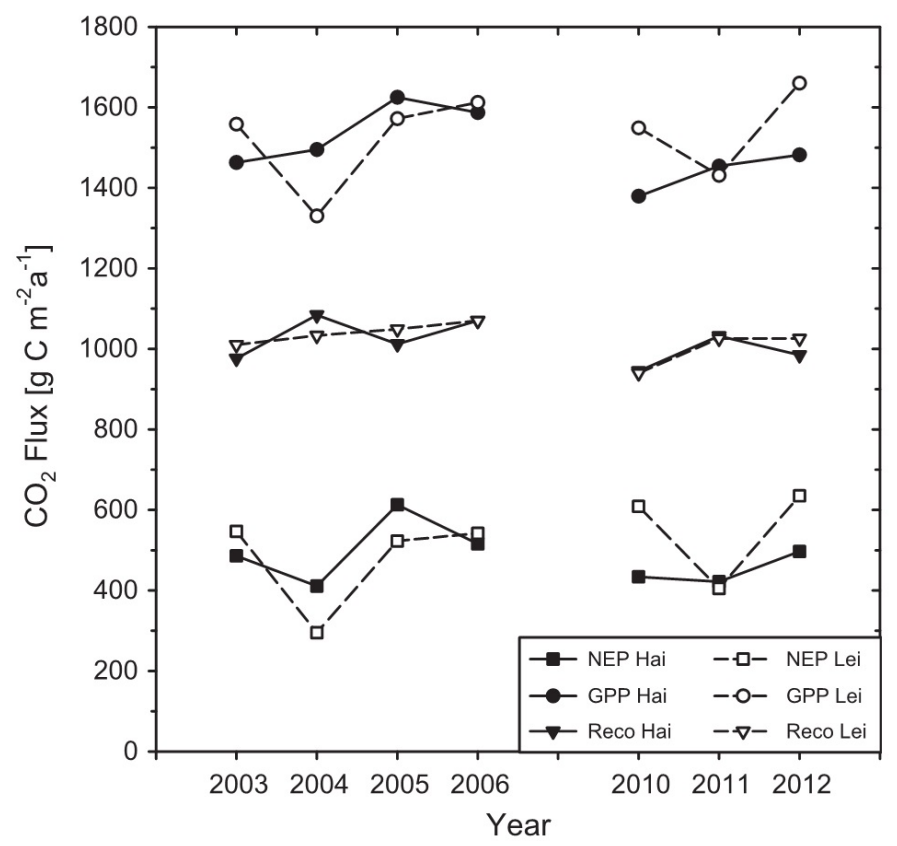

Figure A.2: Annual totals of net ecosystem production (NEP), gross primary production (GPP) and ecosystem respiration $\left(\mathrm{R}_{\mathrm{e}} \mathrm{co}\right)$ for a managed and an unmanaged beech forest over seven years.

Particularly low GPP and NEP rates were observed in 2004 and 2011 for the managed beech forest. At least in 2011 this result from the eddy covariance measurements corresponded well with the measurements of relative stem diameter increment (Figure A.3). Both 2004 and 2011, but also 2006 and 2009, were so-called masting years which were characterised by a high fruit production of the beech trees (Figure A.3). In 2004 and 2011, but not in 2006 or 2009, the period of leaf unfolding in beech was accompanied by unusually low temperatures, which, in combination with the masting, may have caused the 
low net $\mathrm{CO} 2$ exchange (Mund et al., in prep.). The mean NEP values obtained at the two sites over the seven years period did not differ significantly from each other (Figure A.2, Table A.3).

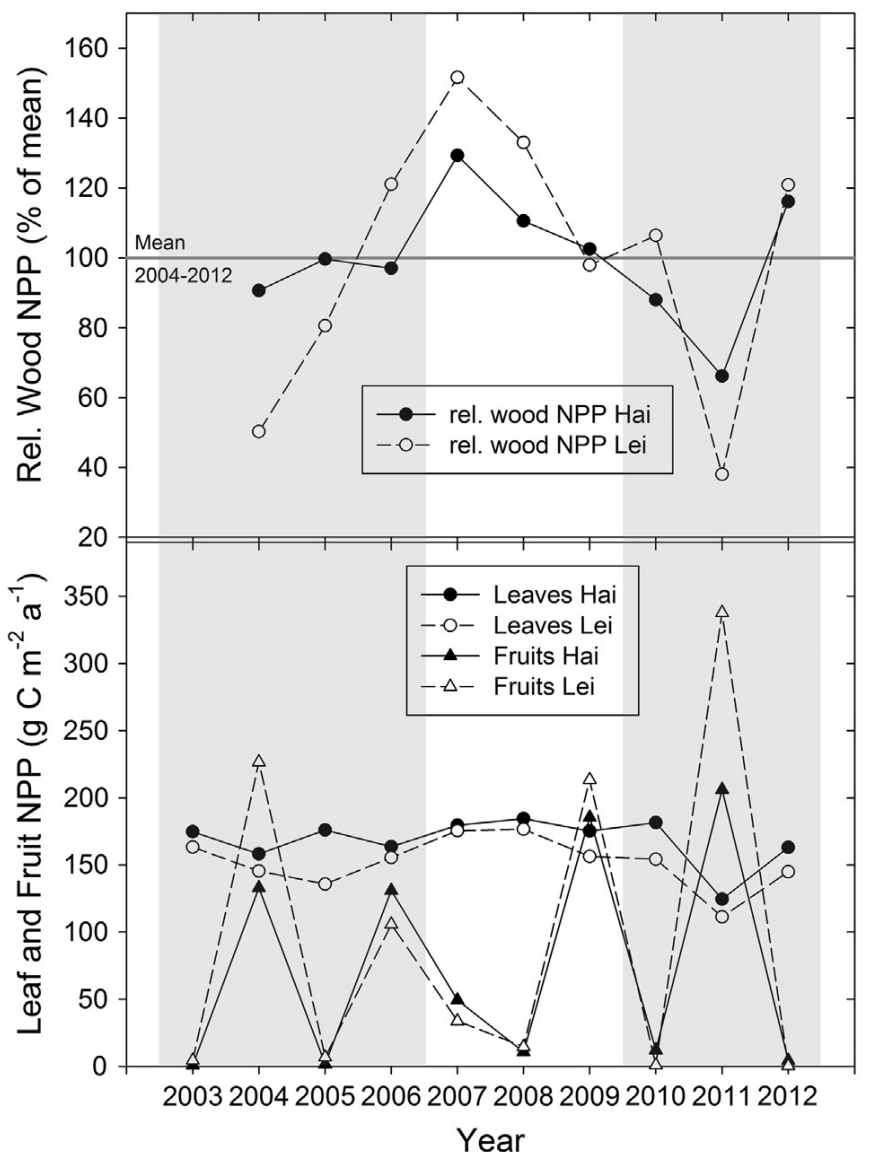

Figure A.3: Relative wood NPP (annual wood NPP in percent of mean wood NPP 2004-2012 per study site) (above) and leaf and fruit NPP (below) of the study sites Hainich and Leinefelde. The grey bands mark the time frame of the eddy covariance data.

Table A.3: Statistical assessment of the observed differences in mean fluxes between the sites, using a t-test for correlated samples with observation years as replicates. $\mathrm{P}$ values in bold type indicate a significant difference between sites.

\begin{tabular}{lllllllll}
\hline Flux & Net radiation & Sensible heat & Latent heat & NEP & Reco $_{e}$ & GPP & WUE & Bowen ratio \\
\hline P-value & 0.28 & 0.004 & 0.003 & 0.56 & 0.59 & 0.52 & 0.11 & 0.003 \\
\hline
\end{tabular}

The deviations between the two forests did not occur evenly throughout the seasons. If GPP during the first three years of the observation period is taken as an example (Figure A.4)then it can be seen that GPP in the managed stand always increased more rapidly in the spring than it did at the other site, but started earlier to decline in late summer, especially so in the masting year of 2004. The year 2003 was characterised by an unusually warm and dry period in late summer which affected large parts of central Europe (GRANIER 
et al., 2007), and interestingly this was detected more strongly in GPP of the unmanaged stand than in the managed, pure beech stand where GPP was affected less (Figure A.4).

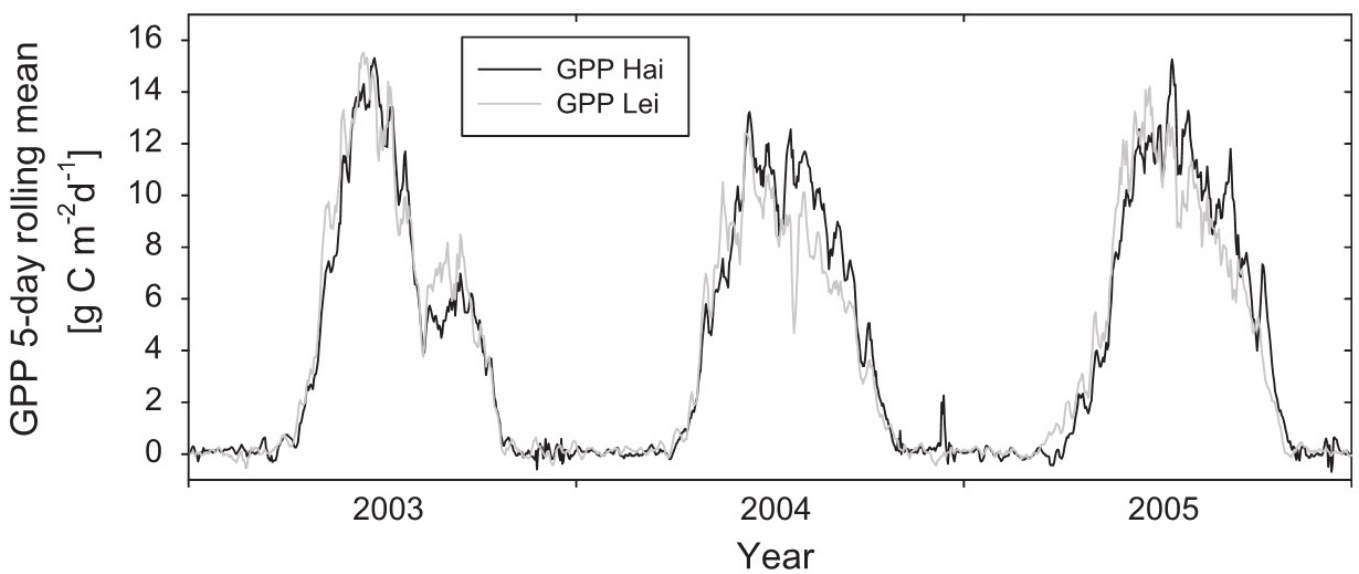

Figure A.4: Five-day running mean of GPP of the two beech forest stands over the first three years of the measurement period as calculated from gap-filled eddy covariance data.

Total annual evapotranspiration varied between 461 and $559 \mathrm{~mm}$ at the managed site and between 476 and $604 \mathrm{~mm}$ at the unmanaged sites (Figure A.5) and was lowest in 2003, the year with the drought period in late summer, at both forests. The corresponding mean values for the two stands were 503 and $549 \mathrm{~mm}$, respectively. This means that the amplitude of the interannual variability was fairly similar but the mean rate was higher at the unmanaged forest. Conversely, the Bowen ratio, i.e. the ratio between sensible and latent heat flux, was consistently higher at the managed forest and peaked at both sites in 2003 (Figure A.5). This observation resulted mainly from differences in sensible heat flux rather than available energy which did not differ significantly between the two sites (Table A.3). As a result of the nearly similar net carbon uptake and the differing water loss, the water use efficiency was higher at the managed beech forest, however this tendency was not significant (Table A.3).

In conclusion, forest management in terms of regular thinning and the establishment of even-aged, homogenous stands thus appears to have reduced the unproductive components of evapotranspiration, in particular interception evaporation, but have increased the interannual variability of carbon fluxes. 


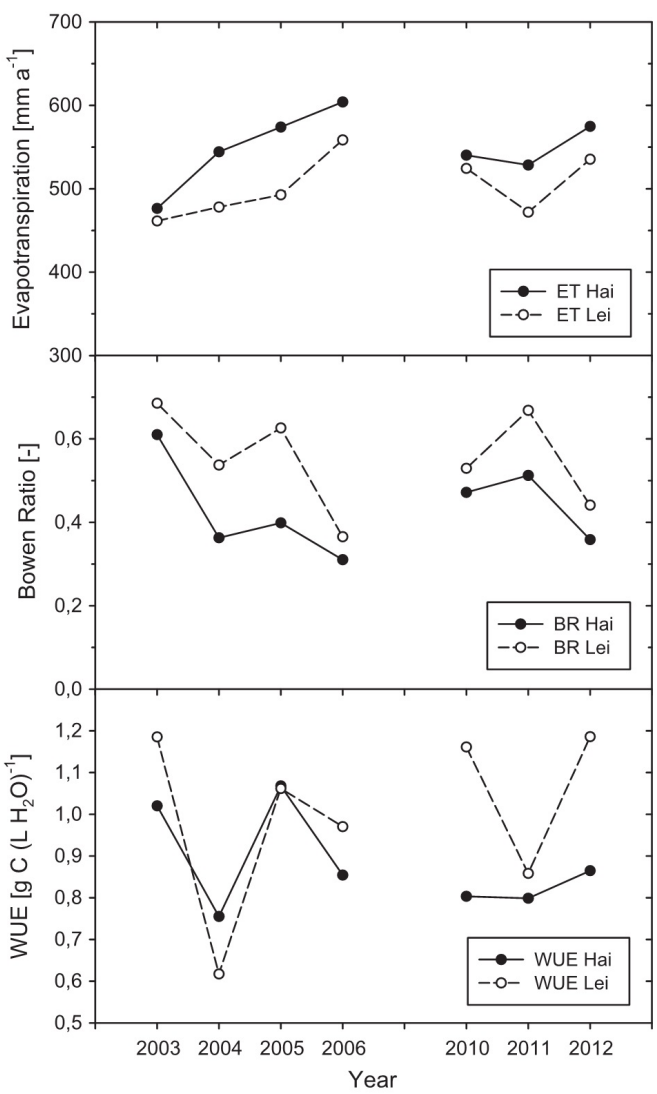

Figure A.5: Total annual evapotranspiration (ET, upper panel) and water use efficiency (WUE, lower panel) as measured over seven years in two beech forests differing in management only.

\section{A.5 Discussion}

\section{A.5.1 Methodological uncertainties}

Some uncertainty in our eddy flux data may have been induced through the method chosen to gap-fill NEE and to partition NEE into GPP and Reco. The common REICHSTEIN et al. (2005) technique based on night-time data faced the problem that night-time data at the two research sites were scarce because of the relatively high $u_{*}$ threshold of 0.5 used for this data set. The threshold was chosen following KUTSCH et al. (2008) who compared the eddy covariance night-time $\mathrm{CO}_{2}$ fluxes with soil chamber measurements. Although the high threshold should not have biased Reco in the long-term, it cannot be excluded that it may have suppressed its apparent interannual variability. The fact that the eddy covariance tower at the Hainich site is located on a gentle slope downwind of a hill (with respect to the main wind direction) and that the measurements had to be carried out 44 $\mathrm{m}$ above the ground, due to the large canopy height, causes considerable advection of $\mathrm{CO}_{2}$ and thus some further uncertainty in the eddy fluxes obtained at this site (FINNIGAN, 2008; Kutsch et al., 2008; KuTsCH et al., 2010). The topography at the other site is not 
flat either and could theoretically also have induced some advective carbon fluxes that would have contributed to the ecosystem carbon exchange. The uncertainties in annual carbon budgets resulting from the choice of the $u_{*}$ threshold (within a reasonable range) and the gap filling of missing night-time respiration data using temperature as a driving factor were quantified as $30 \mathrm{~g} \mathrm{C} \mathrm{m}^{-2} \mathrm{a}^{-1}$ and $50 \mathrm{~g} \mathrm{C} \mathrm{m}^{-2} \mathrm{a}^{-1}$, respectively, according to the sensitivity analysis carried out by KNOHL et al. (2003) for the Hainich site. Although all the potential errors mentioned above are unlikely to occur in the same direction, an overall uncertainty of about $100 \mathrm{~g} \mathrm{C} \mathrm{m}^{-2} \mathrm{a}^{-1}$ for NEP, $\mathrm{R}_{\mathrm{e}} \mathrm{co}$ and GPP should nevertheless be assumed, if possible sensor inaccuracies are also taken into account. As long as this uncertainty remains unsolved we focus more on the observed interannual variability than on long-term average fluxes in our further discussion. Furthermore we use only relative numbers (in relation to the mean of 2004-2012) when comparing the micrometeorological data with the biometric data which were calculated as in Mund et al. (2010). Nevertheless we believe that a possible bias in the eddy fluxes is only small since the annual fluxes in this study correspond well with those from other forest sites in similar regions and of similar age (LUYSSAERT et al., 2007; LUYSSAERT et al., 2008).

As far as evaporation is concerned, we did not use the water vapour measurements by the closed-path gas analyser to calculate eddy fluxes of latent heat because of a large uncertainty and likely bias caused by the very long tubes between the air intake and the gas analyser (IBROM et al., 2007). In fact, the systems at our sites were never intended to measure the water vapour flux accurately, but optimised to obtain accurate $\mathrm{CO}_{2}$ fluxes (E.-D. Schulze, pers. comm.). Therefore we used a well established alternative method in terms of the eddy covariance energy balance (ECEB) technique which relies on accurate measurements of net radiation and sensible heat flux and assumes a closed energy balance. However, for eddy flux sites it is well known that a complete closure is hardly achievable, even at sites where every component is measured accurately (FOKEN et al., 2011; STOY et al., 2013). Horizontal advection and/or transport by low-frequency air motions have been identified as the most important reasons for the missing energy in the total budget. These processes would affect all turbulent fluxes in the same way and could therefore bias the calculation of latent heat as residual of the energy balance if the sensible heat flux is underestimated for the above named reasons. The global average of the energy balance closure, based on 173 sites, is $84 \%$ (STOY et al., 2013). If we assume a similar number for our two sites and a Bowen ratio of about 0.5, then we might have underestimated sensible heat by $16 \%$ and overestimated latent heat (if calculated as residual) by $8 \%$. This uncertainty does not yet include potential errors in the radiation measurements. However, the described uncertainty would likely affect both sites in a similar way and thus not eliminate the observed differences in forest water use. It is also worth mentioning that, in practice, often only a fraction of the energy balance gap can be explained by processes affecting all fluxes, and that the sensible heat flux is often less underestimated than other turbulent fluxes (BARR et al., 2012) which would mean that the error in ET as determined by the ECEB method is even smaller than $8 \%$. 


\section{A.5.2 Interannual variability in carbon fluxes}

When distinguishing between the effects of plant functional type and land use type on the one hand and site management on the other on $\mathrm{CO}_{2}$ exchange (LUYSSAERT, 2014), it needs to be considered which NEE components are particularly sensitive to management activities. It seems likely that GPP and NPP will often be more strongly affected by site management than Reco which is dominated by soil respiration, with autotrophic and heterotrophic respiration having a similar order of magnitude (KUTSCH et al., 2010). Above-ground management activities will therefore not be reflected to the same extent in below-ground biological activity as in canopy processes. Whilst it is unsurprising that GPP was more variable than $\mathrm{R}_{\mathrm{e}} \mathrm{co}$, just as in other beech forests (PILEGAARD et al., 2011), it is somehow unexpected that no difference at all in the average ecosystem respiration rates were found between the two sites despite a much higher proportion of dead wood at the unmanaged site. However, the total above- and belowground wood biomass was about $10 \%$ lower at the unmanaged site (Figure A.1) and the observation of similar respiration rates corresponds to the results of soil organic carbon inventories that observed an ongoing net carbon accumulation in forest soils (KUTSCH et al., 2010; OsterbuRG et al., 2013; SchrumpF et al., 2014; TeFs et al., 2012) but no significant differences in C stocks of the mineral soil among differently managed forests - provided that the forests are sustainably managed without soil disturbances (e.g. GRÜNEBERG et al., 2013; JANDL et al., 2007; Mund, 2004; SCHÖNING et al., 2013; WÄLDCHEN et al., 2013).

The most obvious ecosystem properties related to management activities that may play a role when comparing the gas exchange of the two forests with each other are the structural and physiological traits of the respective canopies. The homogeneity at the managed site caused a higher variability in NEP and GPP due to the same and simultaneous reaction of all trees to weather conditions (incl. masting), whereas at the unmanaged site the opposite was the case since beech and ash had a different climate sensitivity and not all trees (not even all beech trees because of their young age) showed masting. None of the sites showed any consistent trend in annual NEP over the seven years of investigations as observed e.g. in younger forests. A continuous increase in net carbon uptake of a Danish beech forest over 14 years was reported by PILEGAARD et al. (2011) and could possibly result from the relatively young age of their forest, compared to the two sites considered here where no such trend was found.

\section{A.5.3 Evapotranspiration}

The difference in ET between the two sites could possibly result from higher rates of interception evaporation at the unmanaged site, having a denser canopy with a higher storage capacity for intercepted rain (CARLYLE-MOSES et al., 2011), if transpiration is considered as a conservative parameter, independent of forest structure or species composition (Herbst et al., 2008; RoBerTs, 1983). Other authors, in contrast, have found that canopy conductance and hence canopy transpiration scale with LAI (GRANIER et al., 2000), which could just as well explain the difference in ET between the two forests investigated in this study since the unmanaged stand had indeed a higher LAI. However, the similarity of GPP between the sites would rather suggest similar transpiration rates, too, since these two processes share the same pathway of gas exchange through the stomata. 
New measurements of individual ET components at the two sites will hopefully shed more light on this question. The overall effect of management on ET remains controversial anyway (Komatsu et al., 2010). It has been suspected that reduced forest management activities would result in less percolation and runoff (due to higher evapotranspiration in denser forests), but this could not always be verified.

\section{A.5.4 Diversity and resilience}

Tree diversity in beech dominated forests is amenable to management, for example through close-to-nature forestry or through establishing mosaic-like plantations with admixtures of different species instead of maintaining even-aged monocultures. It affects growth at species level through changes in competition and/or small scale soil properties and nutrient stocks but not necessarily at stand scale (e.g. Holzwarth et al., 2011; RATCliffe et al., 2015; Schmid et al., 2015), although some studies found a positive correlation between species number and productivity in temperate forests (MORIN et al., 2011). In case of the two investigated beech forests it seems that species and structural diversity effects on carbon exchange at the tree level were balanced at the stand level where similar average NEP rates were observed.

More relevant at stand scale is the resilience to disturbance which is generally higher in mixed forests (PRETZSCH, 2014). An example for this phenomenon is the response to drought in beech/ oak mixtures where it has been reported that beech benefits from the mixture and is more resilient than in mono-specific stands (PRETzSCH et al., 2013). However, our study shows that the timing of a disturbance such as a drought period is important, too, and may in some cases even cause an opposite effect due to the variability of tree phenology in mixed stands. Fraxinus, for example, is more flexible than Fagus with respect to the time of leaf unfolding in spring (VITASSE et al., 2009a) and can thus more easily avoid damage by late frosts. At Hainich there were years when these two species came into leaf practically simultaneously at the end of April or start of May, whereas in the relatively cold spring of 2011 leaf unfolding in Fraxinus showed a time lag of about four weeks compared to Fagus. The fact that, vice-versa, the flexibility of Fraxinus is lower in autumn (VITASSE et al., 2009b) is not that relevant for NEP due to the much lower irradiance at this time of the year. Whilst maximum incoming shortwave radiation at our sites reached about $850 \mathrm{~W} \mathrm{~m}^{-2}$ in late April (time of leaf out), corresponding to maximum daily totals of about $25 \mathrm{~J} \mathrm{~m}^{-2} \mathrm{~d}^{-1}$, the respective values for late October (time of leaf fall) were $450 \mathrm{~W} \mathrm{~m}^{-2}$ for the maximum irradiance and $9.5 \mathrm{~W} \mathrm{~m}^{-2} \mathrm{~d}^{-1}$ for the daily totals.

GPPmax is reached later in Fraxinus than in Fagus (W.L. Kutsch, pers. comm.) which is also mirrored in the green fraction of the leaves (AHRENDS et al., 2009) and could probably explain why Hainich, in contrast to the aforementioned observation of PRETzSCH et al. (2013), had a stronger GPP reduction than the monospecific Leinefelde stand in the dry year 2003 with the drought only occurring in late summer and thus affecting GPP in Fraxinus more strongly than in Fagus. When looking at the bigger picture regarding drought resilience and tree diversity, the recent paper by GROSSIORD et al. (2014c) produced incongruent results with drought stress increasing with species number in boreal forests but decreasing in some temperateand thermophile forests. The two forests investigated here do not fall into this pattern though, as the monospecific stand appeared to be less 
affected by the 2003 drought than the unmanaged stand containing other, more sensitive species, too. However, the discussion of this observation should not be restricted to soil water uptake as in GrossiorD et al. (2014c). Instead, it seems plausible that interception evaporation, which can amount to $50 \%$ of ET in humid temperate climates (RINGGAARD et al., 2014) may have caused this incongruent behaviour, since interception evaporation depends on forest structure (RINGGAARD et al., 2014) which often depends on species number (PRETZSCH, 2014).

The key finding of our study may be summed up as follows. If different species with different traits and phenology and trees of different age are present in a forest due to reduced (or ceased) management activity it becomes more unlikely that weather extremes or rare biological processes such as fruiting would affect the forest ecosystem as a whole in terms of its annual matter and energy exchange with the atmosphere. The hypothesis that species richness and/or structural diversity leads to more stability and less variation in carbon fluxes (LOREAU, 2001) is confirmed by our study if the years 2004 and 2011 (with cold spring plus high fruit biomass) are considered that showed a more moderate response at the unmanaged site, but not if the late summer drought of 2003 is considered.

\section{A. 6 Conclusions}

Defining the plant functional type is not sufficient to describe and predict the interaction between forests and the atmosphere (GROENENDiJK et al., 2011). Species and size specific traits (LAW, 2014), including forest structure (PRETZSCH, 2014), as well as management activities (LUYSSAERT, 2014) need to be represented in reliable and transferable prediction schemes as well. Looking back at the two hypotheses put forward in the Introduction section of this study we can conclude that hypothesis number two (regarding the enhanced interannual variability of gas exchange in the managed forest) could be confirmed, whereas hypothesis number one(regarding differences in the average exchange rates) was only true for water vapour but not for carbon dioxide if both fluxes are considered at ecosystem scale. Paired tower approaches at neighbouring forest sites can help disentangle control factors of forest-atmosphere exchange as affected by management activities, especially so if they are accompanied by independent biometric measurements.

\section{A.7 Acknowledgements}

We thank the administration of the Hainich National Park and the forestry district Leinefelde for the opportunity for research in their forest areas. We also thank ErnstDetlef Schulze, Olaf Kolle, Kerstin Hippler, Karl Kuebler, Martin Hertel, Agnes Fastnacht (Max-Planck Institute for Biogeochemistry), Peter Anthoni, Corinna Rebmann (Helmholtz Centre for Environmental Research - UFZ), Frank Tiedemann, Dietmar Fellert, Heinrich Kreilein, Martin Lindenberg (University of Goettingen) and Werner Kutsch (ICOS) for their past work at the Hainich and Leinefelde tower sites. This research is financially supported by the German Federal Ministry of Education and Research and is part of the European Integrated Carbon Observation System (ICOS). 


\section{B Stand age and species richness dampen interannual variation of ecosystem-level photosynthetic capacity}

Authors: Talie Musavi, Mirco Migliavacca, Markus Reichstein, Jens Kattge, Christian Wirth, T. Andrew Black, Ivan Janssens, Alexander Knohl, Denis Loustau, Olivier Roupsard, Andrej Varlagin, Serge Rambal, Alessandro Cescatti, Damiano Gianelle, Hiroaki Kondo, Rijan Tamrakar and Miguel D. Mahecha

Published in 'Nature ecology and evolution' (Musavi et al., 2017)

https://doi.org/10.1038/s41559-016-0048

In this paper, I provided data from the Hainich site and edits to the manuscript. 


\section{B.1 Abstract}

The total uptake of carbon dioxide by ecosystems via photosynthesis (gross primary productivity, GPP) is the largest flux in the global carbon cycle. A key ecosystem functional property determining GPP is the photosynthetic capacity at light saturation GPP $_{\text {sat }}$, and its interannual variability (IAV) is propagated to the net land-atmosphere exchange of $\mathrm{CO}_{2}$. Given the importance of understanding the IAV in $\mathrm{CO}_{2}$ fluxes for improving the predictability of the global carbon cycle, we have tested a range of alternative hypotheses to identify potential drivers of the magnitude of IAV in $\mathrm{GPP}_{\text {sat }}$ in forest ecosystems. Our results show that while the IAV in $\mathrm{GPP}_{\text {sat }}$ within sites is closely related to air temperature and soil water availability fluctuations, the magnitude of IAV in $\mathrm{GPP}_{\text {sat }}$ is related to stand age and biodiversity $\left(R^{2}=0.55, P<0.0001\right)$. We find that the IAV of $\mathrm{GPP}_{\text {sat }}$ is greatly reduced in older and more diverse forests, and is higher in younger forests with few dominant species. Older and more diverse forests seem to dampen the effect of climate variability on the carbon cycle irrespective of forest type. Preserving old forests and their diversity would therefore be beneficial in reducing the effect of climate variability on Earth's forest ecosystems.

\section{B.2 Introduction}

Interannual variability (IAV) of the net carbon dioxide exchange over land is globally the main determinant of the variability of atmospheric $\mathrm{CO}_{2}$ growth rate (AHLSTRÖM et al., 2015; LE QuÉRÉ et al., 2009). So understanding the factors controlling the IAV in $\mathrm{CO}_{2}$ fluxes is essential to improve the predictability of the global carbon cycle (LuO et al., 2015). Ecosystem biotic properties - such as soil and canopy nutrient status, rates of change in physiological properties of the vegetation, or the sensitivity of these properties to environmental factors - influence ecosystem $\mathrm{CO}_{2}$ exchange. Recent studies have shown that the IAV of the carbon budget can be better explained by variation in biotic properties of ecosystems such as photosynthetic capacity $\left(\mathrm{GPP}_{\text {sat }}\right)$ than directly by environmental and climatic drivers (MA et al., 2011; REICHSTEIN et al., 2014; RICHARDSON et al., 2007). $\mathrm{GPP}_{\text {sat }}$ is defined as the value of gross primary productivity (GPP) at saturating light under non-stressed conditions, minimizing the influence of anomalous hydrometeorological conditions (for example, droughts and heatwaves), which potentially affect photosynthesis. A robustly retrieved characterization of $\mathrm{GPP}_{\text {sat }}$ can be regarded as an ecosystem functional property reflecting the physiological response of the ecosystem to the environment. Given that IAV of GPP sat must propagate to observed GPP, this quantity is thought to be a key variable in understanding IAV of carbon fluxes (MUSAVI et al., 2015). In fact, recent studies demonstrated that $\mathrm{GPP}_{\text {sat }}$ correlates more strongly than any climatic variable with annual GPP (XIA et al., 2015), but also correlates with net ecosystem $\mathrm{CO}_{2}$ exchange (REICHSTEIN et al., 2014) . The magnitude of IAV in $\mathrm{GPP}_{\text {sat }}$ has been shown to exhibit considerable variation across ecosystems (MUSAVI et al., 2016), yet no obvious explanation for this pattern has been reported in the literature. However, the consequences are important: a low IAV in $\mathrm{GPP}_{\text {sat }}$ would suggest that ecosystem functioning is not very sensitive to climatic variability, and that it preserves its functionality under the influence of that variability and, likewise, high IAV is a consequence of high sensitivity. The capability of an ecosystem 
to preserve its functioning and structure over time (after external disturbances or climate extremes), is often defined as ecosystem stability and is linked to ecosystem resilience (HolLING, 1973). Using this terminology, low values of IAV in GPP sat can be understood as a characterization of high ecosystem functional stability.

The relation of ecosystem functionality, structure and stability has been a matter of debate for many decades in the field of ecology. In particular, the diversity of vascular plants has been investigated as a stabilizing factor with respect to variations in productivity, for example by buffering the ecosystem's sensitivity to climate extremes (JUCKER et al., 2014). However, it is also well known that plant diversity is co-limited by soil properties (García-Palacios et al., 2010), ecosystem management, and climate conditions. Another variable to consider is stand age (the mean age of the forest stand or the number of years after a major stand replacement after disturbance), which may affect ecosystem stability through adaptation, particularly of trees to their environment - hence increasing ecosystem resilience to climate Variability (OHEIMB et al., 2014). Moreover, structural parameters such as canopy cover, rooting depth, canopy height or leaf area index (LAI), which also depend on tree species diversity and stand age (KUTSCH, 2009), have an important effect on the ecosystem response to variation in environmental drivers since they define the capacity of trees to access resources such as water and light (HERBST et al., 2015). For instance, a regional study in the Amazon basin has shown that GPP, derived from the remotely sensed enhanced vegetation index, is less sensitive to environmental influences in regions with high canopy cover (BRANDO et al., 2010).

Despite this growing body of ecological knowledge, it remains largely uncertain which factors stabilize ecosystem functional properties at the global scale. In particular, we do not understand the causes of variability of specific ecosystem functional properties, such as photosynthetic capacity across ecosystem types, which ultimately controls ecosystem productivity. Here we hypothesize that stand age and species diversity play an important role in stabilizing ecosystem photosynthetic capacity. We test this hypothesis while also considering other factors related to climate, water availability, forest structure and soil properties that might have direct or indirect effects on ecosystem photosynthetic capacity.

In this study, we used measurements of ecosystem-level fluxes, and climate variables (temperature, precipitation, and water availability), species richness, stand age, forest structure (canopy cover, height, and LAI), and soil properties (nutrient availability FERNÁNDEZMARTínez et al. 2014) derived from satellite data, in situ observations and the literature (see the Methods).

We used half-hourly ecosystem-level GPP fluxes estimated by the means of the eddycovariance technique at 50 FLUXNET sites (BALDOCCHI, 2008) with at least 4 years of measured fluxes, and with different vegetation types across different climatic regions. We included data from evergreen forest (EF) as well as deciduous broadleaved and mixed forest (DBMF) located in temperate, boreal, mediterranean, tropical and dry climate regions (Supplementary Figure 1 and Table B.1 ). All 50 sites have information on stand age (referred to simply as 'age' in Figure B.1 - B.3) and species richness in addition to the $\mathrm{CO}_{2}$ flux data. Species richness ('sp. no.' in Figures B.1 - B.3) is the number of dominant plant species (for example tree or herb) that account for a cumulative abundance of 90 percent at a given site. We collected additional information on (i) canopy cover, (ii) canopy height, 
(iii) LAI, (iv) temperature and precipitation, and (v) soil water availability index (WAI) for a subset of 44 sites; and (vi) an index of nutrient availability for 36 sites compiled from the literature (FERNÁNDEZ-MARTínez et al. 2014- see Methods).

We characterized the response of half-hourly GPP estimates to incoming shortwave radiation by fitting ecosystem-level light response curves yielding daily estimates of GPP $_{\text {sat }}$ (see Methods). The site-level estimates of annual GPP sat (that is, GPP at saturating light conditions) were then determined by extracting the 90th percentile of the daily estimates of $\mathrm{GPP}_{\text {sat }}$. The magnitude of the IAV in GPP $\mathrm{Gat}_{\text {was }}$ computed as the coefficient of variation of annual estimates of $\operatorname{GPP}_{\text {sat }}\left(\operatorname{cvGPP}_{\text {sat }}=\sigma\left(\operatorname{GPP}_{\text {sat }}(t)\right) / \mu\left(\operatorname{GPP}_{\text {sat }}(t)\right)\right)$, where $\operatorname{GPP}_{\text {sat }}(t)$ is the annual $\mathrm{GPP}_{\text {sat }}$ for year $t$, and $\sigma$ and $\mu$ are the standard deviation and mean of $\operatorname{GPP}_{\text {sat }}(t)$, respectively. Two variable selection methods based on (i) relative importance of regressors (GRÖMPING, 2007), and (ii) multivariate generalized regression models and a stepwise algorithm based on Akaike Information Criteria (stepAIC) were used to select the

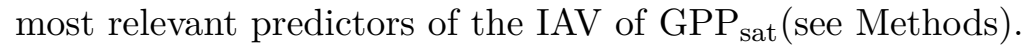
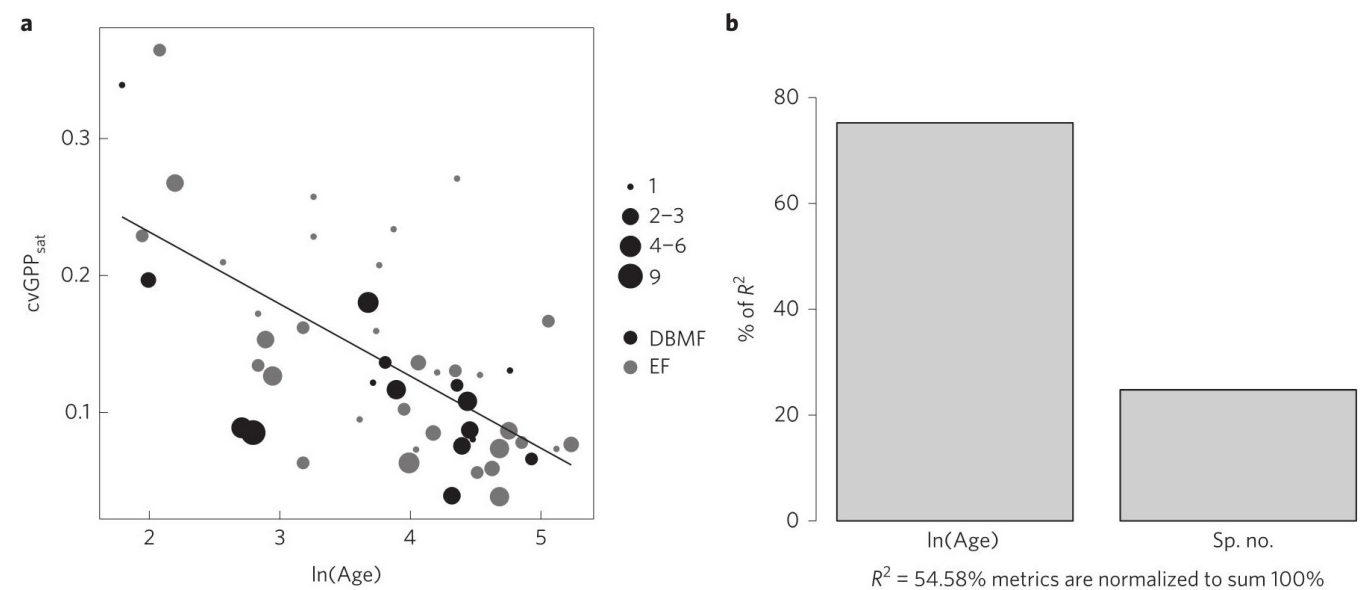

Figure B.1: Relationship of cvGPP $_{\text {sat }}$ with stand age and species richness. (a) The relationship between the interannual variability of ecosystem photosynthetic capacity (cvGPP sat $_{\text {) }}$ computed for each FLUXNET site and stand age (which is transformed using the natural logarithm, $\ln ($ age $)):\left(R^{2}=0.39, P<0.0001, n=50\right)$. The number of plant species at the sites that account for $90 \%$ of the total species abundances (sp. no.) is indicated with the size of the points. DBMF, deciduous broad leaf and mixed forests $(\mathrm{n}=16$; black); EF, evergreen needleleaf and broadleaf forests $(\mathrm{n}=34$; grey). (b) Relative importance metrics of $\ln ($ age) and sp. no. as predictors of $\mathrm{cvGPP}_{\text {sat }}$. For a version of this figure using age without logarithm transformation, see Supplementary Fig. 11

\section{B.3 Material and methods}

\section{B.3.1 Data}

In this study we brought together a wide range of data: ecosystem-atmosphere $\mathrm{CO}_{2}$ fluxes measured at eddy covariance flux sites, information about climate (temperature, precipitation, and water availability index (WAI)), species richness, stand age, and plant traits, derived from field campaigns, and information about forest structure derived from 
satellite data for each of the selected sites; finally, data about nutrient availability was derived from the literature (FERnÁNDEZ-MARTínez et al., 2014). Sites were selected according to the availability of eddy covariance flux measurements for at least 4 years, information about stand age, canopy cover, canopy height, and species abundance. This led to a global dataset of 50 sites with different vegetation types across different climatic regions. We included data from evergreen forest (EF) and deciduous broadleaved and mixed forest (DBMF) located in temperate, boreal, tropical, Mediterranean and dry climate regions.

$\mathrm{CO}_{2}$ fluxes and meteorological data. From the global eddy covariance flux database (BALDOCCHI, 2008) we downloaded half-hourly ecosystem-level gross primary productivity (GPP) fluxes estimated from net ecosystem exchange (NEE) data (REICHSTEIN et al., 2005). Half-hourly shortwave incoming global radiation, temperature, and precipitation were also downloaded. From the dataset WAI was computed according to ref. (TRAmONTANA et al., 2016). Here the WAI is the ratio between soil water storage and plant available water storage capacity at lower layer $(100 \mathrm{~mm})$ (TRAMONTANA et al., 2016).

Average stand age. These data were obtained from the Biological, Ancillary, Disturbance and Metadata (BADM) of the FLUXNET database (LAw et al., 2008). Stand age (expressed in years) reported in the BADM is the average tree age of the stand or the age of the stand since the last major disturbance that caused stand replacement. Stand age was reported for different years at the sites, and so we normalized the data by using the age of all sites at the year 2007 (which is the year of the release of FLUXNET LaThuile Database used in this study).

Species richness. Species identity and abundances from the BADM data and literature search were collected. Because these data come from diverse sources and are collected with different protocols, they can have variable level of details. Therefore, we developed a strategy to guarantee comparability of the plant species richness computed across sites. For each site we sorted the plant species according to their abundance, from the one with highest abundance to the lowest. Then we considered only the number of species that add up to $90 \%$ of the total site abundance.

Canopy structure. For the selected sites we extracted satellite products to characterize canopy structure: canopy cover, plant height and Leaf Area Index (LAI).

Canopy cover was extracted from the Moderate Resolution Imaging Spectroradiometer (MODIS) vegetation products continuous field version $437 \mathrm{http}$ //glcf.umd.edu/data/ vcf/. Plant height was derived for each site from the estimates reported in ref. (SIMARD et al., 2011 http://lidarradar.jpl.nasa.gov/).

We used estimates of LAI derived at $1 \mathrm{~km}\left(0.01^{\circ}\right)$ spatial resolution by the JRC-TIP (PINTY et al., 2007) from the MODIS broadband visible and near-infrared surface albedo products (ScHAAF et al., 2002). The processing for the gap filling and the extraction of the time series from MODIS-TIP LAI products is described in ref. (MUSAVI et al., 2016). Annual maximum LAI values were derived at each site by extracting for each year the 90th percentile of the 16-day LAI time series. Finally for each site the maximum LAI ( LAI $\left._{\max }\right)$ and the coefficient of variation of the annual maximum LAI (cvLAI $\left.{ }_{\max }\right)$ were estimated. In this study we did not use site level LAI data reported in the FLUXNET database for the following reasons: 
1. LAI data have been collected with a variety of different methods, from direct(that is, harvesting and litter fall) to indirect (for example, hemispherical photography or LAI-2000) methods. Site-level method intercomparisons of various techniques always reveal large and non-systematic differences among LAI methodologies, rendering the LAI information reported in the FLUXNET database not always suited for network synthesis studies. Efforts toward the standardization of the collection of these measurements are ongoing in the context of the Integrated Carbon Observation System (ICOS) and National Ecological Observatory Network (NEON), but these data are not yet available. 2. The availability of data in regular annual measurement is very different among sites. For some sites the LAI is available for each measurement year (and sometimes even seasonally), but for many sites only one estimate during the whole measurement period is available.

Considering the limitations of site-level LAI data, we selected the MODIS-TIP LAI product. MODIS-TIP LAI is recognized as one of the most effective LAI products available and it was successfully evaluated at a FLUXNET site included in this study (PINTY et al., 2011).

Nutrient availability. Part of the dataset (36 sites) was complemented with soil nutrient availability classes derived from literature (FERnÁnDEZ-MARTínez et al., 2014). For each site, nutrient availability was computed using site-level specific information about the following variables: carbon, nitrogen and phosphorus concentrations of soil and/or leaves, soil type, soil texture, soil $\mathrm{C} / \mathrm{N}$ ratio, and soil $\mathrm{pH}$. These data were derived for each site from the literature and in some cases provided by the site principal investigator. The sites were eventually classified in three classes: low, medium and high nutrient availability. Afterwards the classification was approved by the site principal investigators (FERNÁNDEZ-MARTínEZ et al., 2014).

\section{B.3.2 Estimation of photosynthetic capacity and its interannual variability magnitude}

Site-level estimates of the annual photosynthetic capacity $\left(\mathrm{GPP}_{\text {sat }}\right)$ were determined from half-hourly GPP estimates and global solar radiation (Rg) (MUSAVI et al., 2016).

In summary, we fit a non-rectangular hyperbolic light response curve (NHLRC) to GPP and Rg data (GILmanov et al., 2003). The NHLRC was fit to 5 days of data selected with a moving window approach. The parameters of the NHLRC were estimated and we computed the GPP at $1,000 \mathrm{~W} \mathrm{~m}^{-2}$ of $\mathrm{Rg}\left(\mathrm{GPP}_{1,000}\right)$, which represents the GPP at saturating light (that is, ecosystem photosynthetic capacity in the selected 5-day window). The estimated parameters and the $\left(\mathrm{GPP}_{1,000}\right.$ values were assigned to the day in the middle of the 5-day window. Parameters estimated with $R^{2}$ of the fitting lower than 0.6 were removed.

To estimate the annual $\mathrm{GPP}_{\text {sat }}$, for each year from the daily $\mathrm{GPP}_{1,000}$ time series, we calculated the 90th percentile. The interannual variability (IAV) of the annual estimates of $\mathrm{GPP}_{\text {sat }}$ was computed as the coefficient of variation of $\left(\mathrm{GPP}_{\text {sat }}\right.$, that is, cvGPP $\mathrm{sat}_{\text {salculated }}$ by dividing the standard deviation by the mean.

$$
\left(\frac{\text { standard deviation }}{\text { mean }}\right)
$$


In young stands cvGPP sat might depend on the trend in annual growth and GPP that can lead to high $\mathrm{cvGPP}_{\text {sat }}$ values that are not related to interannual variability in photosynthetic capacity. To remove this confounding factor we first tested the presence of a significant trend in $\mathrm{GPP}_{\text {sat }}$ time series at each site with the Mann-Kendall non-parametric trend test. Finally, for the sites with a significant trend $(P<0.1)$ we recomputed the $\mathrm{cvGPP}_{\text {sat }}$ by detrending the $\mathrm{GPP}_{\text {sat }}$ time series (that is, the standard deviation of detrended $\mathrm{GPP}_{\text {sat }}$ divided by the mean of the $\mathrm{GPP}_{\text {sat }}$, hereafter referred as detrended cvGPP sat ).

Aggregation of environmental variables: For the estimation of year-to-year variability of climate we used temperature and precipitation measured, and the WAI35 estimated at the flux sites. To aggregate temperature and precipitation we used only daily values with more than $70 \%$ of original half-hourly data (gaps in the half-hourly data are filled using ERA-Interim climate data downscaled at the FLUXNET, http://www.bgc-jena.mpg.de/ $\sim$ MDIwork/meteo/index.php). Average temperature, WAI, and cumulative precipitation over the active growing season were computed. Active growing season was considered as the days with daily GPP higher than the annual median GPP. From these annual estimates we derived the standard deviation (s.d.) of annual mean temperature, WAI and precipitation during the growing season as a measure of their IAV.

\section{B.3.3 Statistical analysis}

We used a variable selection method and relative importance method to select and quantify the contribution of each predictor (for example, average stand age (age), $\ln ($ age), species richness (sp. no.), canopy cover, canopy height, and nutrient availability, temperature, WAI) to the cvGPP $\mathrm{sat}_{\text {; }}$ precipitation was once used in the calculation instead of WAI.

The stepwise algorithm based on the Akaike Information Criteria (AIC) algorithm with generalized linear regression models was used43. The independent variable was $\mathrm{cvGPP}_{\text {sat }}$, while the predictors were stand age (referred to in the figures simply as 'age'), species abundance (sp. no.), ln(age), s.d. of temperature and of WAI, canopy cover, canopy height, LAI, and so on; interactions of age and sp. no., s.d. of temperature and s.d. of WAI and canopy height and $\left(\mathrm{LAI}_{\max }\right.$ were also included (cumulative precipitation was also used in place of WAI with similar results; data not shown). The algorithm was set up with the possibility to account for model pairwise interactions, and imposing a selection only if the model is statistical significant $(P<0.01)$. Although the sites used in this study have at least 4 years of flux data, the number of years (no.years) with available data at each site was different. Therefore, we used

$$
\frac{1}{\sqrt{\text { no.years }}}
$$

to weight the model selection, weighting more the sites with higher numbers of years. A stepwise selection without the weighting was used as well. The distribution of the residuals of the best model was tested for normality using the Shapiro and Kolmogorov-Smirnov test. The results showed that the residuals were normally distributed; therefore the weighting was not strictly necessary, but was used for a comprehensive evaluation. 
In order to assess the uncertainty introduced by the potential trend in $\mathrm{GPP}_{\text {sat }}$ in young stands, we repeated the analysis using the detrended cvGPP sat dataset, and the cvGPP sat $_{\text {s. }}$ for the sites without a significant trend in $\mathrm{GPP}_{\text {sat }}$.

To disentangle the importance of each predictor in determining cvGPP sat we used the Lindeman-Merenda-Gold (LMG) relative importance method19. This method allows the assessment of the importance of correlated predictors in a multiple linear regression model. Moreover, the pairwise linear regression and correlation between the different predictors and cvGPP $_{\text {sat }}$, and between the predictors themselves, was tested.

Both stepwise AIC and the LMG identified ln(age) and sp. no. as the most important variables controlling the $\mathrm{cvGPP}_{\text {sat }}$. We used a generalized linear model to fit the coefficients of the multiple linear model.

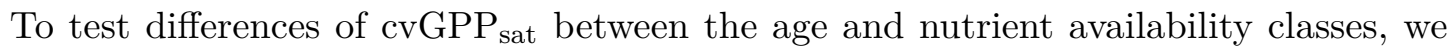
used the Kruskal-Wallis rank sum test. Sites were divided by age class (young, middle aged and mature stands) according to the 33rd and 66th percentiles of the distribution of age. Nutrient availability classes were defined according to ref. (FERNÁNDEZ-MARTínez et al., 2014)(low, medium and high).

The correlation between GPP $_{\text {sat }}$ and climate variables was tested with distance correlation (SzÉKELY et al., 2007). Distance correlation is a measure of statistical dependence between random variables and here we tested the dependence between $\mathrm{GPP}_{\text {sat }}$ and temperature and WAI jointly.

\section{B.4 Results}
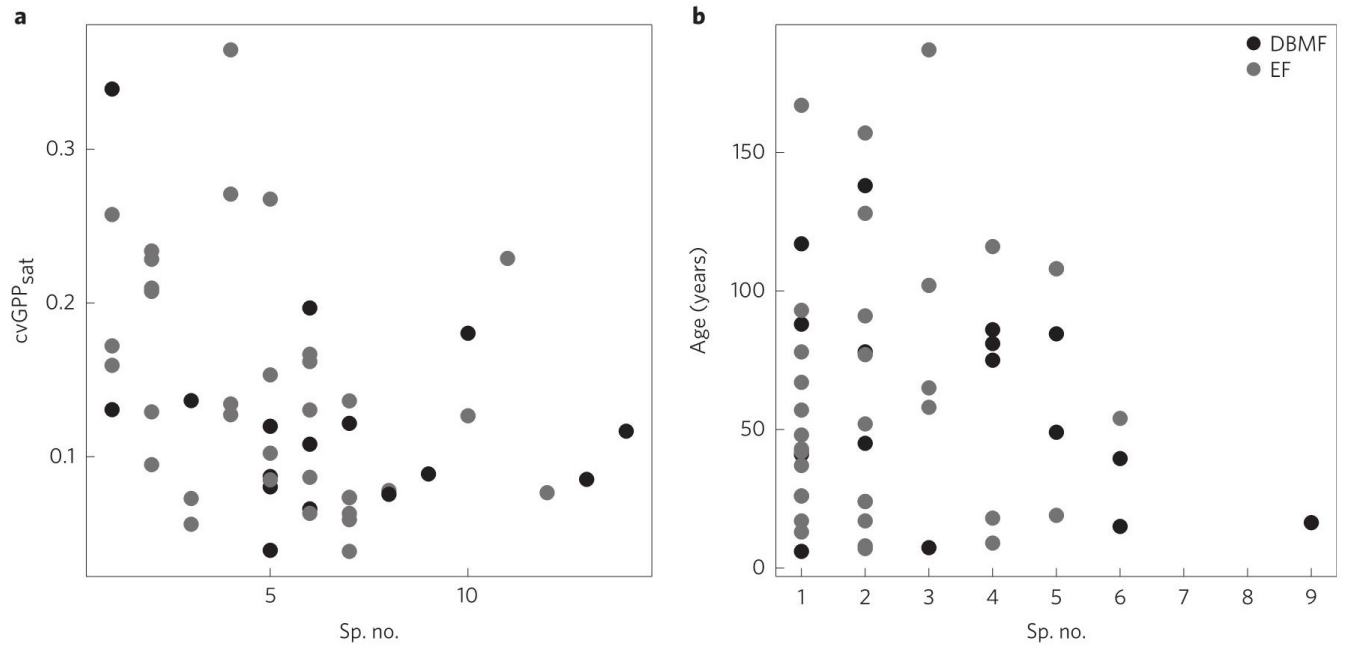

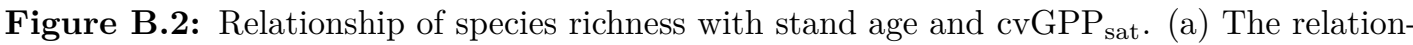
ship between cvGPP sat computed for each FLUXNET site and species richness (sp. no.) $\left(R^{2}\right.$ $=0.12, P=0.01, n=50)$. (b) The relationship between species richness and stand age $\left(R^{2}=\right.$ $0, P=0.68, n=50)$. DBMF are deciduous broad leaf and mixed forests $(n=16$; black $)$ and $\mathrm{EF}$ are evergreen needleleaf and broadleaf forests $(n=34$; grey).

Results from the variable selection and relative importance methods (see Methods) conducted over the 44 sites with all variables are consistent with our hypothesis that stand 
age and species richness of the sites are the most important predictors of cvGPP ${ }_{\text {sat }}$, with stand age being statistically the dominant factor (Figure B.1a). We further tested the performance of a multiple linear model, where cvGPP sat is a function of stand age and species richness, using all sites with data available for these two predictors (50 sites). The model suggests a clear relationship between $\mathrm{cvGPP}_{\text {sat }}$ and the logarithm of stand age and the species richness (Table B.2, $R^{2}=0.55, P<0.0001$ ). Stand age, which is negatively correlated with cvGPP sat , is the most important predictor (from the $55 \%$ explained variance by both variables, the relative contribution to the explained variance by stand age and species richness is $74.5 \%$ and $25.5 \%$, respectively; Figure B.1b and Supplementary

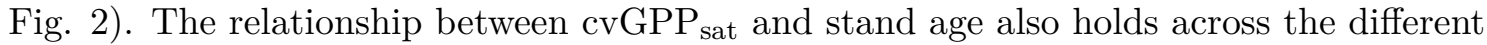
forest types (ENF and DBMF) (Figure B.1a and Table B.1). Species richness has a complementary effect: for the same age class, higher values of species richness yield lower

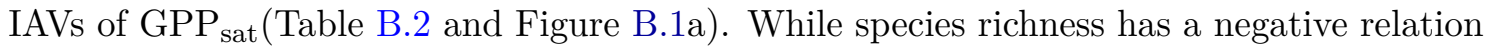
with cvGPP sat $\left(\right.$ Figure B.2a and Table B.1), it is not correlated with stand age $\left(R^{2}=0\right.$, Figure B.2b). Furthermore, Figure B.1 shows that the slope of cvGPP sat versus stand age is similar for the two different forest types, which suggests that the relationship between $\mathrm{cvGPP}_{\text {sat }}$ and stand age is independent of forest type (Table 1). The relationship is also independent of ( $\mathrm{LAI}_{\max }$ of the sites (Supplementary Fig. 3). In young forests, cvGPP sat might depend also on the expected trend in annual growth and GPP, as young stands are expected to rapidly increase their biomass and LAI in the first years of establishment (MAGNANI et al., 2007). Thus, young stands could have a higher variability of GPP $_{\text {sat }}$ - but this does not necessarily reflect instability. To remove this potentially confounding factor, we tested whether there is a temporal trend in our data of annual GPP sat at the sites (Methods). Using a Mann-Kendall test, we found only five sites had a significant trend, two of which were old sites ( $>80$ years). The results of the model selection and the relationship between $\mathrm{cvGPP}_{\text {sat }}$, stand age and species richness remains the same regardless of whether the trend in $\mathrm{GPP}_{\text {sat }}$ from these sites is removed (see Supplementary Information).

Table B.1: Summary of the linear models fitted for cvGPP sat (the interannual variability of ecosystem photosynthetic capacity computed for each FLUXNET site) with the chosen predictors for the different groups of sites classified according to vegetation type.

\begin{tabular}{|c|c|c|c|c|c|c|c|}
\hline \multirow{4}{*}{ DBMF } & $R^{2}$ & $A d j . R^{2}$ & Predictors & Coefficients & s.e. & d.f. & $p$ \\
\hline & \multirow[t]{3}{*}{0.65} & \multirow[t]{3}{*}{0.60} & Intercept & 0.38 & 0.05 & \multirow[t]{3}{*}{13} & $<0.0001$ \\
\hline & & & $\ln$ (Age) & -0.06 & 0.01 & & 0.0004 \\
\hline & & & Sp. no. & -0.01 & 0.00 & & 0.02 \\
\hline \multirow[t]{2}{*}{ DBMF } & \multirow[t]{2}{*}{0.46} & \multirow[t]{2}{*}{0.42} & Intercept & 0.31 & 0.05 & \multirow[t]{2}{*}{14} & $<0.0001$ \\
\hline & & & $\ln$ (Age) & -0.05 & 0.01 & & 0.004 \\
\hline \multirow[t]{3}{*}{$\mathrm{EF}$} & \multirow[t]{3}{*}{0.49} & \multirow[t]{3}{*}{0.46} & Intercept & 0.38 & 0.04 & \multirow[t]{3}{*}{31} & $<0.0001$ \\
\hline & & & $\ln$ (Age) & -0.05 & 0.01 & & $<0.0001$ \\
\hline & & & Sp. no. & -0.02 & 0.007 & & 0.02 \\
\hline \multirow[t]{2}{*}{$\mathrm{EF}$} & \multirow[t]{2}{*}{0.40} & \multirow[t]{2}{*}{0.38} & Intercept & 0.35 & 0.05 & \multirow[t]{2}{*}{32} & $<0.0001$ \\
\hline & & & $\ln ($ Age $)$ & -0.05 & 0.01 & & $<0.0001$ \\
\hline
\end{tabular}

PFT, plant functional types; s.e., standard error; d.f., degree of freedom; DBMF, deciduous broad leaf and mixed forests; EF, evergreen forests. $\ln ($ Age) is the natural logarithm of the average stand age, and sp. no. is the number of dominant plant species that have a cumulative abundance of $90 \%$ at the sites. 
While there is a strong relationship between the annual $\mathrm{GPP}_{\text {sat }}$ and mean growing season temperature and WAI (Figure 3 and Supplementary Figures 4-7) across all sites,

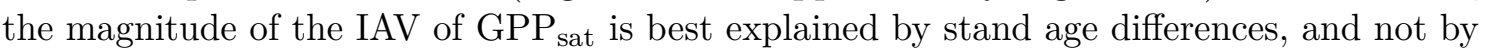
the differences in the IAV of climate and environmental factors (that is, standard deviation of annual growing season temperature and WAI). The distance correlation coefficient between $\mathrm{GPP}_{\text {sat }}$ and climate variables, which can account for nonlinearity in statistical relations, is also not linked to stand age, species richness or cvGPP sat (Supplementary

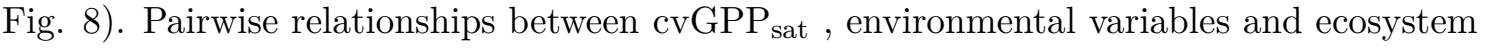
structural variables were also tested. Soil nutrient availability has no effect on the cvGPP sat $_{\text {t }}$ (Supplementary Fig. 9), and neither do the other variables (Supplementary Fig. 10).

Table B.2: Comparison of different models computed using the set of predictors chosen by both stepwise model selection according to aIC and relative importance methods.

\begin{tabular}{llllll}
\hline Model & & $\mathrm{R}^{2}$ & Adj. $\mathrm{R}^{2}$ & Coefficients & $\mathrm{p}$ \\
\hline cvGPP $_{\text {sat }}=$ & Intercept & 0.12 & 0.1 & $0.18 \pm 0.02$ & 0.01 \\
& sp. no. & & & $-0.01 \pm 0$ & \\
\hline cvGPP $_{\text {sat }}=$ & Intercept & 0.25 & 0.24 & $0.19 \pm 0.01$ & 0.0002 \\
& Age & & & $0 \pm 0$ & \\
\hline cvGPP $_{\text {sat }}=$ & Intercept & 0.39 & 0.38 & $0.33 \pm 0.04$ & $<0.0001$ \\
& ln(Age) & & & $-0.05 \pm 0.01$ & \\
\hline cvGPP $_{\text {sat }}=$ & Intercept & 0.55 & 0.53 & $0.39 \pm 0.03$ & $<0.0001$ \\
& ln(Age) & & & $-0.05 \pm 0.01$ & \\
& sp. no. & & & $-0.02 \pm 0$ & \\
\hline cvGPP $_{\text {sat }}=$ & Intercept & 0.55 & 0.52 & $0.42 \pm 0.06$ & $<0.0001$ \\
& ln(Age) & & & $-0.06 \pm 0.01$ & \\
& sp. no. & & & $-0.03 \pm 0.02$ & \\
& $\ln$ (Age):sp. No & & & $0 \pm 0$ & \\
\hline
\end{tabular}

cvGPP $_{\text {sat }}$ is the IAV magnitude of ecosystem photosynthetic capacity, and sp. no. is the number of dominant plant species that have a cumulative abundance of $90 \%$ at the sites. $\ln ($ Age $)$ is the natural logarithm of the average stand age. The number of sites is $n=50$. 


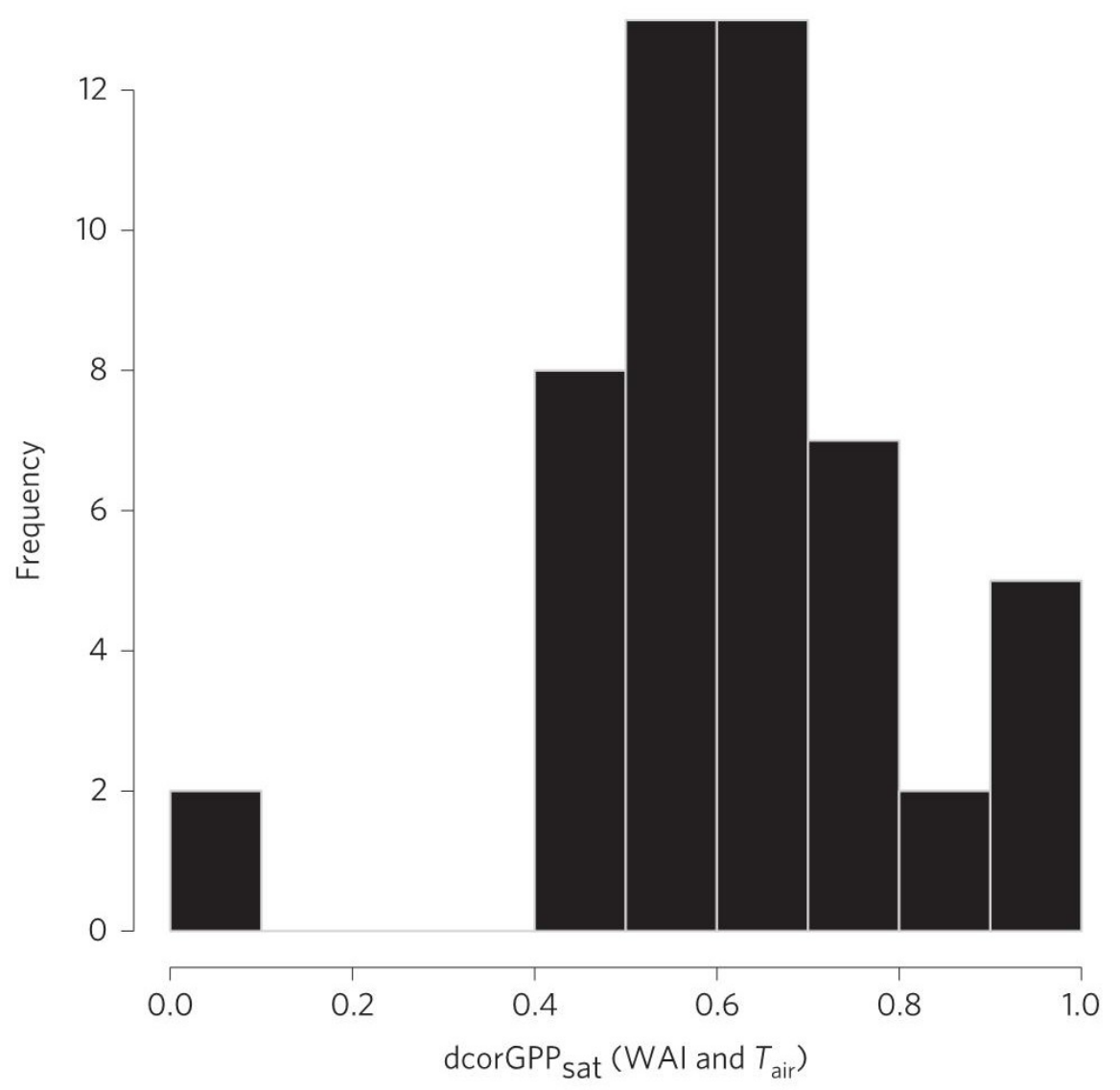

Figure B.3: Frequency distribution of the distance correlation coefficients computed between the annual ecosystem photosynthetic capacity $\left(\mathrm{GPP}_{\text {sat }}\right)$ and the environmental variables WAI and Tair $(n=50)$. WAI, average water availability index; and Tair, temperature (both during the growing season). Using the distance correlation coefficient (dcor) (LuYsSAERT et al., 2008),

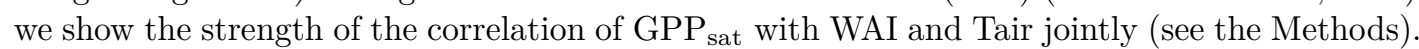

\section{B.5 Discussion and conclusion}

Previous studies have shown that vegetation responses to climate variability can explain the IAV of ecosystem fluxes better than climate variables themselves on longer timescales (MA et al., 2011; RichaRdson et al., 2007; URBANSKI et al., 2007). Here we show further that

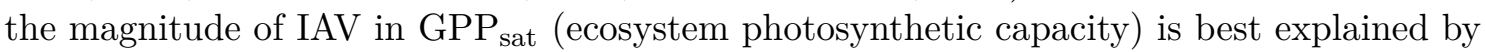
vegetation properties of the sites. We identify a joint control of stand age and biodiversity on the magnitude of the IAV of ecosystem photosynthetic capacity (that is, cvGPP $\mathrm{sat}_{\text {) }}$ ). Part of the unexplained variance in $\mathrm{cvGPP}_{\text {sat }}$ by stand age and species richness could be also associated with management and disturbances that were not included in the ancillary database of the sites, and can therefore not be formally investigated. Accurately simulating GPP in terrestrial biosphere models depends crucially on parameters related to GPP sat (BonAN et al., 2012). These parameters are typically assumed to be constant over time, 
but may vary spatially according to forest types (MeDvigy et al., 2013). Our findings suggest that stand age and species richness should be accounted for to dynamically adjust parameters related to photosynthetic capacity.

Stand age can influence $\mathrm{GPP}_{\text {sat }}$ stability in different ways by enhancing soil conditions over time (for example, a thicker humus layer with favourable microbial communities, increased water storage capacity, and access to deeper water with a tap root system OHEIMB et al. 2014). Also, a forest may develop a more diverse canopy and rooting structure, allowing for more complementary use of nutrients and water. In addition, older forests are more resilient to environmental changes because with time species selection leads to a better adaptation to the environment. Site fertility can also improve with stand age, following the nutrient losses occurring during major disturbances (such as fire or harvest). In fact, the ecosystem internal cycle of macronutrients is particularly relevant (BUTTERBACH-BAHL et al., 2011; SutTon et al., 2011) and leads to a progressive accumulation of nutrients in the living biomass with age (YANG et al., 2011).

Although species diversity is generally assumed to increase ecosystem resilience, exceptions have been reported (Grossiond et al., 2014c). For example, species diversity can enhance forest resistance to drought only if the system is prone to drought (GROssionD et al., 2014c). This is considering the gradual adaptation of the ecosystem to its environment by changing species composition to track environmental changes. Facilitation (species interactions that results in the species benefitting from each other) and complementary functioning of plant species can explain why species richness is important for ecosystem stability and how the interaction of species modulates the climate effect on ecosystem functioning (DEL Río et al., 2014). In addition, mixed forests are able to buffer the effect of climate IAV through competition and facilitation in normal and stressful years, respectively (DEL Río et al., 2014). Facilitation and complementary effects are clearly related to the functional richness of the species pool (that is, species with different functional traits), which is linked to stand age as shown by a regional study in the tropics (BECKNELL et al., 2014). Diverse ecosystems with a higher number of plant species respond less dramatically in their functioning (compared to ecosystems with single or few species) to climate and environmental stresses.

The Earth's forest cover is essential to remove $\mathrm{CO}_{2}$ from the atmosphere, and afforestation is important to compensate for forest loss due to land use changes (such as agriculture). While young forests established on former agricultural lands, or burned and harvested forests for several years cannot compensate for the initial carbon loss nor contribute to $\mathrm{CO}_{2}$ sequestration from the atmosphere, old forest stands retain their capacity to sequester $\mathrm{CO}_{2}$ for long periods (Coursolle et al., 2012; LuYssaerT et al., 2008). We show that the photosynthetic capacity and therefore the gross primary production of old growth forests are more resilient to climate variability than young forests. In addition, our study suggests that species-rich forest stands offer a larger potential for maintaining a stable photosynthetic capacity across time than species-poorer stands. Therefore, preserving our current forest (with old forests covering 15\% of Earth's surface (LUYSSAERT et al., 2008)) and their species diversity may attenuate the annual fluctuations of global forest-atmosphere $\mathrm{CO}_{2}$ exchange. 


\section{B.6 Acknowledgements}

From Max-Planck Institute for Biogeochemistry we thank U. Weber, M. Jung for providing data, and K. Morris and R. Nair for a language check. We thank P. Jassal from the University of British Columbia and Jens Schumacher from University of Jena for their helpful comments. The authors T.M., M.M., M.D.M., J.K., C.W. and M.R. affiliated with the MPI BGC acknowledge funding by the European Union's Horizon 2020 project BACI under grant agreement no. 640176. This work used eddy covariance data acquired and shared by the FLUXNET community, including these networks: AmeriFlux, AfriFlux, AsiaFlux, CarboAfrica, CarboEuropeIP, CarboItaly, CarboMont, ChinaFlux, FluxnetCanada, GreenGrass, ICOS, KoFlux, LBA, NECC, OzFlux-TERN, TCOS-Siberia and USCCC. The ERA-Interim reanalysis data are provided by ECMWF and processed by LSCE. The FLUXNET eddy covariance data processing and harmonization was carried out by the European Fluxes Database Cluster, AmeriFlux Management Project, and Fluxdata project of FLUXNET, with the support of CDIAC and ICOS Ecosystem Thematic Center, and the OzFlux, ChinaFlux and AsiaFlux offices. T.M. acknowledges the International Max Planck Research School for global biogeochemical cycles.

\section{B.7 Author contributions}

T.M. wrote the manuscript and performed the analysis. T.M., M.M., M.D.M. and M.R. designed the study. M.M., M.D.M., M.R., J.K., I.J., A.K., A.C., C.W., T.A.B. and A.V. discussed the interpretation of the results. M.M., M.D.M., M.R., J.K., C.W., T.A.B., A.C.,A.K., D.L. and O.R. contributed significantly to editing the paper. S.R., R.T. and D.G.contributed to editing the paper. T.A.B., I.J., A.K., D.L., O.R., A.V., S.R., A.C., H.K. and T.F. contributed data.

\section{B.8 Additional information}

\section{B.8.1 Code availability}

The analysis was conducted in $\mathrm{R}$ version 3.2 .4 and the script of the analysis is available within the supplementary files of the paper.

\section{B.8.2 Data availability}

The authors declare that the data supporting the findings of this study are available within the Supplementary Information.

\section{B.8.3 Supplementary information}

is available for this paper https://www. nature.com/articles/s41559-016-0048.

\section{B.8.4 Reprints and permissions information}

is available at www.nature.com/reprints.

\section{B.8.5 Correspondence and requests for materials}

should be addressed to T.M. 


\section{B.8.6 How to cite this article}

:Musavi, T. et al. Stand age and species richness dampen interannual variation of ecosystemlevel photosynthetic capacity. Nat. Ecol. Evol.1, 0048 (2017).

\section{B.9 Competing interests}

The authors declare no competing financial interests. 


\section{Bibliography}

Ahlström, A. et al. (2015): 'The dominant role of semi-arid ecosystems in the trend and variability of the land CO2 sink'. Science, vol. 348(6237): pp. 895-899 (cit. on p. 126).

Ahrends, H., S Etzold, W. Kutsch, R Stoeckli, R Bruegger, F Jeanneret, H Wanner, N Buchmann, and W Eugster (Sept. 2009): 'Tree phenology and carbon dioxide fluxes: use of digital photography for process-based interpretation at the ecosystem scale'. Climate Research, vol. 39: pp. 261-274 (cit. on p. 123).

AlcAmo, J. et al. (2003): Ecosystems and Human Well-beingt / Millennium Ecosystem Assessment (cit. on p. 2).

Ali, A., E. R. Yan, H. Y. Chen, S. X. Chang, Y. T. Zhao, X. D. Yang, and M. S. Xu (2016): 'Stand structural diversity rather than species diversity enhances aboveground carbon storage in secondary subtropical forests in Eastern China'. Biogeosciences, vol. 13(16): pp. 4627-4635 (cit. on pp. 3-5).

Allard, V., J. M. Ourcival, S. Rambal, R. Joffre, and A. Rocheteau (2008): 'Seasonal and annual variation of carbon exchange in an evergreen Mediterranean forest in southern France'. Global Change Biology, vol. 14(4): pp. 714-725 (cit. on pp. 48, 68).

Allen, C. D., D. D. Breshears, and N. G. McDowell (Aug. 2015): 'On underestimation of global vulnerability to tree mortality and forest die-off from hotter drought in the Anthropocene'. ECOSPHERE, vol. 6(8): pp. 1-55 (cit. on pp. 5, 7).

Alvarez-Uria, P. and C. KÖRner (2007): 'Low temperature limits of root growth in deciduous and evergreen temperate tree species'. Functional Ecology, vol. 21(2): pp. 211218 (cit. on p. 30).

Anderegg, W. R. L., J. A. Berry, D. D. Smith, J. S. Sperry, L. D. L. Anderegg, and C. B. Field (2012): 'The roles of hydraulic and carbon stress in a widespread climate-induced forest die-off'. Proceedings of the National Academy of Sciences, vol. 109(1): pp. 233-237 (cit. on p. 5).

AnderegG, W. R., J. M. Kane, and L. D. AnderegG (2013): 'Consequences of widespread tree mortality triggered by drought and temperature stress'. Nature Climate Change, vol. 3(1): pp. 30-36 (cit. on p. 5).

AnderegG, W. R. L., A. G. Konings, A. T. Trugman, K. Yu, D. R. Bowling, R. Gabbitas, D. S. Karp, S. Pacala, J. S. Sperry, B. N. Sulman, and N. Zenes (2018): 'Hydraulic diversity of forests regulates ecosystem resilience during drought'. Nature, vol. 561(7724): pp. 538-541 (cit. on pp. 6, 46).

Anderson, E. C. (1999): Monte Carlo methods and importance sampling. Statistical Genetics. Lecture notes for Stat 578 C. (Cit. on p. 116).

Anthoni, P. M., A. Knohl, C. Rebmann, A. Freibauer, M. Mund, W. Ziegler, O. Kolle, and E. D. Schulze (2004): 'Forest and agricultural land-use-dependent CO2 exchange in Thuringia, Germany'. Global Change Biology, vol. 10(12): pp. 2005-2019 (cit. on pp. 15, 16, 18, 114, 115). 
Aubinet, M., B. Chermanne, M. Vandenhaute, B. Longdoz, M. Yernaux, and E. LAitAT (Mar. 2001): 'Long term carbon dioxide exchange above a mixed forest in the Belgian Ardennes'. Agricultural and Forest Meteorology, vol. 108(4): pp. 293-315 (cit. on p. 84).

Aubinet, M. et al. (Jan. 1999): 'Estimates of the Annual Net Carbon and Water Exchange of Forests: The EUROFLUX Methodology'. Advances in Ecological Research. Vol. 30. Academic Press: pp. 113-175 (cit. on p. 18).

Aubinet, M. et al. (2000): 'Estimates of the net annual Carbon and water exchange of forests: The Euroflux Methodology'. Advances in Ecological Research, vol. 30 (cit. on p. 115).

Babst, F., M. Carrer, B. Poulter, C. Urbinati, B. Neuwirth, and D. Frank (2012): '500 years of regional forest growth variability and links to climatic extreme events in Europe'. Environmental Research Letters, vol. 7(4) (cit. on p. 2).

BALDOCCHI, D. (2008): 'Breathing' of the terrestrial biosphere: lessons learned from a global network of carbon dioxide flux measurement systems'. Australian Journal of Botany, vol. 56(1): p. 1 (cit. on pp. 127, 129).

BALDOCCHI, D. and L. XU (2005): 'Carbon exchange of deciduous broadleaved forestes in temperate and Mediterranean regions'. The Carbon Balance of Forest Biomes, vol. Ed. by Griffiths, H and P JARvis: pp. 187-214 (cit. on p. 15).

BALdocchi, D. et al. (2001): 'FLUXNET: A New Tool to Study the Temporal and Spatial Variability of Ecosystem-Scale Carbon Dioxide, Water Vapor, and Energy Flux Densities'. Bulletin of the American Meteorological Society, vol. 82(11): pp. 2415-2434 (cit. on pp. 14, 45).

BALDOCCHI, D. D. (2018): 'Must we incorporate soil moisture information when applying light use efficiency models with satellite remote sensing information?' New Phytologist, vol. 218(4): pp. 1293-1294 (cit. on pp. 19, 31, 42).

Barbeta, A. and J. Penuelas (Aug. 2016): 'Sequence of plant responses to droughts of different timescales: lessons from holm oak (Quercus ilex) forests'. PLANT ECOLOGY \& DIVERSITY, vol. 9(4): pp. 321-338 (cit. on p. 5).

Barr, A., G. van der Kamp, T. Black, J. MCCaughey, and Z. Nesic (Feb. 2012): 'Energy balance closure at the BERMS flux towers in relation to the water balance of the White Gull Creek watershed 1999-2009'. Agricultural and Forest Meteorology, vol. 153: pp. 3-13 (cit. on p. 121).

Barr, A. G., T. A. Black, E. H. Hogg, T. J. Griffis, K. Morgenstern, N. Kluun, A. Theede, and Z. Nesic (2007): 'Climatic controls on the carbon and water balances of a boreal aspen forest, 1994-2003'. Global Change Biology, vol. 13(3): pp. 561-576 (cit. on p. 14).

Barriopedro, D., E. M. Fischer, J. Luterbacher, R. M. Trigo, and R. GarcíaHERRERA (2011): 'The hot summer of 2010: Redrawing the temperature record map of Europe'. Science, vol. 332(6026): pp. 220-224 (cit. on pp. 9, 46).

Bauhus, J., K. Puettmann, and C. Messier (2009): 'Silviculture for old-growth attributes'. Forest Ecology and Management, vol. 258(4): pp. 525-537 (cit. on p. 2). 
Becknell, J. M. and J. S. Powers (June 2014): 'Stand age and soils as drivers of plant functional traits and aboveground biomass in secondary tropical dry forest'. Canadian Journal of Forest Research, vol. 44(6): pp. 604-613 (cit. on p. 136).

Beer, C. et al. (2010): 'Terrestrial Gross Carbon Dioxide Uptake: Global Distribution and Covariation with Climate'. Science, vol. 329(5993): pp. 834-838 (cit. on p. 15).

Beguería, S. (2017): SPEIbase: Version 2.5.1 (cit. on p. 50).

Beguería, S., B. Latorre, F. Reig, and S. M. Vicente-Serrano (2017): SPEIbase v.2.5 [Dataset] (cit. on p. 50).

Beguería, S., S. M. Vicente-Serrano, and M. Angulo-Martínez (2010): 'A multiscalar global drought dataset: The SPEI base: A new gridded product for the analysis of drought variability and impacts'. Bulletin of the American Meteorological Society, vol. 91(10): pp. 1351-1356 (cit. on p. 50).

Bello, J., N. J. Hasselquist, P. Vallet, A. Kahmen, T. Perot, and N. KorBOULEWSKY (Apr. 2019a): 'Complementary water uptake depth of Quercus petraea and Pinus sylvestris in mixed stands during an extreme drought'. Plant and Soil, vol. 437(1-2): pp. 93-115 (cit. on p. 6).

Bello, J., P. Vallet, T. Perot, P. Balandier, V. Seigner, S. Perret, C. Couteau, and N. Korboulewsky (2019b): 'How do mixing tree species and stand density affect seasonal radial growth during drought events?' Forest Ecology and Management, vol. 432(October 2018): pp. 436-445 (cit. on pp. 4-6, 104).

Bittner, S., U. Talkner, I. Krämer, F. Beese, D. Hölscher, E. Priesack, I. Kraemer, F. Beese, D. Hoelscher, and E. Priesack (Sept. 2010): 'Modeling stand water budgets of mixed temperate broad-leaved forest stands by considering variations in species specific drought response'. AGRICULTURAL AND FOREST METEOROLOGY, vol. 150(10): pp. 1347-1357 (cit. on pp. 81, 82, 85, 89, 102).

Bolte, A., T. Rahmann, M. Kuhr, P. Pogoda, D. Murach, and K. V. Gadow (2004): 'Relationships between tree dimension and coarse root biomass in mixed stands of European beech (Fagus sylvatica L.) and Norway spruce (Picea abies [L.] Karst.)' Plant and Soil, vol. 264(1-2): pp. 1-11 (cit. on p. 64).

Bonan, G. B., K. W. Oleson, R. A. Fisher, G. Lasslop, and M. Reichstein (June 2012): 'Reconciling leaf physiological traits and canopy flux data: Use of the TRY and FLUXNET databases in the Community Land Model version 4'. Journal of Geophysical Research: Biogeosciences, vol. 117(G2): n/a-n/a (cit. on p. 135).

Boncina, A., A. KADUnC, and D. RoBic (2007): 'Effects of selective thinning on growth and development of beech (Fagus sylvatica L.) forest stands in south-eastern Slovenia'. Annals of Forest Science, vol. 64(1): pp. 44-57 (cit. on p. 105).

Brando, P. M., S. J. Goetz, A. Baccini, D. C. Nepstad, P. S. A. Beck, and M. C. Christman (Aug. 2010): 'Seasonal and interannual variability of climate and vegetation indices across the Amazon'. Proceedings of the National Academy of Sciences, vol. 107(33): pp. 14685-14690 (cit. on p. 127).

Breda, N., A. Granier, and G. Aussenac (1995): 'Effects of thinning on soil and tree water relations, transpiration and growth in an oak forest (Quercus petraea (Matt.) Liebl.)' Tree Physiology, vol. 15(5): pp. 295-306 (cit. on p. 105). 
Bréda, N., R. Huc, A. Granier, and E. Dreyer (2006): 'Temperate forest trees and stands under severe drought: a review of ecophysiological responses, adaptation processes and long-term consequences'. Annals of Forest Science, vol. 63(6): pp. 625-644 (cit. on pp. $5,65,108)$.

Breshears, D. D., N. S. Cobb, P. M. Rich, K. P. Price, C. D. Allen, R. G. Balice, W. H. Romme, J. H. Kastens, M. L. Floyd, J. Belnap, J. J. Anderson, O. B. Myers, and C. W. Meyer (2005): 'Regional vegetation die-off in response to global-change-type drought'. Proceedings of the National Academy of Sciences, vol. 102(42): pp. 15144-15148 (cit. on p. 7).

Brienen, R. J. W., E. Gloor, S. Clerici, R. Newton, L. Arppe, A. Boom, S. Bottrell, M. Callaghan, T. Heaton, S. Helama, G. Helle, M. J. Leng, K. MieliKÄinen, M. Oinonen, and M. Timonen (2017): 'Tree height strongly affects estimates of water-use efficiency responses to climate and CO2 using isotopes'. Nature Communications, vol. 8(1): p. 288 (cit. on p. 2).

Brunner, I., C. Herzog, M. A. Dawes, M. Arend, and C. Sperisen (2015): 'How tree roots respond to drought'. Frontiers in Plant Science, vol. 6(JULY) (cit. on p. 5).

Bugmann, H. and W. Cramer (1998): 'Improving the behavior of forest gap models along gradients'. Forest Ecology and Management, vol. 103: pp. 247-263 (cit. on p. 76).

Buras, A., A. RAmmig, and C. S. ZANG (2019): 'Quantifying impacts of the drought 2018 on European ecosystems in comparison to 2003'. Vol. (August) (cit. on pp. 108, 109).

Bussotti, F. and M. Pollastrini (2017): 'Traditional and novel indicators of climate change impacts on european forest trees'. Forests, vol. 8(4): pp. 1-12 (cit. on p. 7).

Butterbach-BAHL, K. et al. (2011): 'Nitrogen processes in terrestrial ecosystems'. The European Nitrogen Assessment. Ed. by Sutton, M. A., C. M. Howard, J. W. Erisman, G. Billen, A. Bleeker, P. Grennfelt, H. van Grinsven, and B. Grizzetti. Cambridge: Cambridge University Press: pp. 99-125 (cit. on p. 136).

Cáceres, M. D., J. Martínez-Vilalta, L. Coll, P. Llorens, P. Casals, R. Poyatos, J. G. Pausas, and L. Brotons (2015): 'Coupling a water balance model with forest inventory data to predict drought stress: The role of forest structural changes vs. climate changes'. Agricultural and Forest Meteorology, vol. 213: pp. 77-90 (cit. on pp. 81, 85-87).

Canadell, J. G. J. J. G. and M. M. R. Raupach (2008): 'Managing forests for climate change mitigation.' Science, vol. 320(5882): pp. 320-1456 (cit. on p. 2).

Carlyle-Moses, D. E. and J. H. C. Gash (2011): 'Rainfall Interception Loss by Forest Canopies'. Forest Hydrology and Biogeochemistry. Ed. by Levia, D., D. Carlyle-Moses, and T. TANAKA. Ecological. Dordrecht: Springer: pp. 407-423 (cit. on p. 122).

Cavender-Bares, J. and F. A. Bazzaz (2000): 'Changes in drought response strategies with ontogeny in quercus rubra: Implications for scaling from seedlings to mature trees'. Oecologia, vol. 124(1): pp. 8-18 (cit. on p. 5).

Chaves, M. M., J. S. Pereira, J. Maroco, M. L. Rodrigues, C. P. Ricardo, M. L. Osório, I. Carvalho, T. Faria, and C. Pinheiro (2002): 'How plants cope with water stress in the field. Photosynthesis and growth'. Annals of Botany, vol. 89(SPEC. ISS.): pp. 907-916 (cit. on p. 30). 
Chen, Z., G. Yu, X. Zhu, Q. Wang, S. Niu, and Z. Hu (2015): 'Covariation between gross primary production and ecosystem respiration across space and the underlying mechanisms: A global synthesis'. Agricultural and Forest Meteorology, vol. 203: pp. 180190 (cit. on pp. 14, 15, 45).

Chont, B., T. J. Brodribb, C. R. Brodersen, R. A. Duursma, R. López, and B. E. Medlyn (2018): 'Triggers of tree mortality under drought'. Nature, vol. 558(7711): pp. 531-539 (cit. on p. 5).

Chu, H., J. Chen, J. F. Gottgens, A. R. Desai, Z. Ouyang, and S. S. Qian (2016): 'Response and biophysical regulation of carbon dioxide fluxes to climate variability and anomaly in contrasting ecosystems in northwestern Ohio, USA'. Agricultural and Forest Meteorology, vol. 220: pp. 50-68 (cit. on p. 15).

CiAis, P et al. (2005): 'Europe-wide reduction in primary productivity caused by the heat and drought in 2003'. Nature, vol. 437(7058): pp. 529-533 (cit. on pp. 2, 14, 45, 46, 65, 107).

Clark, J. S. et al. (2016): 'The impacts of increasing drought on forest dynamics, structure, and biodiversity in the United States'. GLOBAL CHANGE BIOLOGY, vol. 22(7): pp. 2329-2352 (cit. on p. 76).

Cole, E. F. and B. C. Sheldon (2017): 'The shifting phenological landscape: Withinand between-species variation in leaf emergence in a mixed-deciduous woodland.' Ecology and evolution, vol. 7(4): pp. 1135-1147 (cit. on p. 30).

Coumou, D., A. Robinson, and S. RAhmstorf (2013): 'Global increase in recordbreaking monthly-mean temperatures'. Climatic Change, vol. 118(3-4): pp. 771-782 (cit. on p. 46).

Coursolle, C., H. A. Margolis, M. A. Giasson, P. Y. Bernier, B. D. Amiro, M. A. Arain, A. G. Barr, T. A. Black, M. L. Goulden, J. H. McCaughey, J. M. Chen, A. L. Dunn, R. F. Grant, and P. M. Lafleur (2012): 'Influence of stand age on the magnitude and seasonality of carbon fluxes in Canadian forests'. Agricultural and Forest Meteorology, vol. 165: pp. 136-148 (cit. on p. 136).

Davi, H., E. Dufrêne, A. Granier, V. Le Dantec, C. Barbaroux, C. François, and N. BRÉDA (2005a): 'Modelling carbon and water cycles in a beech forest'. Ecological Modelling, vol. 185(2-4): pp. 387-405 (cit. on p. 9).

Davi, H., E. Dufrêne, A. Granier, V. Le Dantec, C. Barbaroux, C. François, N. Bréda, H. Davi, C. François, G. le Maire, V. L. Dantec, and A. Granier (2005b): 'Modelling carbon and water cycles in a beech forest'. Ecological Modelling, vol. 185(2-4): pp. 387-405 (cit. on pp. 9, 76).

Davidson, E. A., E. BelK, and R. D. Boone (1998): 'Soil water content and temperature as independent or confounded factors controlling soil respiration in a temperate mixed hardwood forest'. Global Change Biology, vol. 4(2): pp. 217-227 (cit. on p. 30).

Davis, K. J., P. S. Bakwin, C. Yi, B. W. Berger, C. Zhao, R. M. Teclaw, and J. G. Isebrands (2003): 'Modeling canopy $\mathrm{CO}<\inf >2</$ inf $>$ and $\mathrm{H}<\inf >2</$ inf $>\mathrm{O}$ exchange of a temperate mixed forest'. Global Change Biology, vol. 9: pp. 1278-1293 (cit. on pp. 48, 68).

Davis, S. D., F. W. Ewers, J. S. Sperry, K. A. Portwood, M. C. Crocker, and G. C. AdAms (May 2002): 'Shoot dieback during prolonged drought in Ceanothus 
(Rhamnaceae) chaparral of California: a possible case of hydraulic failure'. American Journal of Botany, vol. 89(5): pp. 820-828 (cit. on p. 5).

Davis, T. W., I. C. Prentice, B. D. Stocker, R. T. Thomas, R. J. Whitley, H. Wang, B. J. Evans, A. V. Gallego-Sala, M. T. Sykes, and W. Cramer (2017): 'Simple process-led algorithms for simulating habitats (SPLASH v.1.0): Robust indices of radiation, evapotranspiration and plant-available moisture'. Geoscientific Model Development, vol. 10(2): pp. 689-708 (cit. on pp. 8, 76).

Dawson, T. E. (1996): 'Determining water use by trees and forests from isotopic, energy balance and transpiration analyses: the roles of tree size and hydraulic lift'. Tree Physiology, vol. 16(1-2): pp. 263-272 (cit. on p. 2).

Del Río, M., S. Condés, and H. Pretzsch (2014): 'Analyzing size-symmetric vs. sizeasymmetric and intra- vs. inter-specific competition in beech (Fagus sylvatica L.) mixed stands'. Forest Ecology and Management, vol. 325: pp. 90-98 (cit. on p. 136).

Desai, A. R., P. V. Bolstad, B. D. Cook, K. J. Davis, and E. V. Carey (2005): 'Comparing net ecosystem exchange of carbon dioxide between an old-growth and mature forest in the upper Midwest, USA'. Agricultural and Forest Meteorology, vol. 128(1-2): pp. 33-55 (cit. on pp. $48,68,84$ ).

DHôte, J. F. (1994): 'Hypotheses about competition for light and water in even-aged common beech (Fagus silvatica L.)' Forest Ecology and Management, vol. 69(1-3): pp. 219232 (cit. on p. 2).

Dittmar, C., W. Zech, and W. Elling (2003): 'Growth variations of Common beech (Fagus sylvatica L.) under different climatic and environmental conditions in Europe A dendroecological study'. Forest Ecology and Management, vol. 173(1-3): pp. 63-78 (cit. on p. 15).

Dănescu, A., A. T. Albrecht, and J. Bauhus (2016): 'Structural diversity promotes productivity of mixed, uneven-aged forests in southwestern Germany'. Oecologia, vol. 182(2): pp. 319-333 (cit. on pp. 3, 4, 45, 105).

Dănescu, A., U. Kohnle, J. Bauhus, J. Sohn, and A. T. Albrecht (May 2018): 'Stability of tree increment in relation to episodic drought in uneven-structured, mixed stands in southwestern Germany'. Forest Ecology and Management, vol. 415-416: pp. 148159 (cit. on p. 6).

Dobbertin, M. (2002): 'Influence of stand structure and site factors on wind damage comparing the storms Vivian and Lothar'. Forest Snow and Landscape Research, vol. 77(1-2): pp. 187-205 (cit. on pp. 4, 5).

Dragoni, D., H. P. Schmid, C. A. Wayson, H. Potter, C. S. B. Grimmond, and J. C. RANDOLPH (2011): 'Evidence of increased net ecosystem productivity associated with a longer vegetated season in a deciduous forest in south-central Indiana, USA'. Global Change Biology, vol. 17(2): pp. 886-897 (cit. on pp. 14, 31, 33).

Drexhage, M. and F. Gruber (1999): 'Above- and Below-stump Relationships for Picea Abies: Estimating Root System Biomass from Breast-height Diameters'. Scandinavian Journal of Forest Research, vol. 14(4): pp. 328-333 (cit. on p. 64).

Ehbrecht, M., P. Schall, C. Ammer, and D. Seidel (Aug. 2017): 'Quantifying stand structural complexity and its relationship with forest management, tree species diversity 
and microclimate'. Agricultural and Forest Meteorology, vol. 242(December 2016): pp. 1-9 (cit. on pp. 4, 64).

Ehbrecht, M., P. Schall, J. Juchheim, C. Ammer, and D. Seidel (2016): 'Effective number of layers: A new measure for quantifying three-dimensional stand structure based on sampling with terrestrial LiDAR'. Forest Ecology and Management, vol. 380: pp. 212-223 (cit. on p. 66).

Ehman, J. L., H. P. Schmid, C. S. Grimmond, J. C. Randolph, P. J. Hanson, C. A. WAYSON, and F. D. CROPLEY (2002): 'An initial intercomparison of micrometeorological and ecological inventory estimates of carbon exchange in a mid-latitude deciduous forest'. Global Change Biology, vol. 8(6): pp. 575-589 (cit. on pp. 48, 68).

Etzold, S., N. K. Ruehr, R. Zweifel, M. Dobbertin, A. ZingG, P. Pluess, R. HÄsler, W. Eugster, and N. Buchmann (2011): 'The carbon balance of two contrasting mountain forest ecosystems in Switzerland: Similar annual trends, but seasonal differences'. Ecosystems, vol. 14(8): pp. 1289-1309 (cit. on pp. 48, 68, 84).

Fares, S., G. S. Mugnozza, P. Corona, and M. Palahí (Mar. 2015): 'Sustainability: Five steps for managing Europe's forests'. Nature, vol. 519(7544): pp. 407-409 (cit. on p. 3).

Fehrmann, L. (2006): 'Alternative Methoden zur Biomasseschätzung auf Einzelbaumebene unter spezieller Berücksichtigung der k-Nearest Neighbour (k-NN) Methode.' PhD thesis. University of Göttingen (cit. on p. 116).

Felton, A. et al. (2016): 'Replacing monocultures with mixed-species stands: Ecosystem service implications of two production forest alternatives in Sweden'. Ambio, vol. 45: pp. 124-139 (cit. on p. 104).

Fernández-Martínez, M., S. Vicca, I. A. Janssens, J. Sardans, S. Luyssaert, M. Campioli, F. S. Chapin III, P. Ciais, Y. Malhi, M. Obersteiner, D. Papale, S. L. PiaO, M. Reichstein, F. RodÀ, and J. Peñuelas (June 2014): 'Nutrient availability as the key regulator of global forest carbon balance'. Nature Climate Change, vol. 4(6): pp. 471-476 (cit. on pp. 127-130, 132).

FERnÁndeZ-Martínez, M. et al. (2017): 'Atmospheric deposition, CO2, and change in the land carbon sink'. Scientific Reports, vol. 7(1): pp. 1-13 (cit. on pp. 19, 32, 52).

Ferreira, J. et al. (2018): 'Carbon-focused conservation may fail to protect the most biodiverse tropical forests'. Nature Climate Change, vol. 8(8): pp. 744-749 (cit. on p. 106).

Ferretti, M., L. Baratozzi, E. Cenni, A. Cozzi, and P. Savini (1998): 'Crown transparency of beech (Fagus sylvatica L.) in the northern Apennines (Italy) - Status, changes and relationships with site characteristics and other indices of tree condition'. Chemosphere, vol. 36(4-5): pp. 1037-1042 (cit. on p. 32).

Field, A. P., J. Miles, and Z. Field (2012): Discovering statistics using R. Sage (cit. on p. 18).

FinNigan, J. (Sept. 2008): 'AN INTRODUCTION TO FLUX MEASUREMENTS IN DIFFICULT CONDITIONS'. Ecological Applications, vol. 18(6): pp. 1340-1350 (cit. on p. 120).

Firn, J., P. D. ERskine, and D. LAmb (2007): 'Woody species diversity influences productivity and soil nutrient availability in tropical plantations'. Oecologia, vol. 154(3): pp. 521-533 (cit. on p. 44). 
FluXnet (2017): Fluxnet data processing (cit. on pp. 83, 84).

Foken, T., M. Aubinet, J. J. Finnigan, M. Y. Leclerc, M. Mauder, and K. T. Paw U (Apr. 2011): 'Results Of A Panel Discussion About The Energy Balance Closure Correction For Trace Gases'. Bulletin of the American Meteorological Society, vol. 92(4): ES13-ES18 (cit. on p. 121).

Foken, T., M. Göockede, M. Mauder, L. Mahrt, B. Amiro, and W. Munger (2004): 'Post-Field Data Quality Control'. Handbook of Micrometeorology. Ed. by LEE, X., W. Massman, and B. Law. Atmospheri. Dordrecht: Springer: pp. 181-208 (cit. on pp. 18, $115)$.

ForRester, D. I. (2015): 'Transpiration and water-use efficiency in mixed-species forests versus monocultures: Effects of tree size, stand density and season'. Tree Physiology, vol. 35(3): pp. 289-304 (cit. on pp. 64, 109).

Forrester, D. I., D. Bonal, S. Dawud, A. Gessler, A. Granier, M. Pollastrini, and C. Grossiord (2016): 'Drought responses by individual tree species are not often correlated with tree species diversity in European forests'. JOURNAL OF APPLIED ECOLOGY, vol. 53(6): pp. 1725-1734 (cit. on pp. 6, 46).

Forrester, D. I., S. Theiveyanathan, J. J. Collopy, and N. E. Marcar (2010): 'Enhanced water use efficiency in a mixed Eucalyptus globulus and Acacia mearnsii plantation'. Forest Ecology and Management, vol. 259(9): pp. 1761-1770 (cit. on p. 46).

Fox, J. et al. (2019): Companion to Applied Regression (cit. on p. 54).

Franklin, J. F., T. A. Spies, R. V. Pelt, A. B. Carey, D. A. Thornburgh, D. R. Berg, D. B. Lindenmayer, M. E. Harmon, W. S. Keeton, D. C. Shaw, K. Bible, and J. Chen (2002): 'Disturbances and structural development of natural forest ecosystems with silvicultural implications, using Douglas-fir forests as an example'. Forest Ecology and Management, vol. 155(1-3): pp. 399-423 (cit. on p. 3).

Froelich, N., H. Croft, J. M. Chen, A. Gonsamo, and R. M. Staebler (2015): 'Trends of carbon fluxes and climate over a mixed temperate-boreal transition forest in southern Ontario, Canada'. Agricultural and Forest Meteorology, vol. 211-212: pp. 72-84 (cit. on pp. 19, 31-33, 42).

Gale, M. R. and D. F. Grigal (1987): 'Vertical root distributions of northern tree species in relation to successional status'. Canadian Journal of Forest Research, vol. 17(8): pp. 829-834 (cit. on p. 78).

GAMFELDT, L. et al. (2013): 'Higher levels of multiple ecosystem services are found in forests with more tree species'. Nature Communications, vol. 4 (cit. on pp. 2, 44, 45, 104).

García-Palacios, P., F. T. Maestre, and A. Gallardo (Dec. 2010): 'Soil nutrient heterogeneity modulates ecosystem responses to changes in the identity and richness of plant functional groups'. Journal of Ecology, vol.: no-no (cit. on p. 127).

Gash, J. H. C., C. R. Lloyd, and G. LaChaud (1995): 'Estimating sparse forest rainfall interception with an analytical model'. Journal of Hydrology, vol. 170(1-4): pp. 79-86 (cit. on pp. 78,80 ).

Gash, J., F Valente, and J. David (Apr. 1999): 'Estimates and measurements of evaporation from wet, sparse pine forest in Portugal'. Agricultural and Forest Meteorology, vol. 94(2): pp. 149-158 (cit. on p. 115). 
Gebauer, T., V. Horna, and C. Leuschner (2012): 'Canopy transpiration of pure and mixed forest stands with variable abundance of European beech'. Journal of Hydrology, vol. 442-443: pp. 2-14 (cit. on p. 64).

Gilmanov, T. G., S. B. Verma, P. L. Sims, T. P. Meyers, J. A. Bradford, G. G. Burba, and A. E. Suyker (2003): 'Gross primary production and light response parameters of four Southern Plains ecosystems estimated using long-term $\mathrm{CO}<$ sub $>2</$ sub $>$ -flux tower measurements'. Global Biogeochemical Cycles, vol. 17(2): n/a-n/a (cit. on p. 130).

Göckede, M. et al. (Mar. 2008): 'Quality control of CarboEurope flux data \&ndash; Part 1: Coupling footprint analyses with flux data quality assessment to evaluate sites in forest ecosystems'. Biogeosciences, vol. 5(2): pp. 433-450 (cit. on p. 116).

Göckede, M., C. Rebmann, and T. Foken (Dec. 2004): 'A combination of quality assessment tools for eddy covariance measurements with footprint modelling for the characterisation of complex sites'. Agricultural and Forest Meteorology, vol. 127(3-4): pp. $175-188$ (cit. on p. 116).

Gonzalez-Meler, M. A., F. Hopkins, C. E. Flower, D. J. Lynch, C. Czimczik, J. TANG, and J.-A. SUBKE (2013): 'Ecosystem-level controls on root-rhizosphere respiration'. New Phytologist, vol. 199: pp. 339-351 (cit. on p. 30).

Gossner, M. M., P. Schall, C. Ammer, U. Ammer, K. Engel, H. Schubert, U. Simon, H. Utschick, and W. W. Weisser (2014): 'Forest management intensity measures as alternative to stand properties for quantifying effects on biodiversity'. Ecosphere, vol. 5(9): pp. 1-111 (cit. on pp. 4, 5, 66).

Gough, C. M., C. S. Vogel, K. H. Harrold, K. George, and P. S. Curtis (2007): 'The legacy of harvest and fire on ecosystem carbon storage in a north temperate forest'. Global Change Biology, vol. 13(9): pp. 1935-1949 (cit. on pp. 48, 68).

Granda, E., A. Gazol, and J. J. Camarero (Mar. 2018): 'Functional diversity differently shapes growth resilience to drought for co-existing pine species'. Journal of Vegetation Science, vol. 29(2). Ed. by KIKVIDZE, Z.: pp. 265-275 (cit. on p. 6).

Granier, A., P. Biron, and D. Lemoine (2000): 'Water balance, transpiration and canopy conductance in two beech stands'. Agricultural and Forest Meteorology, vol. 100(4): pp. 291-308 (cit. on p. 122).

Granier, A., N. Bréda, P. Biron, and S. Villette (1999): 'A lumped water balance model to evaluate duration and intensity of drought constraints in forest stands'. Ecological Modelling, vol. 116(2-3): pp. 269-283 (cit. on pp. 8, 18, 76-78, 83, 87).

Granier, A. et al. (2007): 'Evidence for soil water control on carbon and water dynamics in European forests during the extremely dry year: 2003'. Agricultural and Forest Meteorology, vol. 143(1-2): pp. 123-145 (cit. on pp. 2, 5, 77, 118).

Granier, A., N. BrédA, B. Longdoz, P. Gross, and J. NGaO (2008): 'Ten years of fluxes and stand growth in a young beech forest at Hesse, North-eastern France'. Annals of Forest Science, vol. 65(7): pp. 704-704 (cit. on pp. 15, 19, 31-33, 42).

Greve, P. and S. I. Seneviratne (2015): 'Assessment of future changes in water availability and aridity'. Geophysical Research Letters, vol. 42(13): pp. 5493-5499 (cit. on pp. 9, 46). 
Grier, C. C. and S. W. Running (1977): 'Leaf area of mature northwestern coniferous forests : relation to site water balance'. Ecology, vol. 58(4): pp. 893-899 (cit. on p. 76).

Griess, V. C. and T. KNOKE (2011): 'Growth performance, wind throw, and insects: Metaanalyses of parameters influencing performance of mixed-species stands in boreal and northern temperate biomes'. Canadian Journal of Forest Research, vol. 41(6): pp. 11411159 (cit. on pp. 2, 46).

Grimm, V. and C. Wissel (1997): 'Babel, or the ecological stability discussions: an inventory and analysis of terminology and a guide for avoiding confusion'. Oecologia, vol. 109(3): pp. 323-334 (cit. on p. 10).

Groenendijk, M., A. Dolman, M. van der Molen, R. Leuning, A. Arneth, N. Delpierre, J. Gash, A. Lindroth, A. Richardson, H. Verbeeck, and G. Wohlfahrt (Jan. 2011): 'Assessing parameter variability in a photosynthesis model within and between plant functional types using global Fluxnet eddy covariance data'. Agricultural and Forest Meteorology, vol. 151(1): pp. 22-38 (cit. on pp. 112, 124).

GRÖMPING, U. (2007): 'Estimators of relative importance in linear regression based on variance decomposition'. American Statistician, vol. 61(2): pp. 139-147 (cit. on p. 128).

Grossiond, C. (Jan. 2019): 'Having the right neighbors: how tree species diversity modulates drought impacts on forests'. New Phytologist, vol. (cit. on p. 5).

Grossiord, C., A. Gessler, A. Granier, S. Berger, C. Bréchet, R. Hentschel, R. Hommel, M. Scherer-Lorenzen, and D. Bonal (2014a): 'Impact of interspecific interactions on the soil water uptake depth in a young temperate mixed species plantation'. Journal of Hydrology, vol. 519(PD): pp. 3511-3519 (cit. on p. 46).

Grossiord, C., A. Gessler, A. Granier, M. Pollastrini, F. Bussotti, and D. Bonal (Apr. 2014b): 'Interspecific competition influences the response of oak transpiration to increasing drought stress in a mixed Mediterranean forest'. Forest Ecology and Management, vol. 318: pp. 54-61 (cit. on p. 6).

Grossiord, C., A. Granier, S. Ratcliffe, O. Bouriaud, H. Bruelheide, E. Checko, D. I. Forrester, S. M. Dawud, L. Finer, M. Pollastrini, M. Scherer-Lorenzen, F. Valladares, D. Bonal, and A. Gessler (2014c): 'Tree diversity does not always improve resistance of forest ecosystems to drought'. PROCEEDINGS OF THE NATIONAL ACADEMY OF SCIENCES OF THE UNITED STATES OF AMERICA, vol. 111(41): pp. 14812-14815 (cit. on pp. 5, 6, 15, 46, 104, 123, 124, 136).

Grossiord, C., A. A. Granier, A. Gessler, T. Jucker, and D. Bonal (2014d): 'Does Drought Influence the Relationship Between Biodiversity and Ecosystem Functioning in Boreal Forests?' ECOSYSTEMS, vol. 17(3): pp. 394-404 (cit. on pp. 6, 46).

Grüneberg, E., I. Schöning, D. Hessenmöller, E.-D. Schulze, and W. Weisser (Sept. 2013): 'Organic layer and clay content control soil organic carbon stocks in density fractions of differently managed German beech forests'. Forest Ecology and Management, vol. 303: pp. 1-10 (cit. on p. 122).

Grünwald, T. and C. Bernhofer (2007): 'A decade of carbon, water and energy flux measurements of an old spruce forest at the Anchor Station Tharandt'. Tellus, Series B: Chemical and Physical Meteorology, vol. 59(3): pp. 387-396 (cit. on p. 84).

Guckland, A., M. Jacob, H. Flessa, F. M. Thomas, and C. Leuschne (2009): 'Acidity, nutrient stocks, and organic-matter content in soils of a temperate deciduous 
forest with different abundance of European beech (Fagus sylvatica L.)' Journal of Plant Nutrition and Soil Science, vol. 172(4): pp. 500-511 (cit. on pp. 85, 102).

Hakkenberg, C. R., C. Song, R. K. Peet, and P. S. White (Nov. 2016): 'Forest structure as a predictor of tree species diversity in the North Carolina Piedmont'. Journal of Vegetation Science, vol. 27(6). Ed. by Rocchini, D.: pp. 1151-1163 (cit. on p. 3).

Han, Q., D. Kabeya, A. IIo, and Y. KakUbari (2008): 'Masting in Fagus crenata and its influence on the nitrogen content and dry mass of winter buds'. Tree Physiology, vol. 28(8): pp. 1269-1276 (cit. on p. 32).

Hansen, J., M. Sato, and R. Ruedy (2012): 'Public Perception of Climate Change and the New Climate Dice'. Proceedings of the National Academy of Sciences of the United States of America, vol. 2012 (cit. on p. 46).

Hardiman, B. S., G. Bohrer, C. S. Vogel, C. M. Gough, and P. S. Curtis (2011): 'The role of canopy structural complexity in wood net primary production of a maturing northern deciduous forest'. Ecology, vol. 92(9): pp. 1818-1827 (cit. on pp. 4, 5, 104, 105).

Hardiman, B. S., C. M. Gough, A. Halperin, K. L. Hofmeister, L. E. Nave, G. Bohrer, and P. S. Curtis (2013): 'Maintaining high rates of carbon storage in old forests: A mechanism linking canopy structure to forest function'. Forest Ecology and Management, vol. 298: pp. 111-119 (cit. on pp. 4, 45).

Hein, S. and J. F. DHÔTE (2006): 'Effect of species composition, stand density and site index on the basal area increment of oak trees (Quercus sp.) in mixed stands with beech (Fagus sylvatica L.) in northern France'. Annals of Forest Science, vol. 63(5): pp. 457-467 (cit. on pp. 4, 5).

Herbst, M., P. T. W. Rosier, M. D. Morecroft, and D. J. Gowing (June 2008): 'Comparative measurements of transpiration and canopy conductance in two mixed deciduous woodlands differing in structure and species composition'. Tree Physiology, vol. 28(6): pp. 959-970 (cit. on p. 122).

Herbst, M., M. Mund, R. Tamrakar, and A. Knohl (2015): 'Differences in carbon uptake and water use between a managed and an unmanaged beech forest in central Germany'. Forest Ecology and Management, vol. 355: pp. 101-108 (cit. on pp. 12, 15, 31, $32,48,84,104-106,108,111,127)$.

Holling, C. S. (Nov. 1973): 'Resilience and Stability of Ecological Systems'. Annual Review of Ecology and Systematics, vol. 4(1): pp. 1-23 (cit. on pp. 10, 106, 127).

HolmsgaARD, E (1955): 'Tree-ring analyses of Danish forest trees'. Det forstlige forsøgsvæsen i Danmark, vol. XXII: pp. 1-246 (cit. on p. 32).

Holzwarth, F. M., M. Daenner, and H. Flessa (Oct. 2011): 'Effects of beech and ash on small-scale variation of soil acidity and nutrient stocks in a mixed deciduous forest'. Journal of Plant Nutrition and Soil Science, vol. 174(5): pp. 799-808 (cit. on p. 123).

Hommeltenberg, J., H. P. Schmid, M. Drösler, and P. Werle (2014): 'Can a bog drained for forestry be a stronger carbon sink than a natural bog forest?' Biogeosciences, vol. 11(13): pp. 3477-3493 (cit. on p. 15).

Hu, H., G. G. Wang, W. L. Bauerle, and R. J. Klos (2017): 'Drought impact on forest regeneration in the Southeast USA'. ECOSPHERE, vol. 8(4) (cit. on p. 76). 
Huang, C.-Y. and W. R. L. Anderegg (2012): 'Large drought-induced aboveground live biomass losses in southern Rocky Mountain aspen forests'. GLOBAL CHANGE BIOLOGY, vol. 18(3): pp. 1016-1027 (cit. on p. 76).

Hui, D., Y. Luo, and G. Katul (2017): 'Partitioning interannual variability in net ecosystem exchange between climatic variability and functional change'. Vol. (December): pp. 433-442 (cit. on p. 14).

Humphreys, E. R. and P. M. Lafleur (2011): 'Does earlier snowmelt lead to greater $\mathrm{CO}<\mathrm{sub}>2</$ sub $>$ sequestration in two low Arctic tundra ecosystems?' Geophysical Research Letters, vol. 38(9): n/a-n/a (cit. on p. 14).

Hurdebise, Q., B. Heinesch, A. De Ligne, C. Vincke, and M. Aubinet (2017): 'Impact of canopy aerodynamic distance spatial and temporal variability on long term eddy covariance measurements'. Agricultural and Forest Meteorology, vol. 247(January): pp. 131-138 (cit. on pp. 48, 68).

Ibrom, A., E. Dellwik, H. Flyvbjerg, N. O. Jensen, and K. Pilegaard (Dec. 2007): 'Strong low-pass filtering effects on water vapour flux measurements with closed-path eddy correlation systems'. Agricultural and Forest Meteorology, vol. 147(3-4): pp. 140-156 (cit. on p. 121).

Ilvesniemi, H., J. Levula, R. Ojansuu, P. Kolari, L. Kulmala, J. Pumpanen, S. Launiainen, T. Vesala, and E. NikinmaA (2009): 'Long-term measurements of the carbon balance of a boreal Scots pine dominated forest ecosystem'. Boreal Environment Research, vol. 14(4): pp. 731-753 (cit. on p. 68).

InNes, J. L. (1992): 'Observations on the condition of beech (Fagus sylvatica L.) in Britain in 1990'. Forestry, vol. 65(1): pp. 35-60 (cit. on p. 32).

InNES, J. L. (1994): 'The occurrence of flowering and fruiting on individual trees over 3 years and their effects on subsequent crown condition'. Trees, vol. 8(3): pp. 139-150 (cit. on p. 32).

IPCC (2012): Managing the Risks of Extreme Events and Disasters to Advance Climate Change Adaptation. A Special Report of Working Groups I and II of the Intergovernmental Panel on Climate Change. Ed. by Field, C. B., V. Barros, T. F. Stocker, D. Qin, D. J. Dokken, K. Ebi, M. D. Mastrandrea, K. J. Mach, G. K. Plattner, S. K. Allen, M. Tignor, and P. M. Midgley. Cambridge, UK and New York, USA: Cambridge University Press: p. 582 (cit. on pp. 2, 46).

- (2018): Summary for Policymakers. In: Global warming of $1.5^{\circ} \mathrm{C}$. An IPCC Special Report on the impacts of global warming: p. 32 (cit. on pp. 2, 45).

Irvine, J, B. E. Law, M. R. Kurpius, P. M. Anthoni, D Moore, and P. A. Schwarz (2004): 'Age-related changes in ecosystem structure and function and effects on water and carbon exchange in ponderosa pine'. Tree Physiology, vol. 24: pp. 753-763 (cit. on p. 84).

Ishinara, M. I. and K. KikUZAWA (2009): 'Annual and spatial variation in shoot demography associated with masting in Betula grossa: Comparison between mature trees and saplings'. Annals of Botany, vol. 104(6): pp. 1195-1205 (cit. on p. 32).

Ishil, H., W. Azuma, and E. Nabeshima (2013): 'The need for a canopy perspective to understand the importance of phenotypic plasticity for promoting species coexistence 
and light-use complementarity in forest ecosystems'. Ecological Research, vol. 28(2): pp. 191-198 (cit. on p. 45).

IshiI, H. T., S. I. S.-I. TANABE, and T. Hiura (2004): 'Exploring the Relationships Among Canopy Structure, Stand Productivity, and B...' Forest Science, vol. 50(3): pp. 342-355 (cit. on p. 4).

Ives, A. R. and S. R. CARPenter (2007): 'Stability and diversity of ecosystems'. Science, vol. 317(5834): pp. 58-62 (cit. on p. 106).

Jackson, R. B., J. Canadell, J. R. Ehleringer, H. A. Mooney, O. E. Sala, and E. D. Schulze (1996): 'A global analysis of root distributions for terrestrial biomes'. Oecologia, vol. 108(3): pp. 389-411 (cit. on pp. 78, 81, 85).

JaCkson, R. D., S. B. Idso, and R. J. Reginato (1976): 'Calculation of evaporation rates during the transition from energy-limiting to soil-limiting phases using albedo data'. Water Resources Research, vol. 12(1): pp. 23-26 (cit. on p. 86).

Jactel, H., E. S. Gritti, L. Drössler, D. I. Forrester, W. L. Mason, X. Morin, H. Pretzsch, and B. Castagneyrol (2018): 'Positive biodiversity-productivity relationships in forests: Climate matters'. Biology Letters, vol. 14(4): pp. 12-15 (cit. on pp. 104, 105).

Jactel, H., J. Bauhus, J. Boberg, D. Bonal, B. Castagneyrol, B. Gardiner, J. R. Gonzalez-Olabarria, J. Koricheva, N. Meurisse, and E. G. Brockerhoff (2017): 'Tree Diversity Drives Forest Stand Resistance to Natural Disturbances'. Current Forestry Reports, vol. (July) (cit. on p. 104).

JaCtel, H. and E. G. Brockerhoff (2007): 'Tree diversity reduces herbivory by forest insects'. Ecology Letters, vol. 10(9): pp. 835-848 (cit. on p. 104).

Jandl, R., M. Lindner, L. Vesterdal, B. Bauwens, R. Baritz, F. Hagedorn, D. W. Johnson, K. Minkkinen, and K. A. Byrne (Jan. 2007): 'How strongly can forest management influence soil carbon sequestration?' Geoderma, vol. 137(3-4): pp. 253-268 (cit. on p. 122).

Janssens, I. A., D. A. Sampson, J. Cermak, L. Meiresonne, F. Riguzzi, S. OverLOop, and R. Ceulemans (1999): 'Above- and belowground phytomass and carbon storage in a Belgian Scots pine stand'. Annals of Forest Science, vol. 56(2): pp. 81-90 (cit. on p. 84).

JAnsson, P.-E. and L. KARlberg (2011): 'Coupled heat and mass transfer model for soil- plant-atmosphere systems'. COUP Manual, vol. 15(2): pp. 1-327 (cit. on pp. 9, 76).

Jensen, R., M. Herbst, and T. Friborg (2017): 'Direct and indirect controls of the interannual variability in atmospheric $\mathrm{CO} 2$ exchange of three contrasting ecosystems in Denmark'. Agricultural and Forest Meteorology, vol. 233: pp. 12-31 (cit. on pp. 14, 15, $45)$.

Jong, R. de and A. Bootsma (1996): 'Review of recent developments in soil water simulation models'. Canadian Journal of Soil Science, vol. 76(3): pp. 263-273 (cit. on pp. $7,76,77)$.

Jucker, T., D. Avăcăriței, I. Bărnoaiea, G. Duduman, O. Bouriaud, and D. A. Coomes (2016): 'Climate modulates the effects of tree diversity on forest productivity'. Journal of Ecology, vol. 104(2): pp. 388-398 (cit. on pp. 2, 46, 65, 105). 
Jucker, T., O. Bouriaud, D. Avacaritei, and D. A. Coomes (2014): 'Stabilizing effects of diversity on aboveground wood production in forest ecosystems: linking patterns and processes'. Ecology Letters, vol. 17(12): pp. 1560-1569 (cit. on pp. 2, 15, 44, 105, 106, 127).

Kahl, T., M. Mund, J. Bauhus, and E.-D. Schulze (Dec. 2012): 'Dissolved organic carbon from European beech logs: Patterns of input to and retention by surface soil'. Écoscience, vol. 19(4): pp. 364-373 (cit. on p. 115).

Kätterer, T., O. Andrén, and P. E. Jansson (2006): 'Pedotransfer functions for estimating plant available water and bulk density in Swedish agricultural soils'. Acta Agriculturae Scandinavica Section B: Soil and Plant Science, vol. 56(4): pp. 263-276 (cit. on p. 84).

Keenan, T. F., D. Y. Hollinger, G. Bohrer, D. Dragoni, J. W. Munger, H. P. Schmid, and A. D. Richardson (2013): 'Increase in forest water-use efficiency as atmospheric carbon dioxide concentrations rise'. Nature, vol. 499(7458): pp. 324-327 (cit. on pp. 109, 112).

Kitamura, K., Y. Nakai, S. Suzuki, Y. Ohtani, K. Yamanoi, and T. Sakamoto (2012): 'Interannual variability of net ecosystem production for a broadleaf deciduous forest in Sapporo, northern Japan'. Journal of Forest Research, vol. 17(3): pp. 323-332 (cit. on p. 14).

Klatassen, W., F. Bosveld, and E. De Water (1998): 'Water storage and evaporation as constituents of rainfall interception'. Journal of Hydrology, vol. 212-213(1-4): pp. 36-50 (cit. on p. 81).

Knohl, A., E.-D. Schulze, O. Kolle, and N. Buchmann (2003): 'Large carbon uptake by an unmanaged 250-year-old deciduous forest in Central Germany'. Agricultural and Forest Meteorology, vol. 118: pp. 151-167 (cit. on pp. 16-18, 32, 48, 68, 84, 113, 115, 121).

Komatsu, H., T. Kume, Y. Shinohara, Y. Miyazawa, and K. Otsuki (2010): 'Did annual run-off and low flow decrease with reduced forestry practices in Japan?' Hydrological Processes, vol. 24(17): pp. 2440-2451 (cit. on p. 123).

Koop, H. and P. Hilgen (1987): 'Forest dynamics and regeneration mosaic shifts in unexploited beech (Fagus sylvatica) stands at Fontainebleau (France)'. Forest Ecology and Management, vol. 20(1-2): pp. 135-150 (cit. on p. 68).

Koster, R. D. and S. P. P. Mahanama (2012): 'Land Surface Controls on Hydroclimatic Means and Variability'. Journal of Hydrometeorology, vol. 13(5): pp. 1604-1620 (cit. on p. 8).

Kotlarz, J., S. NasiŁowska, K. Rotchimmel, K. Kubiak, and M. Kacprzak (Mar. 2018): 'Species Diversity of Oak Stands and Its Significance for Drought Resistance'. Forests, vol. 9(3): p. 126 (cit. on p. 6).

Kurz, W. A., C. C. Dymond, G. Stinson, G. J. Rampley, E. T. Neilson, A. L. Carroll, T. Ebata, and L. Safranyik (2008): 'Mountain pine beetle and forest carbon feedback to climate change'. Nature, vol. 452(7190): pp. 987-990 (cit. on p. 2).

Kustas, W. P. (2016): 'Soil: Evaporation'. Encyclopedia of Natural Resources: Land, vol.: pp. $444-453$ (cit. on pp. 81,86 ). 
Kutsch, W. (2009): 'Old-Growth Forests: Function, Fate and Value-a Synthesis'. OldGrowth Forests. Ed. by Wirth, C., G. Gleixner, and M. Heimann. Vol. 207. Ecological Studies. Berlin, Heidelberg: Springer Berlin Heidelberg (cit. on p. 127).

Kutsch, W. L., O. Kolle, C. Rebmann, A. Knohl, W. Ziegler, and E.-D. Schulze (Sept. 2008): 'ADVECTION AND RESULTING CO 2 EXCHANGE UNCERTAINTY IN A TALL FOREST IN CENTRAL GERMANY'. Ecological Applications, vol. 18(6): pp. 1391-1405 (cit. on p. 120).

Kutsch, W. L., T. Persson, M. Schrumpf, F. E. Moyano, M. Mund, S. Andersson, and E. D. Schulze (2010): 'Heterotrophic soil respiration and soil carbon dynamics in the deciduous Hainich forest obtained by three approaches'. Biogeochemistry, vol. 100(1): pp. $167-183$ (cit. on pp. $85,102,105,120,122$ ).

Lantschner, M. V., B. H. Aukema, and J. C. Corley (2019): 'Droughts drive outbreak dynamics of an invasive forest insect on an exotic host'. Forest Ecology and Management, vol. 433(December 2018): pp. 762-770 (cit. on p. 76).

Lasslop, G., M. Reichstein, D. Papale, A. D. Richardson, A. Arneth, A. Barr, P. Stoy, and G. Wohlfahrt (Jan. 2010): 'Separation of net ecosystem exchange into assimilation and respiration using a light response curve approach: critical issues and global evaluation'. Global Change Biology, vol. 16(1): pp. 187-208 (cit. on pp. 50, 51).

Law, B. E., T. Arkebauer, J Campbell, J. Chen, O. J. Sun, M. Schwartz, C. van Ingen, and S. Verma (2008): Terrestrial Carbon Observations: Protocols for Vegetation Sampling and Data Submission. Tech. rep. Rome: Global Terrestrial Observing System, FAO (cit. on p. 129).

LAW, B. et al. (2002): 'Environmental controls over carbon dioxide and water vapor exchange of terrestrial vegetation'. Agricultural and Forest ..., vol. 113(1-4): pp. 97-120 (cit. on p. 15).

LAW, B. E. (Dec. 2014): 'Regional analysis of drought and heat impacts on forests: current and future science directions'. Global Change Biology, vol. 20(12): pp. 3595-3599 (cit. on pp. 112, 124).

Law, B. E., T. W. Hudiburg, L. T. Berner, J. J. Kent, P. C. Buotte, and M. E. HARMon (2018): 'Land use strategies to mitigate climate change in carbon dense temperate forests'. Proceedings of the National Academy of Sciences, vol. 115(14): pp. 3663-3668 (cit. on p. 2).

Le BAs, C, D King, and J Daroussin (1997): 'A Tool for Estimating Soil Water Available for Plants Using the 1:1, 000 , 000 Scale Soil Geographical Data Base of Europe'. Itc J. Vol. 3. 4. Enschede: Geo-information for sustainable land management: pp. 1-10 (cit. on p. 84).

Le Quéré, C., L. Barbero, J. Hauck, R. M. Andrew, J. G. Canadell, S. Sitch, and J. I. Korsbakken (2018): 'Global Carbon Budget 2016 Global Carbon Budget 2016'. Earth System Science Data, vol. 0(April 2017): pp. 2141-2194 (cit. on p. 2).

LE QuÉRÉ, C. et al. (2009): 'Trends in the sources and sinks of carbon dioxide'. Nature Geoscience, vol. 2(12): pp. 831-836 (cit. on p. 126).

Lebourgeois, F., N. Gomez, P. Pinto, and P. Mérian (Sept. 2013): 'Mixed stands reduce Abies alba tree-ring sensitivity to summer drought in the Vosges mountains, 
western Europe'. Forest Ecology and Management, vol. 303: pp. 61-71 (cit. on pp. 5, 6, $46,104)$.

Lei, X., W. Wang, and C. Peng (2009): 'Relationships between stand growth and structural diversity in spruce-dominated forests in New Brunswick, Canada'. Canadian Journal of Forest Research, vol. 39(10): pp. 1835-1847 (cit. on pp. 4, 44, 45).

Lenth, R. (2017): 'Package ' lsmeans ". Journal Of Statistical Software, vol. 69(1): pp. 1-33 (cit. on p. 18).

LEXERøD, N. L. and T. EID (2006): 'An evaluation of different diameter diversity indices based on criteria related to forest management planning'. Forest Ecology and Management, vol. 222(1-3): pp. 17-28 (cit. on p. 45).

Liang, J., J. Buongiorno, R. A. Monserud, E. L. Kruger, and M. Zhou (2007): 'Effects of diversity of tree species and size on forest basal area growth, recruitment, and mortality'. Forest Ecology and Management, vol. 243(1): pp. 116-127 (cit. on p. 4).

LiANG, J. et al. (2016): 'Positive biodiversity-productivity relationship predominant in global forests'. Science, vol. 354(6309) (cit. on pp. 2, 44, 45, 104, 105).

Limousin, J.-M., L. Misson, A.-V. Lavoir, N. K. Martin, and S. Rambal (Mar. 2010): 'Do photosynthetic limitations of evergreen Quercus ilex leaves change with long-term increased drought severity?' Plant, Cell \& Environment, vol. (cit. on p. 46).

Lindenmayer, D. B., C. R. Margules, and D. B. Botkin (2000): 'Indicators of biodiversity for ecologically sustainable forest management'. Conservation Biology, vol. 14(4): pp. 941-950 (cit. on p. 3).

Lindner, M., J. B. Fitzgerald, N. E. Zimmermann, C. Reyer, S. Delzon, E. van der Maaten, M.-J. Schelhaas, P. Lasch, J. Eggers, M. van der Maaten-Theunissen, F. Suckow, A. Psomas, B. Poulter, and M. Hanewinkel (Dec. 2014): 'Climate change and European forests: What do we know, what are the uncertainties, and what are the implications for forest management?' Journal of Environmental Management, vol. 146: pp. 69-83 (cit. on p. 7).

Link, T. E., M. Unsworth, and D. MARks (2004): 'The dynamics of rainfall interception by a seasonal temperate rainforest'. Agricultural and Forest Meteorology, vol. 124(3-4): pp. 171-191 (cit. on p. 85).

Liu, D., R. Ogaya, A. Barbeta, X. Yang, and J. Penuelas (2018): 'Long-term experimental drought combined with natural extremes accelerate vegetation shift in a Mediterranean holm oak forest'. ENVIRONMENTAL AND EXPERIMENTAL BOTANY, vol. 151: pp. 1-11 (cit. on p. 76).

LONG, J. N. and J. D. SHAW (2010): 'The influence of compositional and structural diversity on forest productivity'. Forestry, vol. 83(2): pp. 121-128 (cit. on pp. 4, 45).

Loreau, M. (Oct. 2001): 'Biodiversity and Ecosystem Functioning: Current Knowledge and Future Challenges'. Science, vol. 294(5543): pp. 804-808 (cit. on p. 124).

Luo, Y., T. F. Keenan, and M. Smith (May 2015): 'Predictability of the terrestrial carbon cycle'. Global Change Biology, vol. 21(5): pp. 1737-1751 (cit. on pp. 14, 45, 126).

LuYsSAERT, S. et al. (Dec. 2007): 'CO2 balance of boreal, temperate, and tropical forests derived from a global database'. Global Change Biology, vol. 13(12): pp. 2509-2537 (cit. on pp. 112, 121). 
Luyssaert, S., E. D. Schulze, A. Börner, A. Knohl, D. Hessenmöller, B. E. LaW, P. Ciais, and J. Grace (2008): 'Old-growth forests as global carbon sinks'. Nature, vol. 455(7210): pp. 213-215 (cit. on pp. 106, 121, 135, 136).

LUYSSAERT, S. (2014): 'Land management and land-cover change have impacts of similar magnitude on surface temperature'. Nature Climate Change, vol. 4: p. 5 (cit. on pp. 15, $112,122,124)$.

Ma, S., D. D. Baldocchi, S. Mambelli, and T. E. Dawson (2011): 'Are temporal variations of leaf traits responsible for seasonal and inter-annual variability in ecosystem CO2 exchange?' Functional Ecology, vol. 25(1): pp. 258-270 (cit. on pp. 45, 126, 135).

Ma, S., D. D. BAldocchi, L. Xu, and T. Hehn (2007): 'Inter-annual variability in carbon dioxide exchange of an oak/grass savanna and open grassland in California'. Agricultural and Forest Meteorology, vol. 147(3-4): pp. 157-171 (cit. on p. 15).

Magnani, F. et al. (June 2007): 'The human footprint in the carbon cycle of temperate and boreal forests'. Nature, vol. 447(7146): pp. 849-851 (cit. on p. 133).

Magruder, M., S. Chhin, B. Palik, and J. B. Bradford (2013): 'Thinning increases climatic resilience of red pine'. Canadian Journal of Forest Research, vol. 43(9): pp. 878889 (cit. on p. 65).

Marko Stojanović (2017): 'Coppice As a New Perspective for an Adaptive Forest Management'. PhD thesis. Mendel University in Brno (cit. on p. 108).

Mausolf, K. et al. (Nov. 2018): 'Higher drought sensitivity of radial growth of European beech in managed than in unmanaged forests'. SCIENCE OF THE TOTAL ENVIRONMENT, vol. 642: pp. 1201-1208 (cit. on p. 65).

McElhinny, C., P. Gibbons, C. Brack, and J. Bauhus (2005): 'Forest and woodland stand structural complexity: Its definition and measurement'. Forest Ecology and Management, vol. 218(1-3): pp. 1-24 (cit. on pp. 3, 44).

McKee, T. B., N. J. Doesken, and J. Kleist (1993): 'The relationship of drought frequency and duration to time scales'. 8th conference on Applied Climatology. Anheim, CA, USA: American Meteorological Society: pp. 179-184 (cit. on p. 76).

MEA (2005): Ecosystems and human well-bening: Synthesis. Tech. rep. Washington D.C.: Island Press: pp. 1-20 (cit. on p. 106).

Medvigy, D., S.-J. Jeong, K. L. Clark, N. S. Skowronski, and K. V. R. Schäfer (Dec. 2013): 'Effects of seasonal variation of photosynthetic capacity on the carbon fluxes of a temperate deciduous forest'. Journal of Geophysical Research: Biogeosciences, vol. 118(4): pp. 1703-1714 (cit. on p. 136).

Merlin, M., T. Perot, S. Perret, N. Korboulewsky, and P. Vallet (2015): 'Effects of stand composition and tree size on resistance and resilience to drought in sessile oak and Scots pine'. Forest Ecology and Management, vol. 339: pp. 22-33 (cit. on pp. 4, 5, 104).

Messier, C., K. J. Puettmann, and K. D. Coates (2013): 'Managing forests as complex adaptive systems: Building resilience to the challenge of global change'. Managing Forests as Complex Adaptive Systems: Building Resilience to the Challenge of Global Change, vol. (December 2014): pp. 1-354 (cit. on p. 107). 
Metz, J., P. Annighöfer, P. Schall, J. Zimmermann, T. Kahl, E. D. Schulze, and C. Ammer (2016): 'Site-adapted admixed tree species reduce drought susceptibility of mature European beech'. Global Change Biology, vol. 22(2): pp. 903-920 (cit. on p. 6).

Milyukova, I. M., O. Kolle, A. V. Varlagin, N. N. Vygodskaya, E. D. Schulze, and J. LLOYD (2002): 'Carbon balance of a southern taiga spruce stand in European Russia'. Tellus, Series B: Chemical and Physical Meteorology, vol. 54(5): pp. 429-442 (cit. on pp. 48, 68).

Mittelbach, G. G., C. F. Steiner, S. M. Scheiner, K. L. Gross, H. L. Reynolds, R. B. Waide, M. R. Willig, S. I. Dodson, and L. Gough (2001): 'What is the observed relationship between species richness and productivity?' Ecology, vol. 82(9): pp. 2381-2396 (cit. on p. 44).

Mittelbach, H., I. Lehner, and S. I. Seneviratne (2012): 'Comparison of four soil moisture sensor types under field conditions in Switzerland'. Journal of Hydrology, vol. 430-431: pp. 39-49 (cit. on p. 87).

Mölder, A, M Bernhardt-Römermann, and W Schmidt (2006): 'Forest ecosystem research in Hainich National Park (Thuringia): First results on flora and vegetation in stands with contrasting tree species diversity'. Waldoekologie online, vol. 3: pp. 83-99 (cit. on p. 106).

Mölder, I. and C. Leuschner (June 2014): 'European beech grows better and is less drought sensitive in mixed than in pure stands: tree neighbourhood effects on radial increment'. Trees, vol. 28(3): pp. 777-792 (cit. on p. 6).

Monson, R. K., A. A. Turnipseed, J. P. Sparks, P. C. Harley, L. E. ScottDenton, K. Sparks, and T. E. Huxman (May 2002): 'Carbon sequestration in a high-elevation, subalpine forest'. Global Change Biology, vol. 8(5): pp. 459-478 (cit. on pp. 48, 68).

Morin, X., L. Fahse, C. de Mazancourt, M. Scherer-Lorenzen, and H. Bugmann (2014): 'Temporal stability in forest productivity increases with tree diversity due to asynchrony in species dynamics'. Ecology Letters, vol. 17(12): pp. 1526-1535 (cit. on pp. 2, 44).

Morin, X., L. Fahse, M. Scherer-Lorenzen, and H. Bugmann (2011): 'Tree species richness promotes productivity in temperate forests through strong complementarity between species'. Ecology Letters, vol. 14(12): pp. 1211-1219 (cit. on pp. 2, 44, 123).

Mouillot, F., S. RAmbal, and S. LAVorel (2001): 'A generic process-based simulator for meditERRanean landscApes (SIERRA): Design and validation exercises'. Forest Ecology and Management, vol. 147(1): pp. 75-97 (cit. on pp. 8, 76).

MÜLler, S., C. Ammer, and S. Nüsslein (2000): 'Analyses of stand structure as a tool for silvicultural decisions - a case study in a Quercus petraea - Sorbus torminalis stand'. Forstwissenschaftliches Centralblatt, vol. 119(1-2): pp. 32-42 (cit. on p. 3).

Mund, M (2004): 'Carbon pools of European beech forests (Fagus sylvatica) under different silvicultural management'. Vol. 189: p. 256 (cit. on pp. 17, 30, 113, 114, 116, 122).

Mund, M., W. L. Kutsch, C. Wirth, T. Kahl, A. Knohl, M. V. Skomarkova, and E. D. Schulze (2010): 'The influence of climate and fructification on the inter-annual variability of stem growth and net primary productivity in an old-growth, mixed beech forest'. Tree Physiology, vol. 30(6): pp. 689-704 (cit. on pp. 32, 105, 113, 116, 121). 
Musavi, T. et al. (Oct. 2016): 'Potential and limitations of inferring ecosystem photosynthetic capacity from leaf functional traits'. Ecology and Evolution, vol. 6(20): pp. 73527366 (cit. on pp. 45, 126, 129, 130).

Musavi, T. et al. (2017): 'Stand age and species richness dampen interannual variation of ecosystem-level photosynthetic capacity'. Nature Ecology and Evolution, vol. 1(2): pp. 1-6 (cit. on pp. 4, 12, 15, 31, 45, 46, 63, 104, 107, 125).

Musavi, T. et al. (2015): 'The imprint of plants on ecosystem functioning: A data-driven approach'. International Journal of Applied Earth Observation and Geoinformation, vol. 43: pp. 119-131 (cit. on pp. 45, 126).

Myers, B. J. (1988): 'Water stress integral-a link between short-term stress and long-term growth'. Tree Physiology, vol. 4(4): pp. 315-323 (cit. on p. 76).

Nardini, A., M. Battistuzzo, and T. Savi (Oct. 2013): 'Shoot desiccation and hydraulic failure in temperate woody angiosperms during an extreme summer drought'. New Phytologist, vol. 200(2): pp. 322-329 (cit. on p. 5).

Nathans, L. L., F. L. Oswald, and K. Nimon (2012): 'Interpreting Multiple Linear Regression: A Guidebook of Variable Importance'. Practical Assessment, Research $\&$ Evaluation, vol. 17(9): pp. 1-19 (cit. on p. 19).

Nemes, A., Y. A. Pachepsky, and D. J. Timlin (2011): 'Toward Improving Global Estimates of Field Soil Water Capacity'. Soil Science Society of America Journal, vol. 75(3): p. 807 (cit. on p. 85).

Novick, K. A., A. C. Oishi, E. J. Ward, M. B. S. Siqueira, J.-Y. Juang, and P. C. STOY (2015): 'On the difference in the net ecosystem exchange of $\mathrm{CO}<$ sub $>2</$ sub $>$ between deciduous and evergreen forests in the southeastern United States'. Global Change Biology, vol. 21(2): pp. 827-842 (cit. on pp. 15, 42).

Obeso, J. R. (2002): 'The costs of reproduction in plants Author'. New Phytologist, vol. 155(139): pp. 321-348 (cit. on p. 15).

Ogaya, R. and J. Peñuelas (2006): 'Contrasting foliar responses to drought in Quercus ilex and Phillyrea latifolia'. Biologia Plantarum, vol. 50(3): pp. 373-382 (cit. on p. 5).

Oheimb, G. von, W. HÄrdtle, D. Eckstein, H.-H. Engelke, T. Hehnke, B. Wagner, and A. Fichtner (Dec. 2014): 'Does Forest Continuity Enhance the Resilience of Trees to Environmental Change?' PLoS ONE, vol. 9(12). Ed. by LIANG, E.: e113507 (cit. on pp. 127, 136).

Oksanen, J., F. G. Blanchet, M. Friendly, R. Kindt, P. Legendre, D. Mcglinn, P. R. Minchin, R. B. O'Hara, G. L. Simpson, P. Solymos, M. H. H. Stevens, E. Szoecs, and H. Wagner (2019): Community Ecology Package 'Vegan' (cit. on p. 48).

O'Leary, G. J. and D. J. Connor (1985): 'A simulation model of the development, growth and yield of the wheat crop'. Agricultural Systems, vol. 17(1): pp. 1-26 (cit. on p. 77).

Orth, R., R. D. Koster, and S. I. Seneviratne (2013): 'Inferring Soil Moisture Memory from Streamflow Observations Using a Simple Water Balance Model'. Journal of Hydrometeorology, vol. 14(6): pp. 1773-1790 (cit. on pp. 8, 76).

Osterburg, B., S. Rüter, A. Freibauer, and et Al (2013): Handlungsoptionen für den Klimaschutz in der deutschen Agrar- und Forstwirtschaft. Thünen Report. Tech. rep. Braunschweig: Johann Heinrich von Thünen-Institut (cit. on p. 122). 
Otto, J., D. Berveiller, F. M. Bréon, N. Delpierre, G. Geppert, A. Granier, W. Jans, A. Knohl, A. Kuusk, B. Longdoz, E. Moors, M. Mund, B. Pinty, M. J. SChelHAAs, and S. LuYsSAERT (2014): 'Forest summer albedo is sensitive to species and thinning: How should we account for this in Earth system models?' Biogeosciences, vol. 11(8): pp. 2411-2427 (cit. on pp. 48, 68).

Page, S. E., F. Siegert, J. O. Rieley, H. D. V. Boehm, A. Jaya, and S. Limin (2002): 'The amount of carbon released from peat and forest fires in Indonesia during 1997'. Nature, vol. 420(6911): pp. 61-65 (cit. on p. 2).

Pallardy, S. G. (2002): 'Acli.Pdf'. Vol. 68(2): pp. 270-334 (cit. on p. 5).

PAN, Y. et al. (2011): 'A large and persistent carbon sink in the world's forests'. Science, vol. 333(6045): pp. 988-993 (cit. on p. 2).

PApale, D. et al. (2015): 'Carbon, water and energy fluxes of terrestrial ecosystem in Italy'. The greenhouse gas balance of Italy. Ed. by Valentini, R. and F. Miglietta. Heidelberg: Springer-Verlag Berlin. Chap. Carbon, wa: pp. 11-46 (cit. on pp. 48, 68, 84).

Paul, K. I., P. J. Polglase, A. M. O'Connell, J. C. Carlyle, P. J. Smethurst, P. K. Khanna, and D. Worledge (2003): 'Soil water under forests (SWUF): A model of water flow and soil water content under a range of forest types'. Forest Ecology and Management, vol. 182(1-3): pp. 195-211 (cit. on pp. 7, 8, 76, 77, 81).

Pereira, J. S., J. A. Mateus, L. M. Aires, G. Pita, C. Pio, J. S. David, V. Andrade, J. Banza, T. S. David, T. A. PaÇO, and A. Rodrigues (2007): 'Net ecosystem carbon exchange in three contrasting Mediterranean ecosystems - the effect of drought'. Biogeosciences, vol. 4(5): pp. 791-802 (cit. on p. 15).

Pfenninger, S., J. DeCarolis, L. Hirth, S. Quollin, and I. Staffell (2017): 'The importance of open data and software: Is energy research lagging behind?' Energy Policy, vol. 101(November 2016): pp. 211-215 (cit. on p. 108).

Pilegaard, K., P. HummelshøJ, N. O. Jensen, and Z. Chen (2001): 'Two years of continuous CO2eddy-flux measurements over a Danish beech forest'. Agricultural and Forest Meteorology, vol. 107(1): pp. 29-41 (cit. on p. 84).

Pilegaard, K., A. Ibrom, M. S. Courtney, P. Hummelshøj, and N. O. Jensen (July 2011): 'Increasing net CO2 uptake by a Danish beech forest during the period from 1996 to 2009'. Agricultural and Forest Meteorology, vol. 151(7): pp. 934-946 (cit. on pp. 15, 19, 31-33, 42, 122).

Pinty, B., M. Jung, T. Kaminski, T. Lavergne, M. Mund, S. Plummer, E. Thomas, and J.-L. WidLOWSKI (Dec. 2011): 'Evaluation of the JRC-TIP $0.01^{\circ}$ products over a mid-latitude deciduous forest site'. Remote Sensing of Environment, vol. 115(12): pp. 3567-3581 (cit. on p. 130).

Pinty, B., T. Lavergne, M. Vossbeck, T. Kaminski, O. Aussedat, R. Giering, N. Gobron, M. Taberner, M. M. Verstraete, and J.-L. Widlowski (May 2007): 'Retrieving surface parameters for climate models from Moderate Resolution Imaging Spectroradiometer (MODIS)-Multiangle Imaging Spectroradiometer (MISR) albedo products'. Journal of Geophysical Research: Atmospheres, vol. 112(D10) (cit. on p. 129). Pita, G., B. Gielen, D. Zona, A. Rodrigues, S. Rambal, I. A. Janssens, and R. Ceulemans (2013): 'Carbon and water vapor fluxes over four forests in two contrasting climatic zones'. Agricultural and Forest Meteorology, vol. 180: pp. 211-224 (cit. on p. 68). 
Pitkënen, S. (1997): Correlation between stand structure and ground vegetation: An analytical approach (cit. on p. 4).

Pommerening, A. (2002): 'Approaches to quantifying forest structures'. Forestry, vol. 75(3): pp. 305-324 (cit. on pp. 2, 44).

Pommerening, A. and A. SÄrkkÄ (Feb. 2013): 'What mark variograms tell about spatial plant interactions'. Ecological Modelling, vol. 251: pp. 64-72 (cit. on pp. 3, 44, 107).

Potter, K. M. and C. W. Woodall (2014): 'Does biodiversity make a difference? Relationships between species richness, evolutionary diversity, and aboveground live tree biomass across U.S. forests'. Forest Ecology and Management, vol. 321: pp. 117-129 (cit. on pp. 2, 65).

Prentice, I. C., M. T. Sykes, W. Cramer, and I Colin Prentice (1992): 'A simulation model for the transient effects of climate change on forest landscapes'. Ecological Modelling, vol. 65(1-2): pp. 51-70 (cit. on pp. 76, 87).

Pretzsch, H., G. Schütze, E. Uhl, G Schuetze, and E. Uhl (May 2013): 'Resistance of European tree species to drought stress in mixed versus pure forests: Evidence of stress release by inter-specific facilitation'. Plant Biology, vol. 15(3): pp. 483-495 (cit. on pp. $2,5,6,46,108,123)$.

Pretzsch, H. et al. (2015): 'Growth and yield of mixed versus pure stands of Scots pine (Pinus sylvestris L.) and European beech (Fagus sylvatica L.) analysed along a productivity gradient through Europe'. European Journal of Forest Research, vol. 134(5): pp. 927-947 (cit. on pp. 104, 105).

Pretzsch, H. et al. (2016): 'Mixing of Scots pine (Pinus sylvestris L.) and European beech (Fagus sylvatica L.) enhances structural heterogeneity, And the effect increases with water availability'. Forest Ecology and Management, vol. 373: pp. 149-166 (cit. on pp. 3, 44, 64).

Pretzsch, H. (Sept. 2014): 'Canopy space filling and tree crown morphology in mixedspecies stands compared with monocultures'. Forest Ecology and Management, vol. 327: pp. 251-264 (cit. on pp. 113, 123, 124).

Pretzsch, H., J. Block, J. Dieler, P. H. Dong, U. Kohnle, J. Nagel, H. Spellmann, and A. ZINGG (2010): 'Comparison between the productivity of pure and mixed stands of Norway spruce and European beech along an ecological gradient'. Annals of Forest Science, vol. 67(7) (cit. on pp. 2, 105).

Priestley, C. H. B. and R. J. TAYlor (1972): 'On the assessment of surface heat flux and evaporation using large-scale parameters'. Monthly Weather Review, vol. 100(2): pp. 81-92 (cit. on p. 87).

Puettmann, K. J., S. M. Wilson, S. C. Baker, P. J. Donoso, L. Drössler, G. Amente, B. D. Harvey, T. Knoke, Y. Lu, S. Nocentini, F. E. Putz, T. Yoshida, and J. BAunus (2015): 'Silvicultural alternatives to conventional even-aged forest management - what limits global adoption?' Forest Ecosystems, vol. 2(1): p. 8 (cit. on pp. 2, 104, 107).

PukKala, T. (2016): 'Which type of forest management provides most ecosystem services?' Forest Ecosystems, vol. 3(1) (cit. on p. 104).

R Development Core Team (2018): R: A Language and Environment for Statistical Computing. Vienna, Austria (cit. on pp. 19, 52, 54, 77). 
RAdDAtz, R. (Dec. 1993): 'Prairie agroclimate boundary-layer model: A simulation of the atmosphere/crop-soil interface'. Atmosphere-Ocean, vol. 31(4): pp. 399-419 (cit. on p. 7).

Ratcliffe, S., F. Holzwarth, K. Nadrowski, S. Levick, and C. Wirth (Jan. 2015): 'Tree neighbourhood matters - Tree species composition drives diversity-productivity patterns in a near-natural beech forest'. Forest Ecology and Management, vol. 335: pp. 225-234 (cit. on p. 123).

Ratcliffe, S., M. Liebergesell, P. Ruiz-Benito, J. Madrigal González, J. M. Muñoz Castañeda, G. Kändler, A. Lehtonen, J. Dahlgren, J. Kattge, J. Peñuelas, M. A. Zavala, and C. Wirth (2016): 'Modes of functional biodiversity control on tree productivity across the European continent'. Global Ecology and Biogeography, vol. 25(3): pp. 251-262 (cit. on p. 105).

RAtCLIfFe, S. et al. (2017): 'Biodiversity and ecosystem functioning relations in European forests depend on environmental context'. Ecology Letters, vol. 20(11): pp. 1414-1426 (cit. on p. 105).

Rebetez, M., O. Dupont, and M. Giroud (2009): 'An analysis of the July 2006 heatwave extent in Europe compared to the record year of 2003'. Theoretical and Applied Climatology, vol. 95(1-2): pp. 1-7 (cit. on p. 46).

Rebmann, C. et al. (2005): 'Quality analysis applied on eddy covariance measurements at complex forest sites using footprint modelling'. Theoretical and Applied Climatology, vol. 80(2-4): pp. 121-141 (cit. on p. 116).

Reichstein, M., M. Bahn, M. D. Mahecha, J. Kattge, D. D. Baldocchi, and S. W. PACAla (2014): 'Linking plant and ecosystem functional biogeography'. Proceedings of the National Academy of Sciences, vol. 111(38): pp. 13697-13702 (cit. on pp. 45, 126).

Reichstein, M. et al. (2013): 'Climate extremes and the carbon cycle'. Nature, vol. 500(7462): pp. 287-295 (cit. on pp. 2, 5).

Reichstein, M. et al. (Sept. 2005): 'On the separtion of net ecosystem exchange into assimilation and ecosystem respiration: review and improved algorithm'. Global Change Biology, vol. 11(July): pp. 1424-1439 (cit. on pp. 18, 115, 120, 129).

REICHSTEIn, M. et al. (2007): 'Reduction of ecosystem productivity and respiration during the European summer 2003 climate anomaly: A joint flux tower, remote sensing and modelling analysis'. Global Change Biology, vol. 13(3): pp. 634-651 (cit. on pp. 5, 76).

Richards, L. A. (1931): 'Capillary conduction of liquids through porous mediums'. Journal of Applied Physics, vol. 1(5): pp. 318-333 (cit. on pp. 78, 82).

Richards, L. A. (1944): 'Moisture Retention by Some Irrigated Soils as Related to Soil-Moisture Tension'. Journal of Agricultural Research, vol. 69(6): pp. 215-235 (cit. on p. 84).

Richardson, A. D., D. Y. Hollinger, J. D. Aber, S. V. Ollinger, and B. H. BRASWELL (2007): 'Environmental variation is directly responsible for short- but not long-term variation in forest-atmosphere carbon exchange'. Global Change Biology, vol. 13(4): pp. 788-803 (cit. on pp. 45, 126, 135).

Richardson, A. D., D. Y. Hollinger, D. B. Dail, J. T. Lee, J. W. Munger, and J. O'KeEFe (2009): 'Influence of spring phenology on seasonal and annual carbon balance in two contrasting New England forests'. Tree Physiology, vol. 29(3): pp. 321-331 (cit. on p. 14). 
Ringgaard, R., M. Herbst, and T. Friborg (Sept. 2014): 'Partitioning forest evapotranspiration: Interception evaporation and the impact of canopy structure, local and regional advection'. Journal of Hydrology, vol. 517: pp. 677-690 (cit. on p. 124).

Río, M. del et al. (2016): 'Characterization of the structure, dynamics, and productivity of mixed-species stands: review and perspectives'. European Journal of Forest Research, vol. 135(1): pp. 23-49 (cit. on pp. 3, 44).

Río, M. del et al. (2017): 'Species interactions increase the temporal stability of community productivity in Pinus sylvestris-Fagus sylvatica mixtures across Europe'. Journal of Ecology, vol. 105(4): pp. 1032-1043 (cit. on pp. 46, 106).

Ritchie, J. T. (1972): 'Model for predicting evaporation from a row crop with incomplete cover'. Water Resources Research, vol. 8(5): pp. 1204-1213 (cit. on pp. 78, 82).

RoBerts, J. (Oct. 1983): 'Forest transpiration: A conservative hydrological process?' Journal of Hydrology, vol. 66(1-4): pp. 133-141 (cit. on p. 122).

Ruiz-Benito, P., L. Gómez-Aparicio, A. Paquette, C. Messier, J. Kattge, and M. A. Zavala (2014): 'Diversity increases carbon storage and tree productivity in Spanish forests'. Global Ecology and Biogeography, vol. 23(3): pp. 311-322 (cit. on p. 104).

Running, S. W. and J. C. Coughlan (1988): 'A general model of forest ecosystem processes for regional applications I. Hydrologic balance, canopy gas exchange and primary production processes'. Ecological Modelling, vol. 42(2): pp. 125-154 (cit. on p. 76).

Rutishauser, E. et al. (Sept. 2015): 'Rapid tree carbon stock recovery in managed Amazonian forests'. Current Biology, vol. 25(18): R787-R788 (cit. on p. 3).

Sabatini, F. M., R. B. de Andrade, Y. Paillet, P. Ódor, C. Bouget, T. Campagnaro, F. Gosselin, P. Janssen, W. Mattioli, J. Nascimbene, T. Sitzia, T. Kuemmerle, and S. Burrascano (2019): 'Trade-offs between carbon stocks and biodiversity in European temperate forests'. Global Change Biology, vol. 25(2): pp. 536-548 (cit. on p. 106).

Saigusa, N., S. Yamamoto, S. Murayama, and H. Kondo (2005): 'Inter-annual variability of carbon budget components in an AsiaFlux forest site estimated by long-term flux measurements'. Agricultural and Forest Meteorology, vol. 134(1-4): pp. 4-16 (cit. on p. 42).

Sala, A., K. Hopping, E. J. Mcintire, S. Delzon, and E. E. Crone (2012): 'Masting in whitebark pine (Pinus albicaulis) depletes stored nutrients'. New Phytologist, vol. 196(1): pp. 189-199 (cit. on p. 32).

Sasaki, N., G. P. Asner, Y. Pan, W. Knorr, P. B. Durst, H. O. Ma, I. Abe, A. J. Lowe, L. P. Koh, and F. E. Putz (Aug. 2016): 'Sustainable Management of Tropical Forests Can Reduce Carbon Emissions and Stabilize Timber Production'. Frontiers in Environmental Science, vol. 4 (cit. on p. 3).

Saunders, M., B. Tobin, K. Black, M. Gioria, M. Nieuwenhuis, and B. A. Osborne (2012): 'Thinning effects on the net ecosystem carbon exchange of a Sitka spruce forest are temperature-dependent'. Agricultural and Forest Meteorology, vol. 157: pp. 1-10 (cit. on p. 105). 
Saxton, K. E. and W. J. Rawls (2006): 'Soil Water Characteristic Estimates by Texture and Organic Matter for Hydrologic Solutions'. Soil Science Society of America Journal, vol. 70(5): p. 1569 (cit. on pp. 78, 82-84, 89).

SchAAF, C. B. et al. (Nov. 2002): 'First operational BRDF, albedo nadir reflectance products from MODIS'. Remote Sensing of Environment, vol. 83(1-2): pp. 135-148 (cit. on p. 129).

Schall, P., E. D. Schulze, M. Fischer, M. Ayasse, and C. Ammer (2018): 'Relations between forest management, stand structure and productivity across different types of Central European forests'. Basic and Applied Ecology, vol. 32: pp. 39-52 (cit. on pp. 3, $4,44,64,66,107)$.

Schelhaas, M. J., G. J. Nabuurs, W. Jans, E. Moors, S. Sabaté, and W. P. DAAMEN (2004): 'Closing the carbon budget of a scots pine forest in the Netherlands'. Climatic Change, vol. 67(2-3): pp. 309-328 (cit. on p. 84).

Schleussner, C.-F., P. Pfleiderer, and E. M. Fischer (2017): 'Half a degree makes a difference in the observational record'. Nature Publishing Group, vol. 7(7): pp. 1-5 (cit. on p. 46).

Schmid, B., A. Hector, P. Saha, and M. Loreau (June 2008): 'Biodiversity effects and transgressive overyielding'. Journal of Plant Ecology, vol. 1(2): pp. 95-102 (cit. on p. 2).

Schmid, H. P., C. S. B. Grimmond, F. Cropley, B. Offerle, and H. B. Su (2000): 'Measurements of CO2 and energy fluxes over a mixed hardwood forest in the mid-western United States'. Agricultural and Forest Meteorology, vol. 103(4): pp. 357-374 (cit. on p. 84).

Schmidt, M., E. Veldkamp, and M. D. Corre (Feb. 2015): 'Tree species diversity effects on productivity, soil nutrient availability and nutrient response efficiency in a temperate deciduous forest'. Forest Ecology and Management, vol. 338: pp. 114-123 (cit. on p. 123).

Schöning, I., E. Grüneberg, C. A. Sierra, D. Hessenmöller, M. Schrumpf, W. W. Weisser, and E.-D. Schulze (Sept. 2013): 'Causes of variation in mineral soil C content and turnover in differently managed beech dominated forests'. Plant and Soil, vol. 370(1-2): pp. 625-639 (cit. on p. 122).

Schrumpf, M., E. D. Schulze, K. Kaiser, and J. Schumacher (2011): 'How accurately can soil organic carbon stocks and stock changes be quantified by soil inventories?' Biogeosciences, vol. 8(5): pp. 1193-1212 (cit. on p. 116).

SchrumpF, M., K. Kaiser, and E.-D. Schulze (Feb. 2014): 'Soil Organic Carbon and Total Nitrogen Gains in an Old Growth Deciduous Forest in Germany'. PLoS ONE, vol. 9(2). Ed. by BALCAZAR, J. L.: e89364 (cit. on pp. 116, 122).

Schulze, E. D., G. Aas, G. W. Grimm, M. M. Gossner, H. Walentowski, C. Ammer, I. KüHn, O. Bouriaud, and K. von Gadow (Jan. 2016): 'A review on plant diversity and forest management of European beech forests'. European Journal of Forest Research, vol. 135(1): pp. 51-67 (cit. on p. 45).

Schwarz, P. A., B. E. LaW, M. Williams, J. Irvine, M. Kurpius, and D. Moore (2004): 'Climatic versus biotic constraints on carbon and water fluxes in seasonally drought-affected ponderosa pine ecosystems'. Global Biogeochemical Cycles, vol. 18(4): pp. 1-17 (cit. on pp. 48,68). 
Sedlák, P., M. Aubinet, B. Heinesch, D. Janouš, M. Pavelka, K. Potužníková, and M. YERnAUX (2010): 'Night-time airflow in a forest canopy near a mountain crest'. Agricultural and Forest Meteorology, vol. 150(5): pp. 736-744 (cit. on pp. 48, 68).

SEIDL, R. et al. (2017): 'Forest disturbances under climate change'. Nature Climate Change, vol. 7(6): pp. 395-402 (cit. on pp. 44, 104).

Selås, V., G. Piovesan, J. M. Adams, and M. Bernabei (2002): 'Climatic factors controlling reproduction and growth of Norway spruce in southern Norway'. Canadian Journal of Forest Research, vol. 32(2): pp. 217-225 (cit. on p. 15).

Shao, J., X. Zhou, H. He, G. Yu, H. Wang, Y. Luo, J. Chen, L. Gu, and B. Li (2014): 'Partitioning Climatic and Biotic Effects on Interannual Variability of Ecosystem Carbon Exchange in Three Ecosystems'. Ecosystems, vol. 17(7): pp. 1186-1201 (cit. on pp. 15, 31, 42, 105).

SHAO, J. et al. (2015): 'Biotic and climatic controls on interannual variability in carbon fluxes across terrestrial ecosystems'. Agricultural and Forest Meteorology, vol. 205: pp. 1122 (cit. on pp. 14, 15).

- (2016): 'Direct and indirect effects of climatic variations on the interannual variability in net ecosystem exchange across terrestrial ecosystems'. Tellus B: Chemical and Physical Meteorology, vol. 68(1): p. 30575 (cit. on pp. 14, 15).

Sidor, C. G., M. Bosela, U. Büntgen, and R. Vlad (Dec. 2018): 'Mixed effects of climate variation on the scots pine forests: Age and species mixture matter'. Dendrochronologia, vol. 52: pp. 48-56 (cit. on p. 6).

Silva Pedro, M., W. Rammer, and R. Seidl (2015): 'Tree species diversity mitigates disturbance impacts on the forest carbon cycle'. Oecologia, vol. 177(3): pp. 619-630 (cit. on p. 104).

Simard, M., N. Pinto, J. B. Fisher, and A. Baccini (Nov. 2011): 'Mapping forest canopy height globally with spaceborne lidar'. Journal of Geophysical Research, vol. 116(G4): G04021 (cit. on p. 129).

Sitch, S., B Smith, I. C. Prentice, A. Arneth, A. Bondeau, W. Cramer, J. O. Kaplan, S. Levis, W. Lucht, M. T. Sykes, K. Thonicke, and S. Venevsky (2003): 'Evaluation of ecosystem dynamics, plant geography and terrestrial carbon cycling in the LPJ dynamic global vegetation model'. Global Change Biology, vol. 9(2): pp. 161-185 (cit. on pp. 9, 76).

Soetaert, K. and T. Petzoldt (2016): A Flexible Modelling Environment for Inverse Modelling, Sensitivity, Identifiability and Monte Carlo Analysis (cit. on pp. 51, 82, 84).

Sohn, J. A., T. Gebhardt, C. Ammer, J. Bauhus, K. H. Häberle, R. Matyssek, and T. E. Grams (2013): 'Mitigation of drought by thinning: Short-term and long-term effects on growth and physiological performance of Norway spruce (Picea abies)'. Forest Ecology and Management, vol. 308: pp. 188-197 (cit. on p. 108).

Sohn, J. A., F. Hartig, M. Kohler, J. Huss, and J. Bauhus (2016): 'Heavy and frequent thinning promotes drought adaptation in Pinus sylvestris forests'. Ecological Applications, vol. 26(7): pp. 2190-2205 (cit. on pp. 65, 108).

Sousa-Silva, R., K. Verheyen, Q. Ponette, E. Bay, G. Sioen, H. Titeux, T. Van de Peer, K. Van Meerbeek, and B. Muys (Sept. 2018): 'Tree diversity mitigates 
defoliation after a drought-induced tipping point'. Global Change Biology, vol. 24(9): pp. 4304-4315 (cit. on p. 6).

SPEICH, M. J. R. (Feb. 2019): 'Quantifying and modeling water availability in temperate forests: a review of drought and aridity indices'. IFOREST-BIOGEOSCIENCES AND FORESTRY, vol. 12(1): pp. 1-16 (cit. on p. 76).

SpellerberG, I. A. N. F. and P. J. Fedor (2003): 'Tribute To Claude Shannon (1916_2001)'. Global Ecology and Biogeography, vol.: pp. 177-179 (cit. on p. 3).

Spinoni, J., P. Barbosa, A. De Jager, N. McCormick, G. Naumann, J. V. Vogt, D. Magni, D. Masante, and M. Mazzeschi (2019): 'A new global database of meteorological drought events from 1951 to 2016'. Journal of Hydrology: Regional Studies, vol. 22(January): p. 100593 (cit. on pp. 5, 76, 107).

Spinoni, J., G. Naumann, and J. V. Vogt (Jan. 2017): 'Pan-European seasonal trends and recent changes of drought frequency and severity'. Global and Planetary Change, vol. 148: pp. 113-130 (cit. on p. 5).

Stephenson, N. L. (2002): 'Climatic Control of Vegetation Distribution: The Role of the Water Balance'. The American Naturalist, vol. 135(5): pp. 649-670 (cit. on p. 76).

SterbA, H. and A. ZINGG (2006): 'Abstandsabhängige und abstandsun- abhängige Bestandesstrukturbeschreibung.' Allgemeine Forst- und Jagdzeitung, vol. 177: pp. 169-176 (cit. on p. 3).

Stevens-Rumann, C. S., K. B. Kemp, P. E. Higuera, B. J. Harvey, M. T. Rother, D. C. Donato, P. Morgan, and T. T. Veblen (2018): 'Evidence for declining forest resilience to wildfires under climate change'. Ecology Letters, vol. 21(2): pp. 243-252 (cit. on p. 104).

Stocker, B. D., J. Zscheischler, T. F. Keenan, I. C. Prentice, J. Peñuelas, and S. I. Seneviratne (2018): 'Quantifying soil moisture impacts on light use efficiency across biomes'. New Phytologist, vol. 218(4): pp. 1430-1449 (cit. on pp. 65, 77).

Stoy, P. C. et al. (Apr. 2013): 'A data-driven analysis of energy balance closure across FLUXNET research sites: The role of landscape scale heterogeneity'. Agricultural and Forest Meteorology, vol. 171-172: pp. 137-152 (cit. on p. 121).

Stpaul, N. K., J. M. Limousin, J. Rodrígesuez-Calcerrada, J. Ruffault, S. Rambal, M. G. Letts, and L. Misson (2012): 'Photosynthetic sensitivity to drought varies among populations of Quercus ilex along a rainfall gradient'. Functional Plant Biology, vol. 39(1): pp. 25-37 (cit. on p. 46).

Sulman, B. N., D. T. Roman, T. M. Scanlon, L. Wang, and K. A. Novick (2016): 'Comparing methods for partitioning a decade of carbon dioxide and water vapor fluxes in a temperate forest'. Agricultural and Forest Meteorology, vol. 226-227: pp. 229-245 (cit. on p. 42).

Sutton, M. A., C. M. Howard, J. W. Erisman, G. Billen, A. Bleeker, P. GrennFelt, H. van Grinsven, and B. Grizzetti (2011): The European Nitrogen Assessment. Ed. by Sutton, M. A., C. M. Howard, J. W. Erisman, G. Billen, A. Bleeker, P. Grennfelt, H. van Grinsven, and B. Grizzetti. Cambridge: Cambridge University Press (cit. on p. 136). 
SzéKely, G. J., M. L. Rizzo, and N. K. Bakirov (Dec. 2007): 'Measuring and testing dependence by correlation of distances'. The Annals of Statistics, vol. 35(6): pp. 27692794 (cit. on p. 132).

Tamrakar, R., M. B. Rayment, F. Moyano, M. Mund, and A. Knohl (Sept. 2018): 'Implications of structural diversity for seasonal and annual carbon dioxide fluxes in two temperate deciduous forests'. Agricultural and Forest Meteorology, vol. 263(June): pp. 465-476 (cit. on pp. 10, 13, 68, 104-106).

TANG, B., X. ZhaO, and W. Zhao (2018): 'Local Effects of Forests on Temperatures across Europe'. Remote Sensing, vol. 10(4): p. 529 (cit. on p. 109).

Tefs, C. and G. Gleixner (Jan. 2012): 'Importance of root derived carbon for soil organic matter storage in a temperate old-growth beech forest - Evidence from C, N and 14C content'. Forest Ecology and Management, vol. 263: pp. 131-137 (cit. on p. 122).

Thabeet, A., M. Vennetier, C. Gadbin-Henry, N. Denelle, M. Roux, Y. Caraglio, and B. VilA (2009): 'Response of Pinus sylvestris L. to recent climatic events in the French Mediterranean region'. Trees - Structure and Function, vol. 23(4): pp. 843-853 (cit. on p. 108).

Thornthwaite, C. W. (Jan. 1948): 'An Approach toward a Rational Classification of Climate'. Geographical Review, vol. 38(1): p. 55 (cit. on p. 7).

Tilman, D. (1999): 'The ecological consequences of changes in biodiversity: A search for general principles'. Ecology, vol. 80(5): pp. 1455-1474 (cit. on pp. 10, 106).

Toïgo, M., P. Vallet, V. Tuilleras, F. Lebourgeois, P. Rozenberg, S. Perret, B. Courbaud, and T. Perot (2015): 'Species mixture increases the effect of drought on tree ring density, but not on ring width, in Quercus petraea-Pinus sylvestris stands'. Forest Ecology and Management, vol. 345: pp. 73-82 (cit. on p. 6).

Tramontana, G., M. Jung, C. R. Schwalm, K. Ichi, G. Camps-Valls, B. Ráduly, M. Reichstein, M. A. Arain, A. Cescatti, G. Kiely, L. Merbold, P. Serrano-Ortiz, S. Sickert, S. Wolf, and D. Papale (July 2016): 'Predicting carbon dioxide and energy fluxes across global FLUXNET sites with regression algorithms'. Biogeosciences, vol. 13(14): pp. 4291-4313 (cit. on p. 129).

Trenberth, K. E., A. Dai, G. Van Der Schrier, P. D. Jones, J. Barichivich, K. R. BRIfFA, and J. Sheffield (2014): 'Global warming and changes in drought'. Nature Climate Change, vol. 4(1): pp. 17-22 (cit. on p. 5).

Tyree, M. T. and M. H. Zimmermann (2002): Xylem Structure and the Ascent of Sap. New York: Springer (cit. on p. 5).

UMR EEF (1999): Biljou (cit. on p. 87).

Urbanski, S., C. Barford, S. Wofsy, C. Kucharik, E. Pyle, J. Budney, K. McKain, D. Fitzjarrald, M. Czikowsky, and J. W. Munger (2007): 'Factors controlling CO2 exchange on timescales from hourly to decadal at Harvard Forest'. Journal of Geophysical Research: Biogeosciences, vol. 112(2): pp. 1-25 (cit. on pp. 19, 32, 42, 48, 68, $135)$.

VAn Loon, A. F. (2015): 'Hydrological drought explained'. Wiley Interdisciplinary Reviews: Water, vol. 2(4): pp. 359-392 (cit. on p. 5).

Van Loon, A. F. et al. (2016): 'Drought in the Anthropocene'. Nature Geoscience, vol. 9(2): pp. 89-91 (cit. on p. 5). 
Vanhellemont, M., R. Sousa-Silva, S. L. Maes, J. den Bulcke, L. Hertzog, S. R. E. De Groote, J. Van Acker, D. Bonte, A. Martel, L. Lens, and K. Verheyen (Feb. 2019): 'Distinct growth responses to drought for oak and beech in temperate mixed forests'. SCIENCE OF THE TOTAL ENVIRONMENT, vol. 650(2): pp. 3017-3026 (cit. on p. 6).

Vennetier, M., B. Vila, E. Y. Liang, F. Guibal, A. Taahbet, and C. GadbinHENRY (2007): 'Impact of climate change on pine forest productivity and on the shift of a bioclimatic limit in a Mediterranean area'. Proceedings of the international workshop MEDPINE 3: conservation, regeneration and restoration of Mediterranean pines and their ecosystems. Ed. by Leone, V. and R. Lovreglio. Vol. 197. Bari : CIHEAM: pp. 189-197 (cit. on p. 108).

Venturas, M. D., E. D. Mackinnon, H. L. Dario, A. L. Jacobsen, R. B. Pratt, and S. D. Davis (July 2016): 'Chaparral Shrub Hydraulic Traits, Size, and Life History Types Relate to Species Mortality during California's Historic Drought of 2014'. PLOS ONE, vol. 11(7). Ed. by ARMAS, C.: e0159145 (cit. on p. 5).

Vesala, T. et al. (2005): 'Effect of thinning on surface fluxes in a boreal forest'. Global Biogeochemical Cycles, vol. 19(2): pp. 1-11 (cit. on pp. 48, 68, 105).

VETTER, M. et al. (2008): 'Analyzing the causes and spatial pattern of the European 2003 carbon flux anomaly using seven models'. Biogeosciences, vol. 5(2): pp. 561-583 (cit. on p. 107).

Vicente-Serrano, S. M., S. Beguería, and J. I. López-Moreno (2010): 'A multiscalar drought index sensitive to global warming: The standardized precipitation evapotranspiration index'. Journal of Climate, vol. 23(7): pp. 1696-1718 (cit. on p. 76).

Vicente-Serrano, S. M., C. Gouveia, J. J. Camarero, S. Beguería, R. Trigo, J. I. López-Moreno, C. Azorín-Molina, E. Pasho, J. Lorenzo-Lacruz, J. Revuelto, E. Morán-Tejeda, and A. Sanchez-Lorenzo (2013): 'Response of vegetation to drought time-scales across global land biomes'. Proceedings of the National Academy of Sciences of the United States of America, vol. 110(1): pp. 52-57 (cit. on p. 5).

Vitali, V., D. I. Forrester, and J. Bauhus (Sept. 2018): 'Know Your Neighbours: Drought Response of Norway Spruce, Silver Fir and Douglas Fir in Mixed Forests Depends on Species Identity and Diversity of Tree Neighbourhoods'. ECOSYSTEMS, vol. 21(6): pp. 1215-1229 (cit. on p. 6).

Vitasse, Y., S. Delzon, E. Dufrêne, J.-Y. Pontailler, J.-M. Louvet, A. Kremer, and R. Michalet (May 2009a): 'Leaf phenology sensitivity to temperature in European trees: Do within-species populations exhibit similar responses?' Agricultural and Forest Meteorology, vol. 149(5): pp. 735-744 (cit. on p. 123).

Vitasse, Y., A. J. Porté, A. Kremer, R. Michalet, and S. Delzon (Aug. 2009b): 'Responses of canopy duration to temperature changes in four temperate tree species: relative contributions of spring and autumn leaf phenology'. Oecologia, vol. 161(1): pp. 187-198 (cit. on p. 123).

VON ButTlar, J. et al. (2018): 'Impacts of droughts and extreme-temperature events on gross primary production and ecosystem respiration: a systematic assessment across ecosystems and climate zones'. Biogeosciences, vol. 155194: pp. 1293-1318 (cit. on pp. 65, 107). 
Wäldchen, J., E.-D. Schulze, I. Schöning, M. SchrumpF, and C. Sierra (Feb. 2013): 'The influence of changes in forest management over the past 200years on present soil organic carbon stocks'. Forest Ecology and Management, vol. 289: pp. 243-254 (cit. on p. 122).

WANG, W., J. WAng, X. Liu, G. Zhou, and J. Yan (2016): 'Decadal drought deaccelerated the increasing trend of annual net primary production in tropical or subtropical forests in southern China'. SCIENTIFIC REPORTS, vol. 6 (cit. on p. 76).

White, R. E. (2006): Principles and practice of soil science: the soil as a natural resource. 4th ed. Oxford: Wiley-Blackwell (cit. on p. 84).

Wilkinson, M., E. L. Eaton, M. S. Broadmeadow, and J. I. Morison (2012): 'Inter-annual variation of carbon uptake by a plantation oak woodland in south-eastern England'. Biogeosciences, vol. 9(12): pp. 5373-5389 (cit. on pp. 15, 31, 105).

Williams, M., E. B. Rastetter, D. N. Fernandes, M. L. Goulden, S. C. Wofsy, G. R. Shaver, J. M. Melillo, J. W. Munger, S. M. Fan, and K. J. Nadelhoffer (1996): 'Modelling the soil-plant-atmosphere continuum in a Quercus-acer stand at Harvard forest: The regulation of stomatal conductance by light, nitrogen and soil/plant hydraulic properties'. Plant, Cell and Environment, vol. 19(8): pp. 911-927 (cit. on p. 76).

Wilson, K. B. and T. P. Meyers (2001): 'The spatial variability of energy and carbon dioxide fluxes at the floor of a deciduous forest'. Boundary-Layer Meteorology, vol. 98(3): pp. 443-473 (cit. on pp. 31, 42, 105).

World Meteorological Organization (1992): International meteorological vocabulary. Geneva (cit. on p. 5).

Wu, C., J. M. Chen, A. Gonsamo, D. T. Price, T. A. Black, and W. A. Kurz (2012): 'Interannual variability of net carbon exchange is related to the lag between the end-dates of net carbon uptake and photosynthesis: Evidence from long records at two contrasting forest stands'. Agricultural and Forest Meteorology, vol. 164: pp. 29-38 (cit. on p. 15).

Wu, C. et al. (2013): 'Interannual variability of net ecosystem productivity in forests is explained by carbon flux phenology in autumn'. Global Ecology and Biogeography, vol. 22(8): pp. 994-1006 (cit. on p. 14).

Wutzler, T., M. Reichstein, A. M. Moffat, and M. Migliavacca (2018): REddyProc: Post Processing of (Half-)Hourly Eddy-Covariance Measurements. $R$ package version 1.1.3. (Cit. on p. 18).

Wutzler, T., C. Wirth, and J. Schumacher (June 2008): 'Generic biomass functions for Common beech ( Fagus sylvatica ) in Central Europe: predictions and components of uncertainty'. Canadian Journal of Forest Research, vol. 38(6): pp. 1661-1675 (cit. on p. 116).

XIA, J. et al. (Mar. 2015): 'Joint control of terrestrial gross primary productivity by plant phenology and physiology'. Proceedings of the National Academy of Sciences of the United States of America, vol. 112(9): pp. 2788-2793 (cit. on pp. 45, 126).

XIAO, J. et al. (2011): 'Assessing net ecosystem carbon exchange of U.S. terrestrial ecosystems by integrating eddy covariance flux measurements and satellite observations'. Agricultural and Forest Meteorology, vol. 151(1): pp. 60-69 (cit. on p. 2). 
XU, C. Y and V. P. Singh (2002): 'Cross comparison of empirical equations for calculating potential evapotranspiration with data from Switzerland'. Water Resources Management, vol. 16(3): pp. 197-219 (cit. on p. 87).

YACHI, S. and M. LOREAU (2007): 'Does complementary resource use enhance ecosystem functioning? A model of light competition in plant communities'. Ecology Letters, vol. 10(1): pp. 54-62 (cit. on p. 45).

YAnG, Y., Y. LuO, and A. C. FinzI (June 2011): 'Carbon and nitrogen dynamics during forest stand development: a global synthesis'. New Phytologist, vol. 190(4): pp. 977-989 (cit. on p. 136).

Young, B. D., A. W. D’Amato, C. C. Kern, D. N. Kastendick, and B. J. Palik (2017): 'Seven decades of change in forest structure and composition in Pinus resinosa forests in northern Minnesota, USA: Comparing managed and unmanaged conditions'. Forest Ecology and Management, vol. 395: pp. 92-103 (cit. on p. 3).

Yousefpour, R. and M. Hanewinkel (2016): 'Climate Change and Decision-Making Under Uncertainty'. Current Forestry Reports, vol. 2(2): pp. 143-149 (cit. on p. 104).

YUAN, W. et al. (2009): 'Latitudinal patterns of magnitude and interannual variability in net ecosystem exchange regulated by biological and environmental variables'. Global Change Biology, vol. 15(12): pp. 2905-2920 (cit. on p. 14).

Zalloni, E., G. Battipaglia, P. Cherubini, M. Saurer, and V. De Micco (Apr. 2019): 'Wood Growth in Pure and Mixed Quercus ilex L. Forests: Drought Influence Depends on Site Conditions'. Frontiers in Plant Science, vol. 10 (cit. on p. 6).

ZANG, C., H. Pretzsch, and A. Rothe (2012): 'Size-dependent responses to summer drought in Scots pine, Norway spruce and common oak'. Trees - Structure and Function, vol. 26(2): pp. 557-569 (cit. on p. 3).

Zapater, M., C. Hossann, N. Bréda, C. Bréchet, D. Bonal, and A. Granier (2011): 'Evidence of hydraulic lift in a young beech and oak mixed forest using $18 \mathrm{O}$ soil water labelling'. Trees - Structure and Function, vol. 25(5): pp. 885-894 (cit. on p. 46).

Zeng, H., J. Q. Chambers, R. I. Negron-Juarez, G. C. Hurtt, D. B. Baker, and M. D. Powell (2009): 'Impacts of tropical cyclones on U.S. forest tree mortality and carbon flux from 1851 to 2000'. Proceedings of the National Academy of Sciences, vol. 106(19): pp. 7888-7892 (cit. on p. 2).

Zenner, E. K. and D. E. HibBs (2000): 'A new method for modeling the heterogeneity of forest structure'. Forest Ecology and Management, vol. 129(1-3): pp. 75-87 (cit. on p. 3).

Zhang, Y., H. Y. Chen, and P. B. ReICH (2012): 'Forest productivity increases with evenness, species richness and trait variation: A global meta-analysis'. Journal of Ecology, vol. 100(3): pp. $742-749$ (cit. on pp. 2, 44, 45, 104, 105).

Zhou, L., S. Wang, Y. Chi, Q. Li, K. Huang, and Q. Yu (Dec. 2015): 'Responses of photosynthetic parameters to drought in subtropical forest ecosystem of China'. SCIENTIFIC REPORTS, vol. 5 (cit. on p. 46).

Zhou, S., B. Medlyn, S. Sabaté, D. Sperlich, I. C. Prentice, and D. Whitehead (Oct. 2014): 'Short-term water stress impacts on stomatal, mesophyll and biochemical limitations to photosynthesis differ consistently among tree species from contrasting climates'. Tree Physiology, vol. 34(10): pp. 1035-1046 (cit. on p. 46). 
Zotarelli, L. and M. Dukes (2010): 'Step by step calculation of the Penman-Monteith Evapotranspiration (FAO-56 Method)'. Institute of Food and ..., vol.: pp. 1-10 (cit. on p. 81).

Zscheischler, J., M. D. Mahecha, S. Harmeling, and M. Reichstein (2013): 'Detection and attribution of large spatiotemporal extreme events in Earth observation data'. Ecological Informatics, vol. 15: pp. 66-73 (cit. on p. 2).

Zweifel, R., W. Eugster, S. Etzold, M. Dobbertin, N. Buchmann, and R. Häsler (2010): 'Link between continuous stem radius changes and net ecosystem productivity of a subalpine Norway spruce forest in the Swiss Alps'. New Phytologist, vol. 187(3): pp. 819-830 (cit. on pp. 48, 68). 



\title{
Curriculum Vitae
}

\section{Personal details}

\author{
Name: $\quad$ Rijan Tamrakar \\ Date of birth: $\quad 03 / 12 / 1984$ \\ Place of birth: Bhaktapur, Nepal \\ E-mail address: rtamrak@gwdg.de
}

\section{Education and qualifications}

since 03/2015 PhD candidate, Bioclimatology Group, Faculty of forest sciences and forest ecology, Goettingen University

Title of the thesis: 'The effect of forest structure carbon dioxide fluxes' Supervisors: Prof. Dr. Alexander Knohl, Dr. Mark B. Rayment, Dr. Fernando Moyano

09/2011-10/2013 Master in sustainable forest and nature management, School of natural sciences, Bangor University and Faculty of forest sciences and forest ecology, Göttingen University

Title of the thesis: 'Variability of carbon uptake in managed (Leinefelde) and unmanaged old growth forests (Hainich)'

Supervisors: Dr. Mathias Herbst and Prof. Dr. Alexander Knohl

09/2011-10/2013 Bachelor in forestry, Institute of forestry, Tribhuwan University

Work experience

10/2019-11/2019 Stipend from Graduate school of forestry and agriculture (GFA) (for completing PhD studies), Faculty of forest sciences and forest ecology, Goettingen University.

08/2018-01/2019 Stipend of the faculty of forest sciences and forest ecology (PhD studies), Faculty of forest sciences and forest ecology, Goettingen University.

03/2015-07/2018 Stipend of the Erasmus Mundus joint doctorate, forest, nature and society (FONASO) program (for PhD studies), School of natural sciences, Bangor University and Faculty of forest sciences and forest ecology, Göttingen University 
01/2014-10/2014 Research associate, Asian institute of technology (AIT), Bangkok, Thailand

01/2013-12/2013 Program officer, Asia network for sustainable agriculture and biodiversity (ANSAB), Kathmandu, Nepal

09/2011-09/2013 Stipend of the Erasmus Mundus, sustainable forest and nature management (SUFONAMA) program (for master studies), School of natural sciences, Bangor University and Faculty of forest sciences and forest ecology, Göttingen University

12/2009-09/2011 Forest officer, Asia network for sustainable agriculture and biodiversity (ANSAB), Kathmandu, Nepal

\section{Publications}

Mund, M., Herbst, M., Knohl, A., Matthäus, B., Schumacher, J., Schall, P., Siebicke, L., Tamrakar, R., and Ammer, C. (2019): 'It is not just a 'trade-off' - indications for sink- and source-limitation to vegetative and regenerative growth in an old-growth beech forest'. New Phytologist

Tamrakar, R., M. B. Rayment, F. Moyano, M. Mund, and A. Knohl (2018): 'Implications of structural diversity for seasonal and annual carbon dioxide fluxes in two temperate deciduous forests'. Agricultural and Forest Meteorology, vol. 263(June): pp. 465-476

Musavi, T., Migliavacca, M., Reichstein, M., Kattge, J., Wirth, C., Black, T. A., Janssens, I., Knohl, A., Loustau, D., Roupsard, O., Varlagin, A., Rambal, S., Cescatti, A., Gianelle, D., Kondo, H., Tamrakar, R., and Mahecha, M. D. (2017): 'Stand age and species richness dampen interannual variation of ecosystem-level photosynthetic capacity'. Nature Ecology and Evolution, vol. 1(2): pp. 1-6

Herbst, M., Mund, M., Tamrakar, R., and Knohl, A. (2015): 'Differences in carbon uptake and water use between a managed and an unmanaged beech forest in central Germany'. Forest Ecology and Management, vol. 355: pp. 101-108 


\section{Acknowledgments}

My PhD has been a beautiful journey full of ups and downs. I want to thank my supervisors, Alexander, Mark and Fernando from the depth of my heart to supporting me throughout this journey. It wouldn't have been possible without their encouraging support. They provided me with excellent academic support and the same time emotional support. I consider myself lucky to have a great supervising team.

I am also thankful to all my colleagues in Bioclimatology department for encouragement and critical inputs they gave during the seminars and other time. I sincerely thank all my co-authors with whom I got a wonderful opportunity to learn a lot. I am grateful to both thesis reviewers (Mathias Herbst and Christian Ammer) and providing critical comments on my work. Also my heartfelt thanks to the advisory committee in Bangor University (Andy Smith and Prysor Williams) for pointing out my strengths and deficiences every year. With their genuine input I improved my work thoroughly.

I would like to thank Erasmus Mundus Joint DoctoratePr ogramme Forest and Nature for Society (EMJD FONASO), Deutsche Forschungsgemeinschaft (INST 186/1118-1 FUGG), and German Federal Ministry of Education and Research for funding this research. I thank the administration of the Hainich National Park and the forestry district Leinefelde for the opportunity for research in their forest areas. I am also indebted to Ernst-Detlef Schulze, Olaf Kolle, Kerstin Hippler, Karl Kübler, Martin Hertel, Agnes Fastnacht (MaxPlanck Institute for Biogeochemistry), Peter Anthoni (Karlsruhe Institute of Technology KIT, Institute of Meteorology and Climate Research Atmospheric Environmental Research), Corinna Rebmann (Helmholtz Centre for Environmental Research - UFZ), Frank Tiedemann, Dietmar Fellert, Heinrich Kreilein, Martin Lindenberg, Lukas Siebicke (University of Göttingen), Mathias Herbst (Zentrum für agrarmeteorologische Forschung, Deutscher Wetterdienst) and Werner Kutsch (ICOS) for their work at the Hainich and Leinefelde tower sites. I am grateful to researchers in fluxnet sites who provided inventory data (for my third chapter).

Then, I would like to thank my family for accepting me as I am and allowing me to flow as I wished. I want to thank mother, sisters, brother, and my wife. I am indebted to all my friends who have pulled my hands whenever I fell down. In particular I would like to remember, Chandra, Manisha, Pramila, and Netra.

The layout of this thesis is based on a $\mathrm{IAT}_{\mathrm{E} X-T e m p l a t e}$ by Matthias Pospiech http: //www.matthiaspospiech.de/latex/ and I am very thankful that he shared it. 
